\title{
RESEARCH NEEDS FOR STRANDPLAIN/BARRIER ISLAND RESERVOIRS IN THE UNITED STATES
}

\author{
By \\ E. Lance Cole \\ Michael L. Fowler \\ S. Phillip Salamy \\ Partha S. Sarathi \\ Mark A. Young
}

December 1994

Work Performed Under Contract No. DE-AC22-94PC91008

Prepared for

U.S. Department of Energy

Assistant Secretary for Fossil Energy

Edith Allison, Project Manager

Bartlesville Project Office

P.O. Box 1398

Bartlesville, OK 74005

Prepared by

BDM-Oklahoma, Inc.

P.O. Box 2565

Bartlesville, OK 74005 


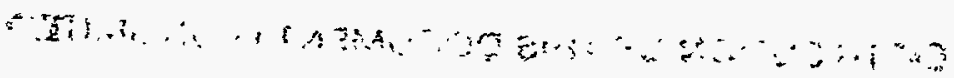




\section{DISCLAIMER}

This report was prepared as an account of work sponsored by an agency of the United States Government. Neither the United States Government nor any agency thereof, nor any of their employees, make any warranty, express or implied, or assumes any legal liability or responsibility for the accuracy, completeness, or usefulness of any information, apparatus, product, or process disclosed, or represents that its use would not infringe privately owned rights. Reference herein to any specific commercial product, process, or service by trade name, trademark, manufacturer, or otherwise does not necessarily constitute or imply its endorsement, recommendation, or favoring by the United States Government or any agency thereof. The views and opinions of authors expressed herein do not necessarily state or reflect those of the United States Government or any agency thereof. 


\section{DISCLAIMER}

Portions of this document may be illegible in electronic image products. Images are produced from the best available original document. 


\section{TABLE OF CONTENTS}

1 BACKGROUND AND OBJECTIVES ...........................1-1

1.1 References..............................................................

2 DESCRIPTION OF THE CLASS 4 RESOURCE AND

THE TORIS PREDICTIVE METHODOLOGY $\ldots \ldots \ldots \ldots \ldots \ldots \ldots .2-1$

2.1 Overview of the Class 4 Oil Resource .......................................... 2-1

2.1.1 Distribution of the Class 4 Resource......................................... 2-1

2.1.2 Heavy Versus Light Oil in Class 4 Reservoirs........................ 2-3

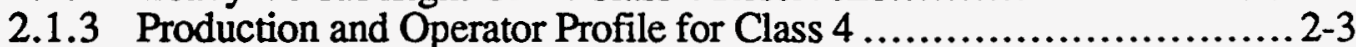

2.1.4 Overview Of Major Class 4 Plays ....................................2-4

2.1.4.1 Reservoir Characteristics of Class 4 Plays ................. 2-5

2.1.4.2 Production and Improved Recovery in Class 4 Plays...........2-6

2.2 Overview of the TORIS Predictive Methodology ..................................... 2-7

2.2.1 Summary of TORIS Methodology ................................ 2-7

2.2.2 Discussion of TORIS Screening Criteria ............................. 2-8

2.2.2.1 Process Screening Criteria Developed by NPC.................. 2-8

2.2.2.2 Screening Criteria For ASR Processes .....................2-11

2.2.3 Discussion of TORIS Predictive Model Methodologies ................2-12

2.2.3.1 Chemical Flood Predictive Model ..............................2-12

2.2.3.2 Miscible Flood Predictive Model ..........................2-12

2.2.3.3 Steamflood Predictive Model ....................................2-13

2.2.3.4 In Situ Combustion Predictive Model...........................2-13

2.2.3.5 Polymer Flood Predictive Model ...........................2-14

2.2.3.6 Profile Modification Predictive Model .....................2-15

2.2.3.7 Infill Drilling Predictive Model ............................2-15

2.2.3.8 Predictive Models for Combination Processes...................2-16

2.2.4 Economic Considerations...........................................2-16

2.2.4.1 Process-Dependent Costs ...................................2-17

2.2.4.2 Process-Independent Costs ...................................

2.2.4.3 Other Economic Considerations ............................2-17

2.3 Relationship Between the Class 4 Resource and the

TORIS Screening Methodology .............................................2-18

2.4 Overview of Class 4 Potential by Process and Region........................2-21

2.4.1 Improved Recovery Potential For Class 4 ........................2-21

2.4.2 Abandonment Risk of the Class 4 Resource ..........................2-25

2.4.3 Discussion of Recovery Potential for Class 4 by Region................2-26

2.4.3.1 Improved Recovery Potential for Texas

Class 4 Reservoirs .....................................2-26

2.4.3.2 Improved Recovery Potential for Oklahoma

Class 4 Reservoirs .....................................2-27

2.4.3.3 Improved Recovery Potential for California

Class 4 Reservoirs .....................................2-28

2.4.3.4 Improved Recovery Potential for Rocky Mountain

Class 4 Reservoirs ..........................................2-29

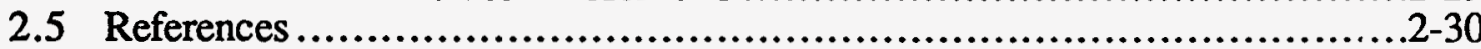

3 RESERVOIR DESCRIPTION AND RESERVOIR

MANAGEMENT RESEARCH NEEDS.........................3-1

3.1 Influence of Heterogeneity on Improved Oil Recovery Processes................3-1

3.1.1 Definition and Importance of Heterogeneity................................... 3-2 
3.1.2 Natural Sources of Heterogeneity ................................. 3-2

3.1.3 Man-Induced Heterogeneities or Alterations ....................... 3-4

3.2 Comparison of the Components of Heterogeneity Among Class 4

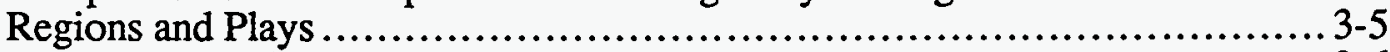

3.2.1 Depositional Environment .............................................. 3-6

3.2.1.1 Texas Plays ............................................. 3-6

3.2.1.2 Oklahoma Plays ........................................... 3-6

3.2.1.3 California Plays......................................... 3-6

3.2.1.4 Rocky Mountain Plays ............................... 3-6

3.2.1.5 Summary of Similarities and Differences Due to

Depositional Environment..................................... 3-7

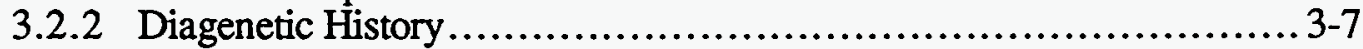

3.2.2.1 Texas Plays ............................................ 3-7

3.2.2.2 Oklahoma Plays ............................................ 3-8

3.2.2.3 California Plays....................................... 3-8

3.2.2.4 Rocky Mountain Plays .................................. 3-8

3.2.2.5 Summary of Similarities and Differences Due to

Diagenetic History ....................................... 3-9

3.2.3 Tectonic and Structural History ......................................... 3-9

3.2.3.1 Texas Plays ....................................................

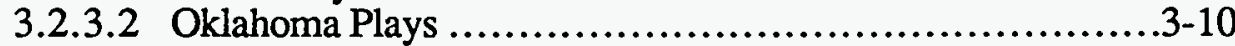

3.2.3.3 California Plays..........................................

3.2.3.4 Rocky Mountain Plays ............................... $3-10$

3.2.3.5 Summary of Similarities and Differences Due to Tectonic

and Structural History .....................................3-10

3.2.4 Variation in Fluid Content ..........................................

3.2.5 Summary of Comparisons of Class 4 Reservoirs, Plays and

Regions....

3.3 The Role of Reservoir Description or Characterization

in Relaxing Constraints on Recovery .................................... $3-12$

3.3.1 Definition of Reservoir Characterization............................. 12

3.3.2 Reservoir Characterization Models, Their Associated Uncertainties

and Research Needs.......................................................3-13

3.3.2.1 Conceptual Models and Associated Research Needs............3-13

3.3.2.2 Stochastic Models and Associated Research Needs............3-19

3.3.2.3 Deterministic Modeling (Data Acquisition and Analysis)

and Associated Research Needs ..............................3-22

3.3.3 Reservoir Characterization Methodology ...........................3-33

3.3.3.1 Steps in Reservoir Characterization ........................3-34

3.3.3.2 Research Needs in Reservoir Characterization

Methodology ..............................................3-36

3.4 The Role of Reservoir Management in Relaxing Constraints on

Recovery ...............................................................

3.4.1 Description of Reservoir Management ..............................3-37

3.4.2 The Reservoir Management Process (Activities and Methodology) ....3-38

3.4.2.1 Plan Construction ................................................3-39

3.4.2.2 Surveillance and Monitoring ...................................3-39

3.4.2.3 Events Triggering Reservoir Management Plan Revision ....3-40

3.4.3 The Reservoir Management Business Environment

(Economic Factors and Organizational Factors) ......................3-40

3.4.4 Research Needs in Reservoir Management...............................3-40

3.5 Current Research in Reservoir Description and Reservoir Management........3-41

3.6 References.......................................................... 


\section{IOR PROCESS AND RELATED RESEARCH NEEDS ........4-1}

4.1 Infill Drilling ................................................................. 4-1

4.1.1 Relationship to the Class 4 Resource.............................. 4-3

4.1.1.1 Infill Drilling in Texas Frio Reservoirs ........................ 4-3

4.1.1.2 Infill Drilling in Oklahoma Deese Reservoirs ................. 4-4

4.1.2 Recent Technology Thrusts ....................................... 4-5

4.1.2.1 Development of Interwell Continuity Concepts................... 4-5

4.1.2.2 Effects Of Infill Drilling on Areal and Vertical Sweep Efficiency ............................................. 4-7

4.1.3 Current Research Related To Infill Drilling......................... 4-8

4.1.4 Research Needs.................................................... 4-8

4.2 Conformance Control Technologies ........................................ 4-9

4.2.1 Relationship to the Class 4 Oil Resource .............................. 4-9

4.2.2 Screening, Well Selection and Treatment Criteria ......................4-10

4.2.3 Constraints .............................................................4-12

4.2.4 Recent Technology Thrusts ...........................................4-13

4.2.4.1 Process and Mechanistic Studies ..............................4-13

4.2.4.2 Alternative Systems and Methods ............................4-13

4.2.4.3 Field Results and Guidelines ................................4-16

4.2.5 Current Research Activity ...........................................4-17

4.2.5.1 DOE Supporting Research ............................4-17

4.2.5.2 DOE Cost-Shared Field Demonstration Program................4-18

4.2.6 Research Needs......................................................4-18

4.2.6.1 Process ...................................................4-18

4.2.6.2 Modeling and Simulation................................4-19

4.2.6.3 Environmental ............................................... $4-19$

4.2.6.4 Demonstration ...............................................4-19

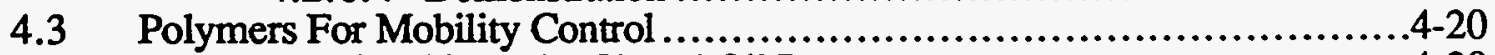

4.3.1 Relationship to the Class 4 Oil Resource ................................4-20

4.3.2 Screening Criteria .................................................4-20

4.3.3 Constraints .....................................................4-20

4.3.4 Recent Technology Thrusts ...........................................4-21

4.3.4.1 Polymers for Harsher Environments ......................4-21

4.3.4.2 Secondary Rather Than Tertiary ..........................4-22

4.3.4.3 Propagation and Retention ................................4-22

4.3.4.4 Mechanical Degradation ..................................4-22

4.3.4.5 Injectivity............................................4-23

4.3.5 Current Research Activity ........................................4-23

4.3.5.1 DOE Supporting Research ..............................4-23

4.3.5.2 DOE Cost-Shared Field Demonstration Program................4-23

4.3.6 Research Needs........................................................4-24

4.4 Microbial Processes ........................................................4-24

4.4.1 Relationship to the Class 4 Oil Resource ...............................4-24

4.4.2 Screening Criteria and Procedures..............................................4-24

4.4.3 Constraints ......................................................... $4-25$

4.4.4 Recent Technology Thrusts ....................................4-26

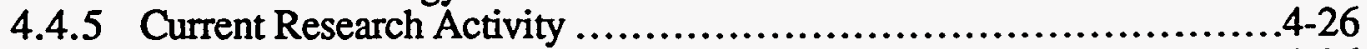

4.4.5.1 DOE Supporting Research .............................4-26

4.4.5.2 DOE Cost-Shared Field Demonstration Program................4-27

4.4.6 Research Needs..................................................4-27

4.5 Alkaline And Alkaline-Surfactant-Polymer (ASP) Processes ...................4-27

4.5.1 Relationship to the Class 4 Resource............................4-28

4.5.2 Screening Criteria....................................................4-28 
4.5.3 Constraints .......................................................4-29

4.5.4 Recent Technology Thrusts ....................................4-30

4.5.4.1 Interfacial Tension (IFT) Lowering ........................4-30

4.5.4.2 Injection Strategy .......................................4-30

4.5.4.3 Polymer and Alkaline-Surfactant Interactions ..............4-30

4.5.4.4 Field Tests of the ASP Process...............................4-31

4.5.5 Current Research Activity ........................................4-31

4.5.5.1 DOE Supporting Research ............................4-31

4.5.5.2 DOE Cost-Shared Field Demonstration Program.............4-32

4.5.6 Research Needs............................................................4-32

4.6 Surfactant Process............................................................4-33

4.6.1 Relationship to the Class 4 Oil Resource ...........................4-33

4.6.2 Screening Criteria .....................................................4-33

4.6.3 Constraints ..............................................................4-34

4.6.4 Recent Technology Thrusts ...........................................4-34

4.6.4.1 Mixed Surfactant Systems ..............................4-34

4.6.4.2 High-Temperature, High-Salinity Surfactants ..................4-35

4.6.4.3 Chemical EOR Database and Expert System...................4-35

4.6.4.4 Laboratory Screening Procedures .............................4-35

4.6.4.5 Cost-Recovery Balance...................................4-36

4.6.5 Current Research Activity ........................................4-36

4.6.5.1 DOE Supporting Research ............................4-36

4.6.5.2 DOE Cost-Shared Field Demonstration Program................4-36

4.6.6 Research Needs..........................................................4-36

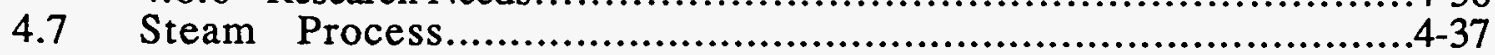

4.7.1 Relationship to the Class 4 Oil Resource ....................................4-37

4.7.2 Screening Criteria..................................................4-37

4.7.3 Constraints ......................................................4-38

4.7.4 Recent Technology Thrusts ....................................4-38

4.7.4.1 Advances in Steam Distribution Practices .....................4-39

4.7.4.2 Steam Flow and Steam Quality Measurement and Control...4-39

4.7.4.3 Subsurface Equipment and Methods ..........................4-39

4.7.4.4 Injection Profiling .............................................4-40

4.7.4.5 Process Improvements........................................4-40

4.7.4.6 Reservoir Management ...............................................4-41

4.7.4.7 Simulation and Performance Prediction .......................4-42

4.7.5 Current Research Activity ....................................................4-42

4.7.5.1 DOE Supporting Research ..............................4-42

4.7.5.2 DOE Cost-Shared Field Demonstration Program.............4-42

4.7.6 Research Needs........................................................4-43

4.8 In Situ Combustion Process ......................................................4-43

4.8.1 Relationship to the Class 4 Oil Resource ................................4-43

4.8.2 Screening Criteria.........................................................4-44

4.8.3 Constraints .....................................................................4-44

4.8.4 Recent Technology Thrusts ...........................................4-45

4.8.4.1 Use of ISC in Carbonate Reservoirs ..........................4-45

4.8.4.2 Double Displacement Process ..................................4-46

4.8.4.3 Horizontal Well ISC Process ......................................4-46

4.8.4.4 Pressure Up-Blowdown Combustion Process .................4-46

4.8.4.5 The Combustion Override Split-Production Horizontal Well (COSH) Process ...........................................4-46

4.8.4.6 Use of Foam in ISC Process..............................4-47

4.8.4.7 Hydrogen Peroxide In Situ Combustion Project ................4-47

4.8.5 Current Research Activity .........................................4-47 
4.8.5.1 DOE Supporting Research ...............................4-47

4.8.5.2 DOE Cost-Shared Field Demonstration Program.............4-47

4.8.6 Research Needs...........................................................4-48

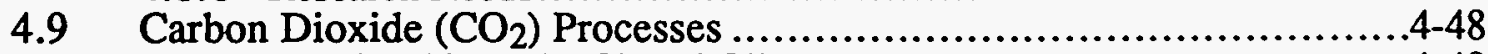

4.9.1 Relationship to the Class 4 Oil Resource .............................4-49

4.9.2 Screening Criteria..................................................4-49

4.9.3 Constraints ...................................................

4.9.4 Recent Technology Thrusts .........................................4-51

4.9.4.1 Mobility Control........................................4-51

4.9.4.2 Predictability Issues..........................................4-54

4.9.4.3 Immiscible $\mathrm{CO}_{2}$ Displacement ............................4-54

4.9.4.4 Cyclic $\mathrm{CO}_{2}$ Treatments (Huff ' $n$ ' Puff) .................4-54

4.9.5 Current Research Activity ...............................................4-55

4.9.5.1 DOE Supporting Research ............................4-55

4.9.5.2 DOE Cost-Shared Field Demonstration Program................4-56

4.9.6 Research Needs....................................................4-56

4.10 Numerical Simulation and Modeling $\ldots \ldots \ldots \ldots \ldots \ldots \ldots \ldots \ldots \ldots \ldots \ldots \ldots \ldots . . . .57$

4.10.1 Public Domain Reservoir Simulators ...........................4-57

4.10.1.1 Black Oil Applied Simulation Tool (BOAST, BOAST II) .4-59

4.10.1.2 Miscible Applied Simulation Techniques for Energy Recovery (MASTER) .................................4-60

4.10.1.3 Black Oil Applied Simulation Tool for Vertical/Horizontal/Slant Wells (BOAST-VHS)..............4-60

4.10.1.4 Polymer Applications Simulator (PC-GEL) .................4-60

4.10.1.5 Microbial Transport Simulator (MTS) ....................4-61

4.10.2 Commercial Reservoir Simulators..................................4-61

4.10.2.1 Recovery Process Simulation Capabilities ...................4-61

4.10.2.2 Computational Algorithms $\ldots \ldots \ldots \ldots \ldots \ldots \ldots \ldots \ldots \ldots . . . .64-62$

4.10.2.3 Artificial Intelligence .................................4-62

4.10.2.4 Modeling Geologically Complex Reservoirs ..............4-62

4.10.2.5 Image Processing ......................................4-62

4.10.3 Reservoir Simulation Research Needs ..............................4-63

4.11 Wellbore and Facilities.................................................4-63

4.11.1 Drilling Technology ........................................4-63

4.11.1.1 Improved Drilling Systems ............................4-64

4.11.1.2 Directional Drilling Methods..............................4-64

4.11.1.3 Horizontal Drilling Methods .............................4-64

4.11.1.4 Drilling Measurement Systems ...............................4-65

4.11.2 Well Completion and Recompletion Technology ......................4-65

4.11.2.1 Completion Methods...................................4-65

4.11.2.2 Recompletion and Workover Methods .....................4-66

4.11.2.3 Well Stimulation Methods.....................................4-66

4.11.3 Production and Injection Facilities................................4-66

4.11.3.1 Separation and Treatment Facilities ........................4-66

4.11.3.2 Distribution and Gathering Systems .....................4-67

4.11.3.3 Artificial Lift Methods ..................................4-67

4.11.4 Field Operations and Reservoir Management ............................4-67

4.12 Environmental Issues ..................................................................4-68

4.12.1 Project and Well Development Issues.............................4-68

4.12.1.1 Environmental Risk Assessment ................................4-68

4.12.1.2 Previously Abandoned Wells.................................4-68

4.12.1.3 Shut-In Wells................................................4-68

4.12.1.4 Drilling ..................................................4-69

4.12.1.5 Remedial Workovers and Stimulation Treatments ..........4-70 
4.12.2 Project Operational Issues ..........................................4-70

4.12.2.1 Production Chemical Usage ............................4-70

4.12.2.2 Radioactive Tracers .................................4-70

4.12.2.3 Class II Injection Wells ...............................4-70

4.12.2.4 Leak and Spill Prevention................................4-71

4.12.2.5 NORM Contamination ..............................4-71

4.12.3 IOR Process-Specific Issues ........................................4-71

4.12.3.1 Conformance Control................................4-71

4.12.3.2 Chemical Flooding...................................4-72

4.12.3.3 $\mathrm{CO}_{2}$ Processes...................................4-72

4.12.3.4 Thermal Processes.................................4-72

4.12.4 General Industry Environmental Trends.........................4-72

4.12.4.1 Waste Management (Minimization) Practices................4-72

4.12.4.2 Integrated Engineering Design .........................4-73

4.12.4.2 Field Demonstration .........................................4-73

4.13 References.......................................................

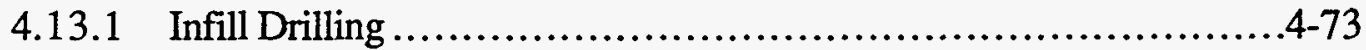

4.13.2 Conformance Control Technologies ...............................4-75

4.13.3 Polymers for Mobility Control .................................4-78

4.13.4 Microbial Processes...........................................4-79

4.13.5 Alkaline and Alkaline-Surfactant-Polymer (ASP) Processes...........4-80

4.13.6 Surfactant Process....................................................4-82

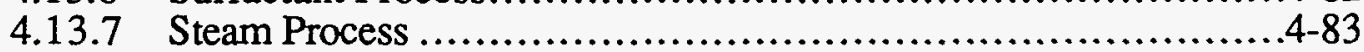

4.13.8 In Situ Combustion Process ............................................4-87

4.13.9 Carbon Dioxide $\left(\mathrm{CO}_{2}\right)$ Processes .......................................4-88

4.13.10 Numerical Simulation ............................................4-91

4.13 .11 Wellbore and Facilities ........................................4-91

4.13.12 Environmental Issues .........................................4-92

5 CONSOLIDATED CLASS 4 RESEARCH NEEDS ..............5-1

5.1 Characteristics of Class 4 Reservoirs and Operators ............................ 5-1

5.2 Research Needs In Reservoir Description and Reservoir

Management ............................................................ 5-2

5.2.1 Research Needs-Reservoir Characterization and Reservoir

Management Methodologies ...................................... 5-2

5.2.2 Class 4-Specific Research Needs in Reservoir Characterization..... 5-3

5.2.3 General Research Needs in Reservoir Characterization................... 5-5

$5.3 \quad$ Infill Drilling Research Needs ...........................................5 5-5

5.4 Conformance Control Technologies Research Needs........................... 5-6

5.5 Polymer Research Needs ................................................... 5-6

5.6 Microbial Process Research Needs.............................................. 5-6

5.7 Alkaline and Alkaline-Surfactant-Polymer (ASP) Process Research Needs..... 5-7

5.8 Surfactant Process Research Needs .................................................. 5-7

5.9 Steam Process Research Needs........................................................ 5-8

5.10 In Situ Combustion Process Research Needs..................................... 5-8

$5.11 \quad \mathrm{CO}_{2}$ Process Research Needs......................................................... 5-8

5.12 Numerical Simulation and Modeling Research Needs .......................... 5-9

5.13 Wellbore and Facilities Research Needs ................................... 5-9

5.14 Environmental Research Needs.................................................. 5-9

5-15 References..................................................................... 


\section{LIST OF FIGURES}

1.1 Distribution of Remaining Oil-in-Place (ROIP) for TORIS Reservoirs.................. 1-2

1.2 Total Recovery Potential for Class 4 Reservoirs ................................... 1-2

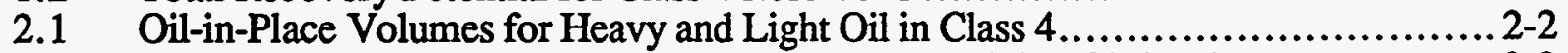

2.2 Distribution of Class 4 TORIS Reservoirs and Remaining Oil-in-Place..............2-2

2.3 Light and Heavy Oil Production for Class 4 Reservoirs...................................... 2-3

2.4 Operator Profile for Class 4 Reservoirs ....................................... 2-4

2.5 Remaining Oil-in-Place Distribution for Class 4 Plays in Major Regions ............ 2-5

2.6 Historical Production for Class 4 Plays in Major Regions ........................... 2-6

2.7 Frequency Distribution of Class 4 Reservoirs by Temperature and Salinity ..........2-18

2.8 Distribution of Remaining Oil-in-Place in Class 4 Reservoirs by Salinity and

Temperature ........................................................................2-18

2.9 Frequency Distribution of Texas Class 4 Reservoirs by Temperature and

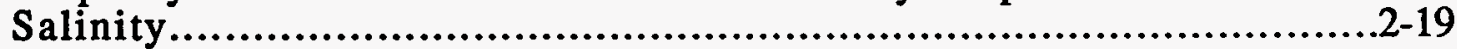

2.10 Distribution of Remaining Oil-in-Place in Texas Class 4 Reservoirs by

Salinity and Temperature ....................................................... 19

2.11 Frequency Distribution of Oklahoma Class 4 Reservoirs by Temperature

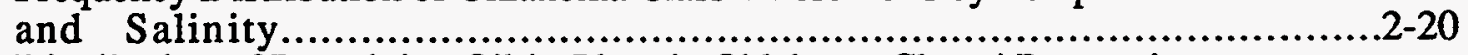

2.12 Distribution of Remaining Oil-in-Place in Oklahoma Class 4 Reservoirs

by Salinity and Temperature .......................................................2-20

2.13 Frequency Distribution of Rocky Mountain Class 4 Reservoirs

by Temperature and Salinity ......................................................2-20

2.14 Distribution of Remaining Oil-in-Place in Rocky Mountain Class 4

Reservoirs by Salinity and Temperature ............................................2-20

2.15 Frequency Distribution of California Class 4 Reservoirs by API

Gravity and Depth...............................................................2-21

2.16 Distribution of Remaining Oil-in-Place in California Class 4 Reservoirs

by API Gravity and Depth...............................................................2-21

2.17 Advanced Secondary Recovery Potential for Class 4 Reservoirs .................2-22

2.18 Enhanced Oil Recovery Potential for Class 4 Reservoirs..................................2-23

2.19 Implemented Technology Case Recovery Potential by Process for

Class 4 TORIS Reservoirs .......................................................2-24

2.20 Advanced Technology Case Recovery Potential by Process for Class 4

TORIS Reservoirs....................................................................2-24

2.21 Total Potential at Risk of Abandonment, Implemented Technology .................2-25

2.22 Total Potential at Risk of Abandonment, Advanced Technology ......................2-25

2.23 Implemented Technology Case Recovery Potential by Process for Texas Class 4 TORIS Reservoirs .................................................2-27

2.24 Advanced Technology Case Recovery Potential by Process for Texas Class 4 TORIS Reservoirs .....................................................2-27

2.25 Implemented Technology Case Recovery Potential by Process for Oklahoma Class 4 TORIS Reservoirs

2.26 Advanced Technology Case Recovery Potential by Process for Oklahoma Class 4 TORIS Reservoirs ..............................................2-28

2.27 Implemented Technology Case Recovery Pontential by Process for California Class 4 TORIS Reservoirs........................................................2-28

2.28 Advanced Technology Case Recovery Potential by Process for California Class 4 TORIS Reservoirs.....................................................2-28

2.29 Implemented Technology Case Recovery Potential by Process for Rocky Mountain Class 4 TORIS Reservoirs.

2.30 Advanced Technology Case Recovery Potential by Process for Rocky Mountain Class 4 TORIS Reservoirs. 
3.1 Increase in Importance of Reservoir Heterogeneity Through the Life of a Reservoir....

3.2 Permeability Distribution and Movement of Injected Water in the

3.3 Scales of Measurement and Relative Resolution of Some Common

3.4 Deterministic Tools.....................................................

4.1 Pay Continuity Functions for Major Facies of the West Ranch Field

4.2 Schematic Illustration-Continuity Functions....

4.3 Schustration of Drain

Illustration of Drainable versus Floodable Continuity ............................... 4-7

4.4 Major $\mathrm{CO}_{2}$ Pipelines Servicing the Permian Basin and the Rocky Mountain States. 


\section{LIST OF TABLES}

2.1 Oil-in-Place Volumes for Heavy and Light Oil in Class $4 \ldots \ldots \ldots \ldots \ldots \ldots \ldots \ldots \ldots . \ldots \ldots$

2.2 Summary of Oil-in-Place Volumes for Class 4 Plays in Major Regions ................ 2-4

2.3 Summary of Average Reservoir Parameters for Major Class 4 Plays in Each Region.......................................................................... 2-5

2.4 Screening Criteria for Improved Recovery Processes, Implemented Technology Case ........................................................................ 2-9

2.5 Screening Criteria for Improved Recovery Processes, Advanced Technology Case .................................................................... 2-9

2.6 Recovery Potential for TORIS Class 4 Reservoirs ................................2-22

2.7 Class 4 Advanced Secondary Recovery Process Potential ...........................2-23

2.8 Class 4 Enhanced Oil Recovery Process Potential..........................................2-24

2.9 Class 4 Recovery Process Potential by Region, Implemented Technology ............2-26

2.10 Class 4 Recovery Process Potential by Region, Advanced Technology ...............2-26

3.1 Some Recent Research Related to Reservoir Characterization and Reservoir Management....

4.1 Incremental Recovery Potential From Infill Drilling in Frio Strandplain /Barrier

Island Play ........................................................................4-4

4.2 Profile Modification Screening Criteria at Different Technology Levels ...............4-10

4.3 Gel Polymer Selection Criteria for Injection Wells ....................................4-11

4.4 Gel Polymer Selection Criteria for Production Wells .................................4-11

4.5 Technical and Economic Success Rates (\%) Reported by Major Oil

Companies for Gel Polymer, Production Well Applications ............................4-12

4.6 Technical and Economic Success Rates Reported by Major Oil Companies for Gel Polymer, Injection Well Applications...

4.7 NPC Polymer Screening Criteria at Different Technology Levels.

4.9 MEOR Screening Procedures ...................................................................25

4.10 NPC Alkaline Screening Criteria at Different Technology Levels ......................4-28

4.11 Screening Criteria for Surfactant-Enhanced Alkline Flooding .......................4-29

4.12 Surfactant Process NPC Screening Criteria at Different Technology Levels...........4-33

4.13 Steam Process NPC Screening Criteria at Different Technology Levels...................4-38

4.14 In Situ Combustion Process NPC Screening Criteria at Different Technology Levels ...............................................................4-44

4.15 Koch's In Situ Combustion Projects Reservoir Properties Versus Published Screening Guides..................................................................4-45

4.16 Publicly Available Reservoir Simulators......................................................4-58 


\section{EXECUTIVE SUMMARY}

The Department of Energy's (DOE's) primary mission in the oil research program is to maximize the economically and environmentally sound recovery of oil from domestic reservoirs and to preserve access to this resource. The Oil Recovery Field Demonstration Program supports DOE's mission through cost-shared demonstrations of Improved Oil Recovery (IOR) processes and reservoir characterization methods. In the past three years, DOE has issued Program Opportunity Notices (PONs) seeking cost-shared proposals for the three highest priority, geologically defined reservoir classes. The classes have been prioritized based on resource size and risk of abandonment. This document identifies the technological and methodological research needs for the fourth geologic class, strandplain/barrier island reservoirs.

The 330 Class 4 reservoirs in the DOE Tertiary Oil Recovery Information System (TORIS) database contain about 30.8 billion barrels of oil or about $9 \%$ of the total original oil-in-place (OOIP) in all United States reservoirs. The current projection of Class 4 ultimate recovery with current operations is only $38 \%$ of the OOIP, leaving 19 billion barrels as the target for future IOR projects. Using the TORIS database and its predictive and economic models, the recovery potential which could result from future application of IOR technologies to Class 4 reservoirs was estimated to be between 1.0 and 4.3 billion barrels, depending on oil price and the level of technology advancement. The analysis indicated that this potential could be realized through (1) infill drilling alone and in combination with polymer flooding and profile modification, (2) chemical flooding (surfactant), and (3) thermal processes. Most of this future potential is in Texas, Oklahoma, California, and the Rocky Mountain region. Approximately two-thirds of the potentially recoverable resource is at risk of abandonment by the year 2000 , which emphasizes the urgent need for the development and demonstration of cost-effective recovery technologies.

A significant portion ( $40 \%$ ) of the Class 4 reservoirs as a whole are owned by small independent operators, with even higher percentages operated by independents in Oklahoma and Texas. Many of these operators have limited technical and financial resources, yet they tend to have characteristically lower operating overhead and can profitably purchase and operate mature production which has reached the economic limit under operation by larger companies. The demonstration of cost-effective reservoir characterization and recovery technologies in Class 4 reservoirs and the transfer of these methodologies to independent and other operators could help to extend the economic life of producing Class 4 reservoirs and improve the ultimate recovery.

Class 4 reservoirs are characteristically in the mature stage of their productive lives, and the majority of the reservoirs were discovered and developed decades ago, when reservoir descriptive techniques were primitive by today's standards. However, advanced technologies such as multidisciplinary reservoir management, targeted infill drilling, and computerized data management have been applied with success in Class 4 reservoirs. Advanced waterflooding techniques such as polymer flooding and profile modification by gel polymers have been applied. Chemical processes such as alkaline flooding and micellar-polymer have been tested. Miscible and cyclic $\mathrm{CO}_{2}$ processes have also been tested, as have steam injection and in situ combustion processes. Expanded application of these technologies could recover additional oil.

This report identifies reservoir characterization and reservoir management research needs and IOR process and related research needs for the Class 4 reservoirs. Many of these research needs apply to reservoirs within other geologic classes, but the demonstration of improved technologies and methodologies within these defined areas, coupled with focused technology transfer activities, could help to improve recovery from Class 4 reservoirs. Specific research needs detailed in this report are summarized below within the categories of reservoir characterization and reservoir management, advanced secondary recovery processes, enhanced oil recovery processes, and related areas. 


\section{Reservoir Characterization and Reservoir Management}

The development and demonstration of improved methodologies and technologies for reservoir characterization and reservoir management are essential elements for increasing the oil recovery from Class 4 reservoirs. Specific research needs in these areas include the following:

- Databases : Development and demonstration of improved methodologies for the design and construction of databases for reservoir characterization and reservoir management purposes.

- Reservoir Characterization Methodologies: Development and demonstration of improved reservoir characterization methodologies for the integration of various geoscience and engineering data types and for the development of strategies over a range of reservoir life, from newly discovered reservoirs to mature reservoirs.

- Conceptual and Stochastic Models: Demonstration of methodologies for the development of conceptual and stochastic models (depositional, diagenetic, tectonic or structural, and fluid content relative to compartmentalization) for application to Class 4 reservoirs. Many of these methodologies will apply to reservoirs in other geologic classes.

- Deterministic Methods: Demonstration of cost-effective current and emerging technologies related to the collection, analysis, and interpretation of reservoir and geologic data, including: rock and fluid samples, production and injection data, open- and casedhole data, pressure transient and tracer data, 3-D seismic methods, extraction of reservoir properties data from seismic records, and wellbore seismic techniques.

- Reservoir Management Methodologies: Development and demonstration of methodologies for the design, implementation, and revision of reservoir management strategies.

\section{Advanced Secondary Recovery (ASR) Processes}

The demonstration of improved methods for the application of advanced secondary recovery processes could result in significant recovery improvements in Class 4 reservoirs. The specific research needs for the ASR processes include the following:

- Infill Drilling: Development and demonstration of improved methods for assessing and predicting recovery potential for infill drilling, including methods for defining interwell continuity methods for defining areal and vertical sweep efficiency and geostatistical or stochastic methods for predicting reservoir characteristics between existing wells.

- Conformance Control: Development of cost-effective, environmentally acceptable alternative technologies to conventional chromium redox gel polymer systems; development of improved simulation and modeling capabilities for treatment design, perhaps utilizing field data in expert systems; and demonstration of new or improved conformance control methods.

- Polymers for Mobility Control: Development of improved polymer injection strategies; development of polymers with improved injectivity and increased ability to propagate through the reservoir.

\section{Enhanced Oil Recovery (EOR) Processes}

The demonstration of improved methods for the application of enhanced oil recovery processes could result in significant recovery improvements in Class 4 reservoirs. The specific research needs for the EOR processes include the following: 
- Microbial EOR: Development of improved simulation and modeling capabilities for microbial processes that incorporate field and laboratory data, demonstration of microbially enhanced waterflooding in reservoirs with high remaining oil saturation, and development of more cost-effective nutrients.

- Alkaline-Surfactant-Polymer (ASP): Development and demonstration of the ASP process including development of injection strategies, investigation of polymer and alkalisurfactant interactions, development of fluid and reservoir databases for reservoir screening; development of field guidelines based on field tests, and continued surfactant and mixed surfactant research to reduce chemical costs.

- Micellar-Polymer (Surfactant): Development of more cost-effective chemical systems such as mixed surfactant systems.

- Steamflooding: Demonstration of improved steam and heat management methodologies, including development of improved steam measurement and distribution technologies, injection profiling and control technologies, subsurface equipment and completion technologies, horizontal well technologies, and sand control technologies for high temperature environments; demonstration of economic development in smaller projects remote from steam infrastructures and in environmentally sensitive areas; and development of cost-effective methods to process bypassed zones.

- In Situ Combustion: Determination of the effects that reservoir heterogeneities have on air and fluid flow and process performance, development of simulators incorporating both process kinetics and geologic complexities, and development of improved equipment and operating practices to solve specific process problems.

- Carbon Dioxide Injection: Development of alternative sources of $\mathrm{CO}_{2}$, demonstration of cost-effective cyclic stimulation treatments; development of improved mobility control technologies; and demonstration of horizontal well technologies for $\mathrm{CO}_{2}$ applications.

\section{Related Research Needs}

General research needs were also identified which could impact the recovery of additional oil from Class 4 reservoirs, including:

- Numerical Simulation: Continued development of more accurate, cost-effective, and user-friendly publicly available simulators for the industry. These types of simulators should be made more readily available to the industry, and a system should be developed to allow less sophisticated operators access to technical experts who can provide guidance for the development of input datasets, the operation of the simulators, and the interpretation of results.

- Wellbore and Facilities: Demonstration of improved technologies for reducing the costs of drilling, completing, recompleting, and stimulating wells and operating production and injection facilities is a significant research need for extending the economic life of producing fields and improving the recovery of oil from Class 4 reservoirs.

- Environmental Research: Demonstration of cost-effective waste management and waste minimization practices, especially in drilling-related operations; demonstration of integrated engineering design concepts in which petroleum engineering and environmental factors are considered in IOR project design. 


\section{ACKNOWLEDGMENTS}

This report was prepared for the U.S. Department of Energy (DOE) Bartlesville Project Office by BDM-Oklahoma under the Management and Operating Contract for DOE's National Oil and Related Programs (Contract Number DE-AC22-94PC91008). The primary authors for this document included E. Lance Cole, Mike Fowler, S. Phillip Salamy, Partha S. Sarathi, and Mark A. Young. The authors wish to acknowledge Edith C. Allison of DOE's Bartlesville Project Office for her technical review of this document during its preparation. The authors also wish to acknowledge the NIPER employees who helped in the technical review of this document, including: Rebecca S. Bryant, Thomas E. Burchfield, Ming-Ming Chang, Frank Chung, Troy R. French, Bonnie L. Gall, Hong W. Gao, Susan R. Jackson, Douglas A. Lawson, Sonny M. Llave, Michael P. Madden, Don J. Remson, Bijon Sharma, Michael J. Szpakiewicz, Liviu Tomutsa, John Tyler (Computer Science Department faculty member from Louisiana State University who was working on numerical simulators at NIPER the summer of 1994) and Robert A. Welch. The authors wish to especially acknowledge Edna Hatcher for support in the overall preparation of this document and Djaun Grissom for the development of most of the graphics. 


\section{CHAPTER 1 BACKGROUND AND OBJECTIVES}

The Department of Energy's (DOE's) Oil Recovery Field Demonstration Program was initiated in 1992 to support DOE's primary mission in the national oil research program of maximizing the economically and environmentally sound recovery of crude oil from known domestic reservoirs and preserving access to this resource. The goals and objectives of this program support the broader strategic goals of the federal government's Comprehensive National Energy Policy Act of 1992 and Domestic Natural Gas and Oil Initiative of 1993. The ongoing field demonstration program supports this mission through the demonstration of improved oil recovery processes and reservoir characterization methods. The cost-shared field demonstration projects are being initiated in geologically defined reservoir classes which have been prioritized relative to the risk of abandonment and potential for incremental recovery. To date, DOE has issued Program Opportunity Notices (PONs) seeking cost-shared proposals for field demonstration projects in the three highest priority geologic classes of reservoirs. The purpose of this document is to identify technological and methodological research, development, and demonstration (RD\&D) needs for the fourth class, strandplain/barrier island reservoirs. This report presents an RD\&D needs overview that is intended as a vehicle to express the subset of general RD\&D needs that, if addressed, are most likely to improve oil recovery from Class 4 reservoirs. Detailed information on the geology, reservoir properties, and production characteristics of Class 4 reservoirs may be found in the Class 4 Department of Energy report: Geological and Production Characteristics of Strandplain/Barrier Island Reservoirs in the United States (NIPER/BDM, 1994).

The reservoir classes are based on depositional environment and were originally defined by the Geoscience Institute for Oil and Gas Recovery Research (1990) in conjunction with the Interstate Oil and Gas Compact Commission. These geologic classifications were applied to the reservoirs that are included in the DOE Tertiary Oil Recovery Information System (TORIS). TORIS contains information on more than 2,500 domestic oil reservoirs, representing two-thirds of the known domestic oil resource, or about 360 billion barrels of original oil-in-place. The first three classes target about half of the 246 billion barrels of remaining oil-in-place for reservoirs listed in TORIS, as shown in Figure 1.1. Class 4 targets an additional $8 \%$ of the remaining oil-in-place, or 19.8 billion barrels.

Future improved recovery potential in these Class 4 reservoirs was analyzed using TORIS's predictive models. This potential ranges from 1 to 4.3 billion barrels, depending on oil price and the level of technology (Figure 1.2). Approximately two-thirds of this potential is at risk of abandonment by the year 2000 , emphasizing the urgent need for the application of recovery technologies in Class 4 reservoirs.

Chapter 2 presents an overview of the Class 4 resource, the TORIS screening and predictive methodologies, and their interrelationship. Chapter 3 discusses the importance with respect to recovery of reservoir description and reservoir management. It summarizes the present state of knowledge concerning these activities and identifies some of the more salient associated general and Class 4-specific research needs. Chapter 4 presents a series of Class 4-oriented discussions on the various individual improved oil recovery (IOR) processes, their relative importance to the Class 4 resource, and current and needed research. Processes addressed include infill drilling, gel polymers for conformance control, polymers for mobility control, alkaline-surfactant-polymer applications, surfactant flooding, steam injection, in situ combustion, and $\mathrm{CO}_{2}$ injection. Chapter 4 also discusses relevant advances in numerical simulation, wellbore and facilities, and environmental areas. Chapter 5 is a consolidated summary discussion of Class 4-focused and prioritized research needs. 


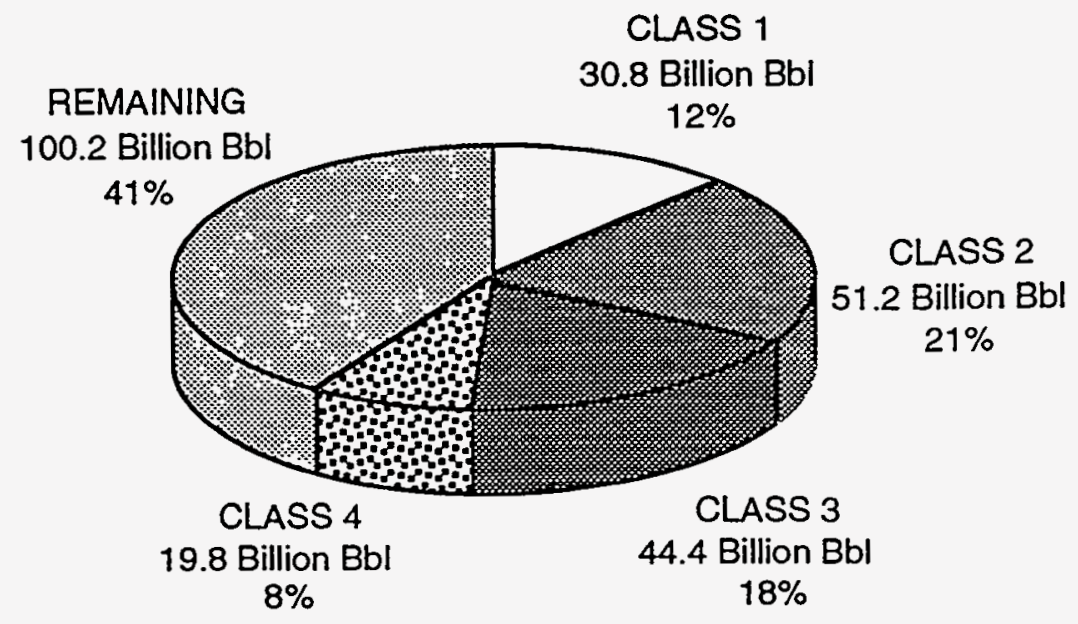

TOTAL ROIP FOR ALL CLASSES $=246$ BILLION BARRELS

Figure 1.1 Distribution of Remaining Oil-in-Place (ROIP) for TORIS Reservoirs (Source: BPO TORIS, 1994)

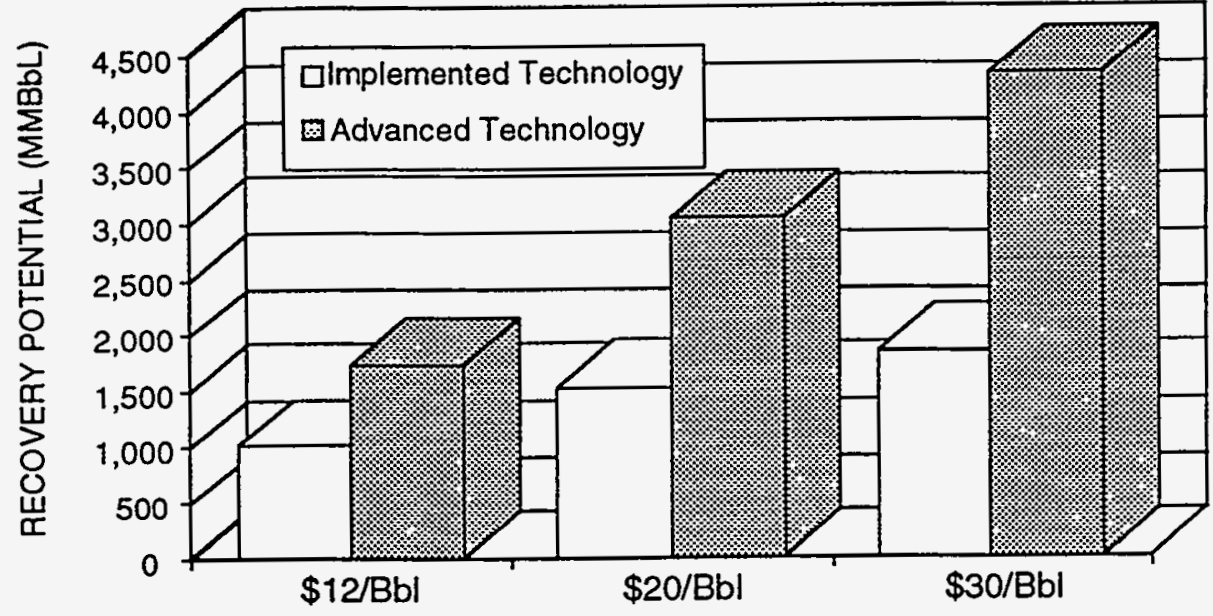

Figure 1.2 Total Recovery Potential for Class 4 Reservoirs (Source: BPO TORIS, 1994) 
Over half of the crude oil discovered in the United States lies in fields already abandoned, and the rate of abandonment is accelerating (LOE, 1994). As much as $70 \%$ of the Nation's remaining oil resources could be lost in a similar manner by shortly after the year 2000 . This research needs report emphasizes the near- and mid-term goals of DOE's Enhanced Oil Recovery (EOR) program to facilitate domestic oil recovery efficiency by increasing recovery rates and delaying or preventing abandonments, particularly for Class 4 reservoirs.

This report focuses on research activities that will foster the economic and widespread application of proven and developing technologies through demonstration, observation, and transfer of application knowledge. A small number of technology application demonstrations can provide tremendous leverage on increased oil recovery if the knowledge gained is effectively transferred to other Class 4 operators, many of whom may be unfamiliar with the technologies' potential or the details of their application. The basis of this report is an extensive review of recent and current literature conducted to identify existing and developing technologies and concepts that appear to have potential for positively affecting Class 4 recovery through demonstration and knowledge transfer.

Although the focus of this report is on Class 4 research needs for the near- and mid-term, it has been guided and substantially aided by work in determination of class-cross-cutting long-term research needs performed by organizations such as the National Research Council and the National Petroleum Council. Further relevant advances to address Class 4 reservoir recovery may be anticipated with completion of a current determination of research, development, and demonstration (RD\&D) needs for the gas and oil industry being conducted by the National Petroleum Council.

\subsection{References}

DOE, 1994, Oil Recovery Program, Program Profile, February.

Geoscience Institute for Oil and Gas Recovery Research, 1990, Reservoir heterogeneity classification system for characterization and analysis of oil resource base in known reservoirs: prepared for U.S. Department of Energy, Office of Fossil Energy, Bartlesville Project Office.

National Petroleum Council, 1984, Enhanced Oil Recovery; Washington, D.C.

National Research Council, 1993, Advanced Exploratory Research Directions for Extraction and Processing of Oil and Gas: National Academy Press, Washington, $61 \mathrm{p}$.

NIPER/BDM, 1994, Geological and production characteristics of strandplain/barrier island reservoirs in the United States: Department of Energy Report, NIPER/BDM-0027, July, 162 p.

United States Federal Government, 1993, The domestic natural gas and oil initiative (DNGOI): Washington, D.C., December.

United States Federal Government, 1992, Conference report on H.R. 776, comprehensive national energy policy act (EPACT): Washington, D.C. 


\section{CHAPTER 2 \\ DESCRIPTION OF THE CLASS 4 RESOURCE AND THE TORIS PREDICTIVE METHODOLOGY}

The Department of Energy has defined Class 4 for the cost-shared oil recovery field demonstration program as strandplain/barrier island reservoirs. This depositionally defined class of reservoirs represents a significant portion of the nation's oil resource, as described in DOE's Tertiary Oil Recovery Information System (TORIS). The purpose of Chapter 2 is to describe the characteristics of the Class 4 resource, as defined by TORIS and to describe the TORIS methodology used to estimate the recovery potential that could result from the application of improved recovery technologies in Class 4 reservoirs. Section 2.1 presents an overview of the Class 4 resource, including a discussion of the distribution of the Class 4 resource, a comparison of the light and heavy oil portions of the resource, a description of the historical production from Class 4 reservoirs and the operator profile, and an overview of the production and reservoir characteristics of the major Class 4 plays in the country. Section 2.2 provides an overview of the TORIS predictive methodology, including a detailed discussion of the process screening criteria and predictive models. Section 2.3 discusses the relationship between the characteristics of the Class 4 TORIS reservoirs in the country and the TORIS process screening criteria. Section 2.4 describes the recovery potential which could result from the application of improved recovery technologies in the TORIS Class 4 reservoirs with details of the potential for Texas, Oklahoma, California, and the Rocky Mountains.

\subsection{Overview of the Class 4 Oil Resource}

The TORIS database contains information on 330 Class 4 reservoirs in the United States. The total original oil-in-place for these reservoirs is 30.8 billion barrels, which represents about $9 \%$ of the nearly 360 billion barrels of original oil-in-place in reservoirs listed in TORIS. As of 1991, the cumulative production from Class 4 reservoirs totaled approximately 10.9 billion barrels, or about $35 \%$ of the original oil-in-place (see Figure 2.1). Using the TORIS decline curve models, the projected remaining reserves at the termination of current production operations were 800 million barrels. Based on this estimation, the ultimate recovery with current operations from the TORIS Class 4 reservoir will be 11.6 billion barrels, or $38 \%$ of the original oil-in-place. The projected remaining oil-in-place at the end of current operations totals 19.1 billion barrels of oil, with an estimated 6.7 billion barrels of mobile oil and 12.3 billion barrels of immobile oil. The remaining mobile oil-in-place is the target for the future application of advanced secondary (ASR) technologies and the remaining immobile oil-in-place is the target for the application of enhanced oil recovery (EOR) technologies. Significant volumes of oil will be left behind unless economic improved recovery technologies can be implemented.

\subsubsection{Distribution of the Class 4 Resource.}

The distribution of the TORIS-defined Class 4 reservoirs in the United States is shown in Figure 2.2, which shows the number of reservoirs and the remaining oil-in-place for each state. Over half of the Class 4 reservoirs listed in the TORIS database are located in Texas (167), and these reservoirs account for almost one-third of the remaining oil-in-place for Class 4 reservoirs, or 6.0 billion barrels. Oklahoma also accounts for a significant portion of the Class 4 reservoirs, with 51 reservoirs and remaining oil-in-place of 5.9 billion barrels. The remainder of the TORIS Class 4 reservoirs are located primarily in California, the Rocky Mountains, other Mid-Continent states, and the Illinois Basin. 


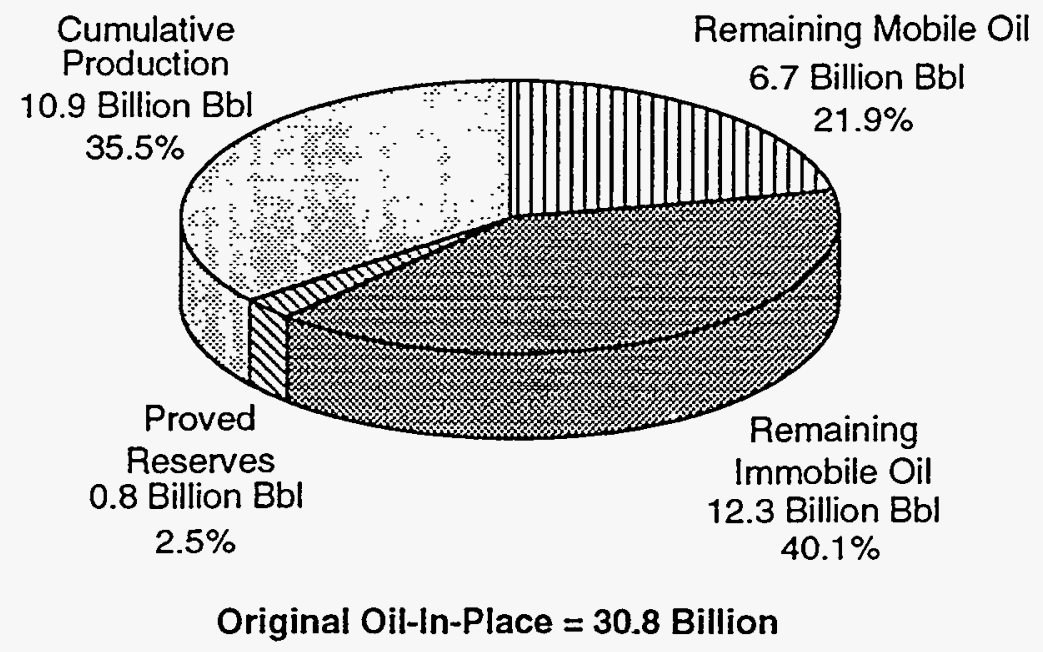

Figure 2.1 Oil-in-Place Volumes for Heavy and Light Oil in Class 4 (Source: BPO TORIS, 1994)

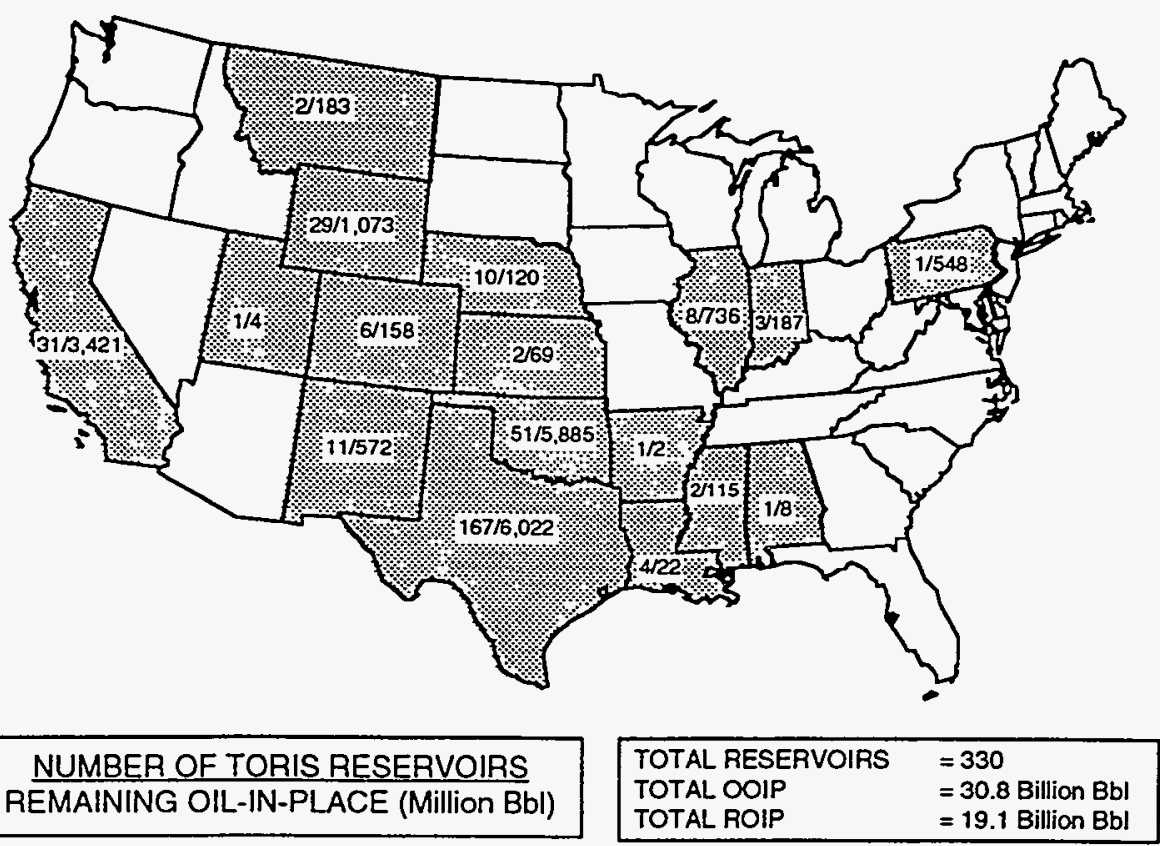

Figure 2.2 Distribution of Class 4 TORIS Reservoirs and Remaining Oil-in-Place (Source: BPO TORIS, 1994) 


\subsubsection{Heavy Versus Light Oil in Class 4 Reservoirs}

Most of the Class 4 oil resource represented in TORIS is light oil. Table 2.1 summarizes the oil-in-place for the Class 4 reservoirs based on API gravity. About $80 \%$ of the original-oil-inplace, cumulative production, and remaining oil-in-place in these reservoirs is light oil, with gravity above $25^{\circ}$ API. The oil volumes in the medium gravity range (between $20^{\circ}$ and $25^{\circ} \mathrm{API}$ ) are almost as large as the heavy oil volumes (between $10^{\circ}$ and $20^{\circ} \mathrm{API}$ ), with each category accounting for approximately $10 \%$ of the total. Many of the medium gravity oil reservoirs could be targets for thermal recovery processes that have most commonly been applied to heavy oil reservoirs.

\subsubsection{Production and Operator Profile for Class 4}

Light and heavy oil production from the TORIS Class 4 reservoirs has dropped significantly since 1970 , as shown in Figure 2.3. The total production from these reservoirs in 1970 averaged approximately 650,000 barrels of oil per day (BOPD), $6 \%$ of which was heavy oil. By 1991 , the

\begin{tabular}{|c|c|c|c|c|c|c|}
\hline \multicolumn{7}{|c|}{ 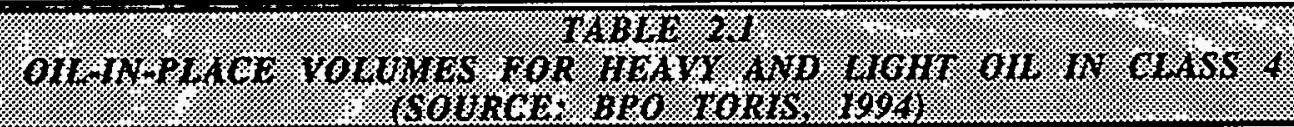 } \\
\hline \multirow[t]{2}{*}{$\begin{array}{l}\text { GRAVITY, } \\
\text { ०API }\end{array}$} & \multicolumn{2}{|c|}{$\begin{array}{l}\text { ORIGINAL } \\
\text { OIL-IN-PLACE }\end{array}$} & \multicolumn{2}{|c|}{$\begin{array}{l}\text { CUMULATIVE } \\
\text { RECOVERY }\end{array}$} & \multicolumn{2}{|c|}{$\begin{array}{l}\text { REMAINING } \\
\text { OIL-IN-PLACE }\end{array}$} \\
\hline & MMBO & $\%$ & MMBO & $\%$ & $\overline{\mathrm{MMBO}}$ & $\%$ \\
\hline LIGHT (API >25) & 24,593 & 80 & 8,835 & 81 & 15,158 & 79 \\
\hline MEDIUM $(20<A P I \leq 25)$ & 2,998 & 10 & 1,163 & 11 & 1,734 & 9 \\
\hline HEAVY $(10 \leq A P I \leq 20)$ & 3,164 & 10 & 870 & 8 & 2,235 & 12 \\
\hline TOTAL & 30,755 & & 10,867 & & 19,126 & \\
\hline
\end{tabular}

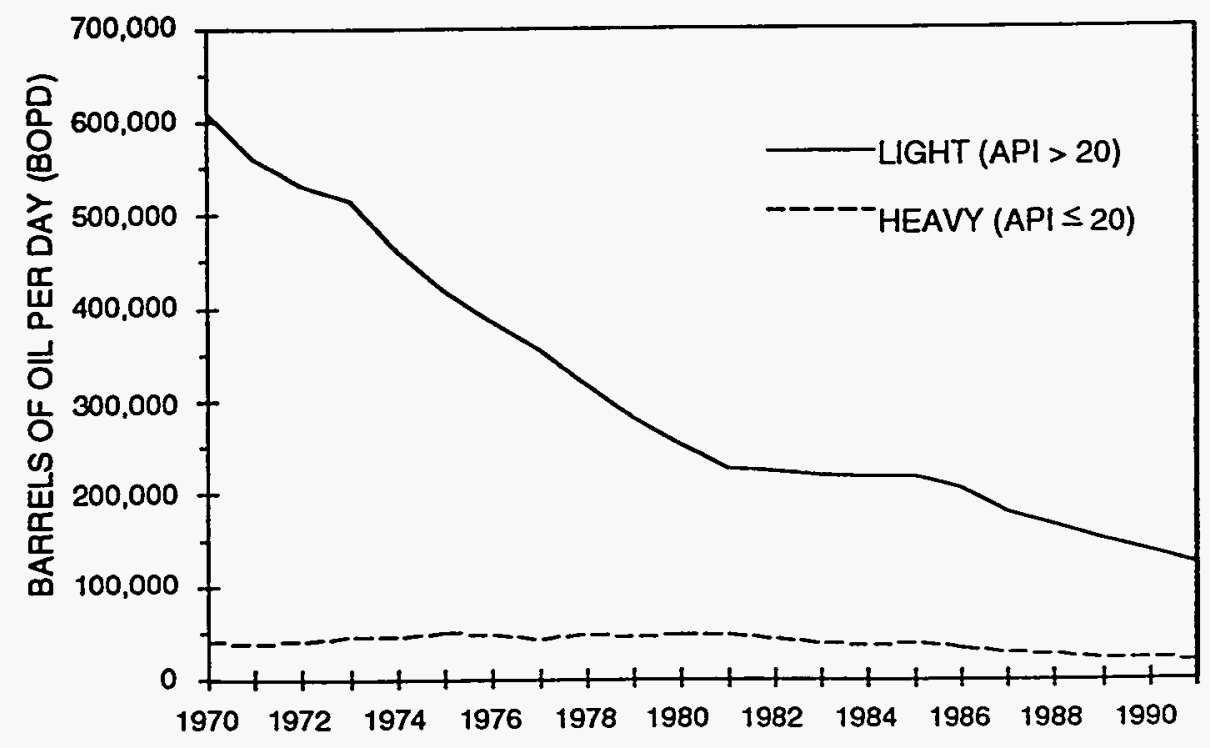

Figure 2.3 Light and Heavy Oil Production for Class 4 Reservoirs (Source: BPO TORIS, 1994) 
total production dropped to 145,000 BOPD, $14 \%$ of which was heavy oil. During this time, light oil production dropped from 610,000 to $125,000 \mathrm{BOPD}$, while heavy oil production dropped from 40,000 to 20,000 BOPD. Based on 1991 production volumes, just over half of the Class 4 production was operated by major oil companies, as shown in Figure 2.4. Medium and large independents contributed $7 \%$. Forty percent of the production is contributed by about 2,800 small independents. Operator size classifications are based on domestic liquid reserve volumes reported in the Oil and Gas Journal 300 Survey (Beck and Biggs, 1992).

\subsubsection{Overview Of Major Class 4 Plays}

The majority of the Class 4 resource is found in the strandplain/barrier island plays in four areas of the country: Texas, Oklahoma, California, and the Rocky Mountains. Table 2.2 summarizes the TORIS oil-in-place volumes for these four regions. The plays in Texas and Oklahoma are the most significant of the Class 4 plays, representing about two-thirds of the total original oil-in-place, cumulative production, ultimate recovery, and remaining oil-in-place. Figure 2.5 illustrates the significance of these regions in terms of the remaining oil-in-place, which is the target for future recovery projects. The plays in Texas and Oklahoma each total about $31 \%$ of this target. An additional $18 \%$ of the remaining oil-in-place is in California plays, and $11 \%$ is in plays in the Rocky Mountain states.

\begin{tabular}{|c|c|c|c|c|}
\hline 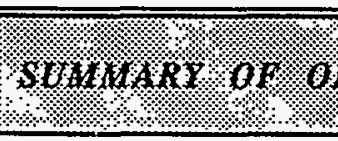 & 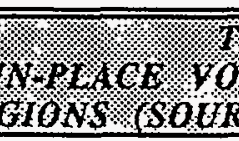 & 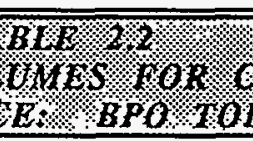 & 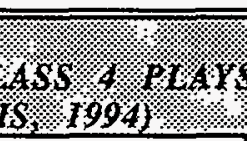 & 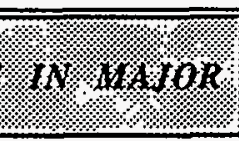 \\
\hline REGIONS & $\begin{array}{c}\text { ORIGINAL } \\
\text { OIL-IN-PLACE } \\
\text { MMBO }\end{array}$ & $\begin{array}{l}\text { CUMULATTVE } \\
\text { RECOVERY } \\
\text { MMBO }\end{array}$ & $\begin{array}{c}\text { REMAINING } \\
\text { OIL-IN-PLACE } \\
\text { MMBO }\end{array}$ & $\begin{array}{c}\text { NUMBER } \\
\text { OF } \\
\text { RESERVOIRS }\end{array}$ \\
\hline TEXAS & 10,184 & 3,933 & $\overline{6,022}$ & 167 \\
\hline OKLAHOMA & 10,071 & 3,757 & 5,855 & 51 \\
\hline CALIFORNIA & 4,790 & 1,322 & 3,421 & 31 \\
\hline ROCKY MOUNTAIN & 3,131 & 998 & 2,106 & 58 \\
\hline OTHER & 2,579 & 858 & 1,693 & 23 \\
\hline TOTAL & 30,755 & 10,867 & 19,126 & 330 \\
\hline
\end{tabular}

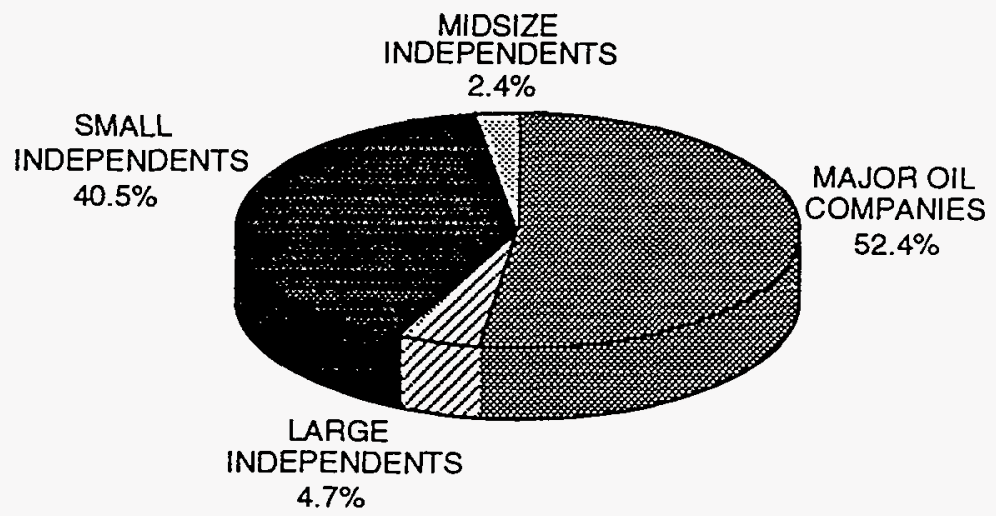

Operator Size Based On Domestic Liquid Reserves (OGJ 300): Majors: Reserves > 250 Million Bbls; Large Independents: Reserves $=100$ to 250 Million Bbls; Midsize Independents: Reserves $=10$ to 100 Million Bbls; Small Independents: Reserves < 10 Million Bbis

Figure 2.4 Operator Profile for Class 4 Reservoirs (Source: BPO TORIS, 1994; Beck and Biggs, 1992)) 


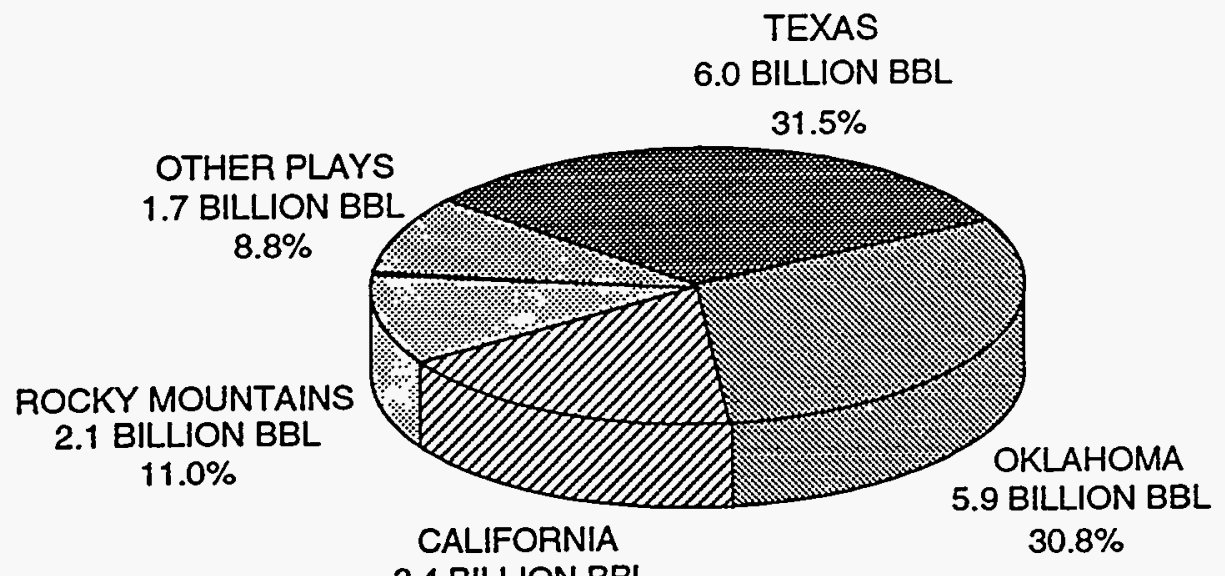

3.4 BILLION BBL $17.9 \%$

TOTAL ROIP $=19.1$ BILLION BBL

\section{Figure 2.5 Remaining Oil-in-Place Distribution for Class 4 Plays in Major Regions (Source: BPO TORIS, 1994)}

\subsubsection{Reservoir Characteristics of Class 4 Plays}

The average reservoir parameters for the major Class 4 play groupings were calculated from TORIS data. Average values for net pay, porosity, initial oil saturation, depth, permeability, gravity, initial pressure, and ultimate recovery factor with existing operations are summarized in Table 2.3. Class 4 reservoirs in these plays range in depth from around 3,000 to 5,300 feet. Average net pay thickness ranges from 21 feet in the Texas plays to 132 feet in the California plays. California plays appear to have the best reservoir quality in terms of porosity $(30 \%)$ and permeability $(1,600 \mathrm{mD})$, but the oil gravity averages only $22^{\circ}$ API. Although pay thickness averages only 21 feet, reservoir quality of the Texas plays is good, with an average porosity of $27 \%$ and permeability of $849 \mathrm{mD}$, and the oil gravity is more favorable at $32^{\circ} \mathrm{API}$. Oklahoma plays seem to have poorer reservoir quality, with average porosity of $18 \%$ and average permeability of $292 \mathrm{mD}$, but average pay thickness is fairly high at 60 feet. Plays in the Rocky Mountain states exhibit the poorest reservoir quality based on these average TORIS parameters, with porosity averaging $17 \%$ and permeability around $170 \mathrm{mD}$.

\begin{tabular}{|c|c|c|c|c|c|c|c|c|}
\hline ? & $4 \%$ & Whatary & 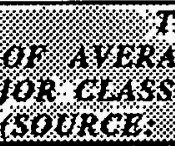 & 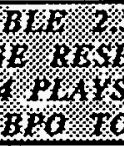 & 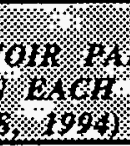 & wask & & \\
\hline MAJOR PLAYS & $\begin{array}{c}\text { NET } \\
\text { PAY, } \\
\text { FT } \\
\end{array}$ & $\begin{array}{c}\text { POROSITY, } \\
\%\end{array}$ & $\begin{array}{c}\text { INIIAL } \\
\text { OIL SAT., } \\
\%\end{array}$ & $\begin{array}{c}\text { DEPTH, } \\
\text { FT }\end{array}$ & $\begin{array}{c}\text { PERM- } \\
\text { EABIITY, } \\
\mathrm{mD}\end{array}$ & $\begin{array}{c}\text { GRAVTTY, } \\
\text { AAPI }\end{array}$ & $\begin{array}{c}\text { INIIAL } \\
\text { PRESSURE, } \\
\text { PSI } \\
\end{array}$ & $\begin{array}{l}\text { ULTIMATE } \\
\text { RECOVERY, } \\
\% \\
\end{array}$ \\
\hline TEXAS & 21 & 27 & 69 & 4,881 & 849 & 32 & 2,080 & 43 \\
\hline OXIAHOMA & 60 & 18 & 69 & 4,431 & 292 & 36 & 1.834 & 38 \\
\hline CALIFORNIA & 132 & 30 & 69 & 2,985 & 1,637 & 22 & 1,233 & 29 \\
\hline ROCKY MOUNTAINS & 27 & 17 & 69 & 5,317 & 169 & 37 & 2,155 & 28 \\
\hline OTHER PLAYS & 22 & 22 & 70 & 4,559 & 511 & 34 & 1,730 & 44 \\
\hline OVERALL AVERAGE & 52 & 23 & 69 & 4,434 & 692 & 32 & 1,806 & 38 \\
\hline
\end{tabular}




\subsubsection{Production and Improved Recovery in Class 4 Plays}

Improved oil recovery activity and production levels in the Class 4 reservoirs listed in the TORIS database vary significantly by region. While some regions like Oklahoma and California have been significantly impacted by improved oil recovery, the region with the largest remaining oil-in-place volume, Texas, has been minimally affected. The Rocky Mountain region has seen significant improved oil recovery activity, but the impact on overall production levels is not obvious.

Production from Texas Class 4 reservoirs listed in the TORIS database exhibits the steepest natural decline of the major regions (Figure 2.6), which indicates a need for improved oil recovery applications. Although several improved oil recovery techniques have been applied, past and current production volumes from improved oil recovery projects are minor when compared to overall production levels from Texas Class 4 reservoirs listed in the TORIS database. Techniques that have been applied include reservoir management, steam, in situ combustion, $\mathrm{CO}_{2}$ miscible injection, polymer, and alkaline polymer.

Improved oil recovery applications have significantly affected production levels from Oklahoma Class 4 reservoirs listed in the TORIS database. Several large polymer projects begun in the early 1980s not only moderated production decline, but actually increased production levels. Recent applications of reservoir management and infill drilling indicate further potential exists. Although applicable to a limited area in Oklahoma, thermal improved oil recovery processes have historically had only minor impact in Oklahoma Class 4 reservoirs.

As expected, considering the concentration of heavy oil in California, steam projects play a major role in production from California Class 4 reservoirs listed in the TORIS database. About 22,000 BOPD (Moritis, 1992), or nearly all of the regional production from Class 4 reservoirs listed in the TORIS database, comes from large steam projects in the Mount Poso, Placerita, and San Ardo fields.

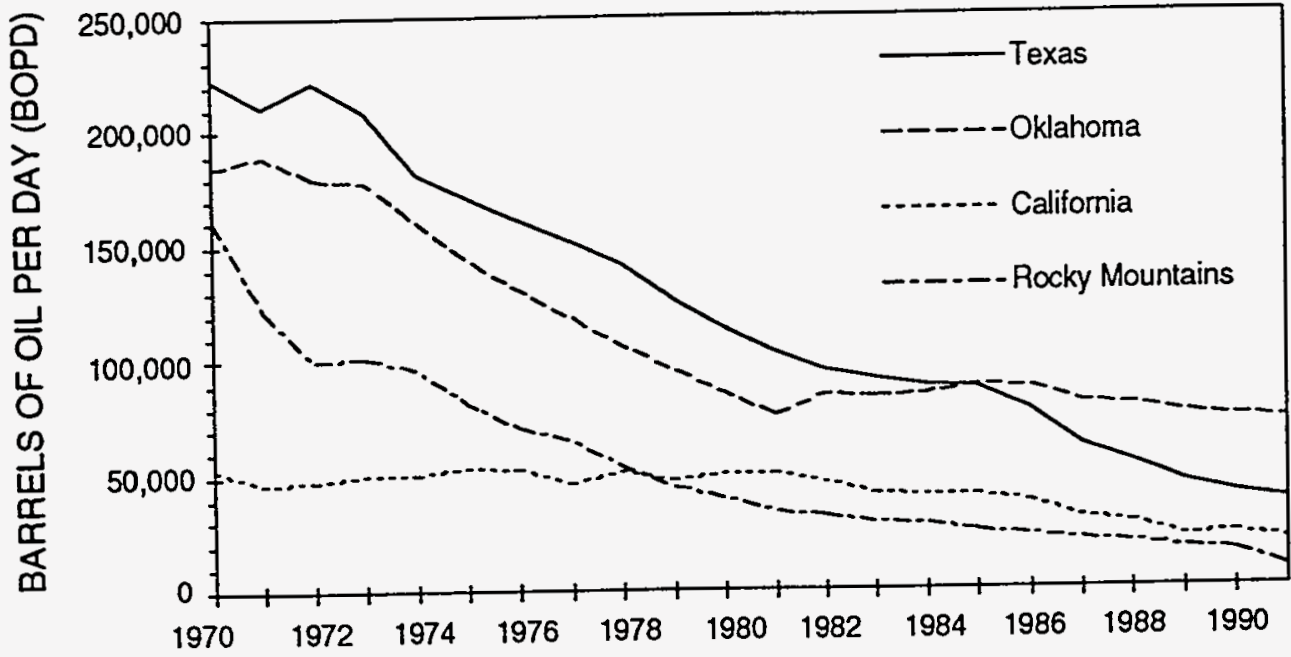

Figure 2.6 Historical Production for Class 4 Plays in Major Regions (Source: BPO TORIS, 1994) 
In Wyoming and the Rocky Mountain region, several improved oil recovery processes impact production. Polymers and gel polymers for either near-wellbore or in-depth conformance control are widely applied in the Rocky Mountain region. Although associated production volumes are as yet small, cyclical $\mathrm{CO}_{2}$ stimulation treatments are receiving considerable attention in Wyoming. Reservoir management techniques have demonstrated value in Rocky Mountain reservoirs. Improved oil recovery applications need to play an increasing role in the Rocky Mountain region to offset the recent production declines illustrated in Figure 2.6.

\subsection{Overview of the TORIS Predictive Methodology}

The recovery potential that could result from the future application of improved recovery technologies in the Class 4 reservoirs included in the TORIS database was estimated using the TORIS predictive and economic models. The TORIS database and predictive models were originally developed by the National Petroleum Council (NPC, 1984) and are maintained and updated by the DOE Bartlesville Project Office. TORIS is used to analyze the recovery potential for various improved oil recovery processes on a reservoir-by-reservoir basis using the average reservoir parameters and historical recovery data in the database and the individual process predictive models, as discussed below.

Section 2.2 is included in this report to provide some background and insights into the TORIS predictive methodology in an effort to illuminate the validity of the Class 4 improved recovery potential presented in Section 2.4 . Simply stating the TORIS recovery potential and not describing the assumptions that have gone into these predictions does not provide any degree of confidence in the numbers. This section describes the more significant assumptions used in the TORIS prediction, and includes a brief summary of the TORIS methodology, a detailed discussion of the screening criteria which are utilized in TORIS, an overview of each of the TORIS predictive models, and a discussion of some of the important economic considerations in the TORIS analyses.

\subsubsection{Summary of TORIS Methodology}

The TORIS reservoir database contains the average geologic and reservoir parameters for over 2,500 reservoirs in the country. The database contains volumetric original oil-in-place values for each reservoir, cumulative production data, and historical production data from 1970 forward. The ultimate recovery that will result from the continued operation of each reservoir is established using decline curve models, and then the target remaining mobile and immobile oil-in-place volumes are calculated. The decline curve analysis is also utilized to determine the projected reservoir abandonment dates with respect to the timing of future improved recovery projects.

The reservoir parameters contained in the database are screened by the TORIS system to determine the recovery processes that are applicable to each reservoir. The enhanced oil recovery screening criteria used in TORIS are those established by the 1984 National Petroleum Council (NPC, 1984) study. The screening criteria for advanced secondary recovery processes were developed by DOE subsequent to the NPC study (see section 2.2.2.2). The implemented technology case is considered to be the state-of-the-art case while the advanced technology case assumes a relaxation of some of the screening criteria due to reasonable technological improvements. For example, the profile modification screening criteria in the advanced technology case assume that the conformance control chemicals are stable at higher reservoir temperature and water salinity than in the implemented technology case. The advanced technology case also assumes some recovery process efficiency improvements, such as decreased chemical retention, increased injectant sweep efficiency, or improved overall process displacement efficiency. (See the 1984 NPC study for details on the assumed individual process improvements between the implemented and advanced technology cases and for more details on the predictive models themselves.) 
The predictive models for each of the applicable recovery processes in each reservoir are run using the average reservoir parameters in the TORIS database. The TORIS predictive models are discussed in detail in Section 2.2.3. Results are obtained for both the implemented and advanced technology cases. The resultant injection and production streams are then used as input to economic models. The economic models consider the capital investments and operating costs required to implement and maintain the individual recovery projects. The economic models examine project economics at various oil prices using West Texas Intermediate as the benchmark. The project economics for the applicable recovery processes in each reservoir are compared at each oil price, and the optimum process is selected based on oil recovery volumes and projected rates of return. The recovery processes are considered to be viable in TORIS if the project rate of return exceeds defined minimum hurdle rates. Because the goal of the DOE R\&D efforts is to maximize the recovery of the remaining oil resource, TORIS is set up to select the viable process that recovers the most oil from each reservoir, rather than to select the process with the best economics. The maximum oil recovery potential for a group of reservoirs can then be defined for both the implemented and advanced technology cases.

\subsubsection{Discussion of TORIS Screening Criteria}

The 1984 National Petroleum Council EOR study defined most of the process screening criteria that are used in the TORIS recovery process predictive analyses. The NPC screening criteria were developed to determine the applicability of chemical flooding processes (polymer, surfactant, and alkaline), miscible gas injection processes, and thermal recovery processes (steam drive and in situ combustion). Screening criteria were developed for both an implemented technology case and an advanced technology case. The implemented technology case screening criteria were developed based on the review of known successful projects. The advanced technology case screening criteria were developed assuming that reasonable technological advancements could be achieved as a result of focused research and development efforts. Subsequent to the NPC study, the DOE developed process predictive models as well as implemented and advanced case process screening criteria for profile modification and infill drilling processes. The process screening criteria are discussed in detail in this section, and the criteria are summarized in Tables 2.4 and 2.5.

\subsubsection{Process Screening Criteria Developed by NPC}

The screening criteria for chemical, miscible gas, and thermal recovery processes are described in detail in the 1984 NPC study. The discussion below is a summary of the information included in the NPC study. The screening criteria for the application of polymer, surfactant, and alkaline flooding processes are primarily based on the characteristics of the rock (permeability and lithology), oil (viscosity and API gravity), and formation brine (ppm dissolved solids), and on the reservoir temperature. Application of miscible gas injection processes is primarily related to the capability to attain miscibility between the crude oil and $\mathrm{CO}_{2}$, or the minimum miscibility pressure (MMP), and on the oil gravity. The screening criteria for the applicability of thermal processes are based on the characteristics of published successful projects and include formation depth, current reservoir pressure, net pay, porosity, oil content, oil gravity, oil viscosity, formation permeability, and formation transmissibility.

Polymer Flooding: The NPC determined that historical polymer flooding projects were only successful when permeability was greater than $20 \mathrm{mD}$, oil viscosity was less than $100 \mathrm{cP}$, formation brine salinity was less than $100,000 \mathrm{ppm}$, and formation temperature was less than $200^{\circ}$ F. These criteria represent the implemented technology case. Polymer flooding was assumed to be applicable in both sandstone and carbonate reservoirs. The permeability limit reflects the fact that high molecular weight polymers cannot be effectively propagated through low permeability rock. Lower molecular weight polymers in higher concentrations could possibly be used in low permeability rock to achieve the desired viscosity or resistance factors, but the low injectivity would increase project life and adversely affect the project economics. The NPC also found that 


\begin{tabular}{|c|c|c|c|c|c|c|c|c|}
\hline \multicolumn{9}{|l|}{ ארא } \\
\hline SCREENING PARAMETERS & UNTS & $\begin{array}{l}\text { PROFILE } \\
\text { MODLF- } \\
\text { CATION }\end{array}$ & $\begin{array}{l}\text { POLYMER } \\
\text { FLOODING }\end{array}$ & $\begin{array}{l}\text { SURFACTANT } \\
\text { FLOODING }\end{array}$ & $\begin{array}{l}\text { ALKAIINE } \\
\text { FLOODING }\end{array}$ & $\begin{array}{l}\text { MISCIBIE } \\
\text { FLOODING } \\
\text { (CARBON } \\
\text { DIOXIDE) }\end{array}$ & \multicolumn{2}{|c|}{ THERMAL RECOVERY } \\
\hline OIL GRAVTYY & ${ }^{\circ} \mathrm{API}$ & - & - & - & $<30$ & 225 & 10 to 34 & 10 to 35 \\
\hline IN SITU OIL VISCOSIIY $(\mu)$ & $\mathbf{c P}$ & $<100$ & $<100$ & $<40$ & $<90$ & - & $\leq 15,000$ & $\leq 5,000$ \\
\hline DEPTH (D) & Feet & - & - & - & - & - & $\leq 3,000$ & $\leq 11,500$ \\
\hline PAY ZONE THICKNESS (H) & Feet & - & - & - & - & - & 220 & 220 \\
\hline RESERVOIR TEMPERATURE $\left(T_{R}\right)$ & ${ }^{\circ} \mathbf{F}$ & $<180$ & $<200$ & $<200$ & $<200$ & - & - & - \\
\hline POROSITY ( & Fraction & - & - & - & - & - & $20.20^{(2)}$ & $\geq 0.20^{(2)}$ \\
\hline PERMEABILIY, AVERAGE (k) & $\mathrm{mD}$ & $>20$ & $>20$ & $>40$ & $>20$ & - & 250 & 35 \\
\hline TRANSMISSIBIITY (kh/1) & $\mathrm{mDxft} / \mathrm{cP}$ & - & - & - & - & - & 25 & 25 \\
\hline RESERVOIR PRESSURE $\left(\mathrm{P}_{\mathrm{R}}\right)$ & psi & - & - & - & - & $\geq \operatorname{MMP}^{(1)}$ & $\leq 1,500$ & $\leq 2,000$ \\
\hline $\begin{array}{l}\text { MINIMUM OIL CONTENT AT START } \\
\text { OF PROCESS }\left(S_{o} \times \phi\right)\end{array}$ & Fraction & - & - & - & - & - & $\geq 0.10$ & $\geq 0.08$ \\
\hline $\begin{array}{l}\text { SALINITY OF FORMATION } \\
\text { BRINE (IDS) }\end{array}$ & Ppm & $<100,000$ & $<100,000$ & $<100,000$ & $<100,000$ & - & - & - \\
\hline ROCK TYPE & - & & $\begin{array}{c}\text { Sandstone } \\
\text { or } \\
\text { Carbonate }\end{array}$ & Sandstone & Sandstone & $\begin{array}{c}\text { Sandstone } \\
\text { or } \\
\text { Carbonate }\end{array}$ & $\begin{array}{c}\text { Sandstone } \\
\text { or } \\
\text { Carbonate }\end{array}$ & $\begin{array}{c}\text { Sandstone } \\
\text { or } \\
\text { Carbonate }\end{array}$ \\
\hline
\end{tabular}

(1) MMP denotes minimum miscibility pressure, which depends on temperature and crude oil composition.

(2) Ignored if minimum oil content criterion is satisfied.

\begin{tabular}{|c|c|c|c|c|c|c|c|c|}
\hline \% & \% & \%ork & 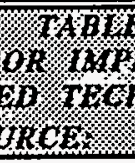 & 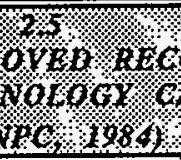 & 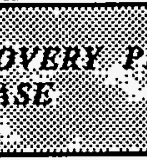 & FST & & \\
\hline SCREENING PARAMETERS & UNITS & $\begin{array}{l}\text { PROFILE } \\
\text { MODIFI- } \\
\text { CATION }\end{array}$ & $\begin{array}{l}\text { POLYMER } \\
\text { FLOODING }\end{array}$ & $\begin{array}{l}\text { SURFACTANT } \\
\text { FLOODING }\end{array}$ & $\begin{array}{l}\text { ALKALINE } \\
\text { FLOODING }\end{array}$ & $\begin{array}{l}\text { MISCIBLE } \\
\text { FLOODING } \\
\text { (CARBON } \\
\text { DIOXIDE) }\end{array}$ & $\begin{array}{l}\text { THERMAL } \\
\text { STEAM }\end{array}$ & $\begin{array}{l}\text { ECOVERY } \\
\text { IN SITU } \\
\text { COMB. }\end{array}$ \\
\hline OIL GRAVITY & ${ }^{\circ} \mathrm{API}$ & - & - & - & $<30$ & 225 & - & - \\
\hline IN SITU OIL VISCOSITY $(\mu)$ & $\mathbf{c P}$ & $<150$ & $<150$ & $<100$ & $<100$ & - & - & $\leq 5,000$ \\
\hline DEPTH (D) & Fot & - & - & - & $\overline{-}$ & - & $\leq 5,000$ & $\overline{-}$ \\
\hline PAY ZONE THICKNESS (H) & Feet & - & - & - & - & - & 215 & 210 \\
\hline RESERVOIR TEMPERATURE $\left(T_{R}\right)$ & ${ }^{\circ} \mathbf{F}$ & $<250$ & $<250$ & $<250$ & $<200$ & - & 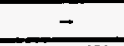 & - \\
\hline POROSITY ( $(\phi)$ & Fraction & - & - & - & - & - & $\geq 0.15^{(2)}$ & $\geq 0.15^{(2)}$ \\
\hline PERMEABIIITY, AVERAGE (K) & $\overline{m D}$ & $>10$ & $>10$ & $>10$ & $>10$ & $=$ & 210 & $\geq 10$ \\
\hline TRANSMISSIBIIITY (kh/p) & $\mathrm{mDxfu} / \mathrm{cP}$ & - & - & - & - & - & - & - \\
\hline RESERVOIR PRESSURE $\left(\mathrm{P}_{\mathrm{R}}\right)$ & psi & - & $\overline{-}$ & - & - & $2 \mathrm{MMP}^{(1)}$ & $\leq 2,000$ & $\leq 4,000$ \\
\hline $\begin{array}{l}\text { MINIMUM OIL CONTENT AT START } \\
\text { OF PROCESS }\left(S_{\text {ox }}{ }^{\circ}\right)\end{array}$ & Fraction & - & - & - & - & - & 20.08 & 20.08 \\
\hline $\begin{array}{l}\text { SALINTTY OF FORMATION } \\
\text { BRINE (IDS) }\end{array}$ & ppm & $<200,000$ & $<200,000$ & $<200,000$ & $<200,000$ & - & - & - \\
\hline ROCK TYPE & - & & $\begin{array}{c}\text { Sandstone } \\
\text { or } \\
\text { Carbonate }\end{array}$ & $\begin{array}{c}\text { Sandstone } \\
\text { or } \\
\text { Carbonate }\end{array}$ & Sandstone & $\begin{array}{c}\text { Sandstone } \\
\text { or } \\
\text { Carbonate }\end{array}$ & $\begin{array}{c}\text { Sandstone } \\
\text { or } \\
\text { Carbonate }\end{array}$ & $\begin{array}{c}\text { Sandstone } \\
\text { or } \\
\text { Curbonate }\end{array}$ \\
\hline
\end{tabular}

(1) MMP denotes minimum miscibility pressure, which depends on temperature and crude oil composition.

(2) Ignored if minimum oil content criterion is satisfied. 
polymer applications were not effective when oil viscosity exceeds $100 \mathrm{cP}$, since higher polymer concentrations are required and lower injection rates are experienced, both of which affect economics. The brine salinity limitation reflects the fact that most synthetic polymers have not been demonstrated to be effective when brine salinity is above $100,000 \mathrm{ppm}$, although some biologically produced polymers are relatively insensitive to salinity. The temperature limitation for polymers is significant due to thermal degradation which results in loss of viscosity. In the advanced technology case, the NPC assumed that improvements in the cost effectiveness and stability of polymers could extend applicability to reservoirs with permeability greater than $10 \mathrm{mD}$, oil viscosity less than $150 \mathrm{cP}$, formation brine salinity less than $200,000 \mathrm{ppm}$, and formation temperatures less than $250^{\circ} \mathrm{F}$.

Surfactant Flooding: The NPC determined that surfactant flooding projects were only successful when permeability was greater than $40 \mathrm{mD}$, oil viscosity was less than $40 \mathrm{cP}$, formation brine salinity was less than $100,000 \mathrm{ppm}$, and formation temperature was less than $200^{\circ} \mathrm{F}$. These criteria represent the implemented technology case. Surfactant flooding was not considered to be applicable in carbonate reservoirs in the implemented technology case. As in the case of polymer flooding, the permeability of the formation impacts surfactant flooding due to the adverse effects on injectivity, project life and economics at low permeabilities. The success of surfactant flooding processes when oil viscosity is greater than $40 \mathrm{cP}$ is limited by the costs associated with the higher polymer concentrations that are required to achieve mobility control. The success of surfactant flooding is severely limited by the brine salinity and formation temperature together due to the adverse impacts on both the surfactants and the associated polymers. In the advanced technology case, the NPC assumed that improvements in the cost effectiveness and stability of surfactants and polymers could extend applicability to reservoirs with permeability greater than $10 \mathrm{mD}$, oil viscosity less than $100 \mathrm{cP}$, formation brine salinity less than $200,000 \mathrm{ppm}$, and formation temperatures less than $250^{\circ} \mathrm{F}$. The advanced technology case also assumes that surfactants could be applicable to both sandstone and carbonate reservoirs.

Alkaline Flooding: The NPC determined that alkaline flooding projects were only successful when permeability was greater than $20 \mathrm{mD}$, oil viscosity was less than $40 \mathrm{cp}$, oil gravity was less than $30^{\circ} \mathrm{API}$, formation brine salinity was less than $100,000 \mathrm{ppm}$, and formation temperature was less than $200^{\circ} \mathrm{F}$. These criteria represent the implemented technology case. Alkaline flooding was not considered to be applicable in carbonate reservoirs in either the implemented or advanced technology case due to the adverse chemical/rock interactions. The permeability, salinity, and temperature criteria reflect the limitations of the polymers used in the alkaline flooding process. The oil viscosity limitation reflects the fact that successful field tests have not been achieved when oil viscosity was greater that $90 \mathrm{cP}$. The oil gravity limitation was established to correspond to the acid number of the oil which, at that time, was considered essential for alkaline flooding. In the advanced technology case, the NPC assumed that improvements in the cost effectiveness and stability of alkaline chemicals, cosurfactants and polymers could extend applicability to reservoirs with permeability greater than $10 \mathrm{mD}$, oil viscosity less than $100 \mathrm{cP}$, and formation brine salinity less than $200,000 \mathrm{ppm}$. The oil gravity and formation temperature limitations were determined to be the same for the implemented and advanced technology cases.

Miscible Flooding: The primary limitation for the application of miscible gas injection processes was the ability to achieve miscibility in the reservoir between the crude oil and the injected solvent $\left(\mathrm{CO}_{2}\right)$. The minimum miscibility pressure (MMP) for the TORIS reservoirs was estimated by the NPC using two correlations. The first correlation estimates the molecular weight of the $\mathrm{C}_{5}+$ portion of the crude oil using oil gravity (Lasater, 1958). The second correlation estimates the MMP using the molecular weight of the $\mathrm{C}_{5}+$ portion of the crude oil and the formation temperature (Holm and Josendal, 1974; Mungan, 1981). The NPC assumed that candidate reservoirs must have an MMP that is less than the original or maximum operating pressure. The NPC also evaluated reservoirs for which the MMP was greater than 200 psi above the current reservoir pressure to determine the feasibility of repressurization. In addition, the NPC assumed that miscible gas injection was not viable for crude oil with gravity less than $25^{\circ}$ API and 
was applicable in both sandstone and carbonate reservoirs. The advanced technology case uses the same screening criteria, but the NPC assumed that higher ultimate recovery could be achieved through the use of larger $\mathrm{CO}_{2}$ slug sizes and mobility control agents in more heterogeneous reservoirs.

Steamflooding: The NPC determined that steamflooding was only successful in projects with formation depth less than 3,000 feet, current reservoir pressure less than 1,500 psi, net pay greater than 20 feet, porosity greater than $20 \%$, oil content (oil saturation-porosity product) greater than 0.1 , oil gravity in the range of 10 to $34^{\circ} \mathrm{API}$, oil viscosity less than $15,000 \mathrm{cP}$, formation permeability greater than $250 \mathrm{mD}$, and formation transmissibility $(\mathrm{kh} / \mu)$ greater than $5 \mathrm{mD}-\mathrm{ft} / \mathrm{cP}$. These criteria represent the implemented technology case. Steamflooding was assumed to be applicable in both sandstone and carbonate reservoirs. The depth limitation is important because heat losses increase with increasing depth. The net pay limitation is important, because excessive heat losses occur in thin reservoirs. Porosity is important because as porosity decreases more energy is required to heat the larger volume of rock. The oil content criterion (oil saturationporosity product saturation) was established since there must be sufficient oil in the reservoir to justify the cost of the steamflood. The oil viscosity and gravity limitations were established to insure that minimum oil mobility requirements are achievable. The reservoir permeability and transmissibility limitations were established to insure that steam injectivity is high enough to successfully propagate the steam front. The advanced technology case screening criteria were developed assuming that reasonable steamflooding techniques and equipment could be developed to extend the process to reservoirs with depth less than 5,000 feet, current reservoir pressure less than 2,000 psi, net pay greater than 15 feet, porosity greater than $15 \%$, oil content (oil saturationporosity product) greater than 0.08 , and formation permeability greater than $250 \mathrm{mD}$.

In Situ Combustion: The NPC determined that in situ combustion was only successful in projects with formation depth less than 11,500 feet, current reservoir pressure less than 2,000 psi, net pay greater than 20 feet, porosity greater than $20 \%$, oil content (oil saturation $x$ porosity) greater than 0.08 , oil gravity in the range of 10 to $35^{\circ} \mathrm{API}$, oil viscosity less than $5,000 \mathrm{cP}$, formation permeability greater than $35 \mathrm{mD}$, and formation transmissibility $(\mathrm{kh} / \mu)$ greater than 5 $\mathrm{mD}-\mathrm{ft} / \mathrm{cP}$. The importance of the in situ combustion screening criteria parallels those for steam flooding. The advanced technology case screening criteria were developed assuming that reasonable in situ combustion techniques and equipment could be developed to extend the process to reservoirs with current reservoir pressure less than $4,000 \mathrm{psi}$, net pay greater than 10 feet, porosity greater than $15 \%$, and formation permeability greater than $10 \mathrm{mD}$.

\subsubsection{Screening Criteria For ASR Processes}

Subsequent to the NPC study, DOE developed additional predictive models for TORIS for the recovery of unrecovered mobile oil (UMO) that are termed advanced secondary recovery (ASR) processes (ICF/BEG, 1990 and IOGCC, 1993). Predictive models were developed to define the recovery potential which could result from the application of profile modification and infill drilling processes. The screening criteria that were developed for profile modification were essentially those that the NPC developed for polymer flooding, except that the temperature limitation for the implemented technology case was reduced to $180^{\circ} \mathrm{F}$. This reflects the fact that cost-effective polymers for use in profile modification applications above $180^{\circ} \mathrm{F}$ are still in the developmental stage with limited success due to thermal degradation of the polymers. No screening criteria were developed specifically for infill drilling, rather the economics of reducing the well spacing in waterflood reservoirs determines the applicability, with the recovery improvement based on the improvement in reservoir continuity. Polymer flooding is also considered to be an ASR process and the screening criteria are those discussed above. 


\subsubsection{Discussion of TORIS Predictive Model Methodologies}

The predictive models used by the NPC and currently used in TORIS were developed by Scientific Software-Intercomp for DOE. Predictive models were developed to assess the recovery potential and economics for chemical flooding, miscible flooding, steam flooding, in situ combustion, and polymer flooding. Subsequent to the NPC study, predictive models were developed for profile modification and infill drilling. The general characteristics of these predictive models are discussed in this section.

\subsubsection{Chemical Flood Predictive Model}

The Chemical Flood Predictive Model (CFPM) was developed by Scientific SoftwareIntercomp for DOE to predict the recovery performance and economics of micellar-polymer (surfactant) floods. This publicly available model was modified somewhat by the NPC for use in the 1984 EOR Study, and the modified model is currently utilized in the TORIS system to predict the results of both surfactant and alkaline floods.

The CFPM predicts the overall recovery efficiency of a chemical flood based on the displacement efficiency, vertical sweep efficiency of the surfactant, and the sweep efficiency of the polymer. The displacement efficiency is determined by the capillary number, which is calculated as a function of the permeability, depth, and well spacing of a reservoir. A constant micellar phase-oil phase interfacial tension of $10^{-3} \mathrm{dyne} / \mathrm{cm}$ is used. The vertical sweep efficiency of the surfactant is estimated from correlations which were derived from simulation results which considered surfactant slug size, surfactant adsorption, and reservoir heterogeneity. The polymer sweep efficiency is empirically derived from numerical simulation results which considered polymer slug size and vertical sweep efficiency. The estimated overall recovery efficiency is then corrected to take into consideration the effects of crossflow between layers based on numerical simulation considering the ratio of vertical to horizontal permeability. Oil-water fractional flow theory is utilized to predict breakthrough, peak oil production rate, and project life. The NPC modified the model slightly to predict the performance of alkaline floods, but basically the alkaline flood results are assumed to be a fraction of the surfactant flood results.

The CFPM generates an oil rate versus time relationship for a single five-spot pattern in a surfactant flood or alkaline flood, and the results are then scaled up to represent the performance of a reservoirwide project using a specified pattern development schedule. The after-tax cash flow for each project is then calculated taking into account the capital costs for drilling, well conversions, chemical and injectant costs, operating costs, depreciation, royalties, and taxes. (See DOE/BC86/11/SP and Paul et al. (1982) for details of the model methodology.)

\subsubsection{Miscible Flood Predictive Model}

The $\mathrm{CO}_{2}$ Miscible Flood Predictive Model (CO2PM) was developed by Scientific SoftwareIntercomp for DOE to predict the recovery performance and economics of miscible $\mathrm{CO}_{2}$ floods. This publicly-available model was used in the 1984 NPC Study and is currently utilized in the TORIS system.

The CO2PM is a three-dimensional (layered, five-spot) two-phase (aqueous and olefinic) threecomponent (oil, water, and $\mathrm{CO}_{2}$ ) model that utilizes fractional flow theory (modified for the effects of viscous fingering, areal sweep, vertical heterogeneity, and gravity segregation) to predict oil, water, and $\mathrm{CO}_{2}$ rates. Fractional flow theory (Buckley and Leverett, 1942) based on a specialized version of the method of characteristics known as coherence or simple wave theory (Patton et al., 1971; Pope, 1980) is applied to represent the results of first contact miscible displacement in the presence of a second immiscible phase. The model incorporates the Koval factor into the fractional flow theory to account for viscous fingering effects (Koval, 1963) and an extension of the Koval approach is utilized to account for the effects of gravity segregation. The modified fractional flow theory is then corrected for areal sweep using a generalization of the method developed by Claridge 
(Claridge, 1972). A reservoir can be described in the model with up to five noncommunicating layers to account for reservoir heterogeneity, and the layer permeabilities are calculated from a reservoir-specific value for the Dykstra-Parsons coefficient.

The CO2PM generates an oil rate versus time relationship for a single five-spot pattern in a miscible flood, and the results are then scaled up to represent the performance of a reservoirwide project using a specified pattern development schedule. The after-tax cash flow for each project is then calculated, taking into account the capital costs for drilling, well conversions, $\mathrm{CO}_{2}$ purchase, compression and recycle costs, operating costs, depreciation, royalties, and taxes. (See DOE/BC86/12/SP and Paul et al. (1984) for details of the model methodology.)

\subsubsection{Steamflood Predictive Model}

The Steamflood Predictive Model (SFPM) was developed by Scientific Software-Intercomp for DOE to predict the recovery performance and economics of steamfloods. This publicly available model was used in the 1984 NPC Study and is currently utilized in the TORIS system.

The SFPM was developed using four algorithms, each of which can be used independently to predict the performance of a steam drive. These four simplified steamflood predictive algorithms are known as: (1) the Williams et al. (1980) or SUPRI (Stanford University Petroleum Research Institute) model, (2) the Jones (1981) model, (3) the Gomaa (1980) model, and (4) the Intercomp model (Aydelotte and Pope, 1983). The SUPRI model provided the basic architecture for the SFPM, including the surface and wellbore heat loss calculations and the economic analysis methodology. This model utilizes the method developed by Marx and Langenheim (1959) for calculation of reservoir heat losses and for predicting the growth of the steam zone as continuous steam injection progresses. The original Jones model was based on the work of Van Lookeren (1977) and Myhill and Stegemeier (1978) and utilizes an injection rate optimization function based on a vertical conformance factor. This function was replaced in SFPM through modification of the heat balance equations to allow for variable injection rates and steam qualities. The oil recovery algorithm is based on the Marx and Langenheim equations as modified by Mandl and Volek (1969). The Gomaa model predicts steamflood performance based on empirical correlations for California reservoirs, developed from numerical simulation using the Coats et al. (1974) implicit steamflood model. Correlations were developed to predict vertical heat losses, vertical sweep, and oil recovery as a function of reservoir thickness and volume, heat injection, steam quality, and oil saturation. The Intercomp model was developed as a simplified extension of these earlier analytical heat balance models and considers fractional flow characteristics, vertical and areal sweep effects, steam injectivity, and wellbore and surface heat losses.

Using any one of these predictive algorithms, the SFPM generates an oil rate versus time relationship for a single five-spot pattern in a steamflood, and the results are then scaled up to represent the performance of a reservoirwide project using a specified pattern development schedule. The after-tax cash flow for each project is then calculated taking into account the capital costs for drilling, well conversions, steam generation costs, operating costs, depreciation, royalties, and taxes.

The four oil recovery predictive algorithms described were compared by the NPC and the Gomaa model was found to yield the most accurate prediction of steamflood performance except when reservoir dip exceeded $10^{\circ}$. The NPC developed a dip correlation through a series of calibration runs, and this correlation is included in the model. The Gomaa model is used in the TORIS steamflood predictions. (See DOE/BC-86/6/SP and the papers cited above for details of the model methodology.)

\subsubsection{In Situ Combustion Predictive Model}

The In situ Combustion Predictive Model (ICPM) was developed by Scientific SoftwareIntercomp for DOE to predict the recovery performance and economics of in situ combustion 
projects. This publicly-available model was used in the 1984 NPC Study and is currently utilized in the TORIS system.

The ICPM predicts oil recovery for in situ combustion projects based on the correlations developed by Brigham et al. (1980). These correlations relate the volumes of oil burned and produced to the volume of air injected and the reservoir volume based on the analysis of the results of 12 field pilot tests. These correlations are valid for the dry combustion process only. The NPC developed a method for predicting the performance of wet combustion processes based on laboratory slim tube test data developed by Garon and Wygal (1984) and Prats (1982). The wet combustion process correlations are applied only if the oil viscosity is above $10 \mathrm{cP}$ and the reservoir permeability is above $100 \mathrm{mD}$. Various assumptions were made about the process specifics as outlined in the model documentation (DOE/BC-86/7/SP) and the NPC Study.

The ICPM generates an oil rate versus time relationship for a portion of a pattern in an in situ combustion project, and the results are then scaled up to represent the performance of a reservoirwide project using a specified pattern development schedule. The after-tax cash flow for each project is then calculated taking into account the capital costs for drilling, well conversions, process costs, operating costs, depreciation, royalties, and taxes.

\subsubsection{Polymer Flood Predictive Model}

The Polymer Flood Predictive Model (PFPM) was developed by Scientific Software-Intercomp for DOE to predict the recovery performance and economics of either polymer floods or waterflooding and to estimate the incremental performance of polymer flooding over waterflooding. This publicly available model was used in the 1984 NPC Study and is currently utilized in the TORIS system to predict polymer flood recovery through the improvement of mobility ratio and sweep efficiency in waterfloods.

The PFPM is a three-dimensional, two-phase (water and oil) simulator that represents the waterflood performance of one-eighth of a five-spot pattern using a stream tube approach (Higgens and Leighton, 1962; Leblanc and Caudle, 1971) and fractional flow theory. The model utilizes five noncommunicating layers of equal thickness to represent some degree of reservoir heterogeneity, and the layer permeabilities are defined using the average reservoir permeability and the Dykstra-Parsons coefficient of permeability variation. The areal and vertical recovery of the waterflood is estimated using eight stream tubes in each layer and a modified version of the Buckley-Leverett fractional flow theory (Buckley and Leverett, 1942) known as the method of characteristics (Patton et al., 1971; Pope, 1980). The model estimates the saturation profile for each stream tube, and these calculations are used to calculate the stream tube conductivity, which determines the flow distribution between stream tubes and the change in injectivity over time. The model takes into account the change in mobility caused by the injection of polymer and considers polymer retention, non-Newtonian effects, and other polymer properties. PFPM first estimates oil recovery using the assumption of continuous polymer injection, and then corrects the results for finite polymer slug sizes using a correlation was developed from rigorous 3-D numerical simulation of polymer floods. (A Scientific Software-Intercomp finite difference polymer flood model was used to develop this correlation.) The model estimates the incremental recovery of the polymer flood by comparison of the results with a prediction of waterflood performance.

The PFPM generates an oil rate versus time relationship for an eighth of a five-spot pattern in a polymer flood project, and the results are then scaled up to represent the performance of a reservoirwide project, using a specified pattern development schedule. The after-tax cash flow for each project is then calculated taking into account the capital costs for drilling, well conversions, polymer costs, operating costs, depreciation, royalties, and taxes. (See DOE/BC-86/10/SP and the references cited above for additional details of the model methodology.) 
According to the methodology devised by the NPC, the TORIS version of PFPM only assessed polymer flood feasibility in reservoirs with severe mobility problems, or where the mobility ratio was greater than 8 . Subsequent to the NPC study, PFPM was modified to allow assessment of polymer floods in reservoirs where the mobility ratio was less than the value of 8 . Polymer concentration schedules were developed for various mobility ratios ranging from below 2 to above 30 (ICF/BEG, 1990).

\subsubsection{Profile Modification Predictive Model}

The Polymer Flood Predictive Model was modified by DOE after the NPC study to evaluate the performance of gel-polymer profile modification treatments (ICF/BEG, 1990). This model is currently utilized in the TORIS system to predict the recovery potential for profile modification treatments, which improve waterflood recovery through the improvement of vertical sweep efficiency.

The profile modification predictive model assumes that the permeability contrast between the five layers in the model is reduced as a result of the gel-polymer treatment. The water injection rate into each of the five layers is calculated in PFPM using a radial-flow equation (Muskat, 1946), thus proportioning injection by layer based on the permeability of each layer. The profile modification model assumes that the sweep efficiency in the model remains constant as the gelpolymer is injected, so the reduction in permeability in each layer is proportional to the fluid intake capacity of each layer, and the permeability in the most permeable zones is reduced the most. The injectivity into each zone is then adjusted to reflect the permeability contrast reduction. The incremental recovery and economics of the profile modification treatment are then analyzed as in PFPM.

\subsubsection{Infill Drilling Predictive Model}

The Infill Drilling Predictive Model (IDPM) was developed by Scientific Software-Intercomp for DOE after the NPC study to predict the recovery performance and economics of infill drilling projects. This model is currently utilized in the TORIS system to predict the recovery potential for infill drilling projects.

The IDPM was developed with an architecture similar to the Polymer Flood Predictive Model with more rigorous calculation methodologies. The IDPM is a three-dimensional, two-phase (water and oil) simulator that represents the waterflood performance of a portion of a five-spot or ninespot pattern using a stream tube approach combined with finite difference solutions techniques. The model utilizes multiple layers (user specified, maximum of 20) for which thickness, porosity, and permeability can be varied to represent some degree of reservoir heterogeneity. For use with the TORIS reservoir data, the layer thicknesses are assumed to be constant and the layer permeabilities are defined using the average reservoir permeability and the Dykstra-Parsons coefficient of permeability variation. The model utilizes a two-dimensional, steady state, finite difference simulation of a pattern element of symmetry to define the geometry of each streamtube within each layer. The number of streamtubes within each layer may be specified by the user. The model calculates the water-oil displacement and oil recovery within each streamtube using finite difference methods and a user specified number of grid blocks within each streamtube. The model has the capability to account for cross flow between layers in each streamtube. The model generates a new set of stream tubes and performs the recovery calculations to predict the performance of infill drilling for drill down from five-spot to nine-spot patterns or from five-spot to smaller five-spot patterns. 
To model the improvement in reservoir continuity which is generally realized as a result of infill drilling, two methodologies are available in IDPM. The original methodology defined by SSI models the improvement in continuity by modifying the relative permeability endpoints to improve recovery as continuity improves. The user-specified relative permeability curve end points are assumed to be at $100 \%$ continuity and are adjusted proportionately based the specified continuity at the original well spacing. The other method for modeling the improvement in continuity adds additional net pay in an additional layer to reflect improved continuity as reservoirs are drilled down. The user specified net pay is assumed to be at $100 \%$ continuity and is adjusted proportionately based on the assumed continuity at the original well spacing. Either method was found to yield reliable infill drilling project performance based on comparison with detailed simulation results (Bigilarbigi et al., 1994).

The IDPM generates an oil rate versus time relationship for an eighth of a five-spot or nine-spot pattern and the results are then scaled up to represent the performance of a reservoirwide infill drilling project using a specified pattern development schedule. The after-tax cash flow for each project is then calculated taking into account the capital costs for drilling, well conversions, operating costs, depreciation, royalties, and taxes. (See Fuller et al. (1992), Bigilarbigi et al. (1994), and the model documentation DOE/BC-94/4/SP for additional details of the model methodology.)

\subsubsection{Predictive Models for Combination Processes}

TORIS models have also been developed to evaluate infill drilling in combination with polymer flooding and profile modification treatments. These models are modified versions of the IDPM. For modeling infill drilling in combination with polymer flooding, the viscosity of the injected water was adjusted so that the mobility ratio is improved. The polymer schedules described in the PFPM were incorporated into the IDPM so that the target mobility ratio of unity or close to unity is achieved. For modeling infill drilling in combination with profile modification, IDPM was modified in the same manner as described in Section 2.2.3.6 above. Accordingly, the incremental economics of these two combination processes over waterflooding are estimated using the appropriate drilling costs, well conversion costs, polymer costs, operating costs, depreciation, royalties, and taxes.

\subsubsection{Economic Considerations}

The TORIS recovery models take into consideration all of the appropriate costs and variables in the economic calculations, including all process dependent costs, all process independent costs, and other factors such as oil price, inflation, depreciation, royalties, and taxes. Since the chemical and miscible processes involve the injection of water, the process independent costs are defined as the typical costs associated with the installation and operation of waterflood projects. Project dependent costs are generally the incremental installation and operating costs above the base waterflood costs. The process dependent and independent costs are adjusted for product price variations, formation depth, and regional aspects according to guidelines developed by the NPC (1984). The sources for the cost information used in TORIS include Energy Information Agency publications, the American Petroleum Institute Joint Association Surveys, and vendor and operator surveys. DOE regularly updates the cost structures used in the predictive models. 


\subsubsection{Process-Dependent Costs}

The process-dependent costs are the incremental costs associated with the installation and operation of the improved recovery projects. The process-dependent costs for chemical (polymer, profile modification, alkaline, and surfactant) processes include the costs for all injected polymer, surfactant, and alkaline agents according to formulation schedules devised by the NPC. The process dependent costs for miscible flooding projects include the cost for installing and operating $\mathrm{CO}_{2}$ injection and recycling plants, and the purchase price for $\mathrm{CO}_{2}$. The $\mathrm{CO}_{2}$ purchase price is adjusted depending upon project location (West Texas or non-West Texas). The steam flood predictive model considers the cost to install and operate steam generators, costs associated with fuel and water treatment for steam generation, costs for drilling producers and injectors, and other process-specific facilities costs. The in situ combustion process model considers the cost for air injection equipment installation and operation, costs for drilling producers and injectors, and other process-specific facilities costs.

\subsubsection{Process-Independent Costs}

The process-independent costs generally include the costs for well drilling and completion, well conversion costs, normal operating costs, and associated equipment and facilities costs. The costs for drilling, completing and converting wells are dependent on the well depth and geographic region. Operating costs on a per-well basis include normal daily expenses, surface maintenance costs, and subsurface maintenance costs. These costs are also defined based on producing depth and geographic region. The facilities costs include production and injection equipment for secondary recovery required by the drilling and conversion of wells, and costs for upgrading surface processing equipment.

\subsubsection{Other Economic Considerations}

Additional considerations of importance in the TORIS economic analysis methodology include the product prices, tax treatment, and economic hurdles for process viability. Crude oil prices used in the economic analyses are specified as the price for West Texas Intermediate with adjustments for oil gravity and project location. The economics also include the appropriate treatment of federal income taxes based on applicable IRS rules, and include EOR tax credits when appropriate. State income and severance taxes are included in the economic calculations. The minimum acceptable rate of return, or hurdle rate, is established for each process and level of technology to determine process viability. The hurdle rates are used to reflect typical required investment efficiencies for project implementation and to account for a certain degree of project risk. In the implemented technology case, the hurdle rate for alkaline, surfactant, and in situ combustion projects is $27 \%$ and the hurdle rate for the other processes is $16 \%$. In the advanced technology case, the hurdle rates are reduced to $10 \%$ for all processes except in situ combustion, which is reduced to $16 \%$. The reduced minimum acceptable rate of return in the advanced technology case reflects anticipated process improvements achieved through R\&D. 


\subsection{Relationship Between the Class 4 Resource and the TORIS Screening Methodology}

The reservoir data for the Class 4 reservoirs in the TORIS database were evaluated with respect to the screening criteria discussed in Section 2.1 to examine the applicability of the improved recovery processes. This discussion illustrates the relationship between the Class 4 resource and some of the more significant TORIS screening parameters. The overall applicability of these processes is primarily reflected by the recovery potential, as discussed in Section 2.4.

Since the applicability of most of the EOR processes is dependent upon the reservoir temperature and salinity, a series of cross plots were constructed to show the distribution of the Class 4 reservoirs with respect to both temperature and salinity. Figure 2.7 shows the frequency distribution for the 196 reservoirs out of the 330 Class 4 reservoirs that have values for both temperature and salinity in the database. A significant number of these reservoirs fall below the implemented technology temperature and salinity screening limits of 180 to $200^{\circ} \mathrm{F}$ and 100,000 $\mathrm{ppm}$. Virtually all of these reservoirs fall below the advanced technology screening limits of 200 to $250^{\circ} \mathrm{F}$ and $200,000 \mathrm{ppm}$. Figure 2.8 shows the remaining oil-in-place totals for the distribution shown in Figure 2.7, which totals over 10 billion barrels out of the total 19 billion barrels for the class. The histograms shown in Figures 2.7 and 2.8 illustrate that a significant portion of the Class 4 reservoirs in the country are amenable to the profile modification, polymer flooding, surfactant flooding, and alkaline flooding processes.

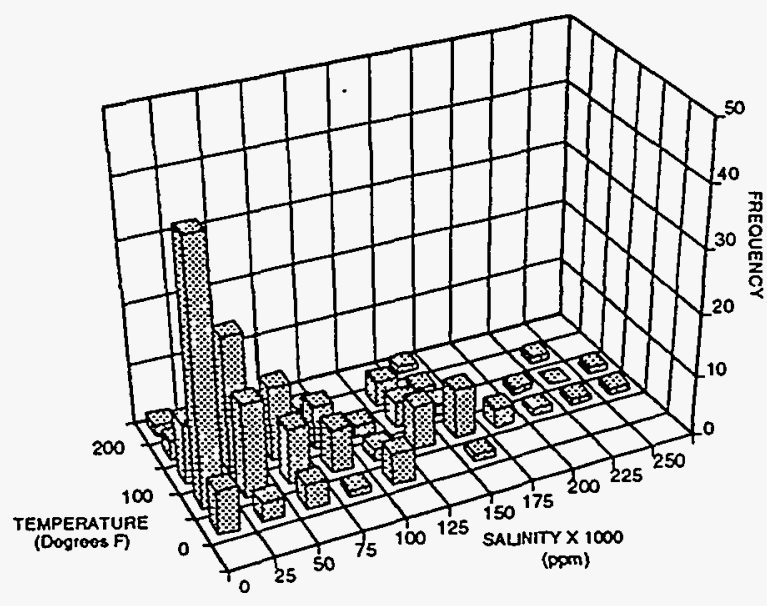

Figure 2.7 Frequency Distribution of Class 4 Reservoirs by Temperature and Salinity (Source: BPO TORIS, 1994)

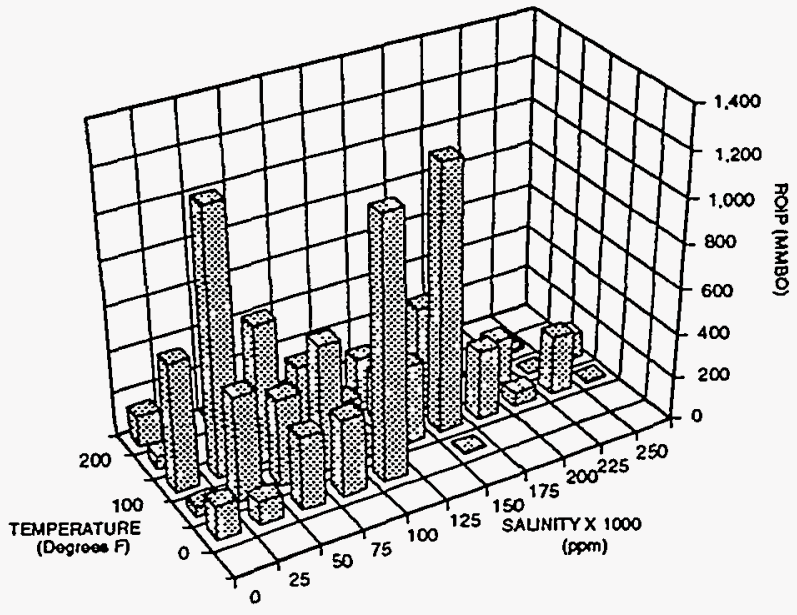

Figure 2.8 Distribution of Remaining Oil-in-Place in Class 4 Reservoirs by Salinity and Temperature (Source: BPO TORIS, 1994) 
The histograms described above for Class 4 were also generated to show the distribution of the reservoirs in Texas, Oklahoma, and the Rocky Mountains. The temperature and salinity values for 90 Class 4 Texas reservoirs out of a total of 167 are depicted in Figure 2.9. These reservoirs account for 4 billion barrels of the 6 billion barrels of remaining oil-in-place in Class 4 reservoirs in Texas, as depicted in Figure 2.10. The majority of the Texas reservoirs have temperature and salinity values below the screening criteria for implemented technology chemical type processes. For Oklahoma, 37 of the 51 Class 4 reservoirs have temperature and salinity values, accounting for 4.8 billion barrels of the 5.9 billion barrels of remaining oil-in-place (Figures 2.11 and 2.12). Many of the Oklahoma reservoirs fall below the temperature screening criterion, but many have characteristically high salinity values. Most of the Class 4 reservoirs in the Rocky Mountains fall within the range of applicability for chemical processes, as shown in Figures 2.13 and 2.14.

Since many of the California Class 4 reservoirs are amenable to thermal processes, histograms were constructed to illustrate the relationship of these reservoir characteristics to the critical thermal screening criteria, API gravity, and depth. The API gravity for the California Class 4 reservoirs fall within the acceptable implemented technology range for steam and in situ combustion of between 10 and $35^{\circ}$ API (Figure 2.15 and 2.16). Most of these reservoirs are located at depths that are less than 3,000 feet, the implemented technology steam screening limit, or 5,000 feet, the advanced technology screening limit. The depths are all shallower than the in situ combustion limit of 11,500 feet.

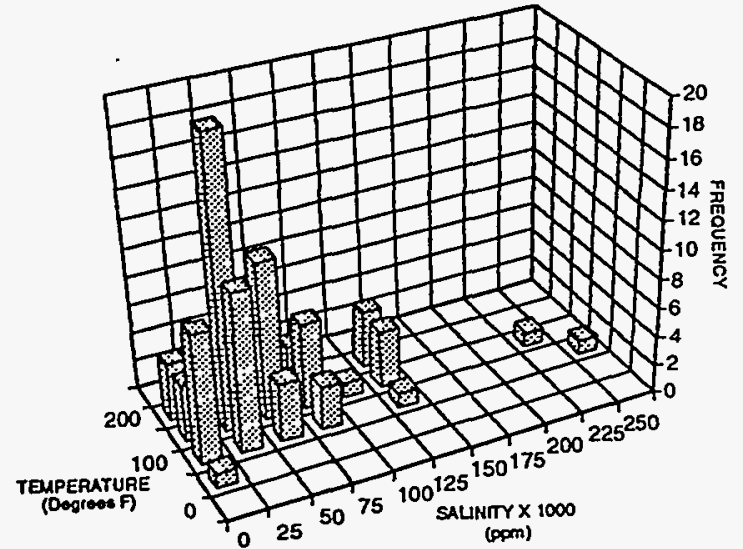

Figure 2.9 Frequency Distribution of Texas Class 4 Reservoirs by Temperature and Salinity (Source: BPO TORIS, 1994)

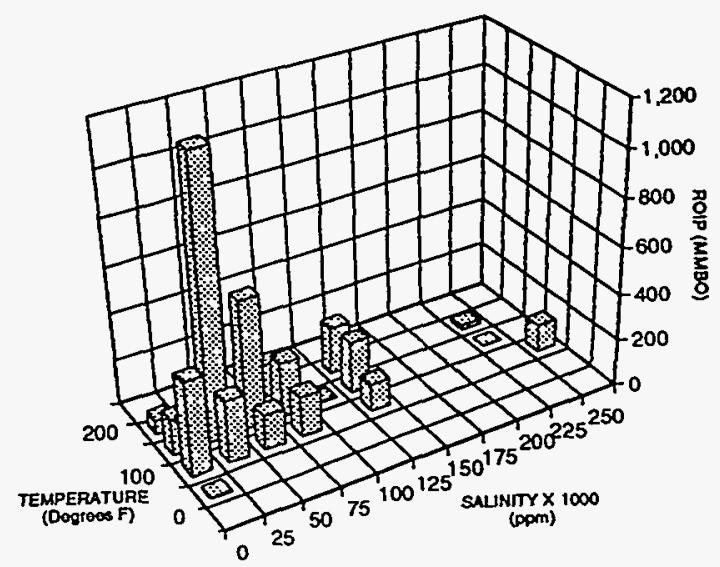

Figure 2.10 Distribution of Remaining Oil-in-Place in Texas Class 4 Reservoirs by Salinity and Temperature (Source: BPO TORIS, 1994) 


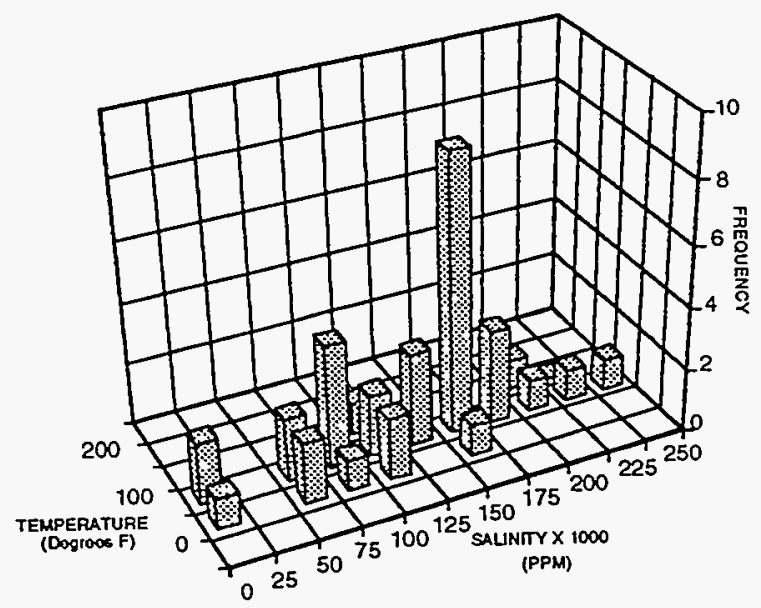

Figure 2.11 Frequency Distribution of Oklahoma Class 4 Reservoirs by Temperature and Salinity (Source: BPO TORIS, 1994)

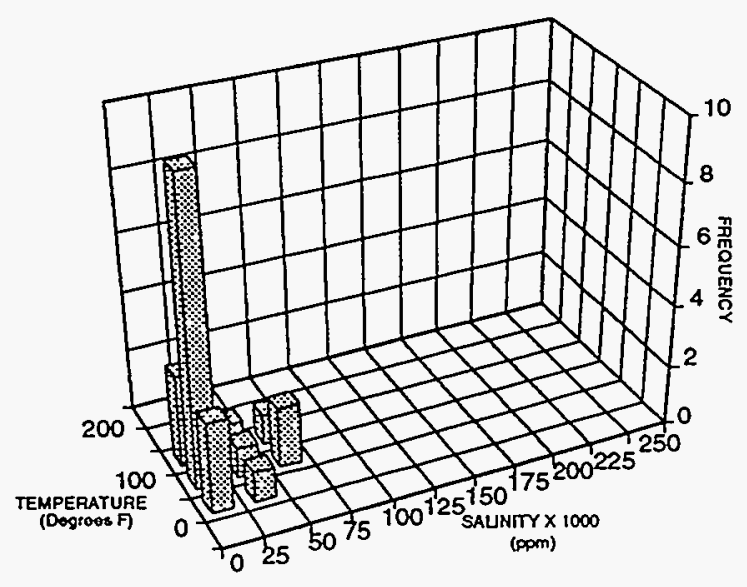

Figure 2.13 Frequency Distribution of Rocky Mountain Class 4 Reservoirs by Temperature and Salinity (Source: BPO TORIS, 1994)

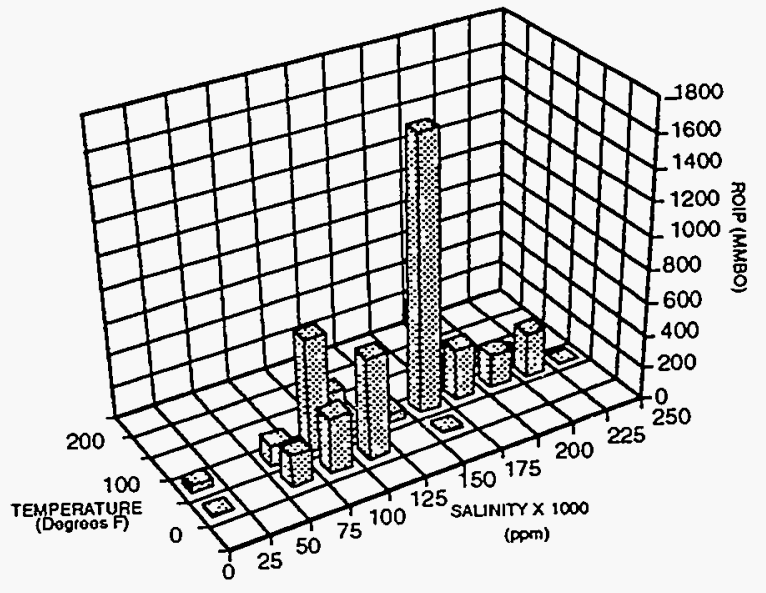

Figure 2.12 Distribution of Remaining Oil-in-Place in Oklahoma Class 4 Reservoirs by Salinity and Temperature (Source: BPO TORIS, 1994)

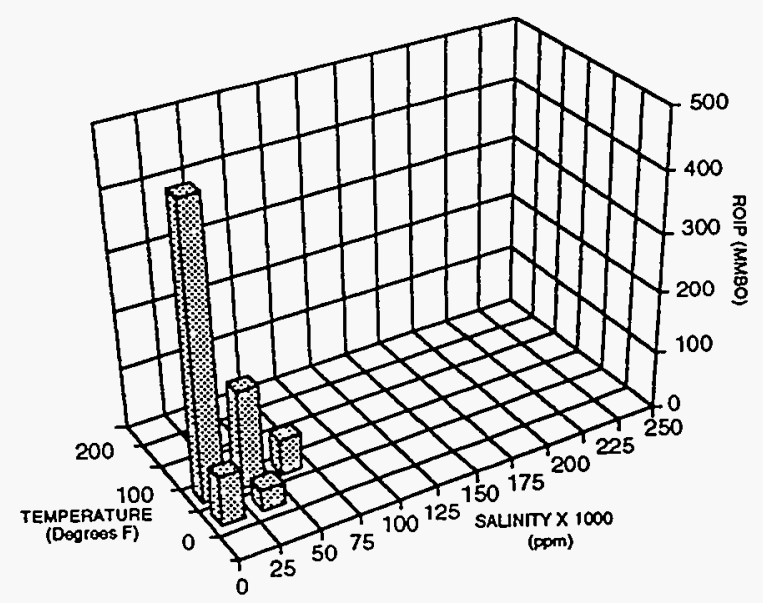

Figure 2.14 Distribution of Remaining Oil-in-Place in Rocky Mountain Class 4 Reservoirs by Salinity and Temperature (Source: BPO TORIS, 1994) 


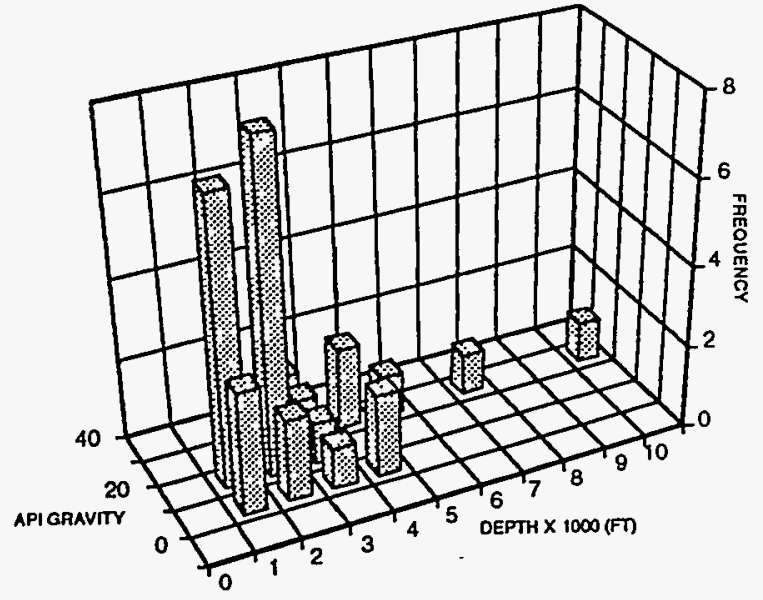

Figure 2.15 Frequency Distribution of California Class 4 Reservoirs by API Gravity and Depth (Source: BPO TORIS, 1994)

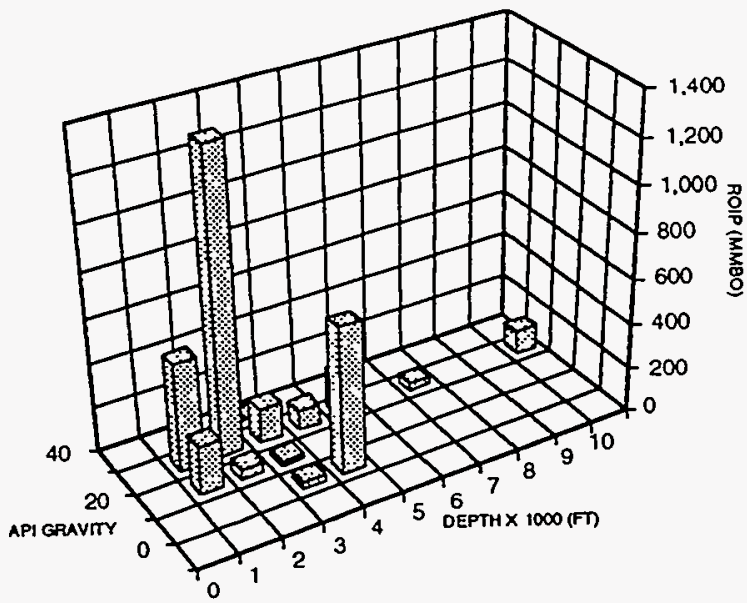

Figure 2.16 Distribution of Remaining Oil-in-Place in California Class 4 Reservoirs by API Gravity and Depth (Source: BPO TORIS, 1994)

\subsection{Overview of Class 4 Potential by Process and Region}

The future improved oil recovery potential for the TORIS Class 4 reservoirs was estimated to be between 1.0 and 4.3 billion barrels, depending on oil price and the level of technology advancement. The analysis indicated that the majority of this potential could be realized through the application of infill drilling (alone and in combination with polymer flooding and profile modification), chemical flooding (surfactant and polymer), and thermal processes. The majority of this potential is in Texas, Oklahoma, California, and the Rocky Mountains. Approximately twothirds of this future potential is at risk of abandonment by the year 2000 , emphasizing the urgent need for the development and implementation of economical improved oil recovery processes in Class 4 reservoirs.

\subsubsection{Improved Recovery Potential For Class 4}

The recovery potential for the Class 4 TORIS reservoirs was evaluated for the implemented and advanced technology cases described above at oil prices of $\$ 12, \$ 20$, and $\$ 30$ per barrel. The total recovery potential for Class 4 ranges between 1.0 and 4.3 billion barrels depending on the prevailing oil price and the level of technology advancement, as summarized in Table 2.6. For the implemented technology case, which is essentially the future application of existing recovery technologies, the recovery potential ranges from 1.0 billion barrels at $\$ 12 /$ barrel to 1.8 billion barrels at $\$ 30 / \mathrm{barrel}$. The majority of this potential can be attributed to the expanded application of advanced secondary recovery processes. If reasonable technological advancements can be achieved, the recovery potential increases significantly for Class 4 , ranging from 1.7 to 4.3 billion barrels at oil prices of $\$ 12$ to $\$ 30 /$ barrel, respectively. The majority of the advanced technology case potential can be attributed to the application of ASR technologies in the $\$ 12$ and $\$ 20 / \mathrm{barrel}$ cases, but EOR technologies have the greater impact in the $\$ 30 /$ barrel case. 


\begin{tabular}{|c|c|c|c|c|c|c|}
\hline \multirow{4}{*}{$\begin{array}{l}\text { OIL PRICE } \\
\text { (WTD) } \\
\text { (\$/BBL) }\end{array}$} & P\&sc & overvirored & 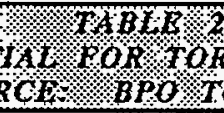 & 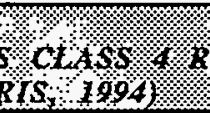 & ERVOMRS & 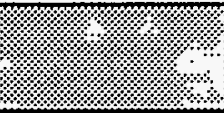 \\
\hline & \multicolumn{6}{|c|}{ RECOVERY POTENTIAL IN MILLIONS OF BARRELS } \\
\hline & \multicolumn{2}{|c|}{$\begin{array}{c}\text { ADVANCED } \\
\text { SECONDARY RECOVERY }\end{array}$} & \multicolumn{2}{|c|}{$\begin{array}{l}\text { ENHANCED OIL } \\
\text { RECOVERY }\end{array}$} & \multicolumn{2}{|c|}{ TOTAL POTENTIAL } \\
\hline & $\begin{array}{l}\text { IMPLEMENTED } \\
\text { TECHNOLOGY }\end{array}$ & $\begin{array}{l}\text { ADVANCED } \\
\text { TECHNOLOGY }\end{array}$ & $\begin{array}{l}\text { IMPLEMENTED } \\
\text { TECHNOLOGY }\end{array}$ & $\begin{array}{l}\text { ADVANCED } \\
\text { TECHNOLOGY }\end{array}$ & $\begin{array}{l}\text { IMPLEMENTED } \\
\text { TECHNOLOGY }\end{array}$ & $\begin{array}{l}\text { ADVANCED } \\
\text { TECHNOLOGY }\end{array}$ \\
\hline 12 & 995 & 1,641 & 10 & 88 & 1,005 & 1,729 \\
\hline 20 & 1,150 & 1,784 & 372 & 1,245 & 1,522 & 3,029 \\
\hline 30 & 1,193 & 1,974 & 646 & 2,354 & 1,839 & 4,328 \\
\hline
\end{tabular}

The advanced secondary recovery potential for Class 4 increases from 1.0 billion barrels at $\$ 12 /$ barrel to 1.2 billion barrels at $\$ 30 /$ barrel for the implemented technology case, while the recovery potential for the advanced technology case increases from 1.6 to 2.0 billion barrels at $\$ 12 /$ barrel and $\$ 30 /$ barrel, respectively (Figure 2.17 ). Most of this ASR potential is attributable to infill drilling alone and in combination with polymer flooding and profile modification. ASR recovery potentials by process for the various cases considered are summarized in Table 2.7.

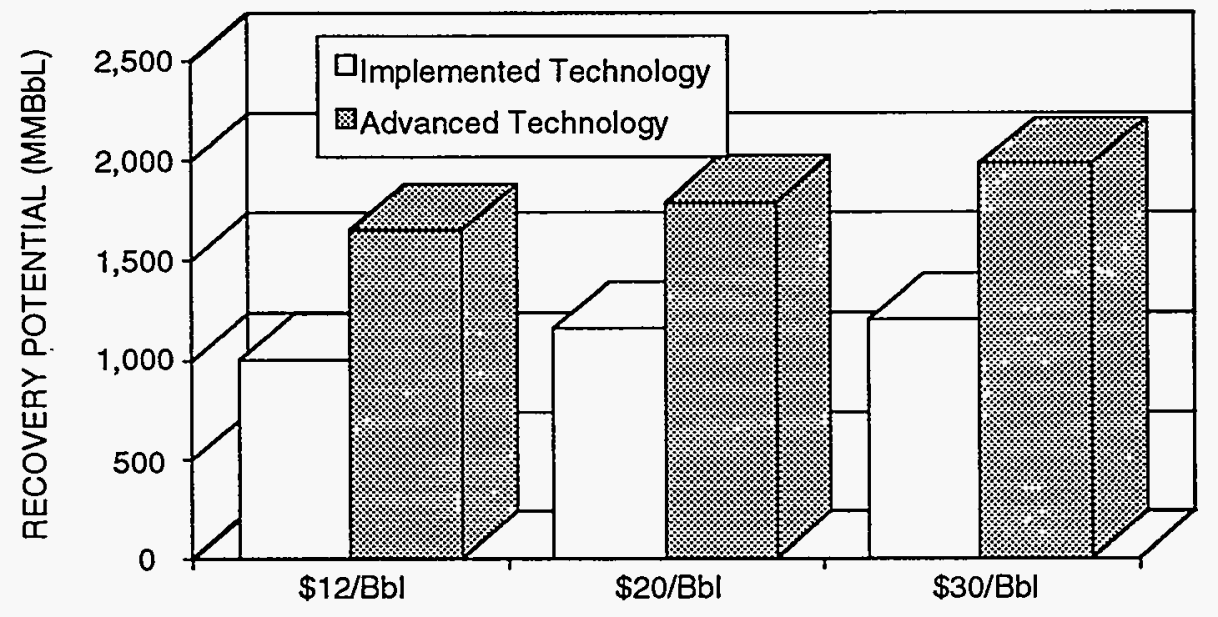

Figure 2.17 Advanced Secondary Recovery Potential for Class 4 Reservoirs (Source: BPO TORIS, 1994) 


\begin{tabular}{|c|c|c|c|c|c|c|}
\hline 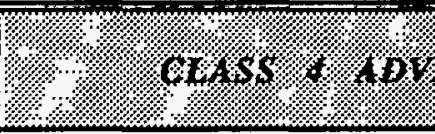 & N960) & SWOKR & R Forks & (1) & rogent & IV \\
\hline \multirow[b]{3}{*}{ RECOVERY PROCESS } & \multicolumn{6}{|c|}{ RECOVERY POTENTIAL IN MILLIONS OF BARRELS } \\
\hline & \multicolumn{3}{|c|}{ IMPLEMENTED TECHNOLOGY } & \multicolumn{3}{|c|}{ ADVANCED TECHNOLOGY } \\
\hline & $\$ 12 / B B L$ & $\$ 20 / \mathrm{BBL}$ & $\$ 30 / \mathrm{BBL}$ & $\$ 12 / B B L$ & $\$ 20 / \mathrm{BBL}$ & $\$ 30 / \mathrm{BBL}$ \\
\hline INFILL DRILLING & 214 & 283 & 289 & 127 & 120 & 164 \\
\hline POLYMER FLOODING & 35 & 50 & 53 & 58 & 49 & 50 \\
\hline PROFILE MODIFICATION & 66 & 60 & 58 & 86 & 80 & 75 \\
\hline INFILL/POLYMER & 370 & 364 & 384 & 558 & 596 & 655 \\
\hline INFILL/PROFILE & 310 & 393 & 409 & 812 & 939 & 1,030 \\
\hline TOTAL & 995 & 1,150 & 1,193 & 1,641 & 1,784 & 1,974 \\
\hline
\end{tabular}

The enhanced oil recovery potential for Class 4 increases from 10 million barrels at $\$ 12 /$ barrel to 646 million barrels at $\$ 30 /$ barrel for the implemented technology case, while the recovery potential for the advanced technology case increases from 88 million barrels to nearly 2.4 billion barrels at $\$ 12 /$ barrel and $\$ 30 /$ barrel, respectively (Figure 2.18 ). Most of the EOR potential in the implemented technology case results from the expansion of ongoing steamfloods, with some additional potential for $\mathrm{CO}_{2}$ and surfactant flooding at the higher oil prices. In the advanced technology case, most of the EOR potential results from the application of chemical flooding processes, with some contribution from in situ combustion, $\mathrm{CO}_{2}$ flooding, and new steamflood projects at higher prices. TORIS only considers expansions to ongoing steam in the implemented technology case. EOR recovery potentials by process for the various cases considered are summarized in Table 2.8 .

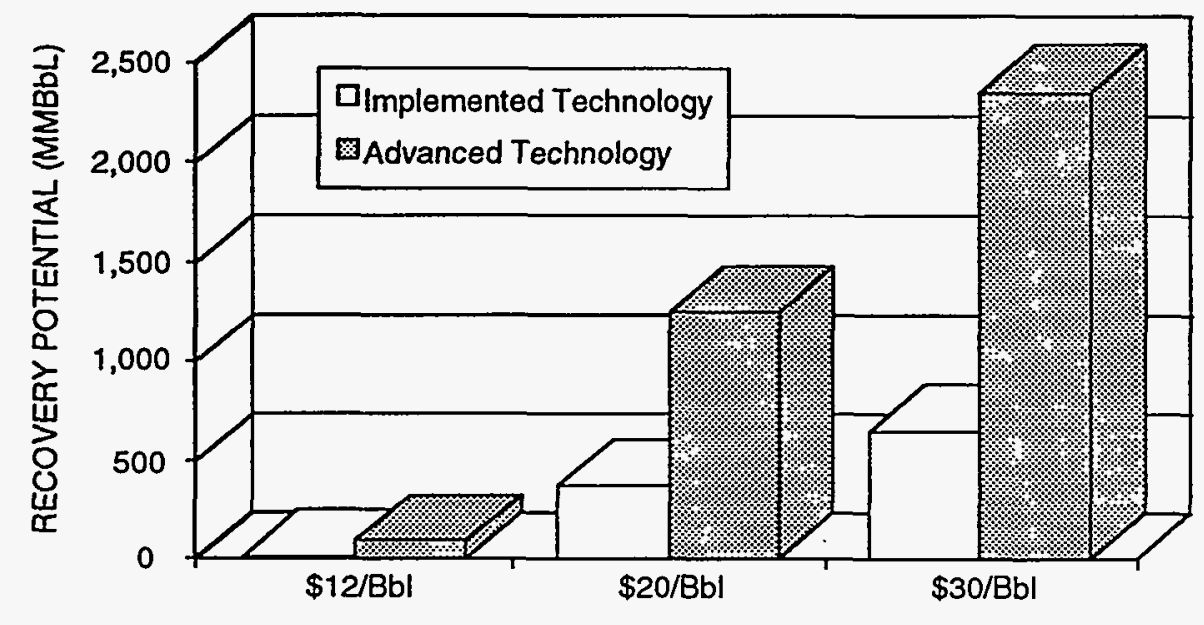

Figure 2.18 Enhanced Oil Recovery Potential for Class 4 Reservoirs (Source: BPO TORIS, 1994) 


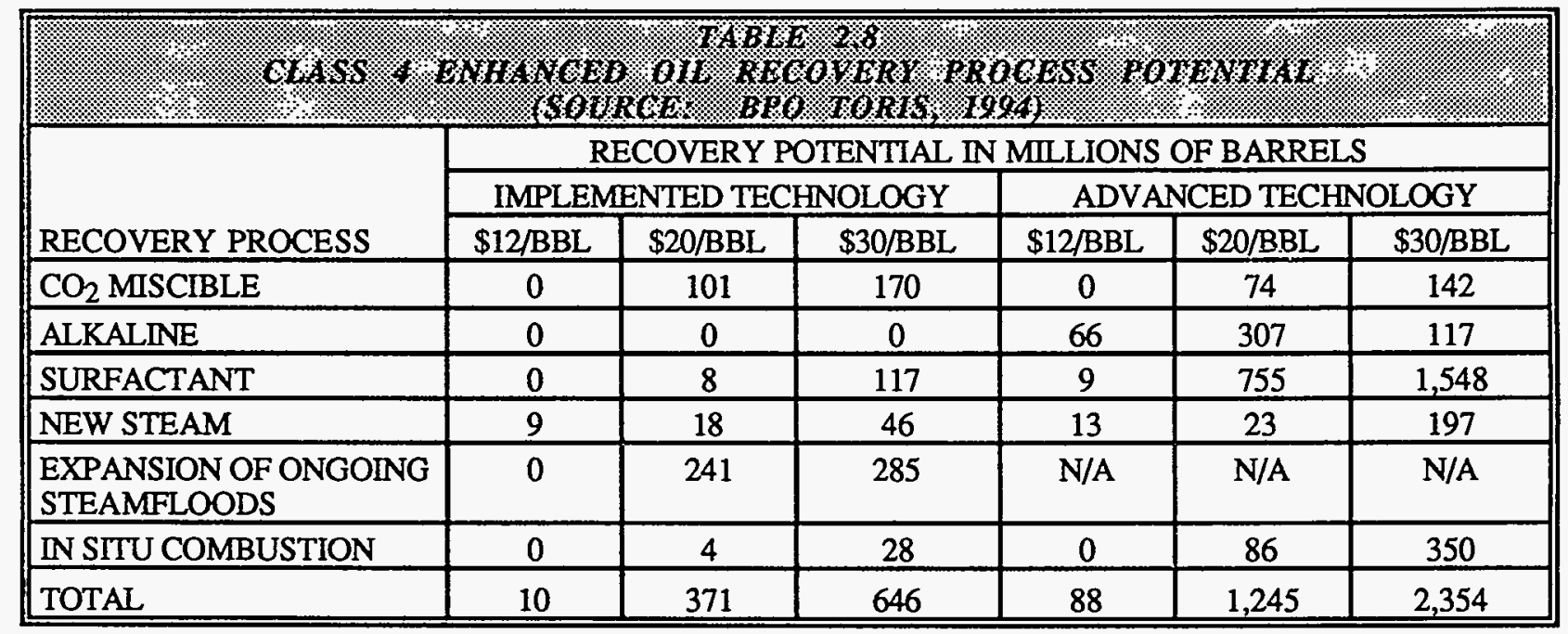

Examination of the data shown in Tables 2.7 and 2.8 reveals that the recovery potential for the individual processes does not necessarily increase as the oil price increases. The relationship of the potentials for the various processes is shown graphically for the implemented and advanced technology cases in Figures 2.19 and 2.20, respectively. This phenomena is a result of the TORIS selection methodology described in Section 2.2.1. At each oil price, TORIS selects the recovery process for each reservoir in order to maximize oil recovery. So for any given reservoir, the selected recovery process may be different at one oil price than at another. For example, infill drilling may be the selected process in a given reservoir at $\$ 12$ or $\$ 20 / \mathrm{barrel}$, but at $\$ 30 / \mathrm{barrel}$, one of the other ASR or EOR processes may recover more oil economically than infill drilling. The end result is that the overall recovery potential for the Class 4 reservoirs does increase as the oil price increases, and oil recovery is maximized.

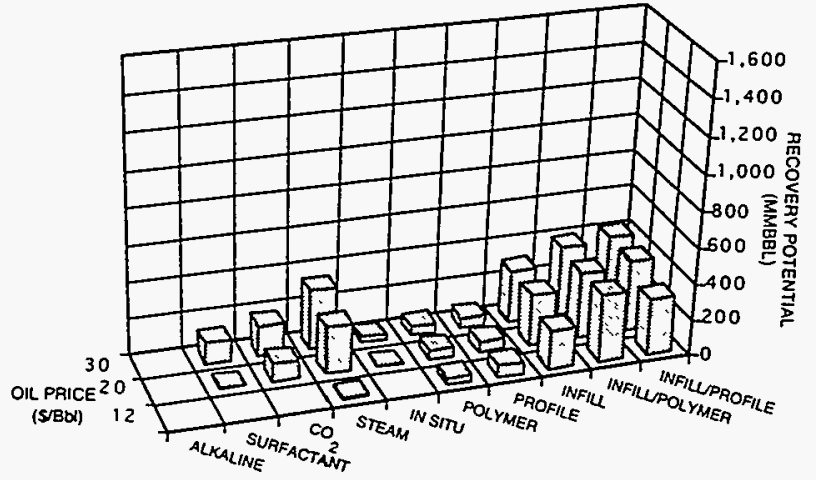

Figure 2.19 Implemented Technology Case Recovery Potential by Process for Class 4 TORIS Reservoirs (Source: BPO TORIS, 1994)

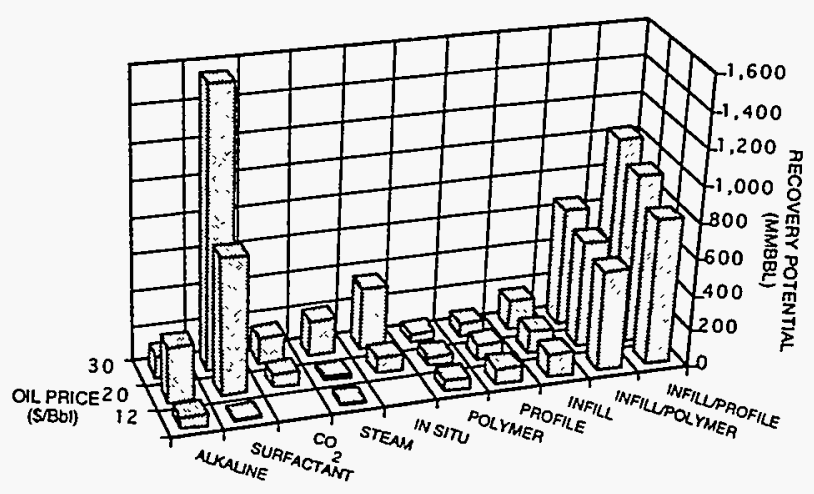

Figure 2.20 Advanced Technology Case Recovery Potential by Process for Class 4 TORIS Reservoirs (Source: BPO TORIS, 1994) 


\subsubsection{Abandonment Risk of the Class 4 Resource}

A significant portion of the Class 4 resource is at risk of abandonment by the year 2000 , meaning that many of the reservoirs that have potential for future application of improved recovery technologies could be abandoned prior to the initiation of these projects. For the implemented technology case considered in this analysis, nearly 740 million barrels of the 1 billion barrel recovery potential at $\$ 12 / \mathrm{barrel}$ is at risk of abandonment by the year 2000 . At $\$ 30 / \mathrm{barrel}, 1.2$ billion barrels of the potential 1.8 billion barrels could be abandoned by the year 2000 (Figure 2.21). For the advanced technology case, 1.4 billion barrels of the 1.7 billion barrel recovery potential at $\$ 12 /$ barrel could be abandoned by the year 2000 , while 2.3 billion barrels of the 4.3 billion barrel potential at $\$ 30 /$ barrel is at risk of abandonment (Figure 2.22). Only a minor portion of both the implemented and advanced recovery potential is at risk of abandonment after the year 2000. The magnitude of the Class 4 recovery potential at risk of abandonment in the next six years illustrates the urgent need for the development and demonstration of cost-effective recovery technologies.

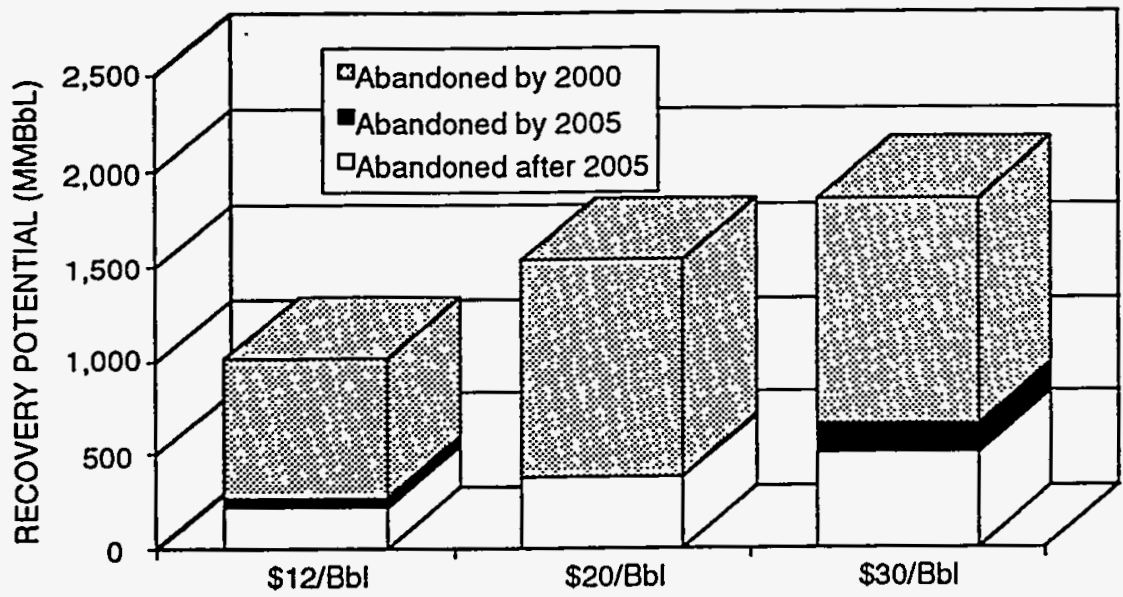

Figure 2.21 Total Potential at Risk of Abandonment, Implemented Technology (Source: BPO TORIS, 1994)

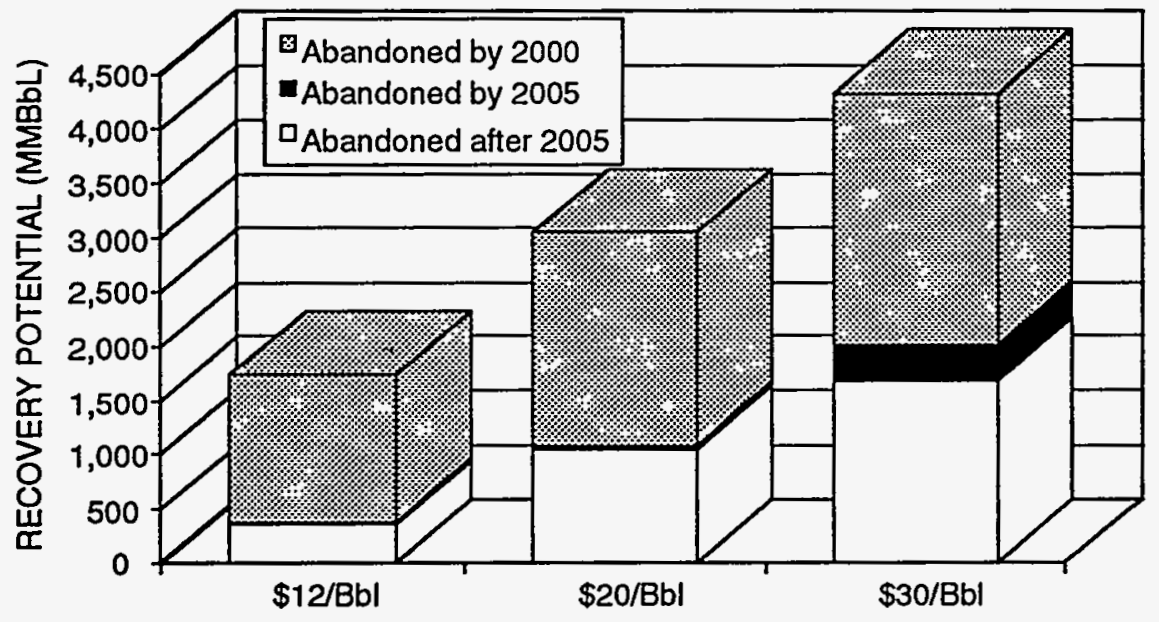

Figure 2.22 Total Potential at Risk of Abandonment, Advanced Technology (Source: BPO TORIS, 1994) 


\subsubsection{Discussion of Recovery Potential for Class 4 by Region}

Most of the improved oil recovery potential for Class 4 results from the future application of recovery technologies in Texas, Oklahoma, California, and the Rocky Mountains. The recovery potentials for these regions at various oil prices are summarized for the implemented and advanced technology cases in Tables 2.9 and 2.10 , respectively. The improved recovery potential in each region is discussed in this section.

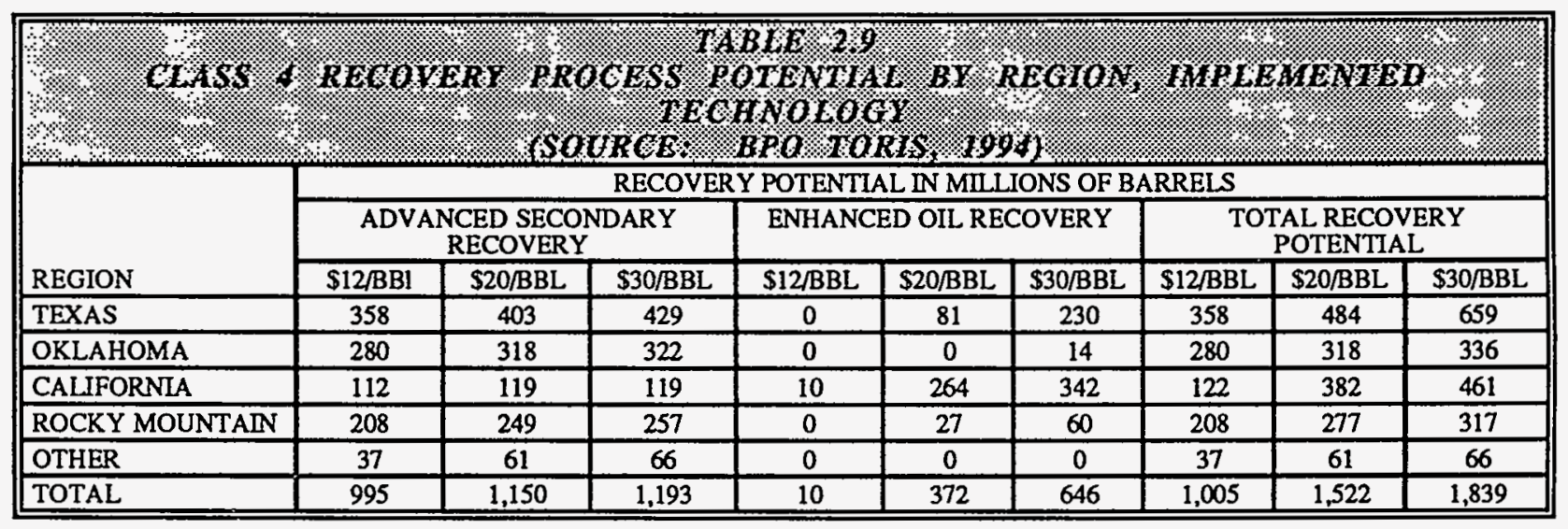

\begin{tabular}{|c|c|c|c|c|c|c|c|c|c|}
\hline \multicolumn{2}{|c|}{ 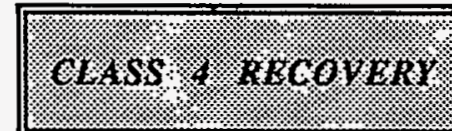 } & 20048 & Rot & 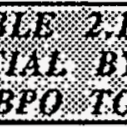 & 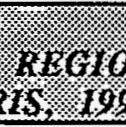 & $\sqrt{4.1 / 2}$ & 40 & \multicolumn{2}{|c|}{ HCHNOLOOY. } \\
\hline \multirow[b]{3}{*}{ REGION } & \multicolumn{9}{|c|}{ RECOVERY POTENTIAL IN MILLIONS OF BARREIS } \\
\hline & \multicolumn{3}{|c|}{$\begin{array}{l}\text { ADVANCED SECONDARY } \\
\text { RECOVERY } \\
\end{array}$} & \multicolumn{3}{|c|}{ ENHANCED OIL RECOVERY } & \multicolumn{3}{|c|}{$\begin{array}{c}\text { TOTAL RECOVERY } \\
\text { POTENTIAL } \\
\end{array}$} \\
\hline & $\$ 12 / \mathrm{BBL}$ & $\$ 20 / \mathrm{BBL}$ & $\$ 30 / \mathrm{BBL}$ & $\$ 12 / \mathrm{BBL}$ & $\$ 20 / \mathrm{BBL}$ & $\$ 30 / \mathrm{BBL}$ & $\$ 12 / \mathrm{BBL}$ & $\$ 20 / \mathrm{BBL}$ & $\$ 30 / \mathrm{BBL}$ \\
\hline TEXAS & 538 & 588 & 620 & 76 & 756 & 993 & 614 & 1,344 & 1,613 \\
\hline OKLAHOMA & 492 & 518 & 588 & 0 & 342 & 802 & 492 & 860 & 1,390 \\
\hline CALIFORNIA & 111 & 114 & 139 & 12 & 65 & 397 & 123 & 178 & 536 \\
\hline ROCKY MOUNTAIN & 447 & 492 & 549 & 0 & 74 & 129 & 447 & 566 & 678 \\
\hline OTHER & 53 & 72 & 78 & $\overline{0}$ & 8 & 33 & 53 & 81 & 111 \\
\hline TOTAL & 1,641 & 1,784 & 1,974 & 88 & 1,245 & 2,354 & 1,729 & 3,029 & 4,328 \\
\hline
\end{tabular}

\subsubsection{Improved Recovery Potential for Texas Class 4 Reservoirs}

The improved recovery potential for the Class 4 reservoirs in Texas ranges from 358 million barrels at $\$ 12 /$ barrel to 659 million barrels at $\$ 30 /$ barrel for the implemented technology case, while in the advanced technology case, the recovery potential ranges from 614 million barrels at $\$ 12 /$ barrel to 1.6 billion barrels at $\$ 30 /$ barrel. In the implemented technology case, most of the recovery potential is realized through the application of infill drilling in combination with polymer applications. At $\$ 30 /$ barrel, over one-third of the implemented technology case recovery potential is realized from the application of chemical and $\mathrm{CO}_{2}$ flooding processes. In the advanced technology 
case, most of the Texas improved recovery potential at the higher oil prices results from the application of the EOR processes, primarily chemical flooding (alkaline and surfactant), in situ combustion, and $\mathrm{CO}_{2}$ flooding processes. The ASR processes contribute between 538 and 620 million barrels of the advanced recovery technology case potential, depending upon oil price. (See Figures 2.23 and 2.24.)

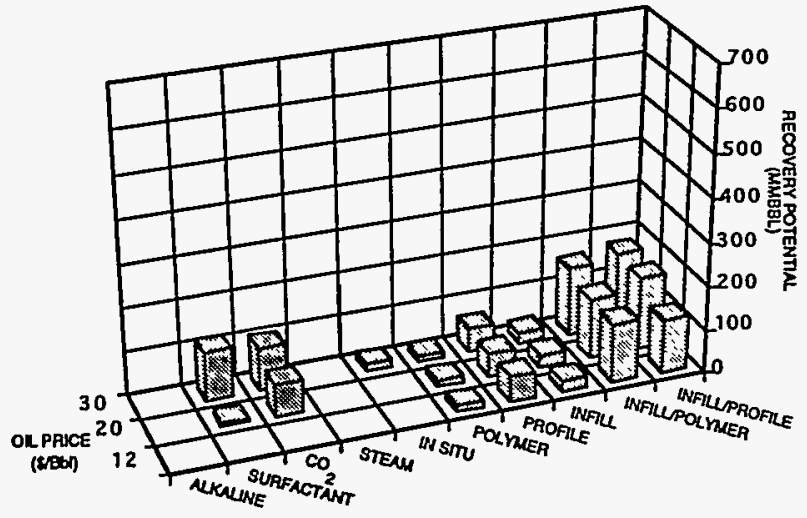

Figure 2.23 Implemented Technology Case Recovery Potential by Process for Texas Class 4 TORIS Reservoirs (Source: BPO TORIS, 1994)

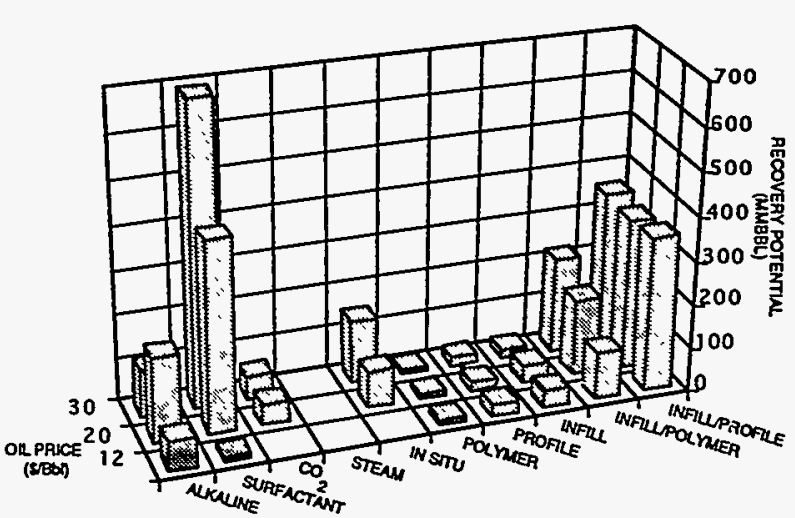

Figure 2.24 Advanced Technology Case Recovery Potential by Process for Texas Class 4 TORIS Reservoirs (Source: BPO TORIS, 1994)

\subsubsection{Improved Recovery Potential for Oklahoma Class 4 Reservoirs}

The improved oil recovery potential for Oklahoma in both the implemented and advanced technology cases is dominated by the ASR technologies at $\$ 12 / \mathrm{barrel}$ and $\$ 20 / \mathrm{barrel}$, but at $\$ 30 / b a r r e l$ in the advanced technology case, the application of EOR technologies results in over 800 million barrels of the total 1.4 billion barrel potential. For the implemented technology case, the future recovery potential for Oklahoma ranges from 280 to 336 million barrels, depending upon oil price. Virtually all of this potential results from infill drilling, with additional potential from polymer flooding and infill drilling in combination with polymer applications. These ASR processes also contribute between 492 and 588 million barrels of the advanced technology case potential at $\$ 12$ and $\$ 30 / \mathrm{barrel}$, respectively. In the advanced technology case, the future application of chemical flooding EOR processes results in recovery potential of 342 million barrels at $\$ 20 /$ barrel and 802 million barrels at $\$ 30 /$ barrel. (See Figures 2.25 and 2.26.) 


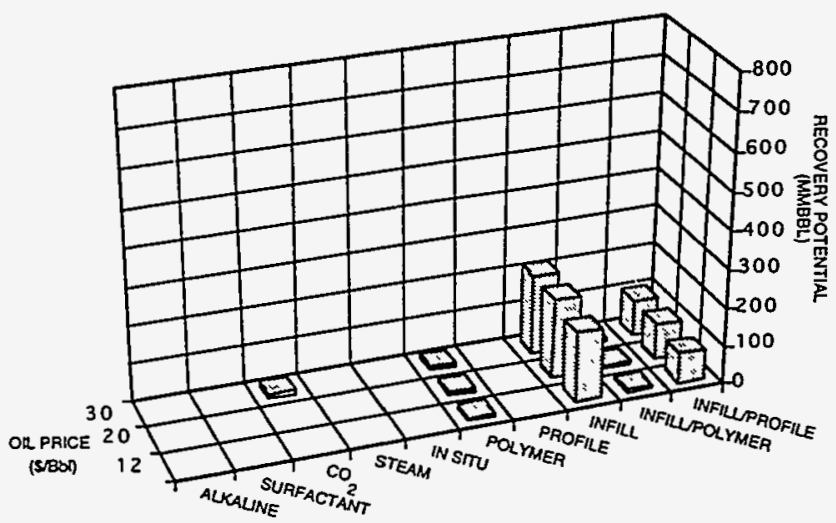

Figure 2.25 Implemented Technology Case Recovery Potential by Process for Oklahoma Class 4 TORIS Reservoirs (Source: BPO TORIS, 1994)

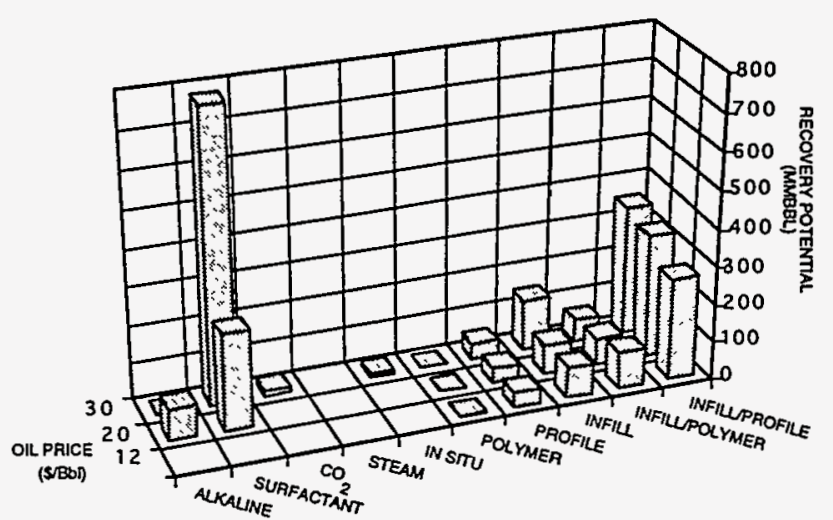

Figure 2.26 Advanced Technology Case Recovery Potential by Process for Oklahoma Class 4 TORIS Reservoirs (Source: BPO TORIS, 1994)

\subsubsection{Improved Recovery Potential for California Class 4 Reservoirs}

The improved recovery potential for California ranges from 122 million barrels at $\$ 12 / \mathrm{barrel}$ to 461 million barrels at $\$ 30 /$ barrel in the implemented technology case and from 123 million barrels at $\$ 12 /$ barrel to 536 million barrels at $\$ 30 /$ barrel in the advanced technology case. Most of this potential results from the expanded application of thermal processes in the Class 4 reservoirs. Additional potential is also realized from infill drilling and profile modification. (See Figures 2.27 and 2.28.)

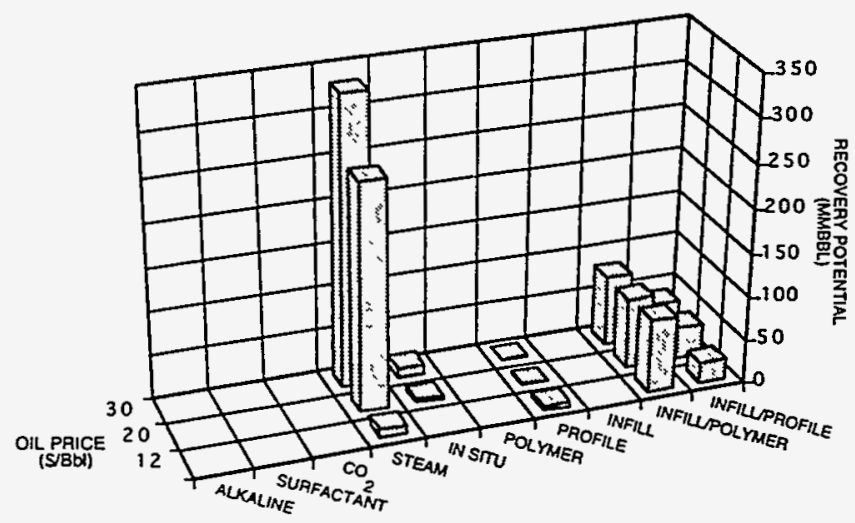

Figure 2.27 Implemented Technology Case Recovery Potential by Process for California Class 4 TORIS Reservoirs (Source: BPO TORIS, 1994)

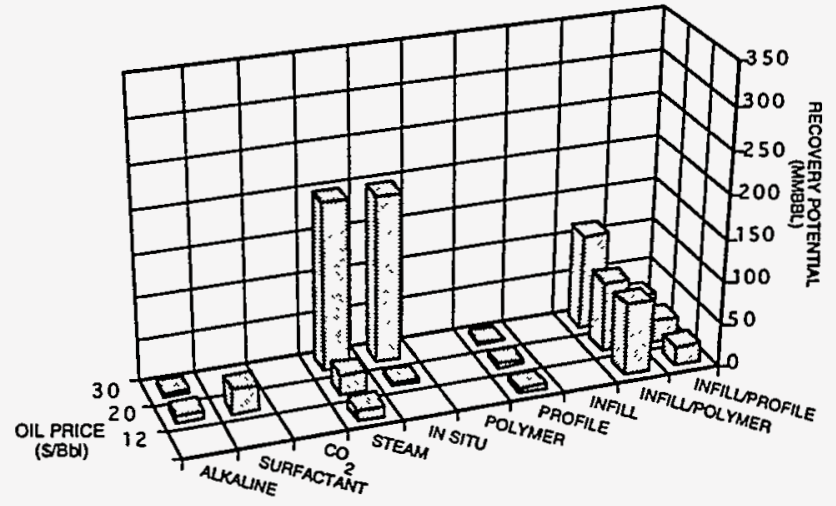

Figure 2.28 Advanced Technology

Case Recovery Potential by Process for California Class 4 TORIS Reservoirs (Source: BPO TORIS, 1994) 


\subsubsection{Improved Recovery Potential for Rocky Mountain Class 4 Reservoirs}

The improved recovery potential in the Rocky Mountain Class 4 reservoirs primarily results from the application of advanced secondary recovery processes. In the implemented technology case, the total recovery potential ranges from 208 to 317 million barrels at $\$ 12$ and $\$ 30 /$ barrel, respectively. This potential results almost exclusively from infill drilling in combination with polymer flooding and profile modification. This potential increases in the advanced technology case to 447 million barrels at $\$ 12 /$ barrel and 678 million barrels at $\$ 30 /$ barrel. Minor potential is also realized in the advanced technology case for chemical flooding, polymer flooding, $\mathrm{CO}_{2}$ flooding, and profile modification processes. (See Figures 2.29 and 2.30.)

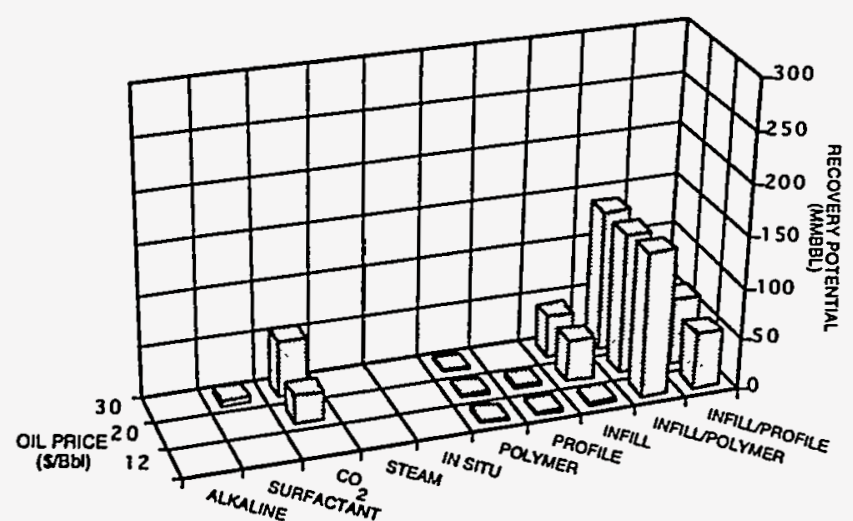

Figure 2.29 Implemented Technology Case Recovery Potential by Process for Rocky Mountain Class 4 TORIS Reservoirs (Source: BPO TORIS, 1994)

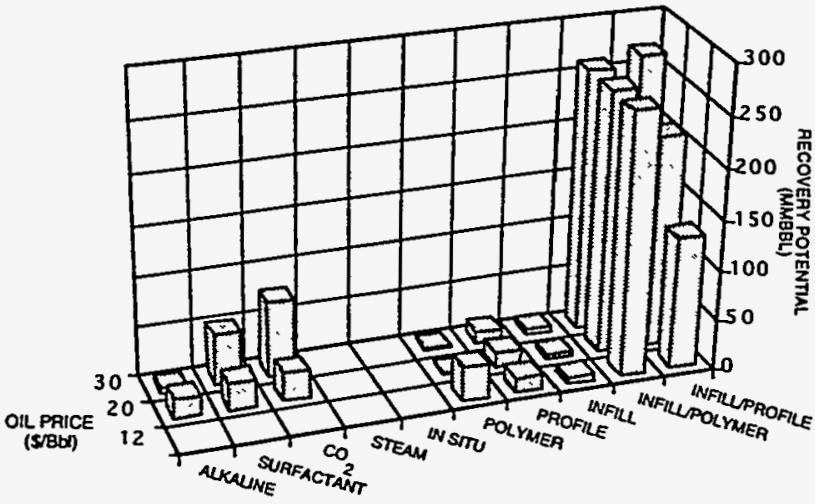

Figure 2.30 Advanced Technology Case Recovery Potential by Process for Rocky Mountain Class 4 TORIS Reservoirs (Source: BPO TORIS, 1994) 


\subsection{References}

Aydelotte, S.R. and G.A. Pope, 1982, A simplified predictive model for steam drive performance: SPE 1074852 Annual California Regional Meeting, San Francisco, California, March.

Beck, R.J. and J.B. Biggs, 1992, OGJ300-Smaller list, bigger financial totals: Oil and Gas Journal 1992 Databook, p. 1-21.

Biglarbigi, K., G.W. Paul, and R.M. Ray, 1994, A methodology for prediction of oil recovery by infill drilling: SPE/DOE 27761 Enhanced Oil Recovery Meeting, Tulsa, Oklahoma, April.

Brigham, W.E., A. Satman, and M.Y. Soliman, 1980, Recovery correlation for in-situ combustion field projects and application to combustion pilots: Journal of Petroleum Technology, vol., 32, No. 12, December, p. 2132-2138.

Buckley, S.E. and M.C. Leverett, 1942, Mechanism of fluid displacement in sands: Trans. American Institute of Mining and Metallurgical Engineers, vol. 146, p. 107-116.

Claridge, E.L., 1972, Prediction of recovery in unstable miscible flooding: Society of Petroleum Engineers Journal, vol. 12, No. 6, April, p. 143-155.

Coats, K.H., W.D. George, and B.E. Marcum, 1974, Three-dimensional simulation of steamflooding: Society of Petroleum Engineers Journal, vol. 14, No. 6, December, p. 573592.

DOE Fossil Energy Report, 1986, III-2 Supporting Technology for Enhanced Oil Recovery (DE87001219), Steamflood Predictive Model: DOE/BC-86/6/SP, December.

DOE Fossil Energy Report, 1986, III-3 Supporting Technology for Enhanced Oil Recovery (DE86000284), In Situ Combustion Predictive Model: DOE/BC-86/7/SP, December.

DOE Fossil Energy Report, 1986, III-5 Supporting Technology for EOR (DE87001208), Chemical Flood Predictive Model: DOE/BC-86/11/SP, December.

DOE Fossil Energy Report, 1986, III-6 Supporting Technology for Enhanced Oil Recovery (DE87001209), $\mathrm{CO}_{2}$ Miscible Flood Predictive Model: DOE/BC-86/12/SP, December.

DOE Fossil Energy Report, 1994, III-7 Supporting Technology for Enhanced Oil Recovery (DE94000145), Infill Drilling Predictive Model: DOE/BC-94/4/SP, Draft, July.

DOE Report, 1986, Producing Unrecovered Mobile Oil: Evaluation of Potential Economically Recoverable Reserves in Texas, Oklahoma and New Mexico, Polymer Predictive Model: DOE/BC-86/10/SP, December, Appendix A p. A-1 through A-54.

Fuller, S.M., A.M. Sarem, and T.L. Gould, 1992, Screening waterfloods for infill drilling opportunities: SPE 22333 International Meeting on Petroleum Engineering, Beijing, China, March.

Garon, A.M. and R.J. Wygal, Jr., 1974, A laboratory investigation of fire-water flooding: Society of Petroleum Engineers Journal, vol. 14, No. 6, December, p. 537-544.

Gomaa, E.E., 1980, Correlations for predicting oil recovery by steamflood: Journal of Petroleum Technology, vol. 32, No. 2, February, p. 325-332.

Higgens, R.V. and A.J. Leighton, 1962, A computer method to calculate two-phase flow in any irregularly bounded porous medium: Trans., American Institute of Mining and Metallurgical Engineers, vol. 225, p. 679-83.

Holm, L.W. and V.A. Josendal, 1974, Mechanism of oil displacement by carbon dioxide: Trans. American Institute of Mining and Metallurgical Engineers, vol. 257, p. 1427-36.

ICF/BEG (Texas Bureau of economic Geology), 1990, Producing Unrecovered Mobile OilEvaluation of Potential Economically Recoverable Reserves in Texas, Oklahoma, and New Mexico: Department of Energy Report DOE/BC/14000-2. 
IOGCC, 1993, The project on advanced oil recovery and the states: DOE funded, Approach to the Analysis, T1264WY3, draft documentation, July, p. III-1 through III-20.

Jones, J., 1981, Steam drive model for hand-held programmable calculators: Journal of Petroleum Technology, vol. 33, No. 9, September, p. 1583-1598.

Koval, E.J., 1963, A method for predicting the performance of unstable miscible displacement in heterogeneous media: Trans., American Institute of Mining and Metallurgical Engineers, vol. 228, June, p. 145-154.

Lasater, J.A., 1958, Bubble point pressure correlation: Trans., American Institute of Mining and Metallurgical Engineers, vol. 379.

LeBlanc, J.L. and B.H. Caudle, 1971, A streamline model for secondary recovery: Society of Petroleum Engineers Journal, vol. 3, No. 71, March, p. 7-12.

Mandl, G and C.W. Volek, 1969, Heat and mass transport in steam-drive processes: Society of Petroleum Engineers Journal, vol. 9, No. 1, March, p. 59-79.

Marx, J.W. and R.H. Langenheim, 1959, Reservoir heating by hot fluid injection: Trans. Society of Petroleum Engineers of American Institute of Mining and Metallurgical Engineers, vol. 216, p. 312-315.

Moritis, G., 1992, EOR increases $24 \%$ worldwide; claims $10 \%$ of U.S. production: OGJ, vol. 90 , No. 16, April 20, p. 51-79.

Mungan, N., 1981, Carbon dioxide flooding fundamentals: Journal of Canadian Petroleum Technology, vol. 20, No. 1, January-March, p. 87-92.

Muskat, M., 1946, Flow of homogenous fluids through porous systems: eds. J.W. Edwards, Inc., Ann Arbor, MI.

Myhill, N.A. and G.L. Stegemeier, 1978, Steam-drive correlation and prediction: Journal of Petroleum Technology, vol. 30, No. 2, February, p. 173-182.

National Petroleum Council, 1984, Enhanced Oil Recovery; Washington, D.C.

Patton, J.T., K.H. Coats, and G.E. Colegrove, 1971, Prediction of polymer flood performance: Society of Petroleum Engineers Journal, vol. 11, No. 1, March, p. 72-84.

Paul, G.W., L.W. Lake, and T.L. Gould, 1984, A simplified predictive model for $\mathrm{CO}_{2}$ miscible flooding: SPE 13238 59th Annual Technical Conference, Houston, Texas, September.

Paul, G.W., L.W. Lake, G.A. Pope, and G.B. Young, 1982, A Simplified Predictive Model for Micellar-Polymer Flooding:.SPE 10733 California Regional Meeting, San Francisco, March.

Pope, G.A., 1980, The application of fractional flow theory to enhanced oil recovery: Society of Petroleum Engineers Journal, vol. 20, No. 3, June, p. 191-205.

Prats, M., 1982, Thermal Recovery: Society of Petroleum Engineering, Monograph, New York Dallas.

Van Lookeren, J., 1977, Calculation methods for linear and radial steam flow in oil reservoirs: SPE 6788 46th Annual Meeting, Denver, Colorado, October.

Williams, R.L., H.J. Ramey, S.C. Brown, and S.K. Sanyal, 1980, An engineering economic model for thermal recovery methods: SPE 8906 50th Annual California Regional Meeting, Los Angeles, California, April. 


\section{CHAPTER 3 \\ RESERVOIR DESCRIPTION AND RESERVOIR MANAGEMENT RESEARCH NEEDS}

Improved reservoir description and reservoir management can result in improved recovery from Class 4 reservoirs. Chapter 3 describes technological and methodological reservoir description and reservoir management research needs with emphasis on relevance to Class 4 reservoirs.

Section 3.1 discusses the definition of heterogeneity to fluid flow and the sources or components of heterogeneity. Four naturally occurring components of heterogeneity (i.e., depositional, diagenetic, tectonic or structural, and fluid content) are identified from past improved or enhanced oil recovery studies. A fifth type, man-induced heterogeneity, is identified and compared in terms of its effects on fluid flow with the effects of naturally occurring sources.

Section 3.2 uses the four naturally occurring components of heterogeneity as a basis for comparison of Class 4 reservoirs and plays within and between basins in the major Class 4 regions. Results of these comparisons emphasize the importance of considering all four components of heterogeneity in the search for predictable similarities and differences within Class 4 reservoirs.

Section 3.3 describes the role played by reservoir description, using various information types collected at various scales and levels of uncertainty, to delineate heterogeneities associated with each of the four component sources. Comparisons between Class 4 reservoirs, plays, etc., discussed in Section 3.2 are used as an aid in identifying Class 4-specific research needs for the various information types. Most Class 4-specific research needs involve the development and demonstration of methodologies for collection, analysis, and integration of data. General research, development, and demonstration (RD\&D) needs for tools and methodologies are also discussed in Section 3.3.

Section 3.4 describes the role played by reservoir management in application of reservoir description or characterization in conjunction with improved oil recovery (IOR) processes to recover additional remaining oil-in-place (ROIP). Research needs are primarily the development, practical demonstration, and transfer of methodologies for efficient reservoir management

Section 3.5 summarizes some current research in reservoir characterization and reservoir management. Class 4-specific and general research needs in reservoir characterization and reservoir management are summarized in Chapter 5.

\subsection{Influence of Heterogeneity on Improved Oil Recovery Processes}

Knowledge of the location and magnitudes of heterogeneities to fluid flow (defined in section 3.1.1) is an important first step toward improved oil recovery. The four naturally occurring sources of reservoir heterogeneity (section 3.1.2) are discussed in the context of examples of Class 4 reservoirs. These sources or origins of heterogeneity, which form the basis for subsequent discussions on reservoir description (sections 3.2 and 3.3), are: depositional, diagenetic, tectonic and/or structural, and variation in fluid content. One additional reservoir heterogeneity type, those induced by man's activities, is discussed in Section 3.1.3. 


\subsubsection{Definition and Importance of Heterogeneity}

In the context of petroleum reservoirs, heterogeneity may be defined as a lack of uniformity in reservoir properties (NIPER, 1986). Heterogeneities that affect fluid flow are essentially spatial variations in fluid or solid (mineralogic) composition, variations in the geometry of fluid-filled spaces (pores, fractures, vugs, etc.) in the rock matrix, and variations in other reservoir parameters such as pressure and temperature. Sharma et al. (1990) defined the term as "any change in geologic reservoir properties that causes a variation in fluid-flow parameters (e.g., permeability, porosity, fluid saturation, and capillary pressure) that results in modification of the flow regime." These variations have a profound influence on the movement characteristics and flow patterns of singleand multiphase fluids in the subsurface. Heterogeneities may be discussed usefully in terms of their genesis, whether of natural origin or as a result of human activities, but it is their expression in terms of effects on fluid flow that is critical to reservoir performance.

Reservoir heterogeneity is an important consideration at all stages of reservoir development. Its relative importance increases as reservoir development progresses from primary to secondary and tertiary stages (Figure 3.1). The importance of recognizing heterogeneities becomes even more critical in advanced stages of reservoir development in geologically complex reservoirs, that is, in reservoirs that have greater inherent heterogeneity. The economics of accessing and producing the remaining-oil-in-place (ROIP) dictates this increase in importance.

\subsubsection{Natural Sources of Heterogeneity}

Heterogeneity can have a definite negative effect, even on waterflood performance. For example, in the North Sea much of the oil in the North Viking Graben area east of the Shetland Islands is contained in two members of the Brent formation; the Etive, a high-permeability barrier bar sandstone, overlying the Rannoch, a barrier face (shoreface) sandstone with about an order of magnitude less permeability (Weber, 1986) (Figure 3.2A). Because there is no perfect seal separating the two units, injection and production, even when perforations are confined to the

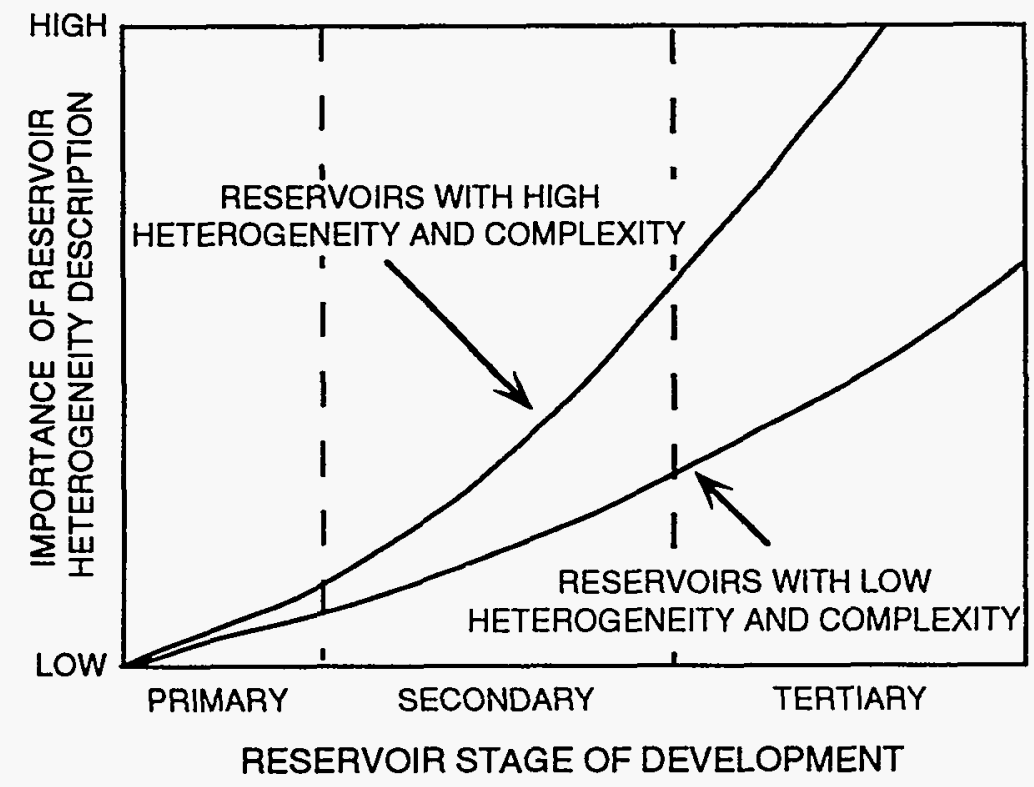

Figure 3.1 Increase in Importance of Reservoir Heterogeneity Through the Life of a Reservoir (Modified from: Pande et al., 1994, p. 14) 
Rannoch interval, result in bypassed oil and early water breakthrough (Figure 3.2B). In some fields, early water breakthrough was so serious and unexpected that water handling facilities were severely strained (Thomas and Bibby, 1993). Attempts to recover the by-passed Rannoch oil by infill drilling have been plagued by problems with early water coning from the Etive sandstones.

In a review of 147 enhanced oil recovery (EOR) field case histories including chemical, gas, in situ combustion, and steam processes, Dauben (1991) found that reservoir heterogeneity was identified as the single most common constraint to successful EOR application. Reservoir heterogeneities can cause injected fluids to move in unexpected and nonuniform paths through the reservoir and may result in lower than anticipated oil recovery and poor economic performance.

Dickey (1979) described several EOR projects that failed because the geological heterogeneities of the reservoir had not been properly considered. He identified reservoir heterogeneity as the most common cause of EOR project failure (Brown, 1986).

Problems related to reservoir heterogeneity encountered in four EOR pilot projects in clastic reservoirs sponsored by the Department of Energy (DOE) were analyzed in detail by Szpakiewicz et al. (1987). Two of these reservoirs, the Big Muddy field producing from the Upper Cretaceous Frontier formation in Wyoming and the Bell Creek field producing from the Lower Cretaceous Muddy formation have been classified as barrier island deposits (i.e., Class 4).

A

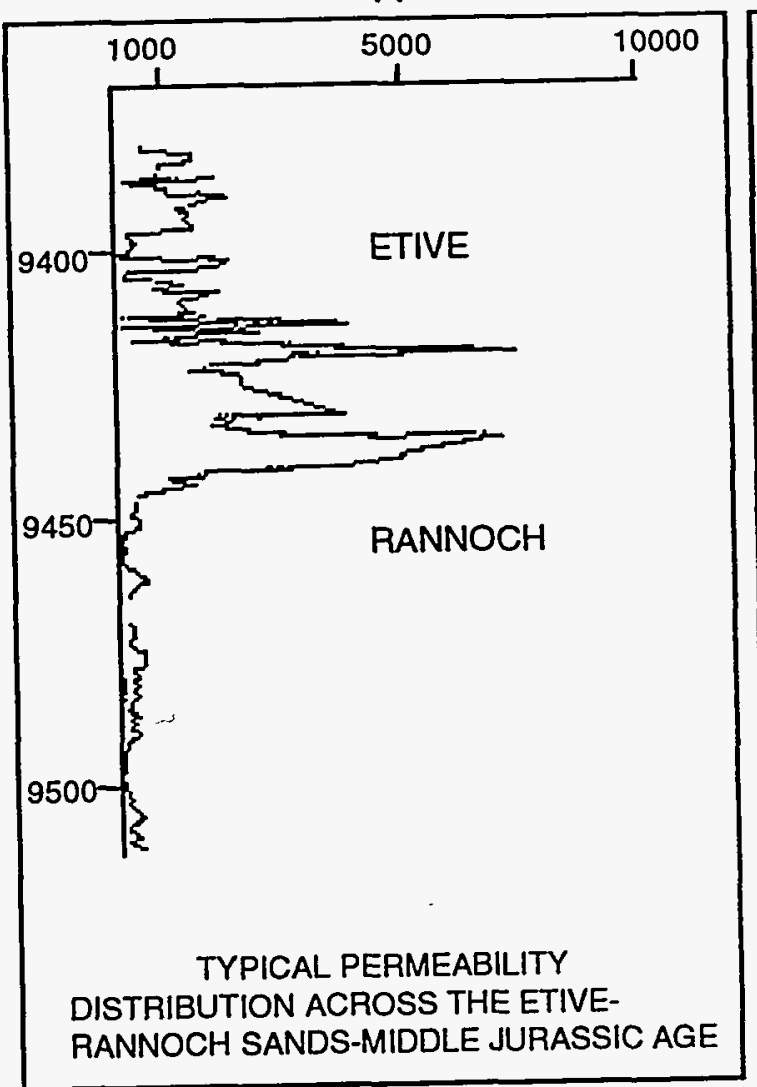

B

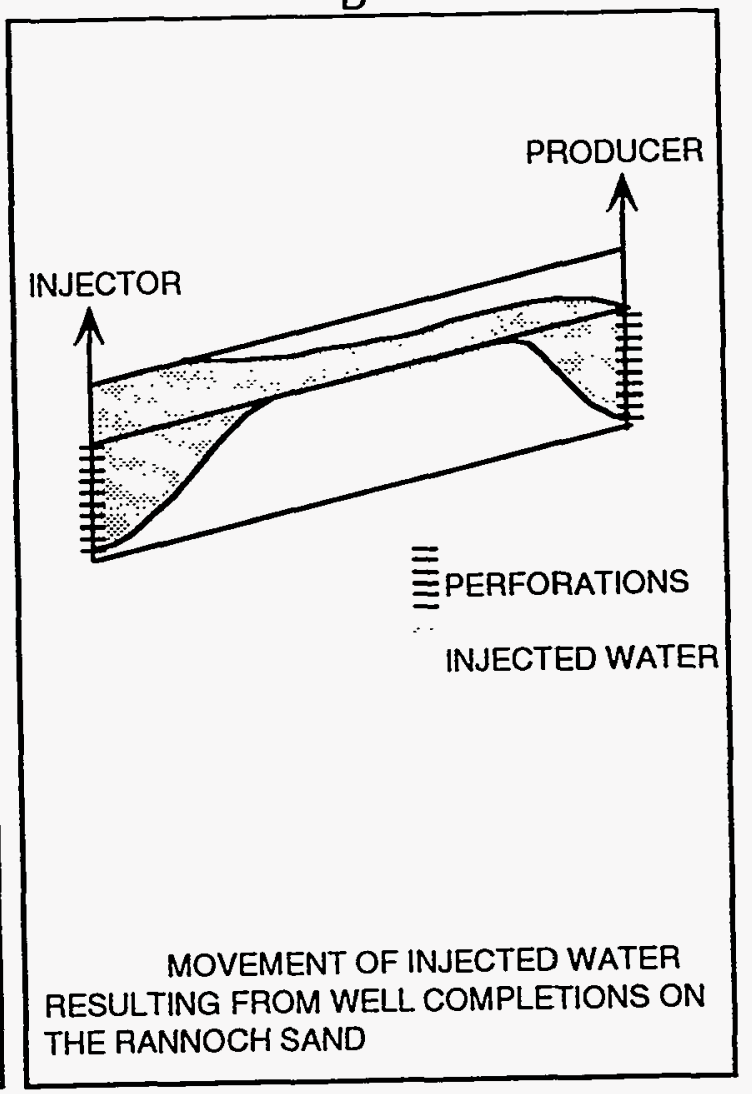

Figure 3.2 Permeability Distribution and Movement of Injected Water in the Etive and Rannoch Sands of the Brent Formation, North Sea (Source: Weber, 1986, p. 493) 
The Bell Creek field consists of six separate barrier island reservoir compartments in which the trapping mechanism is the updip pinch-out of barrier core facies into lagoonal shales. The predominant heterogeneities affecting production in this micellar-polymer project were (1) facies architecture and the presence of incised valleys with lithologically variable fill (Szpakiewicz et al., 1987; Honarpour et al., 1988; Sharma et al., 1990; Burt et al., 1975); (2) distribution, type, and amount of authigenic clay minerals; and (3) presence of previously unrecognized fractures and faults between wells and groups of wells. Production data and pressure-pulse tests confirmed many of these naturally occurring heterogeneities, but interpretation of tracer survey results was not clear because of chemical interaction between the preflush and micellar-polymer solution (Szpakiewicz et al., 1987).

The Big Muddy field is a plunging anticlinal trap. Surfactant-flooding EOR pilot projects encountered excessive formation water production due to a system of inadequately understood natural faults, joints, and fractures superimposed on the low-matrix-permeability (average $56 \mathrm{mD}$ ) reservoir (Szpakiewicz et al., 1987). Tertiary production rates were also lower than anticipated, because of reduced injection rates mandated by low-pressure parting in the formation (Ferrel et al., 1984). Tracer and temperature surveys indicated unanticipated up-section migration of injected fluids in abandoned well annuli.

Szpakiewicz et al. (1987) grouped reservoir heterogeneities from the four pilot projects into four genetic categories: depositional, diagenetic, structural, and formation fluid. To this list of naturally occurring components of heterogeneity, a fifth category, that of man-induced heterogeneities or alterations, may be added to obtain a comprehensive list. Each of these sources or components of heterogeneity can have a variable effect on IOR project performance. This division of heterogeneities by origin or source provides an excellent framework for research, discussion, and pursuit of a better predictive understanding of their effects.

\subsubsection{Man-Induced Heterogeneities or Alterations}

Man's activities in development and depletion of a reservoir can have a profound influence on its basic characteristics and thus on its performance. In some cases, man's activities are equivalent to introduction of whole new and extreme episodes of diagenesis, tectonics, and/or fluid exchange. The nature of these changes is unexpected in many instances and often results in decreased reservoir performance and/or permanent damage.

\section{Problems Associated With Wellbores}

Fluids associated with drilling operations have ample opportunity to interact with rocks and formation fluids in the vicinity of the wellbore. All additives to the drilling fluid can invade the formation and cause damage by interaction with reservoir rocks and fluids to form precipitates, alter minerals, or dissolve components to release fines that can cause pore throat blockage. Borehole condition after drilling activities can affect the quality and effectiveness of subsequent completions and cement jobs. Poor well cementing can lead to unwanted vertical communication of fluids between reservoir layers or out of zone.

Fluids introduced in completion or stimulation treatments provide additional opportunities for adverse reactions with reservoir rocks and fluids. Hydraulic fracturing treatments also run the risk of creating permanent high-permeability pathways (i.e., channels) between wells or reservoir layers.

\section{Problems Associated with Fluid Removal}

Production of oil, gas, and/or water has a tendency to upset fluid equilibria in the reservoir by imposing changes in the pressure regime. These changes may result in unanticipated rock-fluid 
interactions, precipitation of solids (such as mineral scale or paraffins), changes in fluid viscosities, etc. The effects are a function of reservoir drive mechanism, reservoir fluid properties, and local and reservoir wide production rates.

Removal of fluids from the reservoir can change the physical pore structure of the reservoir. Reduction in volume and pressure of contained fluids can cause local and reservoirwide collapse or partial collapse of pore space and/or closing of critical fluid-conducting fractures. In extreme cases, the resulting subsidence may cause well failures, or the reservoir may become compartmentalized by small-scale faulting induced by fluid removal.

\section{Problems Associated with Fluid Injection}

Introduction of fluids (e.g., fresh water, steam, brines, air, $\mathrm{O}_{2}, \mathrm{CO}_{2}$, polymers, acids, etc.) always creates the possibility for adverse reaction of reservoir rocks and fluids either with the injected fluid or with existing reservoir fluids as a result of disequilibrium caused by the introduced fluids. Even native fluids previously extracted from the same reservoir may cause problems when reinjected if their chemical or physical properties have been altered in any way.

Rate and overall volume of fluid injection must also be considered, because they may change the distribution of reservoir pressure and temperature resulting in chemical disequilibrium. Excessive rates of injection may also result in formation parting and creation of unwanted high permeability pathways between wells and poor sweep efficiency.

\section{Avoidance and Minimization of Man-Induced Effects}

Characterization or description of the three-dimensional aspects of reservoir rock and fluid composition and properties is the only way to avoid the problems so often associated with man's activities. If reservoir properties are adequately known and understood, development and operating programs can be tailored to produce an absolute minimum of deleterious effects. The approaches to achieving this goal are discussed in Sections 3.3 and 3.4.

\subsection{Comparison of the Components of Heterogeneity Among Class 4 Regions and Plays}

The purpose of Section 3.2 is to compare and contrast Class 4 reservoirs contained in major plays in the Texas, Oklahoma, California, and Rocky Mountain regions (as defined in the Class 4 Technical Report-NIPER/BDM, 1994) in terms of the four naturally occurring sources of heterogeneity discussed in Section 3.12. Results of these contrasts and comparisons provide insight into the degree of heterogeneity predictability expected in Class 4 reservoirs within and between plays, basins, or regions. These insights can be used to guide determination of Class 4 specific research needs.

The four naturally occurring heterogeneity sources and their variations among Class 4 regions are discussed individually: depositional environment in Section 3.2.1., diagenetic history in Section 3.2.2, tectonic and structural history in Section 3.2.3, and variation in fluid content in Section 3.2.4. Section 3.2.5 summarizes the results of comparison and contrast and discusses the general characteristics of reservoirs and plays within each of the major Class 4 regions.

In the discussion following, statements are offered concerning basin development and causal interrelationships among the four heterogeneity sources. These statements are consistent with and supported by available Class 4 data. Existing Class 4 data alone, however, are often sparse and are generally insufficient to prove some of these statements. 


\subsubsection{Depositional Environment}

Of the four natural factors that influence heterogeneity, depositional environment is the factor that most often exerts predominant influence on reservoir heterogeneity. The expectation of a correlation in at least some important reservoir characteristics (e.g., facies characteristics, architecture, etc.) is an important basis for DOE's geologically defined reservoir class system.

\subsubsection{Texas Plays}

In Texas, Frio formation strandplain/barrier island reservoirs received sediments from active deltaic areas along depositional strike to the northeast and the southwest (ICF and BEG, 1990). Frio deposits exhibit generally aggradational to progradational architectures (Finley and Tyler, 1986) and average about 20 feet of net pay (BPO TORIS, 1994). Jackson strandplain/barrier island deposits received minor contributions of sediment from local sources as well as from a deltaic area to the northeast (Fisher et al., 1970). Jackson formation deposits tend to exhibit progradational architectures to some extent. Average reservoir net pay thickness is 16 feet (BPO TORIS, 1994). Paluxy strandplain/barrier island deposits of the Cretaceous, Salt-Related Play received sediment from a deltaic development immediately to the east (Caughey, 1977). These deposits also exhibit a progradational nature, with individual barrier island sands up to 100 feet thick and more lenticular strandplain sands up to 50 feet thick (Caughey, 1977). Woodbine deposits of the same play exhibit similar depositional characteristics, with maximum individual sand thicknesses less than 100 feet and less than 50 feet in barrier island and strandplain deposits, respectively (Oliver, 1971). Average net pay thickness for Paluxy and Woodbine formation reservoirs in the Cretaceous, SaltRelated Play is 25 feet (BPO TORIS, 1994).

Average net pay thickness for major Texas plays is 21 feet, varying from 16 to 100 feet. Reservoir architecture in individual plays may be largely a function of sediment supply, but tectonic controls are also influential (see section 3.2.3.1).

\subsubsection{Oklahoma Plays}

The Southern Oklahoma Desmoinesian and Bromide Plays and the Arkoma Morrowan Play are all characterized by deposition on moderately to rapidly subsiding shelves adjoining basins undergoing rapid subsidence. Periodic strong clastic influxes onto these shelves (Tomlinson and McBee, 1988; Johnson et al., 1988; GRI, 1993) resulted in aggradational architectures and an average net pay thickness of 50 feet (BPO TORIS, 1994).

\subsubsection{California Plays}

Coarse to very coarse sands dominate the San Ardo-King City, Vaqueros, and Vedder/Pyramid Hills Plays in California. Strandplain/barrier island deposits formed aggradational deposits on the shallow-shelf areas of very rapidly subsiding and narrow Tertiary basins. Sediment supply came primarily from coastal plain areas to the east, but no major delias supplied sediment. Average net pay thickness for reservoirs in these plays is 132 feet (BPO TORIS, 1994).

\subsubsection{Rocky Mountain Plays}

Deposition in basins with highly individualistic developmental histories is characteristic of reservoirs in the Muddy, Gallup, and D-J plays of the Rocky Mountain Region. Jackson (1993) summarizes work done by NIPER in comparison of facies geometries and architecture in outcrop and subsurface reservoir studies of Muddy and Almond formation deposits in the Powder River and Washakie Basins, Wyoming, respectively. Not all facies present in subsurface reservoirs of 
one formation could be found in depositionally analogous nearby outcrop exposures nor in analogous reservoirs or outcrops of the other formation. NIPER also determined in these comparisons that external facies geometries were substantially different. Average net pay thickness for reservoirs in the major Rocky Mountain region plays is 27 feet (BPO TORIS, 1994).

\subsubsection{Summary of Similarities and Differences Due to Depositional Environment}

Texas and Rocky Mountain region plays exhibit lower net pay thicknesses ( 21 and 27 feet, respectively) than do Oklahoma and California plays, with 60 and 132 feet of net pay, respectively. Thinner pays are probably indicative of lower sediment supply. The general depositional setting (i.e., specification as a strandplain/barrier island deposit) appears to impose some similarity on deposits in terms of facies types. However, differences in deposit architecture as reflected in deposit thickness and external facies geometries are probably controlled by factors such as sediment supply and depositional tectonics.

NIPER's work concluded that a more detailed breakdown of depositional classification, perhaps at a level sufficient to identify rocks deposited under identical or very similar sets of processes, might be necessary to achieve similarity in comparing depositional analogues (Jackson, 1993).

\subsubsection{Diagenetic History}

Diagenetic alterations can have a profound influence on reservoir quality. Class 4 reservoirs are distributed over a wide variety of basin settings and range in age from Paleozoic to Tertiary. A correspondingly wide spectrum of diagenetic effects is observed.

\subsubsection{Texas Plays}

In Texas, major plays have different depositional mineralogies, different ages, and different depths of burial. All these factors contribute to different diagenetic manifestations.

Diagenesis in the Oligocene Frio Play was studied by Milliken et al. (1981), using petrographic and isotopic methods. They found that calcite and quartz cementation occur mostly from 5,000 to 8,500 feet of burial. Below 8,500 feet active diagenetic alteration occurs as indicated by : (1) formation of leached porosity, (2) alteration of feldspars, (3) conversion of smectite clays to illite, (4) kaolinite replacement of feldspars and kaolinite filling of primary and secondary porosity, and (5) continued precipitation of carbonate cements (Milliken et al., 1981). This zone of active diagenesis produces material that migrates up section to form calcite and quartz cements above 8,500 feet. Milliken et al. (1981) concluded that mineralogically unstable grains had not yet equilibrated with their burial environments even at 15,000 feet, the deepest depths examined in the study. Frio deposits near the southwest end of the play have higher concentrations of feldspars and rock fragments (volcanic and carbonate) than more quartz-rich deposits to the northeast (Galloway et al., 1982). This difference in initial mineralogy allows diagenesis to have a stronger effect on sediments in the southwest part of the play. Mean depth of production for the Frio Play is 6,200 feet, and average porosity and permeability are $29 \%$ and $1,131 \mathrm{mD}$, respectively (BPO TORIS, 1994). In contrast, the Eocene Jackson Play has an average depth of 2,700 feet, an average porosity of $30 \%$, and average permeability of $650 \mathrm{mD}$ (BPO TORIS, 1994).

Both the Lower Cretaceous Paluxy and Upper Cretaceous Woodbine deposits of the Cretaceous, Salt-Related Play contain very quartz-rich sandstones in the fine sand to coarse silt size range (Oliver, 1971; Caughey, 1977). Both are also characterized by presence of limited amounts 
of calcite cement, pyrite, and iron oxide cements. Outcrop observations of Woodbine deposits reveal the additional presence of selenite and ironstone concretions (Oliver, 1971). Mean depth of production for these Cretaceous, Salt Related Plays is 5,700 feet, and mean porosity and permeability are $22 \%$ and $570 \mathrm{mD}$, respectively (BPO TORIS, 1994).

Loucks et al. (1981) concluded that most Tertiary formations in the Texas Gulf Coast have a similar diagenetic sequence, but significant differences in depositional mineralogy and areal variations in magnitude of diagenetic events control final diagenetic products. Anomalously high permeabilities in the Frio Play with respect to other Texas plays may be due to secondary porosity formed by leaching in the zone of active diagenesis as defined by Milliken et al. (1981). Cretaceous, Salt Related Plays are mineralogically very clean and have not been buried too deeply. These factors may account for the appreciable porosity and permeability they retain despite their age. Deposits in the Jackson Play are at relatively shallow depths and are even less affected by diagenetic alterations. Minor calcite-cemented zones interrupt the otherwise friable, uncemented reservoir sandstones (Seni and Walter, 1994).

\subsubsection{Oklahoma Plays}

Very little diagenetic information is available from the literature on Oklahoma Plays. Smith (1992) refers to "tightly cemented horizontal zones" as factors in compartmentalizing many Simpson (Bromide) reservoirs, and to sections tightly cemented by dolomite in association with faults.

Average depth of Oklahoma Class 4 reservoirs in major plays is 4,400 feet. Porosity averages $18 \%$ and permeability averages $292 \mathrm{mD}$ (BPO TORIS, 1994).

\subsubsection{California Plays}

The friable, unconsolidated nature of the sands in most major California Class 4 plays is an indication of a relatively small amount of diagenesis. Some sands in the King City field are reported as well cemented (Miller, 1953). Rapid subsidence, the relatively young age of these midTertiary plays, and possible early emplacement of hydrocarbons may be an explanation for their general lack of cementation. Average reservoir depth for the major California plays is 3,000 feet with porosity and permeability of $30 \%$ and $1,600 \mathrm{mD}$, respectively (BPO TORIS, 1994).

\subsubsection{Rocky Mountain Plays}

Although Almon and Davies (1979) concluded in a regional study of the Muddy formation that diagenetic clay mineral assemblages can be equated to specific, large-scale sedimentologic or reservoir units; subsequent work by NIPER (Jackson, 1993) indicated major differences in comparison of diagenetic effects between strandplain/barrier island reservoirs in different Wyoming basins. Early-stage leaching led to significant porosity and permeability enhancement in the Bell Creek (Muddy) reservoir in the Powder River Basin. The Patrick Draw (Almond) reservoir in the Washakie Basin received no such porosity or permeability enhancement, but rather underwent later-stage cementation by carbonates and clays that significantly degraded reservoir quality. Initial mineralogic composition at Patrick Draw included a higher percentage of clay-rich rock fragments than the reservoir at Bell Creek, making the Patrick Draw reservoir more susceptible to permeability reduction by compaction.

Diagenetic sequences in outcrops of the Muddy formation compared favorably with those observed in the Bell Creek reservoir 40 miles away, but spatial distributions of diagenetic alterations were significantly different (Jackson et al., 1991). Comparing diagenetic features in Almond outcrops with those in the Patrick Draw reservoir just a few miles away revealed 
significant differences (Schatzinger et al., 1992). Dolomite and pyrite present in the subsurface were not observed in outcrop, and outcrops contained significantly more quartz and less carbonate cement than the Patrick Draw reservoir. Transfer of diagenetic information between outcrop and subsurface reservoirs may be possible, but the associated circumstances need to be well understood.

Class 4 reservoirs in the Rocky Mountain region occur at an average depth of 5,300 feet, deepest of the major Class 4 regions. These reservoirs have an average porosity of $17 \%$ and average permeability of $169 \mathrm{mD}$ (BPO TORIS, 1994).

\subsubsection{Summary of Similarities and Differences Due to Diagenetic History}

Not enough data on diagenesis exist in some Class 4 plays (e.g., Oklahoma plays, the Jackson play in Texas) to include them in any detailed analysis, but some general trends can be observed among the Class 4 plays and regions. Individual basin development history appears to be the key factor controlling diagenetic alteration. Comparison of Class 4 diagenetic features between basins within a single region, such as the Rocky Mountain region or between basins in different regions reveals substantial differences. Plays located at similar depths within a basin can share a common sequence of diagenetic events, but plays concentrated at different depths can have strong diagenetic differences because they are exposed to different parts of a basinwide diagenetic sequence (e.g., Texas plays). Even reservoirs within a play can partake of the basin's diagenetic history differently if located at different depths or in different parts of the basin where the intensity of diagenetic events varied.

Observations on Class 4 outcrops in the Texas and Rocky Mountain regions indicates that under some circumstances, the general diagenetic sequence and porosity versus permeability relationships observed in nearby subsurface reservoirs may be similar. Generally though, enough differences in diagenetic features are found to indicate that the very late-stage diagenetic changes inflicted on outcrops by subaerial exposure are significant.

Average Class 4 reservoir depth, porosity, and permeability data (see Table 2.3 ) in the various major regions correlate with a general trend of decreased porosity and permeability with age and depth of burial. The degree of diagenesis is least in the California region, where young (Tertiary age) sediments have undergone rapid but shallow (3,000 feet) burial with excellent preservation of high initial porosities and permeabilities (possibly by early hydrocarbon emplacement). Cretaceous Rocky Mountain region reservoirs have the greatest average burial depths (over 5,000 feet), and a corresponding degree of diagenesis to reduce porosity and permeability significantly. Texas Plays have variable burial depths and ages and intermediate values of porosity and permeability. Substantial reduction of porosity and permeability observed in Oklahoma plays (see Table 2.3) may be attributable to diagenetic alteration, but few diagenetic data are available to confirm this supposition. The observed increase in porosity with depth in the Texas Frio Play indicates that the tendency for porosity and permeability to decrease with burial depth cannot be considered a general rule for application in all Class 4 plays.

\subsubsection{Tectonic and Structural History}

Tectonic and structural influence is exerted in two observable ways on Class 4 reservoirs. First, depositional architecture is strongly influenced by prevailing tectonic conditions through their effects on sediment supply and subsidence. Second, tectonic control on basin development indirectly controls the basin's diagenetic history and local structural developments that together may significantly modify previously deposited sediments. 


\subsubsection{Texas Plays}

Many reservoirs in the Frio Play owe their aggradational architecture to growth faulting. Subsequent burial subjected these reservoirs to a diagenetic regime shared by most Texas Gulf Coast Tertiary deposits (Loucks et al., 1981) and to compartmentalization and further structural modifications associated with the continued development of growth faults.

Class 4 reservoirs in the Jackson Play are predominantly stratigraphic traps (Fisher et al., 1970) with only minor association with growth faulting. Pinch-out updip of washover and/or flood tidal delta sands against lagoonal shales is the most common trap type. Jackson reservoirs are the thinnest of all major Class 4 plays, averaging only 16 feet of net pay (BPO TORIS, 1994), indicating their lack of aggradational character.

Class 4 reservoirs in the Cretaceous, Salt Related Play developed primarily by depositional aggradation over localized subtle structures associated with salt movement. Subsequent continued salt movement resulted in hydrocarbon traps by faulting or draping of sediments over buried faults or folds.

Major plays in Texas Class 4 reservoirs have markedly different tectonic characteristics. In each play, tectonic influence plays an important role in determining the depositional architecture and in controlling the subsequent trapping mechanisms.

\subsubsection{Oklahoma Plays}

Major Class 4 plays in Oklahoma are under the common influence of plate-scale tectonics. Deposition was associated with incipient plate separation and took place on shelves flanking rapidly subsiding basins receiving large amounts of sedimentary fill. This combination of sediment supply and subsidence led to aggradational architectures and reservoirs with substantial (average 60 feet) net pay thicknesses (BPO TORIS, 1994). Later plate encroachment from the south caused severe compression and reactivation of old faults associated with the early incipient rift. Abundant faulting and folding associated with this reactivation event formed effective traps and even compartmentalized many Class 4 reservoirs. Faults also provided ample conduits for vertical, basinwide migration of diagenetic and other fluids.

\subsubsection{California Plays}

Class 4 plays in California were also deposited under the influence of plate-scale tectonics. Deposition of Class 4 reservoirs took place on the shelves of narrow, very rapidly subsiding basins with ample supplies of coarse sediment, conditions conducive to formation of aggradational architectures. California reservoirs contain the thickest (average 132 feet) net pays of all major Class 4 regions (see Table 2.3). Structures leading to hydrocarbon trapping are often related to lateral faults also associated with plate movement.

\subsubsection{Rocky Mountain Plays}

In the Rocky Mountain region, the nature of tectonic activity varies from basin to basin, and it often varies within individual basins. These differences can lead to significantly different architectures for reservoirs of similar depositional origin between and within basins (Jackson, 1993) as a result of variations in subsidence and sediment supply. Variation in basin scale and smaller scale tectonics also leads to a variety of different diagenetic (Schatzinger et al., 1992) and structural manifestations after deposition.

\subsubsection{Summary of Similarities and Differences Due to Tectonic and Structural History}

Tectonic and structural influences are unique in each major Class 4 region. In the Oklahoma and California regions, plate-scale tectonics had similar effects on deposit architecture in all major plays within numerous basins and sub-basins. Deposits formed on shelves of rapidly subsiding 
basins with abundant supplies of sediment resulted in the thickest Class 4 deposits of the major regions (60 feet and 132 feet for average net pay in the Oklahoma and California regions, respectively)(see Table 2.3). Later tectonic and structural activities in the Oklahoma and California regions led to substantial differences in diagenetic histories and trapping mechanisms. In the Texas region, tectonic and structural influence differed among major Class 4 plays, both during depositional and later modification phases. Reservoirs in the Cretaceous, Salt-Related Play were influenced throughout their history by localized structures related to deep salt movements. Reservoirs in the Jackson and Frio Plays share in a common basin-development history, but their location in different parts of the Texas Gulf Coast Basin (i.e., on the rim versus deeper in the basin, respectively) exposed them to substantially different early and later tectonic events and different diagenetic histories, resulting in significant differences in reservoir characteristics. Rocky Mountain Plays occur in a number of basins, almost all of which have unique tectonically controlled basin development histories that lead to different manifestations of Class 4 depositional architectures and subsequent diagenetic and structural overprints.

\subsubsection{Variation in Fluid Content}

The variation in distribution of contained fluids (i.e., crude oils, brines, and gas) can be considered at several scales: between Class 4 regions or basins, between reservoirs or plays within a basin, and within individual reservoirs.

In Texas, Oklahoma, and the Rocky Mountain regions, average crude in Class 4 reservoirs is light ( $32^{\circ}-37^{\circ}$ API, Table 2.3), but with considerable variation between reservoirs and plays. Texas and Oklahoma have some heavy crude production, down to $14^{\circ}$ API in the Jackson and Desmonesian Plays. In the California Class 4 San Ardo and Vedder/Pyramid Hills Plays, heavier crudes predominate ( $14^{\circ}$ and $22^{\circ}$ API, respectively), while light oil ( $32^{\circ}$ API) is characteristic of the Vaqueros Play (BPO TORIS, 1994). In fluid-content studies of the Rocky Mountain Class 4 Bell Creek and Patrick Draw reservoirs, differences in crude oil type and brine composition as well as in water-oil and gas-oil contacts were found in correspondence with significant internal compartmentalization (Jackson, 1993; Schatzinger et al., 1992).

The wide variety of fluid content observed among the Class 4 reservoirs, plays, and regions corresponds to similar variability in basin development history. Reservoirs at different locations within the same basin may contain different fluids due to variations in basin-scale fluid movement and compositional differences. Changes of migrating fluid composition with time, as a function of basin diagenetic development may be at least partly responsible for differences in fluid composition observed within individual reservoirs. Man-induced effects of production operations can contribute greatly to differences in fluid properties observed among reservoir compartments also.

\subsubsection{Summary of Comparisons of Class 4 Reservoirs, Plays and Regions}

Although depositional environment may be predominant in determining similarities in reservoir characteristics in Class 4 reservoirs, the influence of tectonic and structural history, aside from its traditionally viewed role in forming reservoir traps, plays a role of nearly equal importance. Internal properties such as facies geometries and the distribution of depositional heterogeneities affecting fluid flow have not been described in detail for Class 4 reservoirs in most regions. Tectonic and structural control on sediment supply and on subsidence at the site of deposition, however, result in noticeably different sedimentary architectures among Class 4 reservoirs and plays. This effect may result in markedly diverse depositional geometries and differential preservation of Class 4 facies. To get better transferability of the external geometry and scale of facies may require further subdivision of reservoir Class 4 by tectonic and structural type in addition to general depositional type.

Tectonic and structural influence is also a guiding factor in determining a basin's diagenetic course of events. Tectonics and structure, through their influence on topography and climate, determine mineralogic composition and grain size, and provide both early and late influences on 
basin development that have profound effects on the diagenetic history of a deposit. Reservoirs within the same basin have the best opportunity to share in at least part of a common sequence of diagenetic events, but different locations within the basin may experience the events at different magnitudes or may experience entirely different events.

Class 4 reservoirs and plays within the California region are perhaps most uniform among the major regions, having similar depositional architectures (i.e., thick aggradational deposits laid down on rapidly subsiding shelves) and very subtle diagenetic overprints. Oklahoma plays share common attributes of sedimentary architecture with those of California. Texas plays were deposited in various locations within a broad basin with variable local tectonic and structural regimes. Tectonic and structural variations led to local, play-scale differences in basin development history, and therefore to differences in diagenetic history. Basin development histories among basins in the Rocky Mountain region appear to be relatively variable. Rocky Mountain basins also exhibit internal tectonic and basin development variability on a smaller scale than the Texas Gulf Coast Basin, resulting in diagenetic variability between reservoirs rather than between plays.

\subsection{The Role of Reservoir Description or Characterization in Relaxing Constraints on Recovery}

The purpose of reservoir description or characterization is to assemble information about type, distribution, and magnitude of heterogeneities that can be used to convey a knowledge of subsurface fluid flow. To the extent that the information available is incomplete, imperfect, or at an inappropriate scale, knowledge of subsurface fluid flow will be correspondingly uncertain. The purpose of Section 3.3 is (1) to describe the informational components of reservoir description or characterization, (2) to describe the combination or integration of those components for improved recovery by fluid-flow prediction, and (3) to define general and Class 4-specific research needs. Section 3.3.1 is a brief overview of the concept of reservoir characterization. Section 3.3.2 presents an in-depth review of (1) the sources of information used in reservoir characterization, (2) the associated degrees of uncertainty in prediction and measurement of heterogenity, and (3) the general and Class 4-specific research needs. Section 3.3.3 reviews critical steps in reservoir characterization methodology, that is, the process of merging information collected from various sources, at various scales, and at different levels of uncertainty into a consistent whole to be used in prediction of fluid flow. Reservoir characterization methodological research needs are also identified in this section.

\subsubsection{Definition of Reservoir Characterization}

In discussing the definition of reservoir characterization at the first meeting of the organizing committee for the first Reservoir Characterization Technical Conference in Dallas in 1985, the attendees, who represented a wide spectrum of technical backgrounds, decided on the following definition: "Reservoir characterization is a process for quantitatively assigning reservoir properties, recognizing geologic information and uncertainties in spatial variability" (Lake and Carroll, 1986). Traditionally, the purpose of reservoir characterization has been to quantitatively transfer information on reservoir property distribution with a sufficient degree of detail and accuracy to a numerical reservoir simulator so that simulation predictions would match reservoir performance.

An appropriately detailed and accurate (i.e., with acceptable degree of uncertainty) identification of heterogeneity distribution, type, and magnitude can relax reservoir description constraints on recovery by allowing the operator to avoid the deleterious effects of heterogeneities and/or exploit them to best economic advantage. Above all then, reservoir characterization is a tool used to avoid costly errors in reservoir decision making. 


\subsubsection{Reservoir Characterization Models, Their Associated Uncertainties and Research Needs}

In the past, the aim of reservoir characterization generally has been to create a single, "most probable" representation of the reservoir to be used as input to subsequent decision making. The need for a small number of more extreme but reasonably probable representations to serve as input to decision-making tools is now becoming recognized as a useful if not critical addition. This approach allows bracketing the range of reasonably expected recovery and economic outcomes. The primary objective of reservoir characterization model construction is to accurately represent and minimize, if economically feasible, the range of uncertainty in our knowledge of reservoir parameters that affect fluid flow.

A reservoir characterization model is a representation or estimate of reservoir reality. It represents not only the three-dimensional extent or bounds of the reservoir, but the qualitative (presence or absence) and quantitative (magnitude) values of rock, fluid, and other reservoir parameters affecting fluid flow at every location in the volume of the reservoir. The degree of uncertainty associated with placement and magnitude of fluid-flow parameters is an important facet of the model. Three types of information can generally be called upon for model construction in reservoir characterization. Conceptual information is that information derived from analogous situations. Direct transferability of observed or measured properties is assumed, but associated uncertainty is an inverse function of the overall similarity or appropriateness of the analogous situation. Stochastic information is also derived from an analog source, but in addition makes an attempt to represent the small-scale variability of properties observed in that source. Given an equal degree of analog similarity, a stochastic model can provide less uncertainty through heterogeneity representation at a finer scale. The third information type, deterministic information, involves direct acquisition of data from the reservoir, with no question of transferability and a degree of uncertainty in heterogeneity representation limited only by the scale of measurement and the resolution of the measuring tool.

In practice, information of any one or more of the three basic information types (i.e., conceptual or analog, stochastic, or deterministic) can be used in building a reservoir characterization model. Choice of the appropriate blend of information types depends on (1) availability of each type of information at the location needed, (2) the degree of uncertainty that can be tolerated, and (3) cost to obtain additional information. Information types are employed in a complementary fashion, using "hard" or deterministic information to constrain and calibrate conceptual or stochastic models based on analogs, and using "soft" or analog-based conceptual or stochastic information to extend or interpolate deterministic information.

Difference in the degree of associated uncertainty provides a useful framework for discussing research needs for the various reservoir characterization model-building approaches usually employed. The following discussions on research needs are not meant to be comprehensive. Discussions are intended to provide an overview only, in order to maintain emphasis on (1) how the various forms of information used in reservoir characterization interrelate (i.e., information sources, scales, and their associated uncertainties), (2) methodologies which can be quickly demonstrated with traditional or newly developed technologies and applied in Class 4 reservoirs to prevent abandonment (as opposed to focus on technological advances which could only provide benefits to Class 4 in the long-term), and (3) clastic reservoirs in mature producing areas (which includes most Class 4 reservoirs).

\subsubsection{Conceptual Models and Associated Research Needs}

Conceptual or analog models of reservoir characteristics are derived by knowledgeable, wellsupported assumptions of similarity to other well-studied, well-understood occurrences of those characteristics. The power of conceptual models is in their ability to tie together and extend sporadically distributed hard reservoir information. Conceptual models are frequently used as guides in the early stages of reservoir development when very little deterministic reservoir 
information is available. Conceptual models may cover almost any scale of consideration, from reservoir scale or larger down to pore scale. Reservoir characteristics included in conceptual models may be qualitative, semiquantitative, or quantitative in nature. The degree of transferability of reservoir property information from a conceptual analog to the reservoir of interest is a function of how closely the analog reflects similarity in the conditions that control the presence or magnitude of those properties.

\section{Depositional Conceptual Models}

The scale of consideration for depositional conceptual models ranges from that of the interaction of basin evolution with reservoir architecture to that of individual sedimentary structures. Although the technical literature is probably the most common source, primary sources for depositional conceptual models are genetically similar deposits in (1) modern sedimentary environments, (2) outcrops of ancient sedimentary deposits, (3) other petroleum reservoirs and (4) other subsurface formations. Genetic similarity implies deposition under comparable conditions of geologic control as discussed in Section 2.2.2 of the Class 4 Technical Report (NIPER/BDM, 1994).

\section{Research Needs}

For all reservoir classes, carefully focused depositional analog studies have potential for increasing understanding and predictability of critical sedimentary features such as (1) external reservoir and facies geometries and (2) relative location, frequency, and magnitude of internal depositional heterogeneities likely to influence fluid flow. Such studies may identify correlations between those critical features and simpler, readily observable characteristics, such as facies properties, sedimentary structures, or other reservoir data, that might be obtained from a single well or a small number of wells.

Although the gross trends of reservoir architecture (e.g., thickness, aggradational versus progradational character, etc.) tend to be similar within several Class 4 plays, basins, or regions; detailed comparison of facies architecture and facies characteristics shows significant differences among Class 4 deposits (see section 3.2.1). The transferability problem is large at the class level for Class 4 reservoirs, and some further subdivision of the class, probably based on tectonics, which has a strong influence on sediment supply and deposit architecture, is in order. Studies at this scale may also address predictability of post depositional modification of Class 4 deposits by valley incision and subsequent fill.

Other strandplain/barrier island features that need to be made more predictable through analog studies include: (1) formation of strandplain versus barrier island deposits; (2) presence versus

absence of eolian deposits and their associated swale facies, which can act as internal permeability baffles; and (3) presence and frequency of crosscutting tidal inlets, which tend to divide strandplain/barrier island reservoirs into lateral compartments. These features need to be better understood in relationship to tectonics, sediment supply, tidal influence, and other factors that influence their formation and expression.

\section{Diagenetic Conceptual Models}

There is no universally accepted definition of the term, but a consideration of the diagenesis of a sedimentary deposit should include all the compositional and compactional changes that take place after initial deposition. All such alterations, whether of physical, chemical, or biological origin, have the potential for creating additional heterogeneities affecting fluid flow through their effects on porosity, permeability, and mineralogic composition. Composition of interstitial fluids, including hydrocarbons, may also be affected. In sandstones, the effects of diagenesis are reflected in (1) changes in degree of compaction; (2) precipitation of cements; and (3) replacement, recrystallization-transformation, or dissolution of existing grains, cements, or matrix. A diagenetic conceptual model is a representation of the three-dimensional distribution of these effects. Much 
remains to be accomplished in development of conceptual models of reservoir diagenesis (1) because of our incomplete understanding of the complex physical and chemical processes involved and (2) because the processes that primarily control diagenetic alteration of reservoir deposits operate on a scale much larger in space and time than the individual reservoir, a scale at which data are difficult to obtain, and a scale not generally considered in analyzing reservoirs.

Given the fact that it is common for diagenetic alteration to be the single most important factor contributing to heterogeneities defining reservoir fluid-flow patterns, it is fortunate for engineers and geologists attempting to characterize reservoirs that the effects of diagenesis may be linked in many cases to the sedimentary characteristics initially imposed by the environment of deposition. Because diagenesis results mainly from fluids flushing the deposit at various times during its history, those portions of the deposit with the highest permeability have an opportunity to develop the strongest early diagenetic effects. Early introduction of clay coatings or partial cements to the porous sediment may preclude the development of more extensive cementation and prevent compaction during burial history. Especially in clastic deposits, the tendency is for the relative relationships between porosity and permeability imposed by depositional processes to remain dominant throughout the diagenetic history of the deposit (Johnston and Johnson, 1986; Jackson, 1993). Johnston and Johnson (1986) found in examination of a barrier island reservoir in the Wilcox (Eocene) of Louisiana that secondary porosity tended to develop in the same facies that contained highest primary porosity (i.e., eolian, beach, and upper shoreface), in spite of some reduction of primary porosity in these facies by early cementation. This tendency cannot be relied on under all circumstances, but it can provide conceptual insight or guidelines at the initial stage of reservoir characterization when no additional data are available.

There is no universally applicable division of the various stages of diagenesis; however, it is convenient to think of diagenesis in terms of early diagenesis (in fresh, mostly unconsolidated sediment) and burial diagenesis under the influence of processes and fluid movements acting in the subsurface (Cant, 1986). Uplifting of deeply buried sediments and their exposure to new migrating formation fluids of different origin and chemistry may superimpose additional diagenetic alterations. Mineralogic composition of the sedimentary grains is an important internal control on diagenesis from the time of deposition onward (Loucks et al., 1977; Dutton and Land, 1985; Davies and Ethridge, 1975). Early diagenesis is syndepositional (i.e., may already be taking place while deposition continues in other parts of the deposit) or immediately follows deposition. Climate and the composition of syndepositional connate waters can be expected to be the predominant external controlling factors on diagenesis in this early phase, as found by Khanna et al. (1994) in their study of the North Sea Brent Group sands (including the barrier island, Etive sands). Authigenic kaolinite derived from meteoric waters, and calcite-cemented layers, in which the calcite has been isotopically linked to carbonate clasts in channels within the Brent Group sands; account for the prevailing early diagenesis of the Etive sands. Milliken et al. (1981) found similar authigenic kaolinite and calcite cements derived from incorporated caliche clasts in the Frio sands of the Texas Gulf Coast.

With deeper burial, reservoir diagenesis is controlled by basin development history. Rock mineralogy and fluid composition in the reservoir will attempt to reach thermodynamic equilibrium with the entire progression of pressure and temperature regimes and the complex series of fluid compositions and flow patterns encountered throughout its burial history.

Transport of carbonate, silica, and other minerals from deeper to shallower subsurface burial environments by fluid movement and diffusion is recognized as an important process in burial diagenesis (Jacka, 1970; Milliken et al., 1981; Law, 1992; McKeever et al., 1994: Morse et al., 1994). In the North Sea Brent Group sandstones, which include barrier island deposits, McKeever et al. (1994) found that quartz cements appearing in sediments buried at 6,000 to 10,000 feet were most probably derived from pressure solution processes acting at deeper $(>14,000$ feet) burial 
depths. Circulation of deep basin brines of various composition (often bearing dissolved gases) driven by thermal convection, density differences, bursts of fluid from overpressured sections, or other mechanisms causes substantial transport of carbonate materials by solution and reprecipitation (Morse et al., 1994).

\section{Information from Modern Analog Environments}

Modern environments can provide useful information on early or syndepositional diagenetic alteration patterns. The conditions prevalent in the depositional environment have a strong influence on early diagenetic features that may often be preserved intact or only modified in minor ways by later events in the burial history of a deposit. The patterns and extent of early diagenesis are controlled by (1) inherent properties of the original or fresh sedimentary deposit (i.e., its threedimensional pore structure and mineralogic composition); (2) biological processes; and (3) effects of subaerial exposure and/or circulating meteoric, brackish, marine, or hypersaline water.

Aside from obvious churning effects of larger organisms, the changing $\mathrm{Eh}$ and $\mathrm{pH}$ environment caused by the bioactivity and decay of macro and microorganisms on sediment pore waters can alter chemical equilibria leading to early diagenetic manifestations. Organic and inorganic skeletal remains of organisms incorporated into the sedimentary deposit also have potential for causing diagenetic alteration in later phases of the deposit's burial history.

In some deposits, of which strandplain/barrier island deposits of Class 4 are an example, subaerial exposure may lead to introduction of oxygen-rich meteoric water or to increased concentrations of dissolved solids in the deposit's pore system, depending on prevailing climatic conditions. Such fluid alterations commonly lead to formation of early cements and/or transformation of existing minerals via fluid-fluid or rock-fluid interactions.

In shoreline-associated deposits, such as strandplain/barrier island deposits, it is also common to expect influence from the larger-scale circulation of groundwaters during the early burial phase. Composition of these waters may vary in accordance with the general depositional setting and climate, and their diagenetic effects may be quite distinctive.

The analog early diagenetic model built from observation of similar deposits in modern environments in many cases may have good transferability to the subsurface reservoir. It is probable though, that at least some early diagenetic features will have changed through chemical reequilibration with later events in the deposit's burial history and that subsequent events will have added their own diagenetic features.

\section{Information from Subsurface Formations or Reservoirs}

Conceptual diagenetic models derived from depositionally analogous reservoirs or subsurface formations in the same basin as the reservoir of interest potentially have the highest degree of transferability. Such deposits may have been exposed to similar sequences of basin development events throughout both their early depositionally related and later deep-burial phases. Similar basin tectonic history and climate at the time of deposition leads to the development of similar diagenetic sequences. Caution should be exercised, because reservoirs or formations located in different parts of the same basin do not necessarily experience exactly the same development history. This may be reflected in a different diagenetic overprint (Cant, 1986). Detailed transferability of diagenetic models between reservoirs or formations located in different basins can be similar only to the extent that the development histories of the basins are similar.

\section{Information from Outcrops}

Within the same basin, subsurface reservoirs and depositionally analogous outcrops may show similarity in overall diagenetic sequences. The deposits generally shared at least some part of the basin's depositional history since the presently exposed rocks also were at one time buried in the

subsurface. Outcrops, however, partake in an additional series of major diagenetic modifying events, that is, those associated with uplift and late stage subaerial exposure. These additional 
events may result in substantial diagenetic differences between outcrop and subsurface deposits. Similarity of diagenetic sequences between outcrops in one basin and reservoirs in another basin will be even less probable, unless basin development histories are alike in most respects.

\section{Research Needs}

Diagenetic models are needed for various depositional reservoir types (Szpakiewicz et al., 1989; Jackson and Tomutsa, 1991). Development of general conceptual diagenetic models is needed on a basin-by-basin basis to cover those aspects of diagenesis influenced by basin-scale tectonics, heat flow, and basin-scale fluid movements. Because relatively little research has been done on basin-scale, the methodologies employed to study diagenetic characteristics at this scale will also be valuable products. Studies are also needed to determine what diagenetic sequences are shared in common among reservoirs exposed to similar burial histories in different basins.

Detailed examination of early or syndepositional diagenetic effects in Class 4 reservoirs and depositional analogs from different basins or plays could lead to development of a widely applicable model for this critical early phase of diagenesis in Class 4 deposits. Analysis of later burial phase diagenetic sequences within individual Class 4 plays, or within basins containing Class 4 plays, could lead to complete diagenetic models for use in older Class 4 reservoirs where no deterministic subsurface data on diagenesis exist. Plays in Oklahoma are particularly lacking in diagerietic information, and could benefit most from such studies.

\section{Tectonic and Structural Conceptual Models}

Tectonic and structural stresses and movements have a pronounced effect on the development and preservation of hydrocarbon reservoirs through their governing influences on deposition and diagenetic history, as well as through direct effects. Tectonic and structural conceptual models at various scales can lead to a more complete understanding of a reservoir at all stages of its existence.

Regional-scale tectonic uplift expressed as topographic highs may have strong influence on local climate and on sediment type and amount available for formation of clastic deposits. At the beginning of a deposit's history, basin- and larger-scale tectonic movements and even local structure, affect the factors that control the deposit's location, type, internal and external geometry, and associated sedimentary architecture. Structurally low areas along a basin's edge are optimum sites for deltaic sedimentation, while structurally higher or stable coastal areas tend not to receive as much direct sediment supply from the land. Accumulation of large sediment masses, such as deltas, may lead to differential compaction and development of growth faults, which further affect sedimentary environments and architectures.

Basin-scale tectonic movements also cause changes in the characteristics of a deposit after its burial by controlling rate and maximum depth of burial, tectonic stress, structural deformation, uplift or erosion, and temperature and pressure history. Basin-scale tectonics controls generation and migration of subsurface fluids, (brines, liquid, and gaseous hydrocarbons, and nonhydrocarbon gases), and thus the deposit's diagenetic history and the availability of hydrocarbons for entrapment.

Crustal plate-scale and basin-scale tectonic studies are commonly performed, and these studies provide a conceptual framework for understanding the geology (especially the depositional history) of many petroleum reservoirs. Studies also routinely relate smaller-scale structures (e.g., local folds, faults, etc.) responsible for hydrocarbon traps to basin- or larger-scale tectonic development. Studies may be performed at a still finer scale to relate features such as fractures or joints, which often affect internal fluid-flow patterns in petroleum reservoirs, to associated structures, regional stress, or other factors. 


\section{Information Sources}

Regional-scale subsurface seismic and/or well-log studies, when combined with structural and stratigraphic information derived from surface studies, can be used to formulate a basin development history. A basin development history or model can then provide the framework for predicting the depositional, diagenetic, and structural aspects of subsurface deposits throughout the basin.

Reservoir-scale conceptual structural models built from hard data in depositionally analogous subsurface formations or reservoirs have the best potential for transferability. Well-mapped reservoirs with good well control and/or seismic data may provide good analog models for other reservoirs with little data available. The best transferability will occur when dealing with reservoirs in that part of the basin sharing the same development history. The analog model will have applicability in other parts of the basin or in other basins to a degree commensurate with similarity in basin development history.

Study of depositionally analogous outcrops can be useful, depending on the degree of similarity in early and late-burial structural events between the reservoir-of-interest and the outcrop. Conceptual structural models derived from outcrops should always be used with caution, however, because outcrops by the very nature of their uplift and exposure have been influenced by a different set of late structural history events than subsurface reservoirs, even at nearby locations in the same basin. The advantage of outcrop study is that of detailed observation of different types of heterogeneities, including fault, joint, and fracture characteristics such as orientation, frequency, length, etc., which may be expressed quite differently in different depositional facies. The control exerted by depositional environment in the expression of structural features underscores its importance in controlling reservoir heterogeneity affecting fluid flow (Pollard and Aydin, 1988).

Conceptual models from modern environments can be used to relate syndepositional features, like growth faulting, to other geological factors, like sediment type and supply. More importantly, such study can relate mineralogic composition, internal facies geometry, and depositional architecture to prevailing tectonics to form predictive models for use in subsurface reservoirs where similar tectonic conditions prevailed.

\section{Research Needs}

Basin-scale to local-scale tectonic models may help increase predictive understanding of reservoir fluid content, diagenetic sequences, and internal heterogeneities due to faulting and/or joints and fractures. A more specific Class 4 research need is in relating prevailing tectonics to syndepositional controls on internal and external facies architectures to increase the predictability of heterogeneity on both reservoir and interwell scales. Tectonic influence on the formation of strandplain versus barrier island deposits is also an area inviting further investigation.

\section{Fluid Content Conceptual Models}

The fluid history of any sedimentary basin is inextricably tied to its development history, which in turn is largely a function of its tectonic and structural development. Surface fluids introduced into the shallow subsurface environment shortly after burial reflect the interaction of climatic and tectonic control on sediment types and surface depositional environments. In the deeper subsurface, the entrapped organic and inorganic fluids are released and expelled from their host rocks. Hydrocarbons are generated by physical and chemical processes acting on sedimentary organic materials undergoing progressive burial. The mobilized fluids interact and mix, leaving diagenetic products behind. Process changes are brought about as the pressure and temperature environment changes with burial depth, heat flow, and nature of the overlying sedimentary cover. The potential for fluid movement exists throughout basin development history, as the tectonic and structural development of the basin progresses and/or changes. 


\section{Information Sources}

Understanding of fluid movements in the shallow subsurface is increasing rapidly, both by direct measurement and by monitoring of tracer and contaminant transport. In deep burial environments, circulation patterns are not yet well understood. The sequence of diagenetic events observed at any location reflects the history of fluid movements, however. Therefore, careful observations of diagenetic sequence patterns on a basinwide scale are the best approach to arriving at a conceptual model of fluid movement history and potential fluid content.

\section{Research Needs}

Basin-scale subsurface fluid flow and its link to regional patterns of diagenesis, sedimentary ore deposits, and hydrocarbon migrating and accumulations has become the subject of increasing research during the past decade (Gregg et al., 1994). Research needs should continue along the lines of current activities, including the study of (1) evolution through time and space of the geochemistry of basinal fluids, and the factors controlling that evolution; (2) origin, evolution, and distribution of fluid flow pathways in sedimentary basins; (3) present flow patterns on regional and basinwide scales; (4) nature of subsurface rock-fluid interactions; and (5) interaction of basin development factors (e.g., tectonics, heat flow, sediment fill) that affect the pressure and temperature history of basins.

Class 4 research needs in this area can be met by careful comparison and analysis of existing reservoirs, both within and between plays and basins. It would be useful to know if hydrocarbon and/or brine composition varied in some predictable way between plays, between reservoirs in a play, or within individual reservoirs as a function of depositional, diagenetic, or structural heterogeneities. Observed differences in fluid composition should be related to basin and reservoir development. Differences in observed brine composition might be used as clues to (1) locating untapped hydrocarbon compartments, (2) correct interpretation of log signatures, and (3) evaluation of oil saturations based on salinity-resistivity relationships. Variations in water salinity

have been used to identify barriers within a reservoir, and have been shown to greatly affect oil saturation calculations from wireline logs (Jackson et al., 1993b).

\subsubsection{Stochastic Models and Associated Research Needs}

Stochastic models attempt to express probability or expected variations in properties or features. Stochastic models, for the most part, are probabilistic expressions of conceptual or analog models, and their output is a representation or realization of the spatial distribution of either the qualitative (discrete) or quantitative (continuous) characteristics of the conceptual model. Stochastic modeling approaches do not create new information, but express variability of existing information derived from the source of the analog model. Most techniques are capable of generating numerous realizations in map or cross-section form, which then can be evaluated by numerical simulation or other means to yield potential reservoir performance.

\section{Quantitative or Continuous Models}

Continuous models describe phenomena that vary continuously such as porosity, permeability, residual oil saturation, seismic velocities, and certain reservoir dimension parameters (Haldorsen and Damsleth, 1990). The most common use of continuous models has been for representation on an interwell scale of the spatial heterogeneities in parameters affecting fluid flow.

In the past, simple linear interpolations between values observed at wells were used to represent the interwell area. The resulting smoothed data do not describe the variability of the parameter being estimated and often lead to overly optimistic predictions of reservoir performance when used as input to reservoir simulation. Approaches to alleviate the problem of unrealistic smoothing due to interpolation range from the use of statistically generated pseudowells between existing wells (Johnson and Jones, 1988) to use of Monte Carlo-like simulations of interwell 
properties from detailed distributions of individual parameter values (Hewett and Behrens, 1990). In these simulations based on the theory of randomized variables, the spatial correlations of reservoir parameters are not included.

An increasingly more popular and productive way to look at stochastic interwell prediction is to use geostatistics, a series of stochastic modeling techniques based on regionalized variables, or variables that show certain degrees of correlation between values as a function of their relative spatial location. These techniques, like conventional statistical techniques describe the mean value and the variability about the mean, but in addition describe the strength of the tendency for neighboring points to have similar values (Haldorsen and Damsleth, 1990). Popular and important techniques being investigated include simple kriging, universal kriging (used where trends are present), cokriging (multiple variable), indicator kriging (nonparametric), conditional simulation (also nonparametric), and use of fractals (Da Costa e Silva, 1985; Dubrule and Haldorsen, 1986; Hewett, 1986; Journel and Alabert, 1990; Journel and Huijbregts, 1978).

The first step in building a geostatistical model involves identification and evaluation of potential analog data sources. Two considerations, transferability and scale, are necessary in evaluation of an analog model for geostatistical application. Because quantitative values of reservoir parameters are to be collected, the analog model being employed for data collection should be as similar as possible in terms of its depositional, diagenetic, and structural/tectonic origin to the reservoir in which the geostatistical model will be applied. As discussed in Section 3.3.2.1, the best analog in terms of transferability of information would be a reservoir of similar depositional origin encountered in close proximity in the same basin and having similar structural, diagenetic, and fluid histories.

The second requirement for evaluation, that of appropriate scale or horizontal spacing of data for building the model, must also be considered. If the desired model is to be on the interwell scale, similar nearby reservoirs, although they may represent the best analogies, generally will have similar well spacing to the target reservoir and cannot provide model variability information on the less-than-well spacing scale required. To solve this dilemma, some geostatistical applications translate vertical parameter variability, as observed and measured in wellbores, to horizontal variability via multiplication by a constant. This approach has given acceptable results, but has two potential problems in application: (1) the possibility that significant stratal surfaces such as sequence boundaries (see discussion in Section 2.2.2.4 of the Class 4 Technical ReportNIPER/BDM, 1994) may not be recognized in the calculation of vertical heterogeneity; and (2) conversion of properties occurring in vertical sequence by constant multiplication to properties in horizontal sequence has no observed geological basis. Parameter variability information obtained from cores in horizontal wells is an emerging, but much more realistic, solution to the problem.

The most obvious source of data on the critical interwell scale is depositionally analogous outcrops, and numerous geostatistical studies have been directed at expressing the degree of variability in fluid-flow parameters from outcrop data (Singdahlsen, 1993; Tomutsa et al., 1993). Use of outcrop data, while fulfilling the data requirements of scale, represents somewhat of a tradeoff in the transferability of quantitative information to a subsurface reservoir that may have a substantially different diagenetic overprint affecting parameter values (see discussion in section 3.3.2.1). Detailed comparison of diagenetic effects between outcrop and the subsurface target reservoir is a prerequisite to building and applying such a model.

Geostatistical models are used to create realizations or probable representations of the spatial distribution of reservoir parameter values on the interwell scale. Many such realizations might be created as potential input to numerical simulators for evaluation of reservoir performance. If all or a large number of full-scale numerical simulations were performed, a probability distribution of reservoir performance results could be constructed (Hewett and Behrens, 1990). The computationally associated cost of such an approach, however, would be prohibitive. More efficient solutions must be sought. Less computationally intensive methods used to identify most probable, worst case, and best case reservoir performance scenarios from geostatistical realizations 
include simple stream tube approaches and single-phase flow simulation of passive (nonreacting) tracers in plug flow (Hewitt and Behrens, 1990).

Geostatistical modeling also has application on a scale of consideration that is larger than individual reservoirs. Person et al. (1994) used kriging and conditional simulation approaches to generate realizations of carrier beds for secondary migration of oil on a basin scale. Both techniques produced more realistic results than obtained by assuming homogeneous carrier beds.

\section{Qualitative or Discrete Models}

Models used to create synthetic geology by spatial placement of geologic features of variable type, size, orientation, etc., are referred to as discrete models (Haldorson and Damsleth, 1990). Most such models also contain rules that govern the interaction of geological features as well. Discrete models can be transformed into quantitative realizations for simulation by various methods of fluid-flow property value assignment to individual geological elements. Modeling approaches include marked point processes, Markov fields, truncated random functions, and two-point histograms (Haldorson and Damsleth, 1990).

A large number of discrete statistical applications appear in the literature. Notable work includes that of Long and Witherspoon (1985), who modeled the interconnection of fractures and their associated permeabilities; Haldorsen and Chang (1986), who modeled shale distributions observed in outcrop as barriers to vertical fluid flow; Kossack (1989), who examined sand body dimensions from numerous outcrop studies in various depositional settings in an attempt to relate thickness to lateral extent for input to numerical simulation; Henriquez et al. (1990), who simulated distribution of fluvial sands on a reservoir scale using sand body distribution and size information from wellbores and then quantitatively transformed the model for numerical simulation; and Armitage and Norris (1993), who used a two-point histogram approach to generate synthetic geologic realizations from outcrops of shallow marine Frontier sands in Wyoming and then evaluated the realizations using waterflood simulations.

Analog or conceptual model sources for discrete stochastic models can be subsurface formations or reservoirs, outcrops, or modern environments. Outcrop analogs have been used extensively in building stochastic models of depositional geological features such as shale and sandbody distribution, size, and geometry. Outcrops of depositionally analogous deposits are appropriate sources because (1) the geologic information is accessible on the scale necessary to develop the models, especially for interwell-scale considerations, and (2) the transferability or applicability of the model to the subsurface is generally good if the deposits had closely similar depositional conditions. Models of fracture density, orientation, etc., should be developed from outcrop with more caution, because of likely differences in structural environment between outcrop and subsurface reservoir.

\section{Combined Discrete and Continuous Models}

Discrete models are usually better suited for modeling larger-scale geological features or heterogeneities. Continuous models must assume that geological factors are uniform, i.e., that the patterns of heterogeneity are identical in the model and application areas, or that the patterns are self-similar at all scales. These assumptions are generally not strictly honored in continuous stochastic studies, because different geologic processes operate and exert their influences at different scales.

A two-stage approach, in which a discrete model first describes the larger-scale heterogeneities and is then followed by application of continuous models to describe the variation of quantitative reservoir parameters within each class of heterogeneity, has been described by Haldorsen and Damsleth (1990). Use of such combined approaches has potential for increasing the accuracy of stochastic representations. 


\section{Research Needs in Stochastic Modeling}

Methodologies for selecting and implementing both discrete and continuous stochastic models at interwell and larger scales, using data of various types and based on analog reservoirs, outcrops, and modern deposits are definite needs. In particular, a combined discrete and continuous modeling approach might demonstrate the use of stratal surfaces defined by sequence stratigraphy (see discussion in Section 2.2.2.4 in the Class 4 Technical Report-NIPER/BDM, 1994) as guides to statistical simulation of the occurrence of sediment packages and the spatial correlation of sediment properties, as suggested by Jackson (1993). Such approaches, probably based on analog outcrop data, have potential to give the most realistic representation yet available of the spatial interrelationships of sediment properties affecting fluid flow.

Because stochastic processes can result in many possible realizations of reservoir properties, it is desirable to develop and test simple screening criteria or other computationally simple procedures for identifying best, worst, and most probable realizations (from a recovery or economic point-ofview without resorting to numerous and prohibitively expensive detailed numerical simulations.

General stochastic models considering depositional, diagenetic, and tectonic and structural aspects built specifically for Class 4 reservoirs and based on analogous subsurface reservoirs, outcrops, and modern deposits may prove very useful for improved oil recovery (IOR) evaluation. Models could be of the discrete, continuous, or a combination of the two types. A detailed methodology for construction of these Class 4-specific models addressing commonly encountered heterogeneity types would be an important part of this research.

Equally relevant would be basin- or play-specific stochastic models constructed in a manner similar to that just described for general Class 4 stochastic models. Such models would have more restricted application, i.e., within the same basin or play, but transferability of data might be greater due to greater similarities in diagenetic and structural history.

\subsubsection{Deterministic Modeling (Data Acquisition and Analysis) and Associated Research Needs}

A deterministic model is one constructed from actual measurements of properties of the reservoir of interest. A deterministic model, or a deterministic partial model, may be constructed using information from various tools and disciplines measuring properties on various scales and with different resolution and accuracy. Such data are commonly referred to as "hard" data as opposed to "soft" data based on conceptual models discussed in Sections 3.3.2.1 and 3.3.2.2. However, hard data, due to the nature of the measurement tools and procedures, may also have an appreciable associated uncertainty. Figure 3.3 schematically depicts the scale of measurement usually associated with several common deterministic tools.

The degree of uncertainty associated with the deterministic, quantitative measurement of reservoir properties is often less than that associated with those properties as assigned by a model of conceptual or stochastic origin. Depending on the degree of transferability from available analog sources, a conceptual model may not be able to quantitatively predict certain properties in the reservoir of interest. A deterministic or measurement approach is most commonly necessary to complement (complete) and/or supplement (calibrate or constrain) the conceptual model supplied by analogy.

The following sections discuss several of the common measurement tools and procedures for gathering deterministic data. Associated research needs in order to achieve greater utility in reservoir characterization are also discussed. 


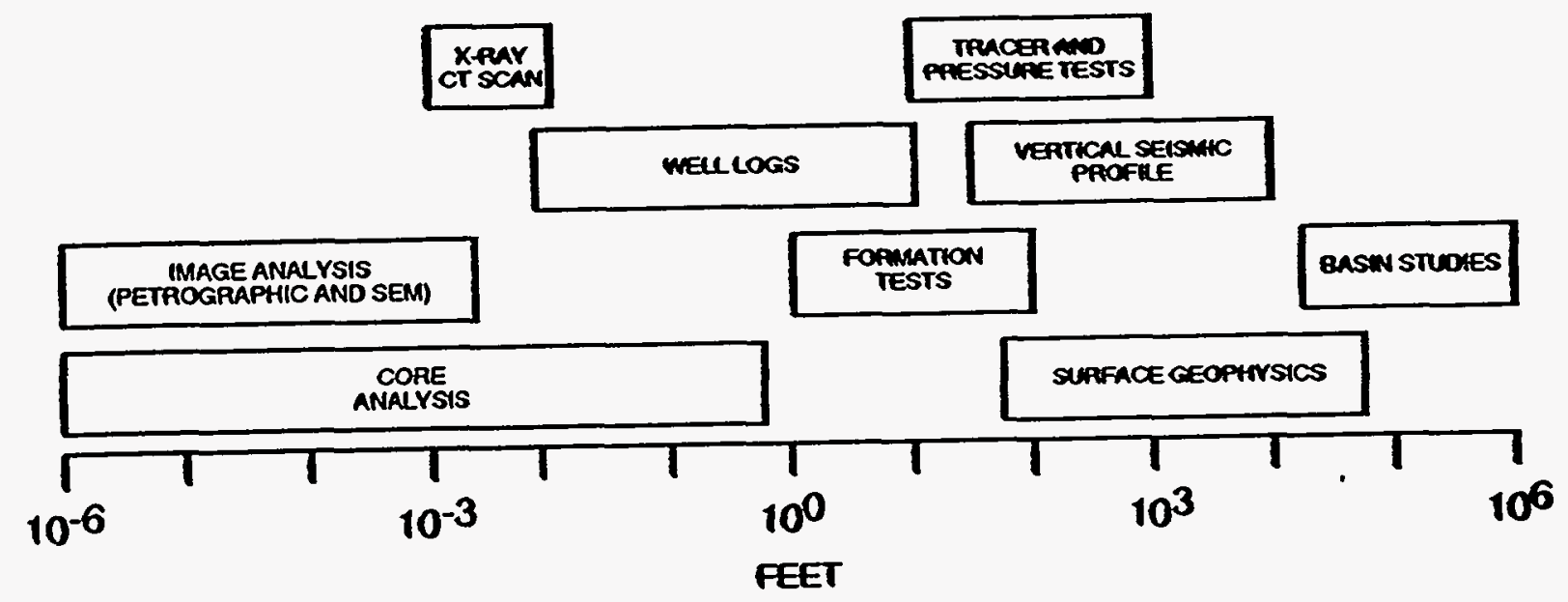

\section{Figure 3.3 Scales of Measurement and Relative Resolution of Some Common Deterministic Tools (Modified from: Jackson and Tomutsa, 1991, p. 150)}

\section{Reservoir Rock and Fluid Sampling}

Samples of reservoir rocks and fluids can be obtained only from boreholes. Rock and fluid samples are used (1) to confirm, calibrate, and complement conceptual, stochastic, and deterministic models derived from other data sources or (2) to construct in situ models of deposition, diagenesis, or fluid content. The particular data collection and analytical procedures applied are determined by the reservoir characterization task to be accomplished, which is, in turn, a function of the reservoir stage of development and/or the improved or enhanced recovery process being considered.

\section{Sample Planning and Collection}

Factors to consider in design and execution of a reservoir rock and fluid sampling program are (1) the stage in reservoir development; (2) selection of lateral and vertical locations within the reservoir; (3) sample size or scale; and (4) method of sample collection, handling, and storage.

Sample locations should contribute to confining the reservoir rock or fluid model within acceptable bounds of uncertainty. Larger numbers of samples can reduce model uncertainty by adding increased detail, but at increased cost.

Because rock samples cannot be collected after boreholes are cased, the most opportune time to sample reservoir lithologies and facies is concurrently with drilling. In some cases, this may mean collection of seemingly expensive core data whose full utility may not be realized for many years into the reservoir's life. Later opportunities for rock sample collection may come with drilling of infill or replacement wells. Formation fluids collected in the early stages of reservoir development, however, may be better representative in laboratory tests of fluid performance in the interwell area. The size or scale of rock samples obtained from the reservoir is a function of the amount of detailed information needed to supplement or complement depositional or diagenetic models. Drill cuttings 
are a byproduct of drilling and are available essentially for the cost of analysis. Drill cuttings are not accurately tied to specific depths, however, and they may be contaminated with uphole material. Their small size also makes them of limited use in determining depositional structures or facies in clastic environments. At intermediate cost, sidewall cores can be obtained from wireline tools. Despite their small (approximately 1-inch diameter) size and their tendency to disturb sedimentary structures in clastic rocks (if a percussion tool is used) they represent a considerable improvement in information content over drill cuttings. Sidewall cores may be taken at any time in an uncased borehole. Full diameter cores sample continuous sections of the reservoir at a scale which allows observation of sedimentary structures, identification of facies relationships, and measurement of vertical permeabilities. Full diameter cores are the most expensive, but by far the most informative, option for sampling reservoir rock types.

One of the objectives of reservoir rock sampling is to obtain information on in situ reservoir rock properties via fluid-flow analysis of full-diameter cores (Skopec, 1994). If no special consideration is given to the coring and handling procedures, most formation fluids will be lost by flushing during coring or will bleed off as the core is removed from the well. Expansion of the core as confining pressure is relieved can also cause changes in its fluid-flow characteristics. Restoration of such cores to reservoir conditions of fluid saturations, pressure, and temperature before analysis commonly will provide more realistic results then ignoring the problem altogether, but it is impossible to reproduce original wettabilities precisely (Goodlett et al., 1986). Obtaining a native-state core in which the core is maintained at reservoir pressure, temperature, and fluid saturation is the most desirable and most expensive approach. Laboratory tests run on native-state cores with native, live crudes and brines under reservoir conditions of pressure and temperature will yield the most reliable results (Goodlett et al., 1986).

\section{Analytical Tools and Procedures}

The objective in collecting rock and fluid samples is to describe and ultimately predict the characteristics of rocks, fluids, and rock-fluid interactions on a reservoirwide scale. Because these characteristics can be measured on samples obtained only at the wellbores, they must be linked to other deterministic data, such as seismic, or to conceptual or stochastic models to obtain estimated values at all locations.

Basic analytical procedures used to obtain rock characteristics depend to some extent on the scale of the material obtained. Drill cuttings can be analyzed visually by microscopic, thin-section petrographic, fluorescent microscopic, cathodoluminescence, and computerized image analysis techniques (Jackson and Tomutsa, 1991). Coupling these observations with information obtained from x-ray diffraction, scanning electron microscopy, electron probe microanalysis, atomic absorption, isotope analysis, fluid inclusion analysis, etc., can provide valuable definition to depositional, diagenetic, and even structural conceptual models. Cores in their nonrestored state yield to the above analytical techniques and in addition, may provide information from a variety of other studies such as (1) megascopic description of sedimentary structures and facies, (2) X-ray tomographic imaging of small-scale rock heterogeneities, and (3) routine core analysis (e.g., porosity, air permeability, grain density, etc.).

Determining the composition and properties of reservoir fluids, including determination of dissolved components, is a critical part of reservoir characterization that is often neglected (Jackson and Tomutsa, 1991). Basic crude oil analytical procedures include traditional PVT analysis (i.e., solution gas content, viscosity, formation volume factor, and density versus pressure relationship) as well as determination of sediment and water content, composition, and API gravity. Additional analyses (e.g., gas chromatography, mass spectrometry) may be necessary to determine crude compatibility with specific EOR processes (Goodlett et al., 1986). Typical basic analyses for reservoir brines include determination of total dissolved solids, resistivity, and ionic composition. Again, additional, and sometimes specialized, analyses are required for evaluation of the age and 
origin of formation waters, potential for cross-formational flow, state of water-rock equilibria, potential for forming scale, and compatibility with specific EOR processes (Collins, 1975, Goodlett et al., 1986, Szpakiewicz, 1991).

Analysis of rock-fluid interaction has traditionally been performed on core samples. The techniques may be applied to nonrestored, restored, and native-state cores, but compared to nonrestored cores reliability of results obviously is greater in restored-state cores, and is significantly greater in native-state cores. Analytical techniques for investigating rock-fluid interaction include coreflooding, and two- and three-phase relative permeability determination, preferably performed under reservoir pressure and temperature conditions with live reservoir crudes and brines. For evaluation of specific EOR processes, additional determinations such as dispersivity, cation exchange capacity, wettability, and wettability alteration may be necessary (Goodlett et al., 1986). Application of nondestrictive imaging techniques such as X-ray, CT, and NMR has shown increasingly improved accuracy, especially in understanding processes in heterogeneous cores.

\section{Research Needs in Measurement and Analysis}

More cost-effective techniques are needed to obtain rock and fluid samples at different reservoir locations during all stages in the life of the reservoir. Special consideration for obtaining nativestate and oriented cores should be emphasized as should methodologies for selecting core sites, handling and analysis methodologies for cores, and distribution and fingerprinting methodologies for fluids. Fluid sampling considerations might further include avoidance of $\mathrm{H}_{2} \mathrm{~S}$ absorption and special techniques for accurate sampling of condensates (Pande et al., 1993). Further development of slimhole drilling techniques may be helpful in pursuing these ends.

Analytical tools and methodologies also are needed to make maximum use of existing sample data. Continued development of laboratory tools and techniques for determination of critical rock, and rock-fluid interaction parameters from small samples such as drill cuttings would prove useful in the analysis of many existing (especially older) reservoirs where no other samples are available. Better wettability-restoration procedures for nonnative-state rock materials are also needed to make more realistic assessments of rock-fluid interaction from existing samples.

Refinement and development of new laboratory analytical tools and methodologies are needed for cheaper, quicker, and more accurate determination of reservoir parameters for practical applications, especially under reservoir conditions (i.e., with reservoir pressure, temperature, and formation fluids). Finally, continued development of quality assurance procedures and standards for (1) field collection and handling of samples and (2) for laboratory collection and analysis of rock, fluid, and geochemical and engineering rock-fluid interaction data is needed.

\section{Research Needs in Process Understanding and Predictive Modeling}

Knowledge of the variation in value of critical reservoir fluid-flow properties throughout the volume of the reservoir is needed. The cost of obtaining and measuring a large number of rock or fluid samples, however, is prohibitive. Therefore, the development of correlations or predictive links between those fluid-flow properties and other more readily obtained data or with the components of conceptual models would be useful. For example, a spatial relative permeability predictive capability for Class 4 reservoirs of a particular play could be built by cataloging any observed relationships between depositional or diagenetic facies and measured relative permeabilities. Such models, developed for specific plays or subplays, could be made more valuable by performing relative permeability measurements at native-state conditions.

Pande et al. (1993) suggest the following additional research areas for fluids: (1) developing better understanding of multiple liquid phase behavior, (2) predictive models for asphaltene precipitation, (3) fluid history modeling on a reservoir scale, and (4) developing correlations for reservoir fluid properties. 


\section{Production and Injection Data}

Production and injection data are often overlooked and inexpensive sources of information on reservoir heterogeneities. These data already exist for most reservoirs, including older reservoirs typical of most Class 4 production. Heterogeneities that may be identified by such data include directional transmissivities, fluid flow patterns, residual oil saturation, layer continuity (baffles and flow barriers), and permeability conduits (thief zones) (Honarpour and Tomutsa, 1990). Although collection of production and injection data involves little inconvenience or cost in terms of lost production (Fetkovich et al., 1987), maximum utility of this data source can only be realized by careful, complete, and consistent record keeping, paying particular attention to man-induced effects on production.

\section{Production Data}

Production data have the potential to convey much information about reservoir and fluid characteristics. A number of natural reservoir characteristics and man-induced factors can influence production data. In order to interpret reservoir characteristics accurately, the influences of well or reservoir operational factors must be eliminated or recognized and accounted for in data analysis. Man-induced influences on production that can affect the interpretation of production information include, for example, unequal lengths of production history from well-to-well, imposed periods of constant or prorated production, paraffin or scale problems, remedial work on producing wells, fluid injection into the reservoir, production problems or shutdowns, limitations of production equipment, and personnel or recordkeeping changes (Gentry et al., 1978). Commingling of production from different reservoirs or zones is an additional complication that must be considered and accounted for.

Production decline curves, in addition to yielding traditional information on oil and gas reserves and productive life, can provide information on (1) reservoir characteristics such as heterogeneities, permeability and relative permeability, dual porosity systems, and drive mechanism; and (2) reservoir fluid characteristics (Gentry et al., 1978; Fetkovich et al., 1987). Traditionally, interpretation of decline-curve data involves matching observed declines with appropriate type-curves in a history-matching approach. A forecast can then be made. Basic reservoir engineering concepts and knowledge are used to select, apply, and interpret type-curves (Fetkovitch et al., 1987). Interpretations are not always unique, though, and other well and reservoir data are needed for support.

Other oil and gas production data such as cumulative or current production, gas-oil ratios, etc., when mapped, can give useful information about reservoir characteristics if man-induced effects are properly considered. Honarpour et al. (1989) mapped waterflood front advancement in a Tertiary Oil Incentive Program (TIP) area of the Bell Creek field (a Class 4 reservoir in Wyoming) by reviewing water-cut production data. Honarpour and Tomutsa (1990) confirmed the presence of geologically inferred faults and, by comparing actual waterflood front advancement with simulations assuming various positions and transmissibilities of faults, determined the sealing versus nonsealing nature of those faults.

\section{Injection Data}

Injection data can also give information about reservoir characteristics if proper attention is paid to removing man-induced effects. Plots of wellhead pressure versus cumulative injection volume (i.e., Hall plots, Hall, 1963) have received considerable attention over the years for determination of reservoir permeability and well skin effects. Honarpour and Tomutsa (1990), in their study of the Bell Creek field, found changes in slope in Hall plots of wells located in the vicinity of known diagenetic and structural heterogeneities. Plot slopes for wells located entirely within diagenetically altered zones were appreciably higher than for other locations. 


\section{Research Needs}

To maximize the utility of production and injection data, widespread, accurate, and complete data are required. Accurate records of all reservoir operational activities affecting production and injection must be kept, as well as records of all appropriate production and injection data on a reservoirwide scale. Low-cost data collection equipment, standard data collection protocols, and low-cost, readily available database management and analysis systems to handle data storage and retrieval tasks and assist with automated display, analysis, and interpretation of production and injection data in a reservoir characterization context are needed.

A need exists for further advancements in analysis of decline curves and injection data, but additional needs are (1) to investigate new ways to extract reservoir descriptive information from existing conventional data or data permutations and (2) to identify any new production, injection, or related data that can be recorded to extract more or better reservoir information in the future. Class 4 contains many reservoirs in mature producing areas, such as those in Texas and Oklahoma, in which production or injection data are the most abundant available sources of reservoir information. Techniques that maximize the reservoir-descriptive utility of existing data from such reservoirs would be of great value. Demonstrations of large scale and complete integration of production and injection information with information derived from other sources of reservoir characterization data would also be desirable.

\section{Wireline Geophysical Logs}

A wide variety of geophysical wireline logging tools, in addition to having great utility in establishing structural and stratigraphic frameworks, are available for direct measurements of reservoir properties. Although the same reservoir property (e.g., porosity, rock composition, fluid content, etc.) may be given by a number of tools, the different logging techniques are based on measurements of entirely different properties of the formation. No wireline logging tools are presently available for direct measurements of certain very important reservoir properties such as permeability, which is of critical importance in characterizing reservoirs.

Different geophysical wireline tools also measure reservoir properties at different scales. Some tools measure only very small volumes of the formation immediately adjacent to the borehole. Such tools may provide good vertical resolution and accurate measurement of borehole effects (i.e., effects of borehole fluids on measured properties of the formation), but do not measure properties at any appreciable depth into the formation. Other tools with deeper penetration into the formation may not give the desired degree of vertical resolution to separate thin geological features that may have profound influence on fluid flow.

The quality of wireline log information is extremely variable also, with quantitative information on reservoir properties from more modern logs being more dependable. The utility of many older logging surveys, run with tools of unknown configuration under unspecified and/or poorly controlled conditions; may be limited to the stratigraphic information they contain.

\section{Research Needs in Logging Tool Development}

New tools to measure desired reservoir properties are under constant development (Prensky, 1994). Enhanced resolution of thin sands is being made possible by development of tools such as the laminated sand analysis (LSA ${ }^{\mathrm{TM}}$ ) tool (U.S. DOE, 1991). Fluid chemistry and saturations bound waters in clays, and pore structures in the vicinity of the borehole are now being measured by electromagnetic propagation and nuclear magnetic resonance tools (U.S. DOE, 1991; Jackson, 1984; Prensky, 1994). Spectrometric tools have been developed to provide more detailed compositional information than ever before available (Hertzog et al., 1987). The stratigraphic highresolution dipmeter and formation microscanner tools allow identification of heterogeneities at the scale of sedimentary structures. 
New tools or tool combinations are yet needed, however, to measure critical reservoir properties such as permeability in both clastic and carbonate reservoirs (Jackson, 1984; Worthington, 1991). New tools and tool improvements are also needed to estimate traditionally measured parameters such as composition, saturation, and porosity with increased vertical resolution and at greater distances from the borehole in the interwell region (Jackson, 1984). Further development of tools is needed for resurvey applications in older fields (many Class 4 reservoirs fall in this category) for cost-effective and accurate measurement of all critical reservoir parameters in steel-cased-holes with variable styles and quality of completion (Prensky, 1994). Work on new tools should be begun immediately to accomplish effective progress in the mid-term.

\section{Research Needs in Methodology and Procedure Development}

Over the short-term, methodologies are needed (1) to optimize logging suite selection for various stages of reservoir development, (2) to provide cost-effective quality control for log data acquisition, and (3) to optimize extraction of information from existing wireline log data. The kinds and amount of information required from geophysical wireline logs for proper reservoir management will vary according to the stage of development of the reservoir. It is critical, however, that baseline distributions of certain reservoir parameters (e.g., saturations) be obtained early in reservoir development for comparison at later stages. Selection of appropriate cased-hole tools to be run as complements to existing old E-logs in mature fields is an important consideration also.

Different reservoir depositional types or classes will require different logging suites and acquisition strategies. In addition, reservoirs in certain basins or plays may require additional considerations due to special diagenetic or structural features they may have in common. Finally, there may be factors specific to individual reservoirs that dictate the need for highly customized logging programs. Development of suite selection methodologies for Class 4 reservoirs needs to be considered at the reservoir, play, and basin scales.

In obtaining wireline log data, there is always a tradeoff between cost and accuracy. The cost of obtaining data (e.g., borehole drilling and preparation, operator selection, tool calibration, number and speed of logging runs, etc.) must always be weighed against the present and future utility of the information. The acceptance of inaccurate or incomplete determinations of important reservoir parameters at the open-hole stage of development, although it may achieve a short-term cost savings, may prove to be extremely noncost-effective at later stages of reservoir development.

Definite quality control protocols for logging programs should be developed early and strictly adhered to for every reservoir. The methodology for establishing these protocols is an important research area for all reservoir classes.

Existing wireline logs in many instances may be the only data available due to economic or technical constraints. Many of these logs, especially those obtained in the last 20 years, are of reasonably good quality and may contain significant unrealized information. Wendt et al. (1986) and Hearn et al. (1986) used multivariate statistical techniques to identify flow facies and flow units and to predict permeability from digital wireline log data. Research on the use of parametric and nonparametric statistics as well as neural net approaches to extraction of lithofacies and fluidflow facies information from digital wireline log data was recommended by Jackson (1993). Development of methodologies for extraction from log data of reservoir fluid-flow parameters may lead in the mid-term to delineation of desired characteristics for new logging tools and suites of logs. Further development of practical, affordable methods for conversion of existing paper logs to digital form is an additional research need. 
Development of nonparametric and neural net approaches for extracting important quantitative and/or qualitative reservoir information from old E-logs may be especially relevant to much Class 4 production, which comes from older, mature reservoirs for which little other subsurface information may be available. Such studies will also help to identify the existing logs that have the greatest utility for reservoir characterization in Class 4 reservoirs.

\section{Pressure Transient Testing}

Pressure transient tests are disturbances on the physical fluid system of a reservoir imposed for the purpose of qualitatively or quantitatively discerning variations in the properties of its pore system. Tests may involve single or multiple wells and may be usefully applied throughout the life of a well or reservoir (Kamal, 1990). The utility of transient tests is widely recognized in that: (1) they provide useful information for reservoir management; (2) they are simple, relatively inexpensive to run, and not dependent on highly specialized tools; and (3) interpretation models are widely available (Kamal, 1990).

\section{Applications of Transient Tests}

Pressure transient tests measure reservoir properties over a large volume approaching that of the drainage volume of the well or wells involved. They may be used to evaluate types of fluids and production potential of wells, to estimate completion efficiency, to monitor changes in reservoir pressure and wellbore skin, to determine communication among wells, to evaluate hydraulic fractures, and to provide performance data on injection wells (Kamal, 1990; Ebinger and Hunt, 1989). Currently available tests include: closed chamber; constant pressure flow; drillstem; formation; horizontal well, impulse; multilayer; multiwell interference; pumped-well; stabilized flow; step-rate; testing while perforating; transient rate and pressure tests; and vertical interference tests (Ehlig-Economides et al., 1990).

\section{Constraints on Application, and Research Needs}

Tests must be carefully designed to answer specific questions about the reservoir, and a measurement sequence must be formulated that will satisfy the objectives of the test in a costeffective manner (Ehlig-Economides et al., 1990). Even with optimum design, well test results may often have nonunique interpretations. Numerous models are available in the literature, but expertise and experience are needed along with guidance from other data such as well logs, seismic, or a geological conceptual model, to select the correct model for interpretation (EhligEconomides, et al., 1990; Ramey, 1990). Kamal (1990) and Gringarten (1986) suggested increased use of sophisticated computer analysis and expert system guidance in selection of models and in interpretation and validation of results. Expert systems should also prove useful in selection and design of appropriate tests to answer specific reservoir questions.

Kamal (1990) suggested more rigorous application of pressure transient test techniques in reservoirs known to be heterogeneous to further develop tools and methodologies. Recent advances in computer-aided well-test interpretation expand the capability of the method to more complex cases such as composite and naturally fractured reservoirs with additional capabilities to quantify the reliability of interpretations (Horne, 1994). Both Kamal (1990) and Ehlig-Economides et al. (1990) recommended better efforts and documentation in integration of pressure transient testing with other reservoir characterization techniques.

\section{Tracer Tests}

Tracer testing is the addition of small quantities of an easily detectable material (often radioactive) to an injected fluid and the subsequent monitoring of its temporal and/or volumetric appearance in the same or adjacent wells (NIPER, 1986). Such tests result in direct measurements of critical well-to-well flow characteristics or, if a reactive tracer is used, of residual oil saturation (Brigham and Abbaszadeh-Dehghani, 1987). 


\section{Uses of Tracer Tests}

Essentially, tracer testing has two approaches: single-well tests and well-to-well (or multiwell) tests. Single-well tracer tests involve injection into the formation of a measured volume of a chemical that reacts with formation fluid. From the recovery volume of the fluid via the same wellbore, formation fluid saturations can be calculated (Brigham and Abbaszadeh-Dehghani, 1987; Allison et al., 1991). Single-well tracer tests can also be used for detection of near-wellbore fractures (Brigham and Abbaszadeh-Dehghani, 1987).

Multiwell tracer tests generally involve injection of a slug of tracer material followed by continued injection with tracer-free fluid. Adjacent producing wells are then monitored to record the time of first appearance of the tracer, and the volume of tracer produced over time is carefully recorded. Tracer tests measure distinctly different characteristics than multiwell pressure transient tests. The latter reflect reservoir characteristics on a fully integrated scale; for example, pressure transient tests may indicate directional permeability but can not identify individual heterogeneities (Mishra, 1989). In contrast, multiwell tracer tests are convective flow tests that can quantitatively detect heterogeneity directly in the form of fluid-flow barriers and channels or fractures as well as permeability anisotropies (Mishra, 1989; Brigham and Abbaszadeh-Dehghani, 1987). Mishra (1989) suggests that pressure transient and tracer techniques be viewed as complementary, rather than competing. The two techniques can be used conjunctively to determine layering of reservoir heterogeneity (Abbaszadeh-Dehghani and Brigham, 1984). Tracer tests have potential to play a significant role in the decision-making process leading to permeability modification.

\section{Constraints and Research Needs}

Tracer tests tend to emphasize the high permeability layers in the reservoir, but it is the relative size and permeability of the higher permeability layers with respect to the average that affects recovery (Brigham and Abbaszadeh-Dehghani, 1987). At present, tracer tests are comparatively inexpensive and in common use. The search for efficiently performing, low-cost, reactive and nonreactive tracers should continue to achieve more widespread application of the technology.

A typical present-day application of tracers is to inject them in aqueous fluids after waterflooding to evaluate fluid flow pathways for EOR. Water-based fluids have a strong tendency to follow water-saturated zones, however, and test results may be biased (Jackson and Tomutsa, 1991). Tracer applications for use in different zones, and in reservoirs at different stages of development need to be investigated more thoroughly. Different tracer carrier fluids may be required.

Similar to other techniques that directly measure physical properties, results of tracer tests often do not have unique interpretations. Other data such as seismic, well log, or geological models (e.g., lithology, porosity, diagenesis, relative permeability, etc.) must provide guidelines for interpretation (Jackson and Tomutsa, 1991). Applications of tracer test techniques in reservoirs with significant heterogeneities are needed for the purpose of development of (1) test design and interpretation methodologies and (2) techniques for integration of well test results with findings and predictions from other data sources and types.

\section{Seismic Data}

Among existing direct measurement techniques, approaches based on the seismic method have the greatest potential to provide reliable information on reservoir property variations in the interwell region. In theory, every location in the reservoir is accessible to seismic signals and therefore 
useful reservoir information may be retrieved from every part of the reservoir by this method. The recent advances in several areas of seismic technology that hold promise for providing reliable subsurface information in the interwell region are as follows:

1. Developments in 3-D seismic technology made possible through improvements in data acquisition instrumentation (larger number of channels for data recording, higher dynamic range recording, high-frequency, high-fidelity recording, etc.), field procedures, data processing software, and 3-D data visualization techniques.

2. Development of field procedures, data processing techniques, and analytical procedures for extracting certain useful information from the seismic signal (e.g., from amplitude, phase, and frequency). These advances greatly facilitate delineation of stratigraphic traps and other subtle geological features and make it possible to determine useful properties like porosity and fluid content in reservoir rocks.

3. Developments in downhole seismic surveys like cross-well tomography and vertical seismic profiling (VSP).

4. Developments in the analysis and interpretation of seismic data (seismic facies mapping, seismic sequence stratigraphy, etc.), and integration of seismic with other data types.

\section{3-D Seismic}

Because of its capability to obtain precise subsurface information, 3-D seismic makes an ideal tool for in-depth investigations of reservoir heterogeneities, and has therefore found wide application in the exploitation of hydrocarbon reservoirs. In the late 1980s, 3-D seismic surveys accounted for about half of the seismic activity in the offshore Gulf of Mexico and North Sea areas (Robertson, 1991). In February of 1994, at least 52 of 97 geophysical crews in the United States were known to be shooting 3-D seismic (Taylor, 1994).

In addition to its utility in exploration, 3-D seismic is an excellent tool for describing reservoir complexities. Compared to conventional 2-D seismic, 3-D seismic has the advantage of greater horizontal resolution with no out-of-plane effects, it displays true structural and stratigraphic dips, and has greater flexibilities in shooting design and in data display (e.g., slices in the vertical, horizontal, or at any azimuth and at any location). In addition to its utility in performing detailed structural and stratigraphic analysis, 3-D seismic may be used to provide information on the variations in certain reservoir properties, like porosity (Zaki et al., 1990) and fluid saturations (particularly if the reservoir is partly or fully gas saturated). Such detailed information will be invaluable for reservoir description for IOR projects, in selecting infill locations, and in monitoring movements of fluid fronts in an EOR process.

Monitoring with seismic data of fluid movements in the reservoir during the progress of an EOR process has experienced some success. Greaves and Fulp (1986) compared the progress of an in situ combustion front depicted via three separate 3-D seismic surveys performed at three different times with hard data collected by temperature monitoring wells and postcombustion coring. They found 3-D seismic to be a good tool for monitoring as well as understanding the in situ combustion process.

Research needs in 3-D seismic are those that will refine the tool to increase the power and ease of its application and lower costs. Robertson (1991) suggests the following areas for attention: (1) development of methodologies for data collection design for specific target reservoirs, (2) implementation of 3-D three-component seismic surveys to exploit shear-wave and converted-wave data, (3) increase use of computer automation and expert guidance systems in many aspects of 3-D 
seismic technology application, (4) development of more powerful computational capabilities to implement more sophisticated processing algorithms, and (5) development of 3-D seismic applications with downhole sources and receivers where higher frequencies can lead to higher resolution and better reservoir description in the interwell region.

\section{Tools and Techniques for Extraction of Rock and Fluid Properties}

Seismic data has a long history of application in determination of subsurface structure and stratigraphy, but more recently, characteristics of seismic waves, such as amplitude and phase, and interval velocity changes between seismic events have been correlated with reservoir properties such as porosity, fluid type, lithology, and pay thickness (Jackson and Tomutsa, 1991). The information content of seismic data, and thus the ability to represent reservoir properties, will increase with recording, in addition to the conventional compressional waves (P-waves), the shear waves ( $\mathrm{S}$-waves) by special three-component geophones.

Although seismic amplitude versus offset (AVO) techniques are being developed primarily as exploration tools for natural gas (Shirley, 1994), the capability of AVO for targeting small anomalies (Allen et al., 1993) indicates that research in this area may also have application in EOR fluid monitoring. Theoretical and laboratory petrophysical studies of acoustical energy inversion over varying offset would provide invaluable information for interpreting fluid saturation (Poggiagliolmi and Allred, 1994).

\section{Downhole Seismic Surveys}

Measurement of seismic attributes at any appreciable depth using surface seismic surveys suffers from attenuation and loss of higher signal frequencies resulting in loss of resolving power. Placement of source and receivers in subsurface boreholes enhances retention of higher frequencies with subsequent increased resolution capabilities and is appropriate for measurement of interwellscale heterogeneities. Downhole seismic surveys include approaches such as vertical seismic profiling (VSP), cross-well seismic reflection surveys, and cross-well transmission tomography. All of these downhole techniques can benefit from research discussed above aimed at extraction of rock and fluid properties.

Vertical seismic profiling run with source and receivers in a single borehole has good potential for illuminating heterogeneities at the interwell scale with a resolution not attainable by surface surveys or by traditional VSP surveys with the source located on the surface. Order of magnitude higher frequencies are attainable (Paulsson, 1991). Surveys with source and receivers in the borehole do not have the depth limitations of traditional VSP surveys. VSP is also a good method for calibration of well and seismic data, probably much better than calibrations attempted from sonic logs alone. Methodology development for routine design and use of these approaches in characterization of interwell heterogeneities is a definite research need.

Cross-well reflection surveys with source and receivers located in the subsurface in different boreholes share the same advantages as downhole VSP techniques over surface surveys (Paulsson, 1991). Such surveys have a definite interwell-scale advantage over downhole VSP techniques and can complement or supplement downhole VSP and surface seismic in characterizing the interwell region. Again, practical methodology development is a primary research need.

Cross-well transmission seismic tomography involves use of P-wave first arrivals to compute images from the spatial distribution of seismic velocities that are influenced in turn, by reservoir heterogeneity. Heterogeneities in lithology, porosity, structure, and fluid content are candidates for imaging by this technique (Jackson and Tomutsa, 1991).

Link et al. (1991) used cross-well tomography to image lithologic heterogeneity between wells at a variety of well spacings (50 feet to $600 \mathrm{feet}$ ) in the Seventy-Six West field, a Jackson-Frio strandplain/barrier island reservoir. Poorly consolidated Frio sands were targeted for imaging at a 
depth of about 550 feet. Shot points and geophones were distributed over an interval from 20 to about 1,300 feet to obtain image data with a maximum resolution of about 6 feet at a 50-foot well spacing.

Majer et al. (1993) imaged fracture configuration by cross-well tomography in fractured igneous rocks. They concluded that structures were resolved that were not directly observable in any existing boreholes or tunnels. They concluded that additional seismic signal information in the form of S-wave data would be helpful in the analysis of fractures by this technique. They also stated that some knowledge of the geological system being explored (i.e., a conceptual model) is necessary for accurate interpretation of results.

One of the major constraints of application of cross-well tomographic methods is the requirement for boreholes to extend below the interval to be imaged a distance more or less equal to the spacing between wells. Progress in relieving this constraint would make the techniques more valuable in many older reservoirs where wellbores do not extend below the producing interval. The spatial resolution of the technique needs significant (order of magnitude) improvement for use as a stratigraphic tool in reservoir characterization.

\section{Integration of Seismic and Other Data Types}

Because seismic data can be obtained from every location within a reservoir, attempts to link seismic response with other reservoir parameters measured only at wellbores have been numerous. Geostatistical techniques of various kinds have been proposed and attempted; they include: kriging and regression analysis, kriging with external drift, cokriging, and cokriging with the MarkovBayes indicator formalism. In their evaluation of the above techniques, Araktingi et al. (1993) found that the products of these integrations showed features not evident from well data alone, but none of the above techniques provided entirely satisfactory results. Much research yet needs to be done on the statistical and mathematical integration of data at different scales.

\section{Other Tools, Measurements, and Techniques}

The preceding discussions of deterministic measurement tools and techniques are not intended to be all-inclusive. Many additional pages of discussion could be written about other approaches such as electromagnetic mapping, remote sensing, surface and borehole gravity surveys, aerial and surface magnetic surveys, surface geochemical sampling surveys, etc., that may have good research potential for characterization of reservoirs, including those of Class 4 . The preceding discussions cover most of the major geoscience and engineering areas of concern, and since it is not the aim of this report to be exhaustive, no further discussions will be presented. It is recognized, however, that a number of technologies not discussed or mentioned in this document could be applicable. The methodologies associated with applying those technologies are a definite research need as well.

\subsubsection{Reservoir Characterization Methodology}

The goal of reservoir characterization is to construct a model or a small number of models to aid in predicting by simulation or other means the outcome or probable range of outcomes of proposed projects, processes, or operating plans and procedures in order to evaluate their economic merit. Reservoir characterization strives to achieve a balance between the risk-associated cost of accepting uncertainty in model predictions of proposed project economics, and the certain cost of obtaining information to reduce that uncertainty. 


\subsubsection{Steps in Reservoir Characterization}

Reservoir characterization activities are complex and variable, but the general methodology governing them may be summarized in a small number of sequential steps. In practical application, these steps may need to be followed through several iterations to achieve an acceptable product. A flowchart of typical reservoir characterization activities is presented in Figure 3.4.

\section{Step 1 Specify the Appropriate Uncertainty Characteristics of the Reservoir Characterization Model}

This step consists of an initial estimate of the degree of uncertainty or level of detail of information that will be acceptable to evaluate the project or process being contemplated. The initial estimate of the required level of detail or uncertainty will be a function of the reservoir type and the reservoir stage of development. The required level of model detail may vary from place to place within the reservoir, or the model may be entirely focused on a local segment of the reservoir.

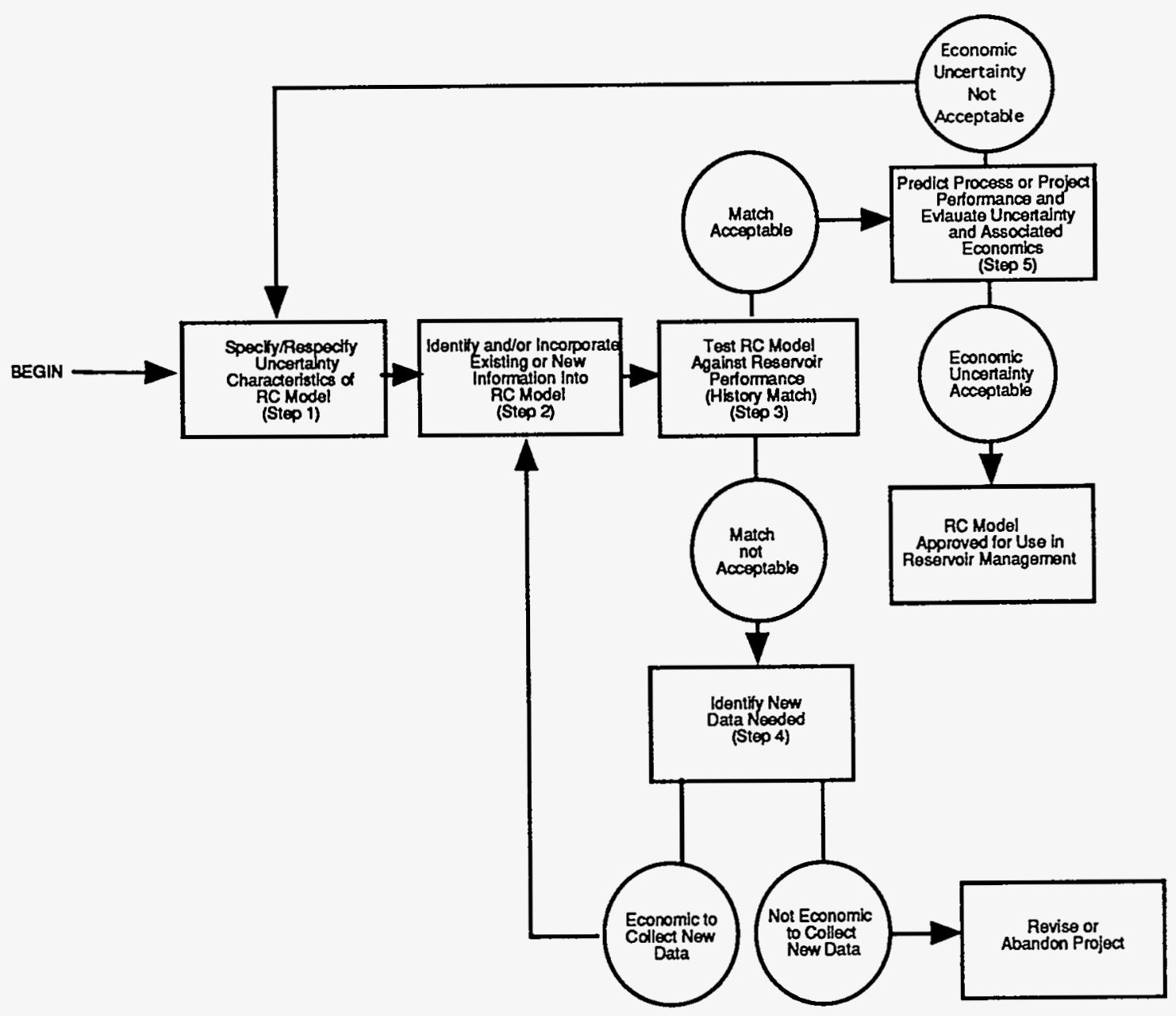

Figure 3.4 Flow Chart of Typical Reservoir Characterization (RC) Activities 
Knowledge of the reservoir type (e.g., its depositional, diagenetic, or structural classification) may not always be available. We know with certainty, however, that reservoirs of different origin in any of the above categories of classification may have predictably different degrees of heterogeneity, and even "simple" reservoirs have complex rock and fluid distributions (Jackson, 1993).

Reservoirs at different stages of development have different requirements in the level of detail needed for adequate characterization. For example, during initial reservoir development, when the primary predictive concern is to define the extent of reservoir facies for additional drilling, only a coarse model capable of predicting external and internal facies geometries may be required. On the other hand, for some advanced EOR process implementations, a great deal of physical, chemical, and fluid-flow information on as fine a scale as possible is desirable.

It is not uncommon to find that after the construction and testing of a reservoir characterization model or models, the uncertainty in prediction is found to be unacceptably high. In this circumstance, the required characteristics of the model need to be redefined at a higher level of detail.

\section{Step 2 Identify and/or Incorporate Existing or New Information into the Reservoir Characterization Model}

Information that goes into the building of a reservoir characterization model originates in: (1) data collected from different sources (e.g., rock and fluid samples, wireline logs, seismic, well tests, production data, etc.), (2) data collected at different scales (i.e., reservoir scale or larger to microscopic scale), and (3) data collected with inherently different degrees of uncertainty (i.e., yielding conceptual, stochastic, or deterministic information). The wide variety of engineering, geoscience, and reservoir operations data and information types useful in reservoir characterization are summarized in Section 3.3.2.

A reservoir characterization model must provide information throughout the 3-D volume of the reservoir (or throughout that portion of the reservoir for which it is built). This does not imply that deterministic data need to be collected at a fine scale throughout the entire volume of interest. Instead, information derived from various data sources is incorporated by interpolation, extrapolation, or correlation with other data of deterministic, stochastic, or conceptual model origin. This diverse information is incorporated in mutual support of a single reservoir characterization model or a small number of models that express the probable range of variation.

Geoscience and engineering efforts do not strive to create separate reservoir characterization models to be merged later into a unified whole. Information derived from geoscience and engineering data are continually compared and contrasted to test various details of the emerging reservoir characterization model until information from all existing sources (i.e., conceptual, stochastic, and deterministic models) is in agreement. Inconsistent or conflicting information, derived from different sources, scales, or uncertainty models, may have to be resolved by additional data collection before full confidence is achieved.

\section{Step 3 Test the Reservoir Characterization Model Against Reservoir Performance}

The reservoir characterization models from the previous step are tested either qualitatively or quantitatively (by simulation or other simpler modeling approaches) against actual pressure, production, and/or injection history of the reservoir as a verification step. This is important even if production and injection data provided information in building the model, because the matching of fluid performance history is a good indicator that the reservoir characterization model is a reasonable representation of the reservoir. 
If simulations are performed, an additional scaling or averaging operation must also be performed to adjust model parameter values to the size of simulator grid blocks (Lake et al., 1988). The information in the models must be represented at grid-block scale in such a way that the numerical values entered in simulation retain the information critical to fluid-flow prediction for the process being considered (Jackson and Tomutsa, 1991).

It is very important that adjustments to parameter values input to simulators not be made to achieve a "history match" unless those changes are consistent with the reservoir characterization models. Failure of the reservoir characterization models to support a reasonable match with actual reservoir past performance indicates that the models need correction through incorporation of new information (see Step 4). If the models perform well in this test, they are ready to test for adequate containment of uncertainty (see Step 5).

\section{Step 4 Identify Sources, Collect, and Incorporate New Information into the Reservoir Characterization Model}

Sampling of the reservoir is never sufficient to satisfy the needs of reservoir characterization (Jackson and Tomutsa, 1991). Collection of additional information can be looked at as a reduction in risk, but several guidelines govern judicious information collection. The primary objective is to obtain the maximum information affordable, in terms of proposed project economics, to reduce uncertainty in prediction of project outcome. If the cost of reducing uncertainty to an acceptable level becomes too high, the project or process may have to be redesigned or abandoned. Information from all potential sources should be evaluated in terms of contribution to reducing the model uncertainties. Potential contributors of low-cost information such as conceptual models from the published literature should not be overlooked. It is important also not to neglect collection of adequate reservoir information that may be useful or necessary at later stages of reservoir development but not obtainable at that time. Examples include collection of rock and fluid samples and measurement of fluid saturations in the early stages of reservoir development, before ongoing production activities alter the information or make it inaccessible.

New information collected from appropriately identified data sources should be incorporated into the reservoir characterization model and the model retested for adequacy (see Steps 2 and 3).

\section{Step 5 Use the Reservoir Characterization Model to Predict Project or Process Performance}

Examine model predictions obtained by simulation (or other means) of project or process results to determine if the degree of uncertainty in outcomes is economically acceptable. If uncertainty is unacceptably high (i.e., if the probable range of economic performance results includes unacceptable outcomes), collection of additional information will be necessary (see Step 4).

\subsubsection{Research Needs in Reservoir Characterization Methodology}

\section{Specific Task-Related Needs}

Database management systems are needed for reservoir characterization that allow storage, retrieval, and combination of information based on data gathered from different sources at different scales, and with varying degrees of uncertainty (Jackson and Tomutsa, 1991). The need for further development of techniques for determining the degree of mutual support or conflict within such information is also required. Further development of methodologies for addressing effective transfer of information stored on finer or coarser scales to the scale of simulator gridblocks is another critical area for research (Jackson and Tomutsa, 1991; Tomutsa et al., 1993). 


\section{Comprehensive Methodologies}

Comprehensive reservoir characterization methodologies need to be developed and demonstrated for different reservoir types. A possible approach might be to develop methodologies for reservoirs in which heterogeneities are predominantly of the same depositional (e.g., Class 4), diagenetic, or structural type. It would also be useful to develop methodologies for reservoirs at different stages of reservoir development. Methodologies for youthful reservoirs might focus on judicious selection of data types and amounts for long-term utility, the interplay of engineering and geoscience information in confirming features of the reservoir characterization model, or other aspects of an "idealized" reservoir characterization approach. Methodologies for older, mature reservoirs (most Class 4) being considered for IOR could focus on making maximum use of existing data (e.g., "old E-logs" and production data) or identifying the most cost-effective ways to obtain or approximate critical reservoir information in cases where records have not been properly kept or have been lost.

Because the methodology of reservoir characterization is complex, multidisciplinary, and reiterative, and because the methodology is not widely practiced or understood throughout the industry, it is a prime candidate for technology transfer by a computer-based or expert system approach. Honarpour et al. (1989) describe a simple deterministic system developed to advise users how to properly collect geoscience and engineering data for building a reservoir characterization model. More complete coverage of the various facets of reservoir characterization methodologies by such tools would be helpful to Class 4 operators seeking to define their reservoir characterization needs.

\subsection{The Role of Reservoir Management in Relaxing Constraints on Recovery}

Reservoir management is an activity that can jointly apply reservoir characterization and improved oil recovery (IOR) processes to recover additional portions of a reservoir's remaining oil-in-place. The purpose of Section 3.4 is to describe the component considerations of reservoir management and to define the reservoir management research areas that will be of most benefit to Class 4 reservoirs.

In the past, reservoir management programs have commonly failed to produce the results desired. Some of the more prominent reasons for these failures are (1) failure to consider the entire reservoir system (i.e., reservoir, wells, and surface facilities), (2) no attempt at reservoir management was made until a "crisis" occurred, and (3) the reservoir was not given minimal maintenance attention (Thakur, 1990). In many cases, poor performance resulted simply from failure to monitor implementation or failure to get input from field personnel.

In this chapter a description of reservoir management (section 3.4.1), its characteristic activities and procedures (section 3.4.2), and its economic and organizational contexts (section 3.4.3) are discussed to provide insights into prevention of such failures. Section 3.4 .4 describes research needs in reservoir management. The most significant needs are in the areas of methodology development, demonstration, and transfer.

\subsubsection{Description of Reservoir Management}

A number of definitions and approaches to reservoir management have evolved over the years, largely due to the wide variety of considerations involved (e.g., definition of applicable resources, determination of appropriate subsurface volume for consideration, and definition of appropriate time spans and schedules). This section discusses the latitude of reservoir management considerations and how it has changed. 


\section{Definition}

Reservoir management is not just preventive maintenance nor problem solving. Neither is it a depletion plan and/or a development plan, but rather a comprehensive, integrated strategy for reservoir exploitation (Wiggins and Startzman, 1990). Thakur (1991) defines reservoir management as "the judicious use of available resources to maximize economic recovery." Wiggins and Startzman (1990) define it as "the application of state-of-the-art technology to a known reservoir system within a given management environment." Regardless of the precise definition, nearly all discussions of reservoir management agree on the following as characteristics of reservoir management: (1) it requires and makes use of resources, (2) it is continuous and longterm, over the life of a reservoir, (3) it concentrates on economic optimization. Reservoir management then could be considered as a sequence of resource-deployment decisions made to maintain optimum economic recovery of petroleum.

\section{Scope or Scale}

The scope of a reservoir management project can be discussed from several points of view. In time, the scope may extend from discovery to abandonment. In space, the scope may be very local (for a project involving only a single well or a few wells), or it may include the entire reservoir, or (as is commonly the case) multiple reservoirs within a field. The resources involved can cover an extremely wide range, but can generally be thought of as people, equipment, technology, and money (Cole et al., 1993). In terms of petroleum-related knowledge involved, reservoir management is nearly all inclusive; however, Wiggins and Startzman (1990) recognize three major groupings; knowledge of technologies, knowledge of the reservoir, and knowledge of the management (e.g., economic, corporate, regulatory, etc.) environment. All are necessary for successful reservoir management. The level of detail in information required for effective reservoir management is also quite variable but in general tends to increase with the (1) age or stage of reservoir development, (2) reservoir complexity, (3) amount of data available, (4) size of any project being considered, and (5) expected economic benefits (Raza, 1990). In particular, the level of effort must be scaled to the potential economic benefits considering the operator's business strategy.

\section{Evolution}

Part of the reason for failure or poor performance of reservoir management programs in the past may have been due to the overly simplistic approach taken. Early hand-calculated methods were typified by a material balance approach in treating the reservoir as a simple tank with no input of detailed information from the reservoir (Craig et al., 1977). Now the capability to use reservoir data usually exceeds its availability. The need for reservoir management has been recognized, although there is yet much to be learned about the details of reservoir management methodology. Progress is being made, however, in the form of recognizing (1) the components of the general reservoir management process and (2) the general business environment needed for successful reservoir management.

\subsubsection{The Reservoir Management Process (Activities and Methodology)}

Reservoir management can be viewed as a time series of choices that are made throughout the life of a reservoir to optimize the economic recovery of petroleum. A plan, therefore, is an important and necessary central concept to reservoir management. A reservoir management plan (1) specifies a schedule of implementation activities; (2) projects timing and volumetric performance of production and injection wells, performance of facilities and equipment, and environmental and other regulatory compliance; and (3) specifies a system of data collection, storage, and analysis to monitor performance in each of the preceding areas. 


\subsubsection{Plan Construction}

A number of considerations and a concentrated synergistic effort on the part of the reservoir management team are required to construct or revise a reservoir management plan.

\section{Scope and Objective Determination}

Ideally, a reservoir management plan will provide guidelines over the entire life of the reservoir, or at least up to some point in time or level of performance specified in the plan as a criterion for re-evaluation. A comprehensive reservoir management plan initiated at the time of discovery will assure early collection of native-state reservoir data vital to implementation of advanced recovery processes many years in the reservoir's future. On the other hand, reservoirs in which data collection has been neglected and reservoirs acquired without adequate accompanying data will require a reservoir management plan designed to correct or alleviate the effects of information deficiencies. Specific objectives of the plan will depend on the necessary plan scope, the current stage of reservoir development, and the type and scale of decision(s) required (e.g., evaluation of a potential new process implementation, local production and injection performance, new facilities or equipment technologies, etc.).

\section{Evaluation of Reservoir Description, Facilities, and Equipment}

It must be determined if a revised reservoir description or characterization is necessary to address the scope and objectives of the plan. The approach to design of a cost-effective reservoir characterization is discussed in detail in Section 3.3.3. The plan or revised plan will consider newly available data (hopefully collected as specified by a previous plan if this is a revision), additional data, and/or new data types. Changes in facilities and/or equipment types and amount or capacity in correspondence to revisions in fluid expectations (e.g., new fluids, new distributions, different volumes, etc.) are an important consideration also.

\section{Predictive Aspects and Specifications of a Reservoir Management Plan}

A reservoir management plan specifies schedules for implementation of technologies, procedures, and reservoir operational activities. The plan projects expected performance by simulation or other means of all aspects of reservoir performance over the plan's duration (i.e., reservoir wellbore injection and production performance, facilities and equipment usage, environmental and other regulatory compliance). The plan specifies surveillance and monitoring activities including data types, collection protocol, database construction, data processing and analysis, and performance variance to be tolerated. The plan also may specify or recommend future plan revisions based on specific criteria such as timing or volume performance of reservoir fluid production or injection.

\subsubsection{Surveillance and Monitoring}

Surveillance and monitoring are continuous activities that take place throughout the life of a reservoir operating under a reservoir management plan. In part, surveillance consists of constant checking or comparison against plan predictions of (1) performance of reservoir or wellbore production or injection in terms of fluid types, timing, and volumes; (2) surface facilities and equipment and downhole equipment performance and usage; and (3) environmental and other regulatory compliance. Surveillance activities apply also to monitoring development and application of new techniques and technologies and the general and operator-specific business and economic environments. Surveillance and monitoring data are collected, stored, and analyzed as specified in the plan. 


\subsubsection{Events Triggering Reservoir Management Plan Revision}

The reservoir management plan may specify a condition or set of conditions that indicate the plan needs reevaluation. These criteria may include such items as volume of specific fluid production, a specific elapsed time, or attaining a particular stage of reservoir development.

At any time, however, performance anomalies of any kind (e.g., production or injection, facilities usage, regulatory compliance) with respect to plan expectations or predictions may indicate immediate need for plan revision. The plan specifies guidelines for tolerance in variation from plan prediction in all critical performance areas, and when these tolerances are exceeded, a review and revision of the plan are necessary.

New information may also be just cause for plan revision at any time. New information may take various forms. It may be information extracted from data collected under specifications of the current plan that indicates a conflict with the assumptions that went into formulating the current plan. It may be in the form of the introduction of new technologies, ideas, or procedures not available or known at the time the current plan was formulated. The critical new information may even be in the form of performance anomalies arising in analogous reservoirs.

Unexpected or unpredicted changes in circumstances or opportunities related to the general or operator-specific business environment may also present cause to reevaluate the reservoir management plan. Examples of factors that may be significant include market economics, new laws and regulations, and decision to buy, sell, or trade reservoirs.

If a plan revision is necessary, the scope and objectives have to be redefined and the plan altered by repeating the considerations discussed in Section 3.4.2.1.

\subsubsection{The Reservoir Management Business Environment (Economic Factors and Organizational Factors)}

The reservoir management business environment includes all factors influencing reservoir management decisions aside from the properties of the reservoir itself (including equipment and facilities) and available technologies. Like technology and the reservoir itself, these factors are dynamic rather than static and must be included in the reservoir management plan.

Reservoir management business environmental factors fall into two categories: those that are external to the operator's organization (i.e., affect all operators equally) and those that are internal (i.e., their influences are different in different organizations). External factors include considerations such as market economics, taxes, operational regulations, safety and environmental laws and regulations, and social perceptions. Internal factors include the company or organization's attitude toward risk, its acceptable rate of return, its ability to raise and/or commit capital, its objectives, its organizational structure (e.g., team versus disciplinary approach to reservoir management), and its ability to commit to execution of long-term plans (Wiggins and Startzman, 1990; Cole et al., 1993). The importance of incorporating external and internal reservoir management environmental factors into the reservoir management plan cannot be overemphasized. The plan must specify surveillance criteria for these factors as well as those concerning the reservoir and technology. Significant changes in any of these reservoir business environmental factors may be just cause for revision of the reservoir management plan.

\subsubsection{Research Needs in Reservoir Management}

Research is needed primarily in the area of methodology development and demonstration for (1) design of data and information management systems, (2) for formulation of reservoir management plans, and (3) for technology transfer. Computer-based information management systems are needed for storage, retrieval, and analysis of all types of reservoir management data (i.e., technological, reservoir description and performance, reservoir management economic and organizational data). Computer-based systems would also be useful to provide guidance in 
building an appropriate reservoir management plan tailored to the particular context of a reservoir, and to aid in subsequent collection and interpretation of surveillance data as specified by the plan. Such computer-based systems may also provide appropriate reservoir management training if designed with that objective in mind, but design and development of cross-training programs for reservoir management personnel (e.g., managers, engineers, geologists, field personnel, etc.) is also a definite need.

\subsection{Current Research in Reservoir Description and Reservoir Management}

The importance to improved oil recovery of heterogeneity prediction is discussed in some detail in Section 3.1. Reservoir description, as an area for concentrated geoscience and engineering research, has been highly recognized in DOE's Fossil Energy Program for a number of years (GIOGRR, 1989; DOE, 1991; DOE, 1992; DOE, 1993). A review of 36 project descriptions from funded and nonfunded projects submitted for DOE's Field Demonstrations in High-Priority Reservoir Classes Program (Classes 1 through 3) revealed that virtually all of the projects employ description or characterization of rocks, fluids, or reservoir properties to some extent (DOE, 1994a; OGJ, 1994). Of the project summaries reviewed, $72 \%$ acknowledged that reservoir characterization will play an important role in the project's success, and most of that $72 \%$ implied that reservoir characterization will be one of the major focal points of the project.

A cursory review of recent DOE-supported EOR-related research and Gas Research Institute (GRI) planned and supported research in the geoscience area reveals a wide variety of subjects related to reservoir characterization (DOE, 1993b-e, 1994b-d; GRI, 1994). In 35 existing and proposed geoscience research projects spanning the period from 1992 to 1998, 45 areas of major emphasis related to reservoir management and reservoir characterization were identified. Table 3.1 shows the approximate percentage distribution of these areas of research emphasis.

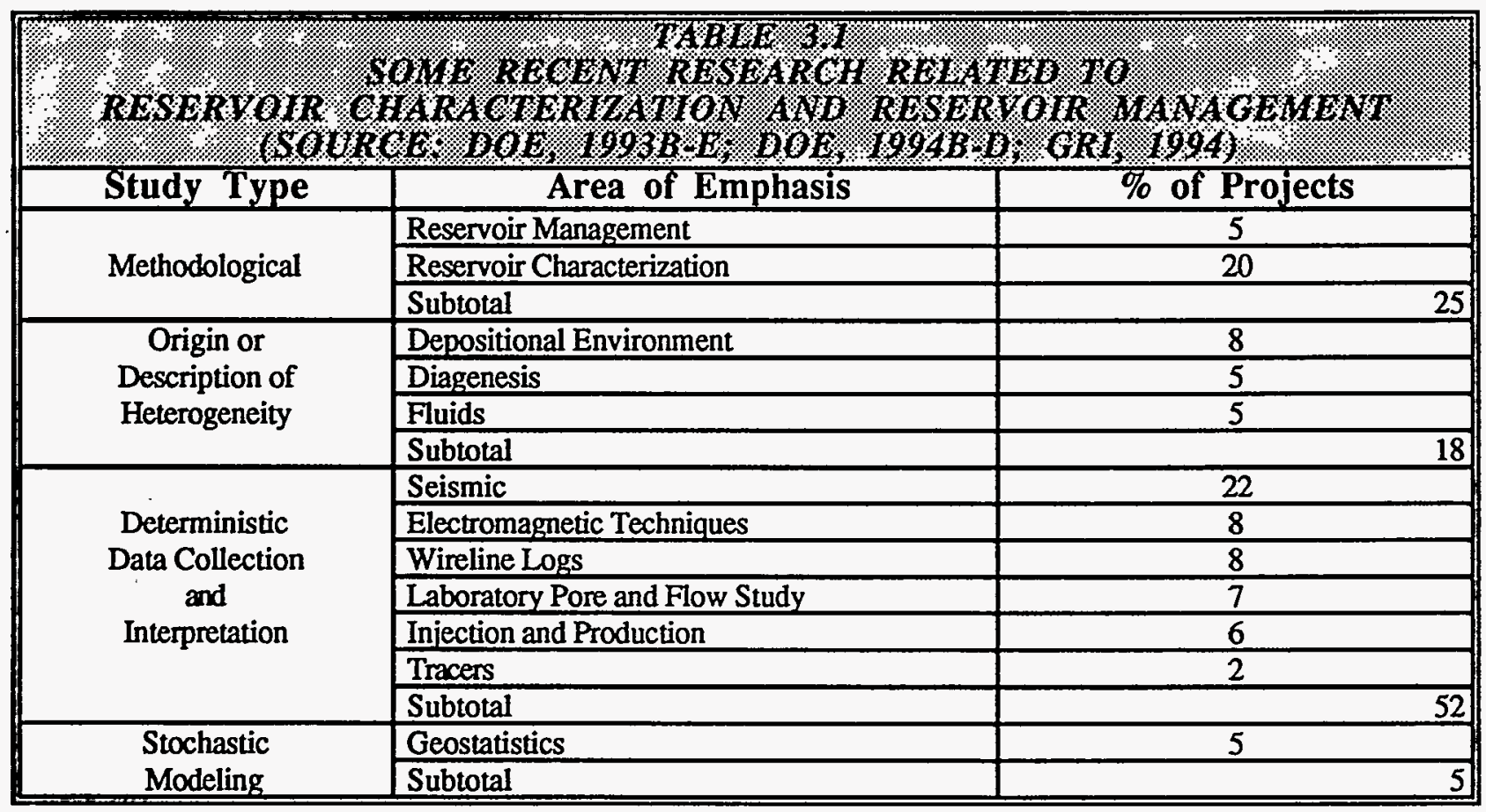


The combined programs show a good balance between general methodological research (25\% emphasize reservoir characterization and reservoir management) and research focused on more specific reservoir characterization topics $(75 \%)$. Research emphasis in the area of deterministic measurements accounts for about $52 \%$ of the total. The $22 \%$ figure for seismic reflects the perceived future importance of seismic techniques in reservoir characterization. Many of these seismic areas of research are concerned with downhole techniques and cross-well imaging.

\subsection{References}

Abbaszadeh-Dehghani, M. and W.E. Brigham, 1984, Analysis of well-to-well tracer flow to determine reservoir layering: Journal of Petroleum Technology, vol. 36, No. 11, October, p. 1753-1762.

Allen, J.L., C.P. Peddy, and T.L. Fasnacht, 1993, Some AVO failures and what (we think) we have learned: The Leading Edge, vol. 12, No. 3, March, p. 162-167.

Allison, S.B., G.A. Pope, and K. Sepehrnoori, 1991, Analysis of field tracers for reservoir description: Journal of Petroleum Science and Engineering, vol. 5, p. 173-186.

Almon, W.R. and D.K. Davies, 1979, Regional diagenetic trends in the Lower Cretaceous Muddy Sandstone, Powder River Basin: Society of Economic Paleontologists and Mineralogists Special Publication No. 26, p. 379-400.

Araktingi, V.G., W.M. Bashore, T.T.B. Tran, and T.A. Hewett, 1993, Integration of seismic and well $\log$ data in reservoir modeling: in B. Linville, ed., Reservoir Characterization III, PennWell Publishing Company, Tulsa, Oklahoma, p. 515-554 of 1008.

Armitage, P. and R.J. Norris, 1993, An application of the ROCKIT geological simulator to the Frontier formation, Wyoming: in B. Linville, ed., Reservoir Characterization III, PennWell Publishing Company, Tulsa, Oklahoma, p. 372-397 of 1008.

Brigham, W.E. and M. Abbaszadeh-Dehghani, 1987, Tracer testing for reservoir description: Journal of Petroleum Technology, vol. 39, No. 5, May, p. 519-527.

Brown, D., 1986, Geologists are developing future: American Association of Petroleum Geologists Explorer, January, p. 20-21.

Burt, R.A., F.A. Haddenhorst, and J.C. Hartford, 1975, Review of Bell Creek waterflood performance-Powder River County, Montana: SPE 5670 50th Annual Meeting, Dallas, Texas, September.

Cant, P.J., 1986, Diagenetic traps in sandstones: American Association of Petroleum Geologists Bulletin, vol. 70, No. 2, p. 155-160.

Caughey, C. A., 1977, Depositional systems in the Paluxy formation: The University of Texas at Austin, Bureau of Economic Geology, Geologic Circular 77-8, 60 p.

Collins, A.G., 1975, Geochemistry Of Oilfield Waters: Elsevier Scientific Publishing Company, Amsterdam, $496 \mathrm{p}$.

Cole, E.L., R.S. Sawin, and W.J. Weatherbie, 1993, Reservoir management demonstration project: The University of Kansas, Energy Research Center, Technology Transfer Series 93-5, August, $236 \mathrm{p}$.

Craig, F.F., Jr., P.J. Wilcox, J.R. Ballard, and W.R. Nation, 1977, Optimized recovery through continuing interdisciplinary cooperation: Journal of Petroleum Technology, July, SPE Reprint Series 13, p. 755-760.

Dauben, D.L., 1991, Part II-EOR field case histories: in Research Needs to Maximize Economic Productivity of the Domestic Oil Resource, Department of Energy Report NIPER-527, 521 p. 
Davies, D.K. and F.G. Ethridge, 1975, Sandstone composition and depositional environment: American Association of Petroleum Geologists Bulletin, vol. 59, No. 2, p. 239-264.

Da Costa e Silva, A.J., 1985, A new approach to the characterization of reservoir heterogeneity based on the geomathematical model and kriging technique: SPE 14275 Annual Technical Conference, Las Vegas, Nevada, September.

Dickey, P.A., 1979, Petroleum Development Geology: PennWell Publishing Co., Tulsa, Oklahoma, $350 \mathrm{p}$.

DOE, 1991, Opportunities to improve oil productivity in unstructured deltaic reservoirs: Department of Energy Report DOE/BC--91/6/SP, 154 p.

DOE, 1992, Program research and development announcement (PRDA) for geoscience/engineering reservoir characterization: PRDA \# DE-RA-22-92BC14816.

DOE, 1993a, The domestic natural gas and oil initiative (DNGOI): United States Federal Government, Washington, D.C., December.

DOE, 1993b, Enhanced Oil Recovery Progress Review No. 70, Quarter Ending March 31, 1992 : Department of Energy report, DOE/BC--92/2, March.

DOE, 1993c, Enhanced Oil Recovery Progress Review No. 71, Quarter Ending June 30, 1992: Department of Energy report, DOE/BC--92/3, June.

DOE, 1993d, Enhanced Oil Recovery Progress Review No. 72, Quarter Ending September 30, 1992: Department of Energy report, DOE/BC--92/4, September.

DOE, 1993e, Enhanced Oil Recovery Progress Review No. 73, Quarter Ending, December 31 1992: Department of Energy report, DOE/BC--93/1, December.

DOE, 1994a, Field demonstrations in high-priority reservoir classes program, Class 1 and 2 project fact sheets, unpublished, Department of Energy, Bartlesville Project Office, July.

DOE, 1994b, Enhanced Oil Recovery Progress Review No. 74, Quarter Ending March 31, 1993: Department of Energy report, DOE/BC--93/2, March.

DOE, 1994c, Enhanced Oil Recovery Progress Review No. 75, Quarter Ending June 30, 1993: Department of Energy report, DOE/BC--93/3, June.

DOE, 1994d, Enhanced Oil Recovery Progress Review No. 76, Quarter Ending September 30, 1993: Department of Energy report DOE/BC--93/4, August.

Dubrule, O. and H.H. Haldorsen, 1986, Geostatistics for permeability estimation: in L.W. Lake and H.B. Carroll, Jr., eds., Reservoir Characterization, Academic Press, Orlando, Florida, p. 223-247 of 659.

Dutton, S.P. and L.S. Land, 1985, Meteoric burial diagenesis of Pennsylvanian arkosic sandstones, southwestern Anadarko Basin, Texas: American Association of Petroleum Geologists Bulletin, vol. 69, No. 1, p. 22-38.

Ebinger, C.D. and E. Hunt, 1989, Keys to good fracturing-2; pressure transient analysis key to fracs: Oil and Gas Journal, vol. 87, No. 16, April 17, p. 39-44.

Ehlig-Economides, C.A., J.A. Joseph, R.W. Ambrose, Jr., and C. Norwood, 1990, A modern approach to reservoir testing: Journal of Petroleum Technology, vol. 42, No. 12, December, p. $1554-1563$.

Ferrell, H.H., M.D. Gregory, and M.T. Borah, 1984, Progress report: Big Muddy Field lowtension flood demonstration project with emphasis on injectivity and mobility: SPE 12682 SPE/DOE Enhanced Oil Recovery Symposium, Tulsa, Oklahoma, April. 
Fetkovich, M.J., M.E. Vienot, M.D. Bradley, and V.G. Kiesow, 1987, Decline-curve analysis using type curves-case histories: SPE Formation Evaluation, vol. 2, No. 4, December, p. 637656.

Finley, R.J. and N. Tyler, 1986, Geological characterization of sandstone reservoirs: in Lake, L.W. and H.B. Carroll, Jr. eds., Reservoir Characterization, Academic Press, Orlando, Florida, p. 1-62 of 659.

Fisher, W.L., C.V. Proctor, Jr., W.E. Galloway, and J.S. Nagle, 1970, Depositional systems in the Jackson Group of Texas-Their relationship to oil, gas, and uranium: The University of Texas at Austin, Bureau of Economic Geology, Geologic Circular 70-4, 28 p.

Galloway, W.E., D.K. Hobday, and K. Magara, 1982, Frio formation of the Texas Gulf Coast Plain-depositional systems, structural framework, and hydrocarbon distribution: American Association of Petroleum Geologists Bulletin, vol. 66, No. 6, p. 649-688.

Gentry, R.W. and A.W. McCray, 1978, The effect of reservoir and fluid properties on production decline curves: Journal of Petroleum Technology, vol. 30, No. 9, September, p. 1327-1341.

GIOGRR, 1989, Major program elements for an advanced geoscience oil and gas recovery research initiative: Geoscience Institute for Oil and Gas Recovery Research, Department of Energy Report DOE/BC--89/9/SP, 50 p.

Goodlett, G.O., M.M. Honarpour, H.B. Carroll, Jr., and P.S. Sarathi, 1986, Screening for EOR1-Lab evaluation requires appropriate techniques: Oil and Gas Journal, vol. 84, No. 25, June 23, p. 47-53.

Greaves, R.J. and T.J. Fulp, 1986, Three-dimensional seismic monitoring of an enhanced oil recovery process: Geophysics, vol. 52, No. 9, p. 1175-1187.

Gregg, J.M., I.P. Montanez, and K.L. Shelton, 1994, Introduction: in Basin-wide diagenetic patterns: Integrated Geochemical, and Hydrologic Considerations-Program, Abstracts, and field Guide: Society of Economic Paleontologists and Mineralogists Research Conference, Lake Ozark, Missouri, May.

GRI (Gas Research Institute), 1993, Atlas of major midcontinent gas reservoirs: D.G. Bebout, W.A. White, T.F. Hentz, and M.K. Grasmick, 85 p.

GRI, 1994, 1994-1998 Research and Development Plan and 1994 Research and Development Program: Gas Research Institute, $147 \mathrm{p}$.

Gringarten, A.C., 1986, Computer-aided well test analysis: SPE 14099 International Meeting on Petroleum Engineering, Beijing, China, March, p. 373-392.

Haldorsen, H.H. and D.M. Chang, 1986, Notes on stochastic shales; from outcrop to simulation model: in L.W. Lake, and H.B. Carroll, Jr., eds., Reservoir Characterization, Academic Press, Orlando, Florida, p. 445-485 of 659.

Haldorsen, H.H. and E. Damsleth, 1990, Stochastic modeling: Journal of Petroleum Technology, vol. 42, No. 4, April, p. 404-412.

Hall, H.N., 1963, How to analyze waterflood injection well performance: World Oil, vol. 157, October, p. 128-133.

Hearn, C.L., J.P. Hobson, and M.L. Fowler, 1986, Reservoir characterization for simulation, Hartzog Draw field, Wyoming: in L.W. Lake; and H.B. Carroll, Jr., eds., Reservoir Characterization, Academic Press, Orlando, Florida, p. 341-372 of 659.

Henriquez, A., K.J. Tyler, and A. Hurst, 1990, Characterization of fluvial sedimentology for reservoir simulation modeling: SPE Formation Evaluation, vol. 5, No. 3, September, p. 211 216. 
Hertzog, R., L. Colson, B. Seeman, M. O'Brian, H. Scott, D. McKeon, P. Wraight, J. Grav, D. Ellis, J. Schueitzer, and M. Herron, 1987, Geochemical logging with spectrometry tools: SPE 16792 Annual Technical Conference, Dallas, Texas, September.

Hewett, T.A., 1986, Fractal distributions of reservoir heterogeneity and their influence on fluid transport: SPE 15386 Annual Technical Conference, New Orleans, Louisiana, October.

Hewett, T.A. and R.A. Behrens, 1990, Conditional simulation of reservoir heterogeneity with fractals: SPE Formation Evaluation, vol. 5, No. 3, September, p. 217-225.

Honarpour, M.M. and L. Tomutsa, 1990, Injection-production monitoring - an effective method for reservoir characterization: SPE 20262 Seventh SPE/DOE Symposium on EOR, Tulsa, OK, April.

Honarpour, M.M., M.J. Szpakiewicz, R.A. Schatzinger, L. Tomutsa, H.B. Carroll, Jr., and R.W. Tillman, 1988, Integrated geological/engineering model of barrier island deposits in Bell Creek field, Montana: SPE 17366 Sixth SPE/DOE Symposium on EOR, Tulsa, OK, April.

Honarpour, M.M., M.J. Szpakiewicz, B. Sharma, M.M. Chang, R. Schatzinger, S.R. Jackson, L. Tomutsa, N. Maerefat, 1989, Integrated reservoir assessment and characterization: Department of Energy Report NIPER-390, 336 p.

Horne, R.N., 1994, Advances in computer-aided well-test interpretation: Journal of Petroleum Technology, vol. 46, No. 7, July, p. 599-606.

ICF and BEG (The University of Texas at Austin, Bureau of Economic Geology), 1990, An assessment of the reserve growth potential of the Frio Barrier-Strandplain Play in Texas: Department of Energy Report DOE/BC/14000-6, August, 128 p.

Jacka, A.D., 1970, Principles of cementation and porosity occlusion in Upper Cretaceous sandstones, Rocky Mountain region: Wyoming Geological Association, 22nd Annual Field Conference Guidebook, p. 265-285.

Jackson, J.A., 1984, Nuclear magnetic resonance well logging: The Log Analyst, vol. 35, No. 5, September-October, p. 16-30.

Jackson, S.R., 1993, Reservoir assessment and characterization: in J.M. Deterding, F.D. Sutterfield, and T.E. Burchfield, Final Report, National Institute for Petroleum and Energy Research (NIPER), Department of Energy Report NIPER-685, December, p. 17 - 101 of 603.

Jackson, S.R. and L. Tomutsa, 1991, Reservoir characterization-state-of-the-art review: in Research Needs to Maximize Economic Producibility of the Domestic Oil Resource, Part I literature review and areas of recommended research, Department of Energy Report NIPER527, p. 143-172 of 521 p.

Jackson, S.R., R.A. Schatzinger, M.J. Szpakiewicz, M.M. Chang, and B. Sharma, 1993, Integration of the geological/engineering model with production performance for Patrick Draw field: Department of Energy Report NIPER-634, March, 122 p.

Jackson, S.R., L. Tomutsa, M. Szpakiewicz, M.M. Chang, M.M. Honarpour, and R.A. Schatzinger, 1991, Construction of a reservoir model by integrating geological and engineering information-Bell Creek field, a barrier/strandplain reservoir: in L.W. Lake, H.B. Carroll, Jr., and T.C. Wesson, eds., Reservoir Characterization II, Academic Press, San Diego, California, p. $524-556$ of 726 .

Johnson, C.R. and T.A. Jones, 1988, Putting geology into reservoir simulation: a threedimensional modeling approach: SPE 18321 63rd Annual Technical Conference, Houston, Texas, October. 
Johnson, K.S., T.W. Amsden, R.E. Denison, S.P. Dutton, A.G. Goldstein, B. Rascoe, Jr., P.K. Sutherland, and D.M. Thompson, 1988, Southern midcontinent region: in L.L. Sloss, ed., The Geology of North America, Volume D-2, Sedimentary Cover-North American Craton, U.S.: The Geological Society Of America, p. 307-359.

Johnston, D.D. and P.J. Johnson, 1987, Depositional and diagenetic controls on reservoir quality in First Wilcox Sandstone, Livingston field, Louisiana: American Association of Petroleum Geologists Bulletin, vol. 71, No. 10, p. 1152-1161.

Journel, A.G. and F.G. Alabert, 1990, New method for reservoir mapping: Journal of Petroleum Technology, vol. 42, No. 2, February, p. 212-218.

Journel, A.G. and C.J. Huijbregts, 1978, Mining Geostatistics, Academic Press, New York, New York, $600 \mathrm{p}$.

Kamal, M.M., 1990, Expected developments in transient testing: SPE 20593 65th Annual Technical Conference, New Orleans, Louisiana, September.

Khanna, M., K. Bjorlykke, G.C. Saigal, R. Sorlie, and J.P. Nystuen, 1994, Controls of climate and meteoric flow on early diagenesis in sandstones of the North Sea: (abstract) in: Basin-Wide Diagenetic Patterns: Integrated Petrologic, Geochemical, and Hydrologic ConsiderationsProgram, Abstracts, and Field Guide: Society of Economic Paleontologists and Mineralogists Research Conference, Lake Ozark, Missouri, May 21-25, p. 37.

Kossack, C.A., 1989, Prediction of layer lengths from layer heights for reservoir simulation-a statistical analysis of outcrop data: Journal of Petroleum Technology, vol. 41, No. 8, August, p. 867-871.

Lake, L.W., and H.B. Carroll, Jr., 1986, Preface: in L.W. Lake and H.B. Carroll, Jr., eds., Reservoir Characterization, Academic Press, Orlando, Florida, p. xi of 659.

Lake, L.W., G.A. Kocurell, and M.A. Miller, 1988, Systematic procedure for reservoir characterization: Department of Energy Report DOE/BC 19849-10, November, 253 p.

Law, B.E., 1992, Paleofluid flow paths-evidence from thermal maturity mapping, Greater Green River Basin, Wyoming and Utah: (abstract): Annual American Association of Petroleum Geologists, Calgary, Canada, June 21-24, p. 73.

Link, C.A., J.A. McDonald, H.W. Zhou, J. Jech, and B.J. Evans, 1991, Crosshole tomography in a shallow clastic reservoir in the Seventy-Six West Field, South Texas: 61 Annual International Society of Exploration Geophysicists Meeting, Houston, Texas, November.

Long, J.C.S. and P.A. Witherspoon, 1985, The relationship of the degree of interconnection to permeability in fracture networks: Journal of Geophysical Research, vol. 90, No. 34, p. 30873098.

Loucks, R.G., D.G. Bebout, and W.E. Galloway, 1977, Relationships of porosity formation and preservation to sandstone consolidation history-Gulf Coast Lower Tertiary Frio formation: Transactions of Gulf Coast Association of Geological Societies, vol. 27, p. 109-120.

Loucks, R.G., D.L. Richmann, and K.L. Milliken, 1981, Factors controlling reservoir quality in Tertiary sandstones and their significance to geopressured geothermal production: The University of Texas at Austin, Bureau of Economic Geology Report of Investigations No. $111,44 \mathrm{p}$.

Majer, E., L. Myer, and J. Peterson, 1993, High resolution seismic imaging of fractured rock: in B. Linville, ed., Reservoir Characterization III, PennWell Publishing Company, Tulsa, Oklahoma, p. 923-942 of 1008 . 
McKeever, P.J., S.C. Guscott, G.E. McAulay, and S.D. Burley, 1994, Regional aspects of quartz cementation from the North Sea: (abstract) in: Basin-Wide Diagenetic Patterns: Integrated Petrologic, Geochemical, and Hydrologic Considerations-Program, Abstracts, and Field Guide: Society of Economic Paleontologists and Mineralogists Research Conference, Lake Ozark, Missouri, May 21-25, p. 44.

Miller, H.O., 1953, San Ardo field - a history of development: Journal of Petroleum Technology, vol. 5, No. 1, January, p. 11-13.

Milliken, K.L., L.S. Land, and R.G. Loucks, 1981, History of burial diagenesis determined from isotopic geochemistry, Frio formation, Brazoria County, Texas: American Association of Petroleum Geologists Bulletin, vol. 65, No. 8, p. 1397-1413.

Mishra, S., 1989, On the use of pressure and tracer test data for reservoir description: Department of Energy Report, DOE/BC/14126-6, April, 121 p.

Morse, J.W., J.S. Hanor, and S. He, 1994, The role of brines in carbonate mineral mass transport in sedimentary basins: (abstract) in Basin-Wide Diagenetic Patterns: Integrated Petrologic, Geochemical, and Hydrologic Considerations-Program, Abstracts, and Field Guide: Society of Economic Paleontologists and Mineralogists Research Conference, Lake Ozark, Missouri, May 21-25, p. 54-55.

NIPER/BDM, 1994, Geological and production characteristics of strandplain/barrier island reservoirs in the United States: Department of Energy Report NIPER/BDM-0027, July, 162 p.

NIPER, 1986, Enhanced Oil Recovery Information, 40 p.

OGJ, 1994, DOE tallies Class III oil recovery field projects: Oil and Gas Journal, vol. 92, No. 30, July, p. 108-111.

Oliver, W.B., 1971, Depositional systems in the Woodbine formation (Upper Cretaceous), northeast Texas: The University of Texas at Austin, Bureau of Economic Geology, Report of Investigations No. 73, 28 p.

Pande, P.K., B.J. Meyer, and B.S. Banthia, 1993, Overview of key remaining issues in reservoir fluid properties and phase behavior for successful reservoir development applications: SPE 26115 Western Regional Meeting, Anchorage, Alaska, May.

Pande, P.K., M.B. Clark, T.A. Blasingame, and L. Doublet, 1994, Data acquisition design and implementation-opportunities and challenges for effective programs in mature reservoirs: SPE 27760 Ninth Symposium on Improved Oil Recovery, Tulsa, Oklahoma, April.

Paulsson, B.N.P., 1991, Cross-well seismology-a tool for reservoir geophysics: in L.W. Lake, H.B. Carroll, and T.C. Wesson, eds; Reservoir Characterization II, Academic Press, San Diego, California, p. 460-476 of 726.

Person, M., E. Bekele, and G. deMarsily, 1994, Geostatistical models of secondary oil migration within heterogeneous carrier beds-a theoretical example and preliminary application to the Paris Basin: (abstract) in Basin-Wide Diagenetic Patterns: Integrated Petrologic, Geochemical, and Hydrologic Considerations-Program, Abstracts, and Field Guide: Society of Economic Paleontologists and Mineralogists Research Conference, Lake Ozark, Missouri, May 21-25, p. 64-65.

Poggiagliomi, E. and R.D. Allred, 1994, Detailed reservoir definition by integration of well and 3D seismic data using space adaptive wavelet processing: The Leading Edge, vol. 13, No. 7, July, p. 749-754.

Pollard, D.D. and A. Aydin, 1988, Progress in understanding jointing over the past century: Geological Society of America Bulletin, vol. 100, p. 1181-1204.

Prensky, S.E., 1994, A survey of recent developments and emerging technology in well logging and rock characterization: The Log Analyst, vol. 35, No. 2, p. 15-45. 
Ramey, H.J., Jr., 1990, Advances in practical well test analysis: SPE 29592 65th Annual Technical Conference, New Orleans, Louisiana, September.

Raza, S.H., 1990, Data acquisition and analysis-foundational to efficient reservoir management: SPE 20749 65th Annual Technical Conference, New Orleans, Louisiana, September.

Robertson, J.D., 1991, Reservoir management using 3-D seismic data: in L.W. Lake, H.B. Carroll, and T.C. Wesson, eds., Reservoir Characterization II, Academic Press, San Diego, California, p. 340-354 of 726.

Schatzinger, R.A., M.J. Szpakiewicz, S.R. Jackson, M.M. Chang, B. Sharma, M.K. Tham, 1992, Integrated geological-engineering model of Patrick Draw field and examples of similarities and differences among various shoreline barrier systems: Department of Energy Report NIPER-575, April, 146 p.

Seni, S.J. and T.G. Walter, 1994, Geothermal and heavy-oil resources in Texas: The University of Texas at Austin, Bureau of Economic Geology, Department of Energy Report DOE/ID/10412-6, January, 52 p.

Sharma, B., M.M. Honarpour, M.J. Szpakiewicz, and R.A. Schatzinger, 1990, Critical heterogeneities in a barrier island deposit and their influence on various recovery processes: SPE Formation Evaluation, vol. 5, No. 1, March, p. 103-112.

Shirley, K., 1994, Yegua gives AVO a complex test: American Association of Petroleum Geologists Explorer, vol. 15, No. 4, April, p. 10-13.

Singdahlsen, D.S., 1993, Reservoir characterization and geostatistical modeling - The integration of geology into reservoir simulation; East Painter field, WY: in B. Linville, ed., Reservoir Characterization III, PennWell Publishing Company, Tulsa, Oklahoma, p. 973-982 of 1008.

Skopec, R.A., 1994, Proper coring and wellsite core handling procedures-the first step toward reliable core analysis: Journal of Petroleum Technology, vol. 46, No. 4, April, p. 280.

Smith, P.W., 1992, Factors controlling Simpson Group production in central Oklahoma, Part 1: The Shale Shaker, vol. 34, No. 2, January-February, p. 12-26.

Szpakiewicz, M.J., 1991, Identification of cross-formation flow in multireservoir systems using isotopic techniques: Department of Energy Report NIPER-538, 38 p.

Szpakiewicz, M.J., K. McGee, and B. Sharma, 1987, Geologic problems related to characterization of clastic reservoirs for EOR: SPE Formation Evaluation, vol. 2, No. 4, December, p. 449-460.

Szpakiewicz, M.J., R.A. Schatzinger, M.M. Honarpour, M.K. Tham, and R.W. Tillman, 1989, Geological and engineering evaluation of barrier island and valley fill lithotypes in Muddy formation, Bell Creek field, Montana: in E.B. Coalson, ed., Petrogenesis and Petrophysics of Selected Sandstone Reservoirs of the Rocky Mountains Region: Rocky Mountain Association of Geologists, Denver, Colorado, p. 159-182.

Taylor, G., 1994, Demand for 3-D boosts activity: American Association of Petroleum Geologists Explorer, vol. 15, No. 4, April, p. 1, 14, 15.

Thakur, G.C., 1990, Implementation of a reservoir management program: SPE 20748 65th Annual Technical Conference, New Orleans, Louisiana, September.

Thakur, G.C., 1991, Waterflood surveillance techniques-a reservoir management approach: Journal of Petroleum Technology, vol. 43, No. 10, October, p. 1180-1188.

Thomas, J.M.D. and R. Bibby, 1993, The depletion of the Rannoch-Etive sand unit in Brent Sands reservoirs in the North Sea: in B. Linville, ed., Reservoir Characterization III, PennWell Publishing Company, Tulsa, Oklahoma, p. 675-713 of 1008. 
Tomlinson, C.W. and W. McBee, Jr., 1988, Pennsylvanian sediments and orogenies of Ardmore District, Oklahoma: in Petroleum Geology of the Mid-Continent, Tulsa Geological Society Special Publication Number 3, p. 85-89.

Tomutsa, L., M.M. Chang, and S.R. Jackson, 1993, Application of outcrop data for characterizing reservoirs and deriving grid-block scale values for numerical simulation: in $B$. Linville, ed., Reservoir Characterization III, PennWell Publishing Company, Tulsa, Oklahoma, p. 151-194 of 1008.

United States Department of Energy, 1991, Opportunities to improve oil productivity in unstructured deltaic reservoirs-technical summary and proceedings of the technical symposium: DOE/BC-91/6/SP, 163 p.

Weber, K.J., 1986, How heterogeneity affects oil recovery: in L.W. Lake and H.B. Carroll, eds., Reservoir Characterization, Academic Press, Orlando, Florida, p. 487-544 of 659.

Wendt, W.A., S. Sakurai, and P.H. Nelson, 1986, Permeability from well logs using multiple regression: in L.W. Lake and H.B. Carroll, eds., Reservoir Characterization, Academic Press, Orlando, Florida, p. 181-221 of 659.

Wiggins, M.L. and R.A. Startzman, 1990, An approach to reservoir management: SPE 20747 65th Annual Technical Conference, New Orleans, Louisiana, September.

Worthington, P.F., 1991, Reservoir characterization at the mesoscopic scale: in L.W. Lake, H.B. Carroll, and T.C. Wesson, eds., Reservoir Characterization II, Academic Press, San Diego, California, p. 123-165 of 726.

Zaki, S. Abou Zeid and S.H. El Bishlawy, 1990, 3-D seismic interpretation in Jarn Yaphour field, Abu Dhabi: Journal of Petroleum Technology, vol. 42, No. 6, June, p. 700-707. 


\section{CHAPTER 4}

\section{IOR PROCESS AND RELATED RESEARCH NEEDS}

The purpose of this chapter is to define the IOR process and related research needs for which demonstration projects and technology transfer activities could help to increase the recovery of oil from Class 4 reservoirs. The research needs are defined in this chapter relative to the following areas: (1) infill drilling, (2) conformance control technologies, (3) polymers for mobility control, (4) microbial processes, (5) alkaline and alkaline-surfactant-polymer processes, (6) micellarsurfactant processes, (7) steam injection process, (8) in situ combustion process, (9) carbon dioxide injection processes, (10) numerical simulation and modeling, (11) wellbore and facilities, and (12) environmental issues. The advanced secondary recovery (ASR) sections (sections 4.1 through 4.3) and enhanced oil recovery sections (sections 4.4 through 4.9) define the research needs for each process through discussions of the relationship of the process to the Class 4 resource, process screening criteria, constraints limiting the application of the process, recent technology thrusts, and current research activity, including DOE supporting research and costshared projects with industry. The discussions of numerical simulation (section 4.10), wellbore and facilities (section 4.11), and environmental (section 4.12) issues are presented relevant to the implementation and operation of improved recovery processes. The identified research needs for these areas are summarized in Chapter 5.

\subsection{Infill Drilling}

Infill drilling has been a common practice in oil fields since the early days of the petroleum industry. It didn't take investors long to realize that more wells and faster withdrawal rates provided faster return on investment, yet the damage that overdrilling and overproduction practices often caused in terms of reduced ultimate recovery was not realized for years. The reduced productivity of wells resulting from overdrilling usually was the reason for curtailment of drilling activity in a field, as operators recognized points of diminishing returns. Many states (e.g., Texas) adopted spacing limitations to conserve the hydrocarbon resources and prevent over-drilling and overproduction practices. As waterflooding gained in popularity; the need for controlled injection and production rates was recognized and regular injection patterns became an important method to increase the efficiency of waterfloods. Often additional wells were drilled in waterfloods to install, align, or realign patterns in desired configurations, with adherence to spacing limitations, as required. With the development of enhanced oil recovery processes, operators drew upon the experience gained from waterflooding and began developing reservoirs on reduced spacing using defined patterns to improve process efficiency. The industry recognized early on that different reservoir conditions and process requirements resulted in different spacing requirements. It really wasn't until the 1980s that infill drilling began to be considered as a recovery process in and of itself, with significant potential for improving recovery. Since that time, numerous attempts have been made to quantify the potential for infill drilling in the country, beginning with van Everdingen and Kriss in 1980 up through the present work of the Interstate Oil and Gas Compact Commission and Department of Energy, as discussed in this section.

van Everdingen and Kriss (1980) suggested that infill drilling, if done properly, can be used to recover at least as much oil as the U.S. already has produced, or nearly 120 billion barrels. This unsubstantiated estimate was considered by many in the industry to be an overexaggeration of infill drilling potential. In 1980, Holm estimated that infill drilling in the country could add between 1 and 1.5 billion barrels of reserves per year for about 10 years and that recovery per well would be between 34,000 and 47,000 batrels of oil. Realistic analysis of infill drilling potential in west Texas carbonate fields was conducted by Driscoll (1974), Barber et al. (1983), and Ghauri (1980). This work, later compiled by Gould and Sarem (1989), indicated that recovery potential averaged about 107,000 barrels per infill well. This value is substantially higher than Holm's estimate, but is 
specific to the heterogeneous West Texas carbonates. In 1984, the National Petroleum Council study estimated that, at $\$ 20 /$ barrel oil price, the recovery potential for the expanded application of thermal, miscible, and chemical processes totals 7.4 billion barrels (NPC, 1984). Gould and Sarem (1989) stated that "infill drilling would appear to have potential equal to or greater than EOR processes."

In 1990, DOE funded a project conducted by ICF and the Texas Bureau of Economic Geology to develop a methodology for estimating the potential for the recovery of unrecovered mobile oil (UMO) in Texas, Oklahoma and New Mexico (ICF/BEG, 1990a, 1990b, 1990c, 1990d). This study estimated the recovery potential which could be obtained through the expanded application of infill drilling, profile modification, polymer flooding, and infill drilling in combination with profile modification and polymer flooding. This work indicated that the recovery potential for infill drilling in these states at $\$ 20 /$ barrel oil price was between 1 and 2 billion barrels (1 to $2 \%$ of the original oil in place) depending upon the level of understanding of reservoir heterogeneity. This potential increases to between 1.2 and 4.5 billion barrels if infill drilling is conducted in waterfloods in combination with polymer flooding and profile modification. This work was subsequently modified and expanded by the Interstate Oil and Gas Compact Commission (DOE funded) to estimate the infill drilling potential for the country (IOGCC, 1993). At $\$ 20 / \mathrm{barrel}$, the infill drilling potential in the country was estimated to be between 1.3 and 1.7 billion barrels, depending on the level of technology advancement. If infill drilling is conducted in combination with polymer applications, this potential increases to between 6.3 and 10.8 billion barrels.

In 1980, Holm (Holm, 1980) researched the idea of infill drilling versus tertiary oil recovery and listed the advantages and disadvantages of applying (1) infill drilling followed by a tertiary flooding process, or (2) applying infill drilling and tertiary or EOR processes simultaneously.

In the first approach (infill drilling followed by EOR process), Holm cited several advantages, including: (1) expense, (2) no delays for chemical acquisition or injection plant construction, and (3) closer-spaced, paid-for patterns would already be in place for eventual tertiary operations. On the other hand, this approach is faced by several disadvantages, such as: (1) the amount of oil left in patterns after the extended waterflooding will be less, thereby resulting in less oil recovered by tertiary process, since these processes become less efficient as the oil saturation approaches the critical capillary residual-oil saturation to water flow; (2) the infill drilling program may not be designed for optimum tertiary flooding; and (3) the infill drilling projects may produce less oil than required to keep the program economical, and thereby be unable to support the additional expenditures for tertiary recovery.

The second approach that Holm suggested is to conduct the infill drilling and tertiary or EOR process simultaneously. This approach could have many advantages: (1) more total oil reserves will be achieved, (2) total production or recovery elapsed time is decreased, (3) cost of the required wells can be shared, (4) early production of additional oil will occur, (5) higher oil saturation will be present in patterns at the start of the tertiary project, and (6) well patterns can be tailored to optimize both infill drilling and tertiary recovery. This approach is particularly advantageous for the chemical floods such as micellar, polymer, and surfactant because it provides new wells that can be designed to permit better distribution of injected chemicals, and faster and more efficient completion of the designated water preflush required for most projects than is possible with larger spacing.

Regardless of the actual estimates of potential of infill drilling or the application of infill drilling with waterflooding or tertiary recovery projects, it is apparent that infill drilling is a viable process for improving recovery from many oil reservoirs in the country. The key to the success of infill drilling is the understanding of the reservoir heterogeneities and complexities which limit recovery potential at current well spacing and the relationship of these complexities to recovery at reduced well spacing. 


\subsubsection{Relationship to the Class 4 Resource}

Infill drilling is an effective process for producing unrecovered mobile oil, mainly from reservoirs that are characterized as heterogeneous or discontinuous in nature. The estimated recovery potential for infill drilling in Class 4 reservoirs ranges between 120 and 289 million barrels, depending on the oil price and the level of technology advancement. More importantly, infill drilling in combination with polymer flooding and profile modification increases this potential to between 894 million and 1.8 billion barrels. Historical applications of infill drilling in Class 4 reservoirs include work in the Frio Play in Texas and the Deese reservoirs in Oklahoma.

\subsubsection{Infill Drilling in Texas Frio Reservoirs}

In 1990, the US DOE funded a research project to determine infill drilling potential and economic feasibility in the oil reservoirs of the Frio Strandplain Play (ICF/BEG, 1990d). Three infill drilling scenarios were studied: (1) playwide blanket infill drilling, (2) selective reservoirwide infill drilling, and (3) strategic or geologically targeted infill drilling.

Reserve addition potential from geologically targeted infill drilling considered the facies distributions in reservoirs and facies continuity functions. Facies distributions were estimated from net sand maps, cross sections, and type logs. Facies continuity functions were based on facies continuity observed in the 41-A reservoir in West Ranch Field, a major Frio strandplain/barrier island reservoir. Figure 4.1 illustrates facies continuity functions for the predominant facies (barrier core, back-barrier, and tidal inlet) and a combination of these facies. Facies with steeply declining curves require closer well spacing patterns to arrive at high pay-continuity values. The pay-continuity functions indicate that the back-barrier facies exhibits the greatest reservoir heterogeneity, the barrier core facies exhibit the least heterogeneity, with intermediate heterogeneity for the tidal inlet facies.

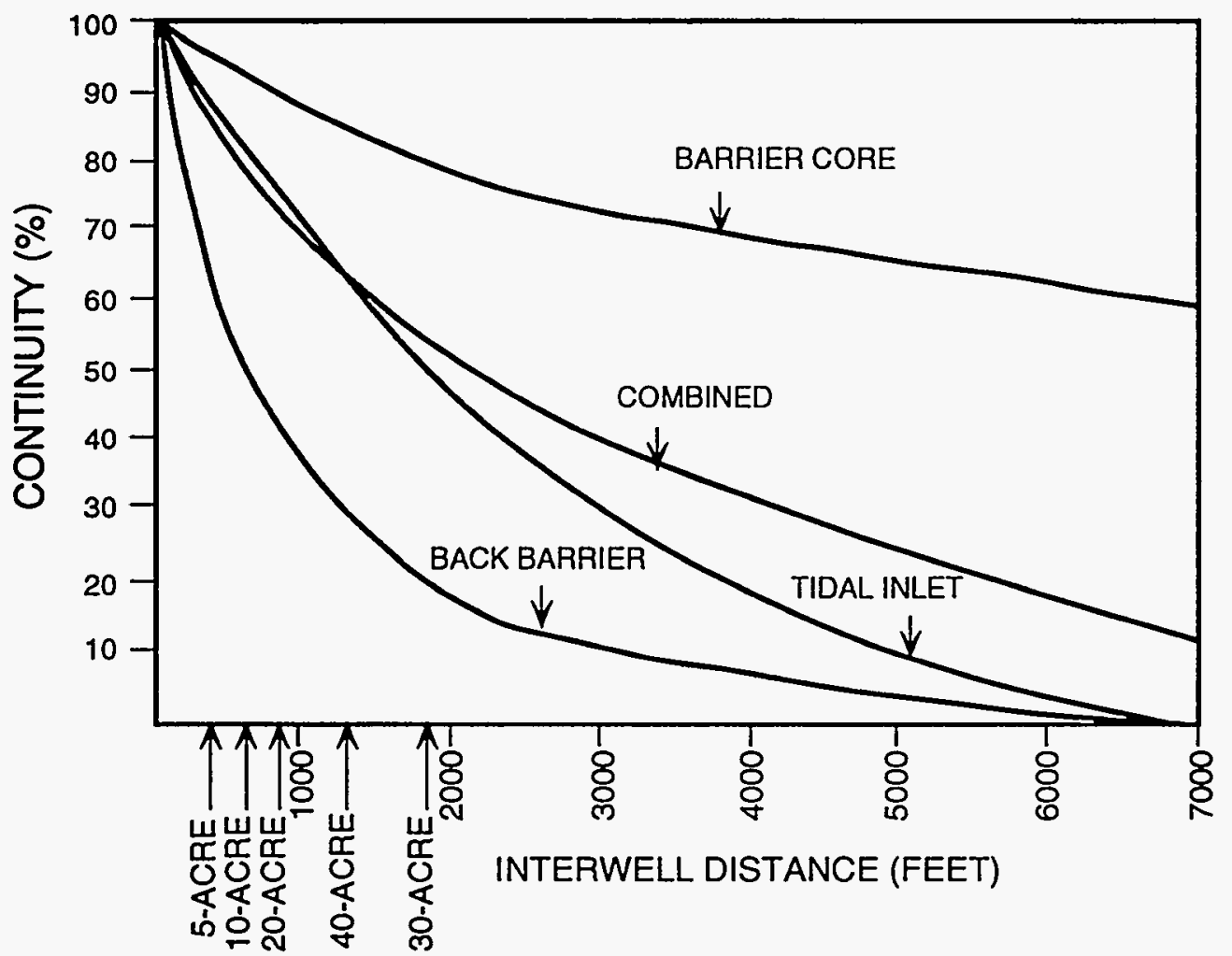

Figure 4.1 Pay Continuity Functions for Major Facies of the West Ranch Field 41-A Reservoir, a Class 4 Reservoir in the Texas Frio Play (Source: ICF and BEG, 1990d) 
Reserves from infill drilling were calculated as a function of oil price for the three drilling scenarios. Playwide incremental reserves are summarized in Table 4.1. In all cases, geologically targeted infill drilling recovers significantly more oil than blanket infill drilling. As oil price rises, incremental reserves from selective reservoirwide drilling approach those recovered with strategic infill drilling. However, even though incremental reserves are nearly the same, costs per barrel with geologically targeted infill drilling are about one-half those experienced with selective reservoirwide drilling.

\subsubsection{Infill Drilling in Oklahoma Deese Reservoirs}

The enhancement of oil production by infill drilling was tested in the Sho-Vel-Tum oil field in southern Oklahoma. After producing more than 1.3 billion bbl over almost 80 years, production from the field was declining rapidly. In the 1950s the production began declining. Waterflooding was introduced in 1955, stabilizing production rates until 1970s. In 1978, Mobil formed the Countyline Unit near the crest of one of Sho-Vel-Tum's northwest-southeast anticlinal structures (Kendall et al., 1992). Waterflood operations began in 1980, and production from Pennsylvanian Deese sands peaked in 1988 at 2400 BOPD. However, due to complex faulting, structural deformation, stratigraphic heterogeneity, and depleted gas caps, the ultimate oil recovery under this waterflood was estimated at $11.2 \%$. As a result, Mobil decided to launch an extensive multidisciplinary effort to better define the structure, characterize the reservoir, and determine the recovery potential of the field (Zambrano et al., 1992).

This multidisciplinary approach incorporated (1) 3-D seismic to define the reservoir structure and fault blocks and (2) implementing new geological interpretation software that provided integrated well-log correlation, cross-section generation, and mapping in a single application.

Reservoir characterization of the "flow units" present in each fault block was required to define the sand bodies' geometry, their continuity, and the reservoir's dip and fluid contacts. Finally, a black-oil reservoir simulator was used to history match the original waterflood performance, and to predict the reservoir performance using various well configurations and waterflood scenarios.

Redesign of waterflood pattern in the first three fault blocks, and the infill drilling of eight wells in the steep dip areas, has resulted in an increase in production from about 20 BOPD to approximately 400 BOPD of oil. In addition, the projected ultimate recovery has improved by at least $78 \%$. Furthermore, vertical sweep efficiency was improved by mechanically isolating the smaller reservoir units. Aerial efficiency was also improved by converting structurally lowproducing wells into injectors.

\begin{tabular}{|c|c|c|c|c|c|c|}
\hline স/ & 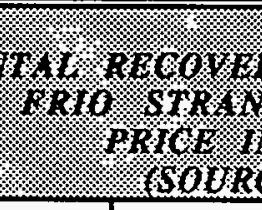 & 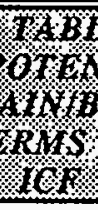 & \% & $\frac{16 \%}{10 \%}$ & $17 \%$ & 4. \\
\hline & $@$ & $\mathrm{BL}$ & & & $@$ & \\
\hline SCENARIO & MMB & $\mathrm{BCF}$ & MMB & $\mathrm{BCF}$ & MMB & $\mathrm{BCF}$ \\
\hline BLANKET PLAYWIDE & 90 & 50 & 120 & 65 & 130 & 75 \\
\hline $\begin{array}{l}\text { SELECTIVE } \\
\text { RESERVOIRWIDE }\end{array}$ & 115 & 60 & 190 & 100 & 240 & 125 \\
\hline $\begin{array}{l}\text { GEOLOGICALLY } \\
\text { TARGETED }\end{array}$ & 150 & 80 & 215 & 110 & 245 & 130 \\
\hline
\end{tabular}


A cost/benefit analysis conducted by Mobil revealed that it took only two months of production to repay Mobil's investment in the new interactive workstations and software that were used in the 3-D seismic interpretation and reservoir characterization which proved to be vital to the project's success.

\subsubsection{Recent Technology Thrusts}

The major thrust of research activity related to infill drilling has focused on defining and understanding the mechanisms which impact recovery from infill drilling projects. In 1974, Driscoll defined the factors which control the improved recovery of infill drilling in pattern waterfloods. These factors, in order of importance, include: (1) improved reservoir continuity, (2) improved areal sweep, (3) improved vertical sweep, (4) recovery of wedge-edge oil, and (5) improved economic limit. These factors also impact infill drilling in enhanced oil recovery projects. The development of continuity concepts and the impacts of infill drilling on areal and vertical sweep are discussed below (Gould and Sarem, 1989; DOE, 1994).

\subsubsection{Development of Interwell Continuity Concepts}

The concept of reservoir pay continuity has been developed beginning in the 1970 s to define areal heterogeneities in reservoirs by defining the percentage of reservoir pay which can be contacted as well spacing or interwell distance is reduced. These continuity functions are generated through detailed well log correlation for wells at various spacings in project areas or reservoirs. The typical display of continuity is a coordinate plot of the percentage of continuous net pay versus interwell distance. As interwell distance is reduced, a higher percentage of net pay is contacted (see Figure 4.1). These relationships are not widely reported in the literature, but they have been developed primarily for highly stratified West Texas carbonate reservoirs. Realized improvement in continuity is considered to be the primary recovery improvement mechanism associated with infill drilling and has resulted in higher than expected recovery from infill wells in the projects discussed below (ICF, 1991).

The first published continuity relationship was generated for the Wasson Denver Unit in Texas to support Shell Oil Company allowable hearings with the Texas Railroad Commission to illustrate that reduction in well spacing could increase ultimate recovery (Driscoll, 1974). Early geologic correlation work in the field revealed that the numerous definable pay stringers were not necessarily continuous over the entire field, giving rise to the concept of "continuous" and "discontinuous" pay (Ghauri et al., 1974).

The best definition of continuity was given by Stiles (1976): "Continuous pay is defined as the volume of porous rock that is connected between any two wells. The fraction of pay continuity between two wells is then the ratio of the continuous porous rock volume to the total porous rock volume." This concept is shown graphically in Figure 4.2. In this work, Stiles defined continuity relationships for the Fullerton Clearfork Unit, Texas. Using this methodology, Esso developed an innovative, computerized geologic modeling technique to draw and analyze cross sections using hundreds of wells in order to define the continuity in the Judy Creek Field, Canada (Delaney, 1982). Stiles methodology was also utilized in later work in the Wentz (Clearfork) Field, Texas, to justify a marginal waterflood project (Hunter, 1990).

Subsequent work by George and Stiles (1978) in the Means San Andres Unit, Texas, gave rise to the concept of floodable pay continuity. This work indicated that, although pay zones may be continuous between well pairs, the zones may not be entirely floodable due to irregularities in bed geometry, ineffective well completions, or lack of injection support. Work by Exxon in the Robertson Clearfork Unit, Texas utilized geological correlations, pressure transient analysis, and numerical analysis of infill results to define both floodable and drainable continuity relationships as shown in Figure 4.3 (Barbe and Schnoebelen, 1987). The floodable pay continuity relationships derived for Robertson Clearfork Unit were extended by ICF and BEG (1990c) to estimate the potential for targeted and blanket infill drilling in the entire Clearfork carbonate play in the Permian 
Basin. ICF and BEG developed modified floodable and drainable pay continuity relationships for the Grayburg/San Andres reservoir in the Dune Field, Texas, taking into account the loss in reservoir quality between well pairs. This work was used to define the infill drilling potential for the Grayburg/San Andres play in the Permian Basin (ICF/BEG, 1990b).

Recently, developments in the area of geostatistics have resulted in more advanced methods of characterizing and predicting interwell permeability and porosity trends using stochastic methods (Lucia and Fogg, 1989). The use of the results from the geostatistical approaches in reservoir simulations have adequately matched infill drilling performance in highly stratified carbonate fields.

In related work to reservoir continuity, Texas A\&M University conducted a study on Hydraulic Interwell Connectivity (HIC) Concept based on reservoir characterization, geostatistics, production performance, and reservoir engineering (Malik et al., 1993). HIC is quantitatively defined as the ratio of observed fluid flow rate to a maximum ideal or possible flow rate between any combination of two wells in the producing unit. This approach was used as a guide for selecting infill well locations to optimize waterflood infill drilling. As a result of the simulation study, three production wells were realigned according to HIC distribution, which resulted in an additional $10 \%$ of waterflood oil recovery.

The approach outlined in the Texas A\&M study is based on geologic and engineering study of a highly stratified carbonate reservoir in the Johnson Field, Texas. The study involved the development of porosity and permeability correlations and the use of experimental semivariograms to define permeability trends between wells. A linear mathematical model was then utilized to calculate the HIC for each pair of wells in the study area. A three-dimensional distribution of HIC provided a better understanding of reservoir compartmentalization and interwell connectivity. It was determined that a steep HIC distribution represents a poor interwell connectivity.

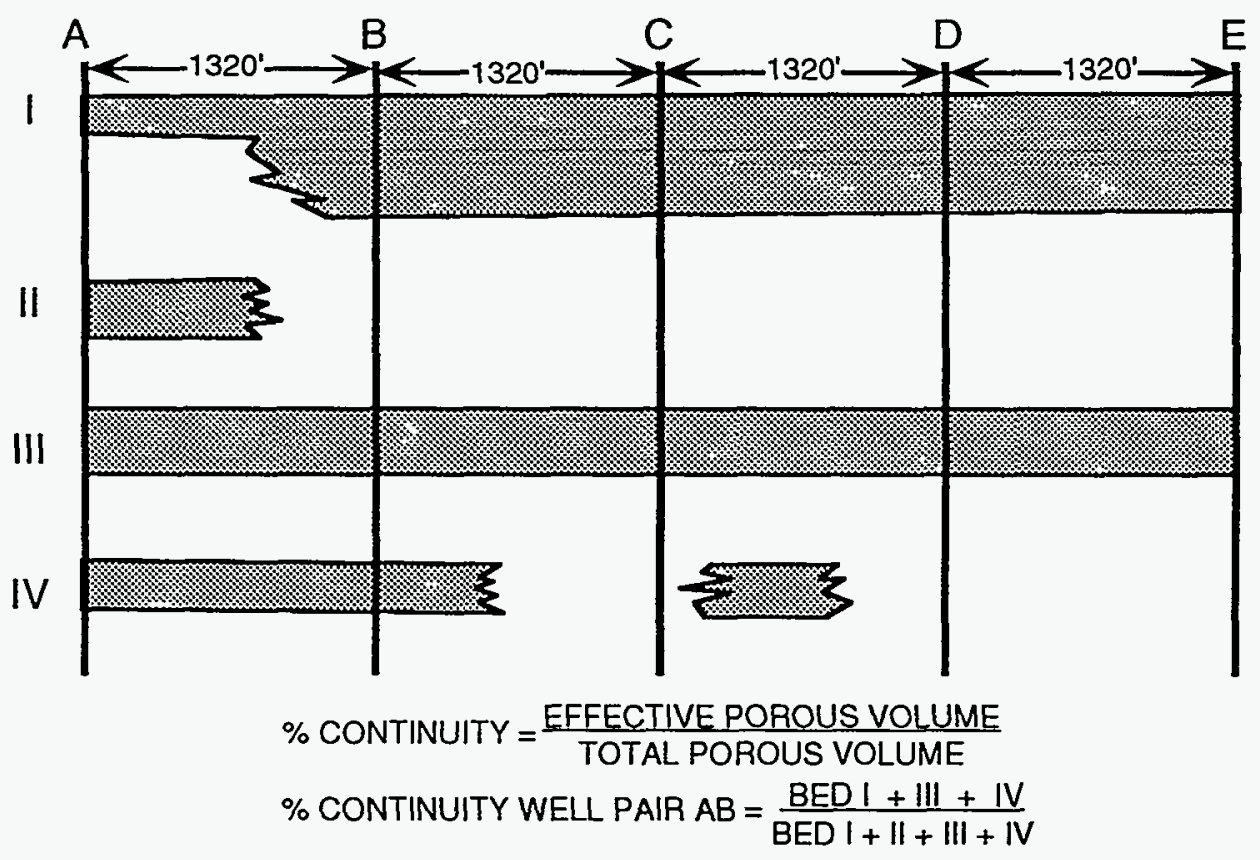

Figure 4.2 Schematic Illustration-Continuity Functions (After: Stiles, 1976) 


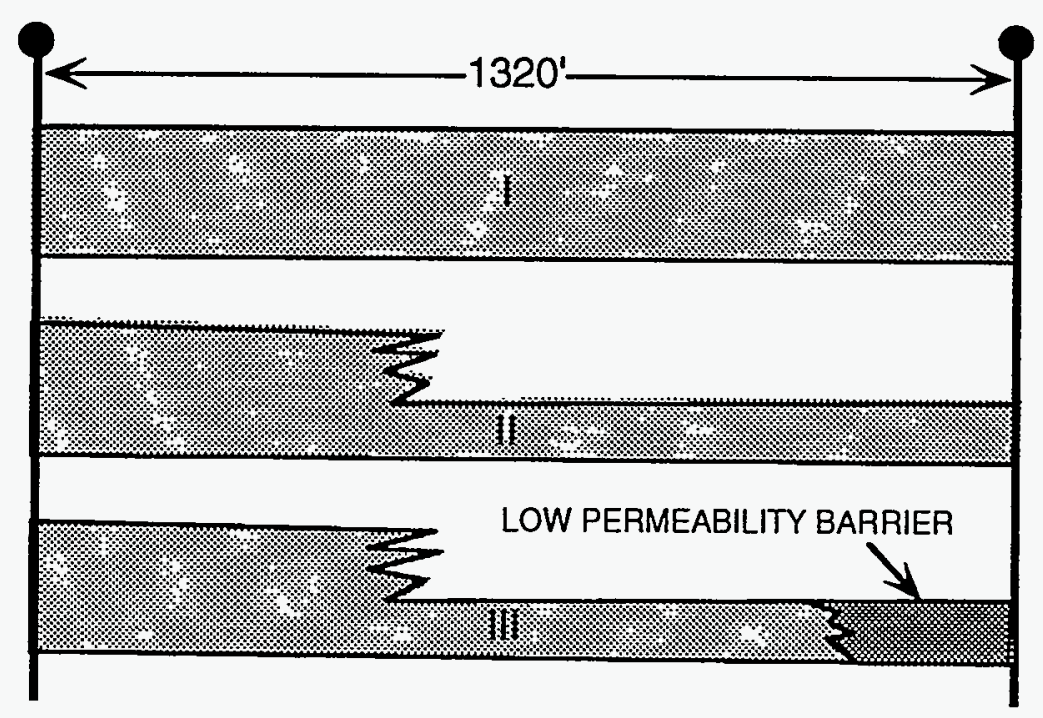

SUMMARY

BED I - $100 \%$ DRAINABLE AND FLOODABLE CONTINUITY

BED II - 100\% DRAINABLE CONTINUITY; PARTIAL FLOODABLE CONTINUITY

BED III - 100\% DRAINABLE CONTINUITY; 0\% FLOODABLE CONTINUITY

Figure 4.3 Illustration of Drainable versus Floodable Continuity (Source: Biglarbigi et al., 1994)

\subsubsection{Effects Of Infill Drilling on Areal and Vertical Sweep Efficiency}

Areal and vertical sweep efficiency improvements result from infill drilling due to the contacting of previously unswept portions of the reservoir. When patterns in a waterflood are modified through infill drilling, the original streamlines are often reversed resulting in the sweeping of unswept areas with higher oil saturations. These effects have been defined, along with the effects of oil-water viscosity ratio and permeability anisotropy, through detailed simulation studies (Gould and Munoz, 1982). This work indicated that the amount of incremental recovery due to improved areal sweep depends on (1) the degree of areal heterogeneity or anisotropy, (2) the water cut at the economic limit, (3) the water cut at the time of infill drilling, and (4) the mobility ratio. Areal sweep improvements are similarly realized in enhanced oil recovery projects.

Improved vertical sweep efficiency can be realized through infill drilling projects, because new injection or production wells are added and old wells are recompleted, providing an opportunity to mechanically isolate previously swept or thief zones. The efficiency of the isolation is dependent upon the degree of cross flow between new zones and the isolated zones (Gould and Sarem, 1989). The improved vertical sweep is usually expressed relative to the Dykstra-Parsons coefficient, $V_{d p}$, which is, in turn, an expression of the vertical distribution of permeability among the layers of a reservoir. Heterogeneous reservoirs (high $V_{\mathrm{dp}}$ ) benefit the most from mechanical isolation to improve vertical sweep.

Recovery of wedge or edge oil volumes can be achieved through infill drilling by reduction of pattern size and installation of additional patterns to effectively flood unswept segments of the reservoir. Uncontacted oil volumes near the oil-water contact, on the flanks of reservoirs, or near stratigraphic features are often the target of infill drilling programs. 


\subsubsection{Current Research Related To Infill Drilling}

Several of the industry cost-shared projects with the Department of Energy have focused on infill drilling to improve recovery. These projects are discussed below.

In an effort to maximize the economic producibility of resources from the Frio fluvial-deltaic reservoirs of South Texas, DOE awarded the University of Texas Bureau of Economic Geology (BEG) a contract in 1992 with an anticipated completion date in December 1994. The objective of this effort is the implementation of advanced reservoir characterization techniques to define untapped, incompletely drained, and new-pool reservoirs for near-term recovery methods. The project will develop inter-well geologic facies models of Frio fluvial-deltaic reservoirs, similar to those developed for the Frio strandplain/barrier island reservoirs by ICF/BEG, as previously discussed. The developed facies models, when combined with engineering assessments, will assist in characterizing reservoir architecture, flow unit boundaries, and the controls that these characteristics exert on the location and volume of unrecovered mobile and residual oil. The results of these studies are designed to lead directly to identification of specific opportunities for incremental recovery by recompletion and strategic infill drilling of these reservoirs.

As part of the project, two field areas were selected for the study on the basis of preliminary assessments of additional reserve growth potential and the availability of abundant geologic and production data. These areas are the western portion of the Tijerina-Canales-Blucher (TCB) Field, located in Jim Wells County and operated by Mobil, and the Rincon Field, located in Starr County and operated by Conoco. Initial reservoir characterization efforts will be tailored to geologic and engineering data analysis, leading to geologic interpretations of the reservoirs and identification of compartmentalized reservoirs in order to quantify the reserve growth potential.

Another research effort demonstrating the effectiveness of geologically targeted infill drilling is being conducted by Diversified Operating Company and funded by DOE. This research effort will focus on infill drilling and improved reservoir management to maximize recovery from the $D$ sandstone reservoir of the Sooner Unit Field in Weld County, Colorado, using water injection and gas recycling as secondary methods. Phase I of the project involves well site selection and development of a reservoir operations plan. Phase II involves drilling three geologically targeted infill wells and establishing production and injection schedules. Reservoir simulation, transient well tests, and production monitoring will be used to evaluate the results. Phase II of the project involves technology transfer efforts.

A detailed geologic data analysis and interpretation of vertical Seismic Profile (VSP) and 3-D seismic data revealed that there are several promising locations for infill drilling. Furthermore, production and pressure histories have identified a total of seven reservoir compartments. These operational or production compartments consist of one to four wells. The anticipated date of completion for this project is March 31, 1995.

\subsubsection{Research Needs}

Significant potential exists for the recovery of additional oil from Class 4 reservoirs through the implementation of infill drilling projects. Infill drilling can be applied to improve recovery as a stand alone process or in conjunction with other improved oil recovery processes. The key to the success of infill drilling is identifying the reservoir heterogeneities and complexities which limit 
recovery potential at current well spacing and understanding the relationship of these complexities to recovery at reduced well spacing. The research needs specific to infill drilling include the following:

- Development and demonstration of improved methods for assessing and predicting the recovery potential for infill drilling through definition of interwell continuity and sweep efficiency improvements which can be attained by infill drilling. The application of improved reservoir characterization methods for defining these improvements is a key research need which could impact the oil recovery potential for infill drilling.

- Development and demonstration of improved methods for predicting reservoir characteristics between existing wells using geostatistical methodologies. The prediction of porosity, permeability, and fluid saturations between known datapoints is a significant research need for defining reservoir continuity and sweep efficiency and for the determination of infill drilling potential.

\subsection{Conformance Control Technologies}

Conformance control technologies address unrecovered mobile oil (UMO) potential. In the proper application environment, field experience indicates that the technologies are applicable at moderate oil price levels. Topics covered in this section include the relationship of conformance control technologies to the Class 4 oil resource, screening criteria, well selection and treatment criteria, constraints, recent technology thrusts, Class 4 field activity, and current research directions. A discussion of research needs for conformance control applications completes this section.

\subsubsection{Relationship to the Class 4 Oil Resource}

The TORIS analysis of future oil recovery potential (see Chapter 2) indicates that profile modification or conformance control technologies, particularly in combination with infill drilling, are applicable to the Class 4 oil resource. As technology moves from the implemented to the advanced level, the potential contribution from the infill drilling and profile modification combination increases in importance. Historical contributions from conformance control technologies in Oklahoma and Rocky Mountain reservoirs lend credence to future potential estimates made using the TORIS methodology. Potential combination applications with $\mathrm{CO}_{2}$ or surfactant processes, which become important at higher oil prices and advanced technology levels, can also be foreseen. Although conformance control technologies will not exhibit high recovery efficiencies like miscible $\mathrm{CO}_{2}$ or surfactant processes can, the technologies will have their niche in recovering additional amounts of the Class 4 oil resource.

Impact of conformance control technologies in Class 4 reservoirs listed in the TORIS database varies by geographic region. Gel systems using biopolymers have significantly impacted IOR production in Southern Oklahoma's Desmoinesian (Pennsylvanian) and Missourian Plays (NIPER/BDM, 1994a). Higher formation water salinity levels in these reservoirs direct most applications to biopolymers. Polyacrylamide-based gel polymers have been widely applied in the Rocky Mountain region where salinity levels are generally lower. Conformance control applications in Texas and California Class 4 reservoirs are not noted in the technical literature. 


\subsubsection{Screening, Well Selection and Treatment Criteria}

The screening criteria for the implemented and advanced technologies are summarized in Table 4.2. Screening criteria primarily determine which reservoirs are not candidates. Gel polymer applications must go beyond screening criteria to candidate selection criteria, treatment design considerations, and application procedures.

In a survey of major oil companies and gel vendors, Seright and Liang (1994) found that producing water-oil ratio was usually the only criterion used to select individual wells. Through their analysis of field data and discussions with major oil companies and gel vendors, Seright and Liang developed more comprehensive candidate selection criteria for both injection and production wells (Tables 4.3 and 4.4). Besides producing water-oil ratio, these criteria emphasize defining the problem, defining the target mobile oil, considering injectivity and productivity, and, in the case of injection wells, evaluating the mechanical condition of the candidate wells. While industry accepts problem definition as being essential, it often receives inadequate attention in actual practice.

Having selected an appropriate candidate well, the gel polymer treatment must be matched to the well and problem. Decisions must be made whether to use near-wellbore or in-depth treatments, and which of the available systems to use. Once appropriate gel system(s) are selected, the treatment must be tailored to the individual well and reservoir conditions. Treatment size, gel time, and gel strength are important variables which must be properly assessed to ensure success.

Despite the importance of sizing, treatment sizing remains more art than science. Seright and Liang (1994) document the sizing guidelines used by various vendors and major oil companies for both injection and production well treatments. Their analysis suggests different sizing guidelines for different reservoir problems (individual fractures, network of fractures, high permeability strata

\begin{tabular}{|c|c|c|}
\hline PROPIIT) & 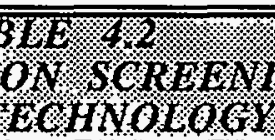 & 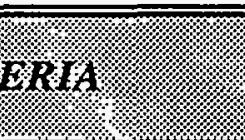 \\
\hline Parameter & $\begin{array}{l}\text { Implemented } \\
\text { Technology }\end{array}$ & $\begin{array}{c}\text { Advanced } \\
\text { Technology }\end{array}$ \\
\hline Reservoir Temperature, ${ }^{\circ} \mathrm{F}$ & $<180$ & $<250$ \\
\hline Brine Salinity, ppm & $<100,000$ & $<200,000$ \\
\hline Permeability, $\mathrm{mD}$ & $>20$ & $>10$ \\
\hline Oil Viscosity, cP & $<100$ & $<150$ \\
\hline
\end{tabular}




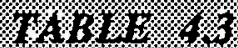

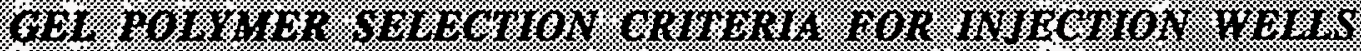

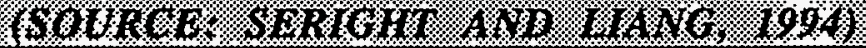

1. Reservoir and production data indicate low sweep efficiency during waterflooding.

a. Water breakthrough occurs much earlier than expected (i.e., from standard calculations or simulations or from comparison with the performance of other patterns in the field).

b. Water-oil ratio (WOR) values at offset producers are much higher than expected.

c. Recovery calculations indicate that considerable mobile oil remains that could be recovered more cost-effectively if a blocking agent could be realistically placed in the proper location.

2. If barriers to crossflow do not exist, then interwell tracers must show very rapid transit times (probably indicating that fractures or formation parting cause the channeling problem).

3. In unfractured wells,

a. Poor injection profiles must be correlatable from well to well.

b. Effective barriers to crossflow must exist (very low $k_{\mathrm{v}} / \mathrm{k}_{\mathrm{h}}$, no flow behind pipe, no vertical fractures).

c. Gel can be placed in the offending channel without damaging oil zones (e.g., using zone isolation).

4. Reduced injectivity (caused by the gel) can be tolerated.

5. The well to be treated is in good mechanical condition.

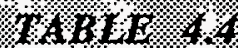

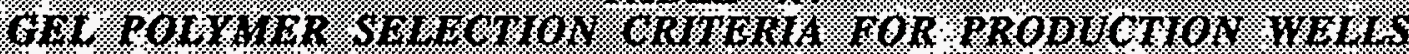

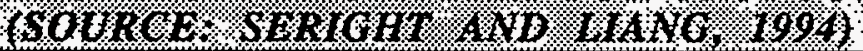

1. Recovery calculations indicate that considerable mobile oil remains that could be recovered more cost-effectively if a blocking agent could be realistically placed in the proper location.

2. High water-oil ratio (WOR) values are observed.

3. The source of the excess water production is identified (e.g., using profiles, logs, or tracers).

4. The candidate well exhibits high productivity.

5. The gelant can be placed without damaging oil zones (e.g., using zone isolation). 
separated from oil-productive zones by nonpermeable strata, strata with crossflow, flow behind pipe). Seright and Liang (1994) considered sizing guidelines/approaches to be an important research need.

Application practices heavily influence treatment success rates. Important application considerations include properly designed equipment, pretreatment wellbore preparation, compatibility testing with well-site fluids, and "during treatment" adjustments in concentration and rate in response to injectivity changes as the treatment proceeds (Mody, 1992). Treatment adjustments as the treatment is being performed adapt planned procedures to unique well conditions.

\subsubsection{Constraints}

Dauben (1991) analyzed field projects to determine those parameters which limited success in field applications of gel polymers. He concluded that, like polymers, gel polymer applications are constrained by polymer degradation, instability when temperature and/or salinity limits are exceeded, and, in the case of sequentially injected polymer and crosslinking agents, polymer propagation. Additional identified constraints specific to gel polymers included (1) identifying appropriate reservoir or well candidates, (2) gel placement techniques, and (3) improved definition of design parameters affecting treatment success.

A major constraint in gel polymer applications is the uncertainty in treatment results. Mody et al. (1988) reported success rates of less than 50\%. Petroleum Engineer International also reported technical and economic success rates less than $50 \%$ in a 1992 survey (PEI, 1992). Vendors generally claim higher success rates, often in the $75 \%$ to $90 \%$ range (Seright, 1993). In Seright's survey (1993) of major oil companies, technical and economic success rates between the extremes were reported. Success rates reported by various companies for producing-well and injection-well treatments are summarized in Tables 4.5 and 4.6.

Risk or uncertainty can be controlled by (1) careful problem definition (i.e., candidate selection), (2) matching gel system to the problem, (3) designing and sizing the gel treatment, and (4) field application techniques. For injection-well treatments, tracer studies are important in identifying communication problems. Seright's survey found, that while experts felt tracers should be used in $80 \%$ of the applications, tracer studies were performed in less than half of the injectionwell treatments (Seright and Liang, 1994).

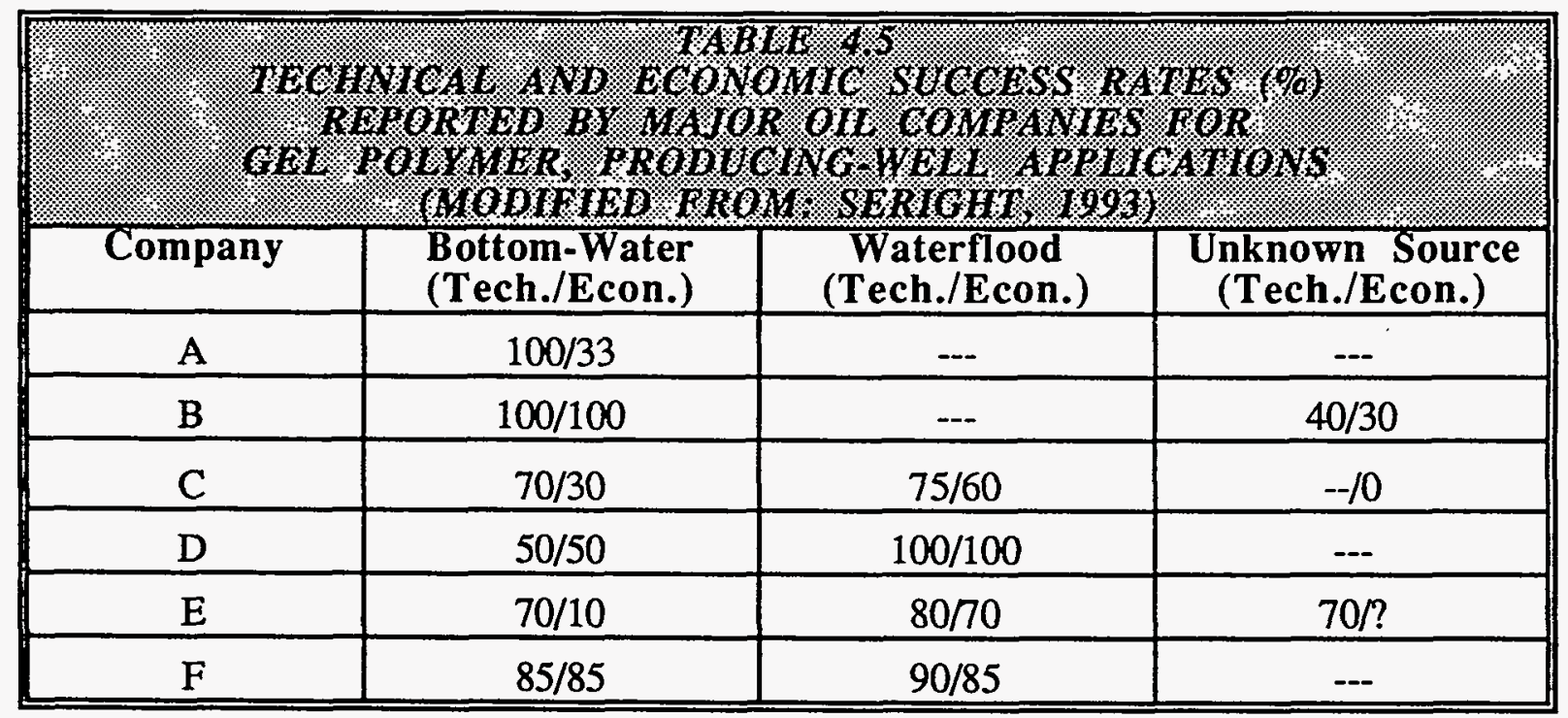




\begin{tabular}{|c|c|c|}
\hline 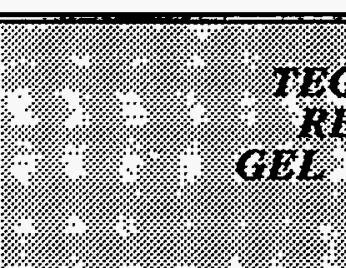 & 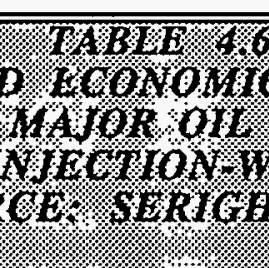 & 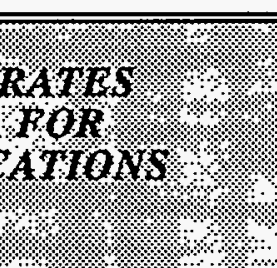 \\
\hline Company & $\begin{array}{c}\text { Technical } \\
\text { Success Rate }\end{array}$ & $\begin{array}{c}\text { Economic } \\
\text { Success Rate }\end{array}$ \\
\hline C & 70 & 35 \\
\hline D & 50 & 50 \\
\hline E & 80 & 50 \\
\hline F & 90 & 85 \\
\hline
\end{tabular}

\subsubsection{Recent Technology Thrusts}

Recent technology thrusts have been process and mechanistic studies, development of alternative systems and methods, and documentation of field results leading to field application guidelines. Process and mechanistic studies have focused on modeling and simulator development. Development work associated with alternative systems focuses on expanding application environments, reducing costs, and reducing environmental hazards. Several systems under development employ mechanisms other than polymer crosslinking. Field data analysis focuses on learning from both failures and successes and on developing application guidelines.

\subsubsection{Process and Mechanistic Studies}

NIPER developed a three-phase permeability modification simulator to assist in mechanistic evaluation of the gel polymer process and to facilitate the design and assessment of potential reservoirs for permeability modification treatments. This model has been used to explore the effects of various parameters including treatment timing, degree of crossflow, permeability, and permeability contrast on oil recovery in waterfloods and polymer floods (Gao and Chang, 1990; Gao et al., 1990, Gao, 1991a; Gao, 1991b; Gao and Burchfield, 1993; Gao et al., 1993).

Conclusions (Deterding et al., 1993) based on these studies include: (1) in reservoirs with low crossflow, gel treatments in both injection and production wells result in an improvement in incremental oil recovery and cash flow over that of treating only injection wells; (2) gel treatments are less effective in reservoirs with high crossflow; (3) polymer flooding initially shows a greater increase in incremental oil production than does the gel treatment, but in reservoirs with low crossflow, the gel treatment eventually produces more incremental oil; and (4) in reservoirs with low crossflow, combined near-wellbore gel treatment with a polymer flood is more effective than either a polymer flood alone, a deep gel treatment, or a deep gel treatment combined with a polymer flood.

\subsubsection{Alternative Systems and Methods}

Alternative systems and methods for conformance control include: (1) higher temperature and salinity systems, (2) the Marathon process (chromium [II] carboxylate gel), (3) the Phillips process (chromium [II] propionate gel), (4) brine- and ph-initiated gels, and (5) the surfactantalcohol system. Details of these alternative approaches are presented in the following section. 


\section{Higher Temperature and Salinity Systems}

Hostile environmental conditions have been defined as temperatures greater than $167^{\circ} \mathrm{F}$ with brine hardness (divalent ion) levels above 2,000 ppm (Moradi-Araghi, 1994). Although temperature conditions in most Class 4 reservoirs are less severe, research efforts to develop polymers (and gel polymers) with higher temperature limits are applicable to the Class 4 oil resource. Polymer stability, whether in a mobility control flood or gel polymer application, can be affected by temperature, salinity, and hardness levels. Temperature limits for hydrolyzed polyacrylamides (HPAM) range from $167^{\circ} \mathrm{F}$ when total hardness is greater than $2,000 \mathrm{ppm}$ to $200^{\circ}$ $\mathrm{F}$ when total hardness is $400 \mathrm{ppm}$ (Gao, 1987). Ryles (1988) considered the temperature limit to be even lower, around $160^{\circ} \mathrm{F}$ if brines contained more than $200 \mathrm{ppm} \mathrm{Ca}^{+2}$.

Temperature limit estimates for Xanthan biopolymers range from about $160^{\circ} \mathrm{F}$ (Ryles, 1988) to $200^{\circ} \mathrm{F}$ (Doe et al., 1987; Needham and Doe, 1987). Xanthan temperature limits can vary significantly depending on the biopolymer source. Xanthan temperatire limits are relatively insensitive to salinity or hardness variations. A different class of biopolymers, scleroglucan, exhibits higher temperature limits due to its triple-helix structure. Kalpakci et al. (1990) suggest that scleroglucan may be used at temperatures up to $220^{\circ} \mathrm{F}$.

Doe et al. (1987) evaluated copolymers of vinylpyrrolidone (VP) and acrylamide (AM) and found them stable in seawater at temperatures up to $250^{\circ} \mathrm{F}$. It was noted that improvements in molecular weight were needed to improve field economics. Needham and Doe (1987) noted that most advanced polymers might be of questionable utility in today's (1987) economic situation.

\section{The Marathon Process (Chromium [III] Carboxylate Gel Technology)}

Marathon developed an acrylamide polymer/chromium (III) carboxylate gel system (MARCIT system) using a chromium acetate (nontoxic) rather than toxic hexavalent chromium system. The gel system is a single-fluid system avoiding sequential slug injections used in some processes. Gel properties can be easily tailored by varying chemical concentrations (Sydansk and Moore, 1992). Gels can be formulated for temperatures up to $255^{\circ} \mathrm{F}$, $\mathrm{pH}$ values in the 4 to 12.5 range, and they are tolerant of high salinities and $\mathrm{H}_{2} \mathrm{~S}$ (Sydansk, 1988). If required, gels can be degraded with chemicals like hydrogen peroxide or sodium hyperchlorite (Sydansk, 1988). The system is primarily intended for naturally fractured reservoirs or single porosity reservoirs with vugs or high permeability channels (Southwell and Posey, 1994).

\section{The Phillips Process (Chromium [III] Propionate Gel Technology)}

Because the crosslinking systems of most gel systems are incompatible or unstable in hard brines, gel polymer applications can be constrained. In the laboratory, Phillips Petroleum has evaluated a chromium [III] propionate crosslinking system for use in hard brines. This gel system, which does not require fresh water, exhibited good stability in brines with hardness levels up to $14,000 \mathrm{ppm}$ (Mumallah, 1988). The system is applicable for both near-well and in-depth treatments. Although chromium propionate is not available on a commercial scale, screening economics indicate roughly comparable costs with conventional gel systems. Data from field applications were not reported.

\section{Chromium [III] Malonate Gel Technology}

With conventional gel systems, in-depth treatments in high temperature reservoirs are constrained by the ability to control when gelation occurs. Lockhart and Albinoco (1992) describe a chromium [III] malonate gel system which provides longer delays at high temperatures $\left(194^{\circ} \mathrm{F}\right.$ to $275^{\circ} \mathrm{F}$ ). Laboratory data indicate gelation times can be delayed more than an order of magnitude longer and that gelation times are easily controlled and predictable. Data indicate that $\mathrm{pH}$ has a complex influence on the gelation rate. Field applications of the system were not reported by Lockhart and Albacino. 


\section{Colloidal Dispersion Gels for In-Depth Diversion}

In-depth fluid diversion treatments have historically relied upon in situ crosslinking with one approach being to sequentially inject slugs of polymer and aluminum citrate, the crosslinking agent. Alternatively, weak gels can be formed prior to injection using low polymer and crosslinker concentrations creating a colloidal dispersion gel. Since gels are formed prior to injection, the process provides greater flexibility than in situ crosslinking. Gel stability has been proven at temperatures to $200^{\circ} \mathrm{F}$ (Mack and Smith, 1994). Injection water salinity is limited to 30,000 ppm total dissolved solids. Identified future research needs for this system (Mack and Smith, 1994) include addressing temperature and salinity limitations and forming stronger gels.

\section{Crosslinking System for Powdered, Xanthan Biopolymer}

Xanthan biopolymer crosslinking treatments typically use Xanthan broth. Powdered Xanthan biopolymers, which reduce transportation costs and field storage problems, are an option for reducing the cost of crosslinked polymer treatments using Xanthan biopolymer. Cost reductions result from using $100 \%$ powdered Xanthan biopolymer versus typical 5\% broths and from easier storage and handling. French et al. (1988) investigated polymer and crosslinker (chromium [III]) concentrations for surface-prepared and in situ gels. Polymer concentrations of 1,400 to 2,000 were recommended, while recommended chromium [III] concentrations were 5 to 25 ppm for surface-prepared gels and 10 to $25 \mathrm{ppm}$ for in situ gels. Injectability of surface-prepared gels was found to be dependent on the shear history of the gels.

\section{Precipitation Methods}

Alcohol-induced salt precipitation methods are being explored for profile modification treatments. Permeability in higher permeability, water-saturated zones is reduced by salt precipitates formed as alcohol and concentrated brine slugs mix in the reservoir. Zhu and Raible (1994) evaluated the process in laboratory corefloods. Their results indicated a $60 \%$ increase in oil recovery above that experienced with waterflooding. Permeability reductions with salt were resistant to subsequent water injection with only 5 to $10 \%$ of original permeability being recovered after several pore volumes of $5 \% \mathrm{NaCl}$ injection. Potential advantages of the salt precipitation process include (1) decreased viscous crossflow effects, (2) selective placement in higher permeability thief zones, and (3) $\mathrm{pH}$-independence of the precipitation process. The $\mathrm{pH}$ independence is of particular importance when using the gel system in $\mathrm{CO}_{2}$ flooding applications.

A thermal precipitation method is also being evaluated for conformance control (Acock and Reis, 1994). The thermal precipitation method consists of preheating the near-wellbore region with hot water or steam, injecting a hot, saturated chemical solution, and, as cooling occurs, precipitation occurs due to reduced solubility. A primary, potential advantage of this system is that identified chemicals (including potassium carbonate and sodium carbonate) do not have the environmental hazards associated with conventional chromium redox gel polymer systems.

\section{Brine-Initiated Gels}

An alternative gel system, which does not rely on crosslinkers and whose formation is independent of $\mathrm{pH}$, is a brine-initiated gel system. The gel forms in situ when a freshwater solution of a water soluble polymer (hydroxypropyl cellulose) and a surfactant (sodium dodecyl sulfate) mix with brine. Whittington et al. (1994) reported $95 \%$ permeability reductions in both linear and radial corefloods using this system. Laboratory evaluation indicated that (1) the gel was resistant to subsequent brine flushing and (2) adverse divalent ion effects could be counteracted with cosurfactants. However, Raible and Zhu (1992) evaluated the system in sandpacks and expressed concern about gel placement and long-term resistance of the formed gel to subsequent brine injection. 


\section{pH-Initiated Gels}

$\mathrm{pH}$-initiated gels are being evaluated for conformance control applications. The Unocal process of using the aluminate ion as a source of aluminum consists of injecting the pregel at $\mathrm{pH} 10$, then depending on alkali consumption to reduce $\mathrm{pH}$ below about 9.6. At that point, the aluminum is activated as a crosslinking agent (Dovan and Hutchins, 1987).

The University of Kansas has developed an aqueous polysaccharide polymer that can be injected in strong alkali and set by injecting alternating slugs of strong acid (Vossoughi and Buller, 1989). KU's biopolymer gelation process depends on polymer solubility as a function of $\mathrm{pH}$ rather than crosslinking. Laboratory data in sandpacks indicate a high degree of permeability reduction can be achieved, and the gel can be remobilized by raising the $\mathrm{pH}$ of the injected fluid (Vossoughi and Putz, 1991).

\section{Surfactant-Alcohol System}

Llave et al. (1990) are evaluating a surfactant-alcohol blend for achieving in-depth permeability modification. With this system, permeability modification results from normal chromatographic separation of the surfactant and alcohol components in the reservoir resulting in a viscous surfactant slug. Penetration depths can be controlled by varying component concentrations (Llave et al., 1990), and the slug can be remobilized by subsequent injection of alcohol slugs. Since the initial slug is relatively nonviscous, injectivity and formation damage problems during treatment are minimized.

The surfactant-alcohol system performed well in an initial pilot field test in the Stone Bluff field, Wagoner County, Oklahoma (Llave and Dobson, 1994). Waterflooding operations are characterized by poor sweep efficiency resulting from high permeability contrasts. A prior gel polymer program had been disappointing, because bottomhole samples indicated poor quality gels were formed. Shear degradation was suspected. Following extensive reservoir screening, a single injection well was treated with 500 barrels of a $2 \mathrm{wt} \%$ surfactant solution (one part surfactant: two parts alcohol). No injectivity problems were experienced. Posttreatment monitoring and analysis noted: (1) increased oil production, (2) reduced water production, (3) reduced water injectivity, (4) improved fluid injection profiles, and (5) increased tracer breakthrough time (Llave and Dobsen, 1994). Costs were comparable to conventional gelled-polymer applications.

\subsubsection{Field Results and Guidelines}

Industry is directing significant effort towards improved documentation of field results with gel polymer treatments and, based on field results, developing guidelines for candidate selection, treatment design, and application. This joint research and technology transfer effort improves operator confidence levels and should stimulate additional applications.

As part of their research effort in developing improved techniques for fluid diversion in oil recovery, the New Mexico Institute of Mining and Technology (Seright, 1993; Seright and Liang, 1994) surveyed both (1) the technical literature for injection and production well treatment results and (2) operators and vendors for their beliefs regarding various aspects of gel polymer treatments. Partial results are discussed in Sections 4.2.2 and 4.2.5.1. This effort represents an important step towards using field data and experience to develop more comprehensive treatment guidelines.

As part of a technology transfer grant, the University of Kansas (KU) developed a permeability modification demonstration project report (Schoeling et al., 1993). This report describes gel systems, applications technologies, and monitoring techniques in a simplified, down-to-earth manner for the independent's use. Field results with selected systems are also discussed. Additional field results from gel polymer applications in Kansas have been reported at KU's Tertiary Oil Recovery Project (TORP) conferences (Avery and Sutphen, 1989; Jack et al., 1991). TORP's efforts in documenting field results represent some of the early work in the field. Subsequent documentation efforts, described below, have been more comprehensive. 
Mack and Smith (1994) documented the results of 29 injection well treatments using in-depth colloidal dispersion gels in the Rocky Mountain area. Twenty-two of the projects were reported as successful. Factors involved in unsuccessful projects were: (1) starting the project too late, (2) outof-zone injection, (3) premature shutdown of injection, (4) poor wellbore completions, (5) poor water quality, and (6) inadequate gel strength.

Southwell and Posey (1994) documented field results with the Marathon acrylamidepolymer/chromium (III) carboxylate gel system. Forty-three treatments have been performed in Wyoming's Big Horn Basin; an initial group of 17 treatments during 1985-1989 and 26 treatments during 1989-1992. Development costs for the two groups of treatments were reported at $\$ 0.21$ and $\$ 0.99$ per incremental barrel for the initial and second groups, respectively. The characteristic application was in naturally fractured waterflood reservoirs. Results from production well treatments in the Grayburg formation in the Big Lake Field in West Texas, a fractured, natural waterdrive reservoir, were also reported (Southwell and Posey, 1994). In this water shut-off application, treatments were economical based solely on lifting cost reductions. Amoco reported results of injection well conformance control treatments in their Wertz $\mathrm{CO}_{2}$ flood in southwest Wyoming (Borling, 1994). Payout times from 1.1 to 3.7 months were noted with pattern lives extended for up to 2 years.

Fielding et al. (1994) describe how both colloidal dispersion and Marathon gels were applied in the North Rainbow Ranch Unit, a Minnelusa (non-Class 4 reservoir) in Wyoming. The reservoir is not fractured, but the Dykstra-Parsons coefficient of 0.9 indicates a highly heterogeneous reservoir. Reservoir temperature is about $200^{\circ} \mathrm{F}$. Projected ultimate recovery with polymeraugmentation is $61 \%$ of the original oil-in-place. Problems were experienced with fines and solids production leading to shortened submersible pump life.

\subsubsection{Current Research Activity}

\subsubsection{DOE Supporting Research}

At the University of Kansas, DOE is funding research directed toward (1) identifying and developing improved gel polymer systems, (2) determining their performance, and (3) developing better predictive methods (Green and Willhite, 1994). Work in gel development is focusing on three types of gel systems: (1) an aqueous polysaccharide (developed by $\mathrm{KU}$ ) that gels as a function of $\mathrm{pH},(2)$ conventional chromium-based crosslinking systems, and (3) an aluminum citrate-polyacrylamide system. The aluminum citrate-polyacrylamide system was determined to be less toxic than several organic crosslinkers which were evaluated. Laboratory work is focusing on chemical reaction kinetics with the goal of developing mathematical models for predicting performance.

At the University of Michigan, research which was completed in 1993 examined a variety of new fluid diversion or profile modification techniques (Fogler, 1994). Among others, strategies investigated included a particulate system, a foamed gel for injection wells, and a water-reactive gel for water shutoff at production wells.

At the Petroleum Recovery Research Center in New Mexico, DOE is funding research directed toward (1) comparing the effectiveness of gels with other fluid diversion techniques (foams, emulsions, particulates) and (2) identifying the mechanisms by which gels selectively reduce water permeability more than oil permeability. Early work is focusing on documenting field applications, operator and vendor experience, and application guidelines (Seright and Liang, 1994; Seright, 1993). Significantly, their work is considering production as well as injection well treatments. Survey information indicates that, in the early 1980 s, injection well treatments were most common. Since 1990 , over $80 \%$ of gel treatments have been in production wells, with the majority of those being in wells in fractured bottom-waterdrive reservoirs rather than injection well treatments in 
waterfloods (Seright and Liang, 1994). Seright and Liang (1994) contend that the difficulty and delay in measuring technical and economic performance of injection well treatments is partially responsible for the trend toward production well treatments.

At NIPER, research is focused on developing alternative conformance control systems which do not pose the environmental hazards of the chromium redox system. An initial task in the research effort is developing a sweep improvement literature database covering gel polymers and other systems. Alternative technologies being evaluated include a surfactant-alcohol system and biopolymer-based systems (NIPER/BDM, 1994b). The surfactant-alcohol system relies on chromatographic separation in the reservoir, leaving a viscous surfactant gel blocking pore throats in high-permeability zones. Laboratory research is focusing on the salinity and temperature conditions where the surfactant and alcohol system is effective.

\subsubsection{DOE Cost-Shared Field Demonstration Program}

DOE has initiated cost-shared field demonstration projects with operators in Class 1 fluvialdominated deltaic and Class 2 shallow-shelf carbonate reservoirs. Proposals in Class 3 slope-basin and basin clastic reservoirs are currently being evaluated. Two Class 1 projects specifically note profile modification applications, one using gel polymer and one using indigenous microorganisms. One Class 2 project incorporates gel polymer technology. Several of the Class 3 proposals incorporate gel polymer technologies (OGJ, 1994).

The Class 1 project led by the University of Kansas' Center for Research incorporates gel polymers, polymer flooding, and reservoir management technologies. Production problems being addressed include (1) poor volumetric sweep, (2) plugging of injection wells, and (3) lack of production optimization through simulation and management.

The Class 2 project by Beard Oil proposes to systematically evaluate fluorescent, ionic, and radioactive tracers as tools to design and apply crosslinked polymer gel treatments. Tracer data will be integrated with reservoir and production data.

\subsubsection{Research Needs}

Research needs for gel polymer applications fall within process, modeling and simulation, environmental, and demonstration realms. Field demonstration, an important final step in the development process, optimizes development, builds confidence levels, and fosters increased application. Since gel polymer applications are economically viable at moderate oil prices and have the potential for extending reservoir economic life, these research needs are all considered nearterm needs. The highest priority research needs are directed toward developing environmentally acceptable systems as alternatives to the conventional chromium redox system and reducing uncertainty associated with gel polymer usage.

\subsubsection{Process}

System development work in gel polymer or conformance control applications takes two directions: systems which are stable in higher temperature and salinity environments and more environmentally acceptable systems. Since Class 4 reservoirs generally fall within the temperature and salinity guidelines of implemented technology, the primary system development focus, at least for Class 4 applications, should be toward developing alternative, environmentally acceptable systems. Ongoing research with organic crosslinking systems, surfactant-alcohol systems, and alternative precipitation systems appears on target with those needs.

Advances in several areas are needed to reduce the uncertainty associated with gel polymer applications. On the basic research end of the spectrum, an improved understanding of rheological properties is needed. Further mechanistic studies regarding gel placement and treatment design, involving both laboratory and simulation work, are important. Current research activity appears to address these needs. 
Successful applications depend on reservoir problem definition, gel system selection, and treatment design. Field-oriented research addressing these needs will help reduce uncertainty and foster increased usage of gel polymer applications. Seright and Liang (1994) note the need for a better understanding of treatment sizing guidelines. Their work (Seright, 1993) also noted (1) the gap between tracer need and tracer application and (2) the need for monitoring and evaluation approaches to more quickly evaluate the success or failure of injection-well treatments. Welldocumented field applications are needed to address these issues.

Further guidelines regarding problem definition, candidate selection, matching gel systems to reservoir problems, treatment design, and performance prediction are needed to assist operators in developing optimum treatments. The problem definition, candidate selection, gel system selection, and treatment design processes are amenable to an expert or knowledge-based system approach, especially if the system incorporated statistical data on technical and economic success rates of different gel systems in different environments. Statistical data imply development of a welldocumented database of field treatment results, a significant research need alone. For maximum utility, the knowledge-based system would need to be linked to a permeability modification simulator to provide predictive capacity. A comprehensive written report documenting information in the above areas would represent a logical precursor to development of an expert system.

\subsubsection{Modeling and Simulation}

The publicly available, PC-based permeability modification simulator developed by NIPER has proven to be a valuable tool for mechanistic studies of gel permeability applications. Although some validation of model predictions with field data has been performed, additional validation under a variety of application environments is needed. Maximum utility of the simulator will come as it is linked with a treatment database and knowledge-based system (section 4.2.6.1).

\subsubsection{Environmental}

Seright and Liang's survey (1994) of operators indicated that over $50 \%$ of gel treatments used polyacrylamides, with most treatments using the chromium (VI) redox process. Considering the high usage level and environmental problems associated with this process, a strong driving force exists for developing alternative conformance control systems. Current research is focusing on systems using organic crosslinkers, surfactant-alcohol systems relying on chromatographic separation, thermal- and alcohol-initiated precipitation systems, and brine- or pH-initiated gels. Considering the strength of the driving force, research on these several fronts should be continued.

\subsubsection{Demonstration}

Field demonstration projects serve to validate new or improved technologies, and, as such, are important for reducing uncertainty and changing operator perceptions. The following technology concepts would benefit from field demonstration:

(1) tracer applications to assist in problem definition and treatment sizing,

(2) sizing guidelines for field applications addressing different reservoir problems,

(3) monitoring and evaluation approaches for injection-well treatments to more quickly discern success or failure of injection well treatments,

(4) knowledge-based system (if developed) for problem definition, gel system selection, treatment design, and performance prediction, and

improved gel systems or alternative conformance control technologies as they become ready for field application.

Although gel polymer and conformance control technologies are proven, more widespread application and improved success rates in field applications depend on additional research, field demonstration, and effective technology transfer. 


\subsection{Polymers For Mobility Control}

The polymer process is an economical process, when applied in the proper environment, for recovering additional unrecovered mobile oil (UMO). Increased oil recovery from polymer flooding can result from one or more of three different mechanisms: fractional flow effects, mobility ratio effects, and fluid diversion effects (Needham and Doe, 1987). Fractional flow and mobility ratio effects favor starting polymer floods early. Fluid diversion effects are more significant for tertiary polymer floods.

Topics covered in this section include the relationship of polymer flooding to the Class 4 oil resource, screening criteria, constraints, recent technology thrusts, and current research directions. Research needs for the polymer flooding process complete this section.

\subsubsection{Relationship to the Class 4 Oil Resource}

The TORIS analysis of future oil recovery potential (see Chapter 2 ) indicates that polymer floods, particularly in combination with infill drilling, are applicable to the Class 4 oil resource. As technology moves from the implemented to the advanced level, the potential contribution from the infill drilling/polymer flood combination increases by $50 \%$ to $70 \%$, depending on oil price. Historical contributions from polymers in Oklahoma and Rocky Mountain reservoirs lend credence to future applications in these regions. Although polymers have been used in the Texas plays, impact on overall production has not been significant.

Potential contributions from polymer flooding estimated by TORIS may be optimistic. Pautz et al. (1994) compared oil recovery experienced in 16 polymer projects with that predicted by the TORIS polymer predictive model. On aggregate, predicted total production was $363 \%$ higher than actual production. Polymers will have their greatest impact in conjunction with alkaline-surfactantpolymer (ASP) (section 4.5) or surfactant-polymer (section 4.6) projects.

Polymer flooding's impact in Class 4 reservoirs varies by geographic region. Although polymer projects have been performed in Texas, most polymer applications have been in Oklahoma and Rocky Mountain plays. In Oklahoma, higher formation water salinity levels have directed most applications to biopolymers. Hydrolyzed polyacrylamide polymers have been widely applied in the Rocky Mountain region where salinity levels are generally lower. Polymer flooding and gel polymer applications are often combined in field projects.

\subsubsection{Screening Criteria}

The screening criteria used by the NPC (1984) for implemented and advanced technology levels are summarized in Table 4.7. For the advanced technology level, advances in polymer chemistry expand the temperature and salinity limits for the polymer process. Since salinity and temperature levels in Class 4 resources typically fall below the screening criteria limits for the implemented technology case, polymer field applications in Class 4 reservoirs are not limited by advances in polymer chemistry. However, note that higher salinity applications requiring biopolymer (or preconditioning) could exceed the practical $160^{\circ} \mathrm{F}$ temperature limit for conventional Xanthan biopolymers.

\subsubsection{Constraints}

Dauben (1991) analyzed field projects to determine those parameters which limited success in polymer floods. He concluded that polymer floods were constrained by three factors: (1) inadequate polymer propagation, (2) polymer degradation, and (3) polymer stability in high temperature, high-salinity environments. Poor propagation often results from formation plugging. Degradation can result from mechanical, microbial, or chemical causes. Each type of polymer has certain temperature and salinity restrictions, and effort is ongoing to develop polymers suitable for harsher environments. 


\begin{tabular}{|c|c|c|}
\hline \multicolumn{3}{|c|}{ 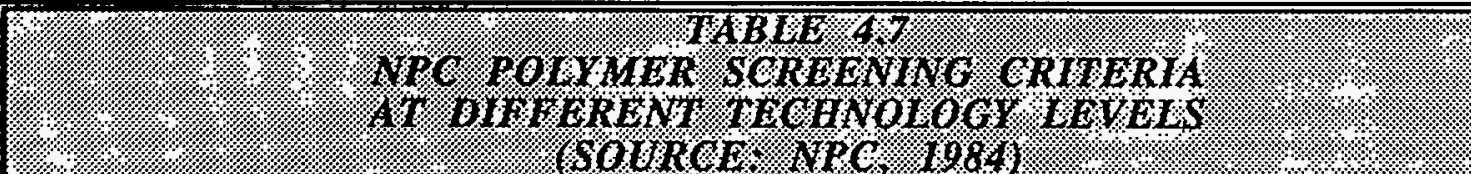 } \\
\hline Parameter & $\begin{array}{c}\text { Implemented } \\
\text { Technology }\end{array}$ & $\begin{array}{c}\text { Advanced } \\
\text { Technology }\end{array}$ \\
\hline Reservoir Temperature, ${ }^{\circ} \mathrm{F}$ & $<200$ & $<250$ \\
\hline Brine Salinity, ppm & $<100,000$ & $<200,000$ \\
\hline Permeability, mD & $>20$ & $>10$ \\
\hline Oil Viscosity, cP & $<100$ & $<150$ \\
\hline
\end{tabular}

Inadequate polymer propagation leads to formation plugging which leads to reduced injectivity which, in turn, often leads to injecting at pressures above the formation parting pressure. Injection at pressures above the parting pressure was noted in the Big Muddy (Cole, 1988), North Burbank (Tracy and Dauben, 1981), Manvel (Hamaker and Frazier, 1982; Widmeyer and Pindell, 1981), Robinson M-1 (Cole and Dauben, 1987), and West Burkburnett (Talash and Strange, 1981) projects. When formation parting occurs, sweep efficiency is reduced resulting in reduced recovery.

\subsubsection{Recent Technology Thrusts}

Recent polymer technology development efforts have focused in the following areas: (1) developing polymers for harsher environments, (2) applying polymers in the secondary rather than tertiary stage, (3) polymer propagation and retention, (4) mechanical degradation, and (5) polymer injectivity. Since temperature and salinity of most Class 4 reservoirs are within environmental stability limits for existing polymers, the other technology thrusts will impact Class 4 polymer potential more significantly.

\subsubsection{Polymers for Harsher Environments}

Polymer stability can be affected by temperature, salinity, hardness, $\mathrm{pH}$, and mechanical shear. Existing hydrolyzed polyacrylamide (HPAM) polymers exhibit temperature limits ranging from $167^{\circ} \mathrm{F}$ when total hardness is greater than $2,000 \mathrm{ppm}$ to $200^{\circ} \mathrm{F}$ when total hardness is $400 \mathrm{ppm}$ (Gao, 1987). Ryles (1988) considered the temperature limit to be even lower, around $160^{\circ} \mathrm{F}$ if brines contain more than $200 \mathrm{ppm} \mathrm{Ca}+2$. Xanthan biopolymers have a useful temperature limit of about $160^{\circ} \mathrm{F}$ (Ryles, 1988), although some sources (Doe, et al, 1987; Needham and Doe, 1987) state a useful temperature limit of $200^{\circ} \mathrm{F}$. Different levels of substitution with pyruvate and acetate in different Xanthan biopolymers cause the thermal stability limits to vary (Gall, 1993). Xanthan stability is less affected by divalent ions than HPAM polymers (Ryles, 1988). Alternative polymers are being evaluated to extend the useful temperature and salinity limits of polymer applications.

A different class of biopolymers, scleroglucan, exhibits higher temperature limits due to its triple-helix structure (Gall, 1993). Scleroglucan also exhibits relatively high salinity and divalent ion limits. Kalpakci et al. (1990) suggest that scleroglucan may be used at temperatures up to $220^{\circ}$ F. Although early scleroglucan applications experienced plugging problems, modifications in the biosynthesis process and in post-treatment have led to enhanced filterability (Rivenq et al., 1989).

Doe et al. (1987) evaluated copolymers of vinylpyrrolidone (VP) and acrylamide (AM) and found them stable in seawater at temperatures up to $250^{\circ} \mathrm{F}$. It was noted that improvements in molecular weight were needed to improve field economics. Needham and Doe (1987) noted that advanced polymers might be too expensive for economic conditions prevailing in 1987. 
Sohn et al. (1990) address polymer salinity limitations through the concept of preconditioning. Preconditioning recognizes the economic benefits of using less expensive hydrolyzed polyacrylamides. Rather than using freshwater preflushes to protect the polyacrylamides from saline waters, a small slug of a more salt-tolerant polymer is injected first. This slug represents only $10-15 \%$ of the total polymer slug (Sohn et al., 1990). When compared to freshwater preflush, this process shortens both preconditioning time and project life. Sohn et al. documented two applications in Germany where preconditioning was successful. Injection protocol or strategy, of which preconditioning is just one example, has been identified as a research need (Lorenz, 1991; Gall, 1993).

Polymers can be affected by the $\mathrm{pH}$ of the injected fluids. Hydrolyzed polyacrylamides are quite stable in the high $\mathrm{pH}$ environment of an alkaline flood. Xanthans, however, can be degraded at temperatures below $130^{\circ} \mathrm{F}$ in alkaline floods (Rivenq et al., 1989). The biopolymer used in KU's pH-initiated gel system (section 4.2.4.2) has advantages for alkaline flooding since it is soluble and stable in higher $\mathrm{pH}$ environments (Vossoughi and Putz, 1991). Polymer stability under alkaline conditions and polymer effects on interfacial tension reductions with the alkalinesurfactant-polymer (ASP) process (section 4.5.4.3) should be considered when designing alkaline floods.

\subsubsection{Secondary Rather Than Tertiary}

Higher oil recovery can be experienced when polymer floods are started earlier in waterflood life; i.e., as secondary rather than tertiary floods. Fractional flow and mobility ratio effects favor starting polymer floods earlier. In Germany where projects are started earlier, polymer flood recoveries are significantly higher than experienced in typical U.S. floods (Lorenz, 1991). By eliminating freshwater preflushes, Sohn et al.'s (1990) preconditioning concept takes advantage of early polymer injection. Based on their analysis of 27 polymer floods, Needham and Doe (1987) determined that potential was four times higher in secondary floods and significantly less polymer was required. In Wyoming's non-Class 4 Minnelusa reservoir, early polymer floods are recognized as the state-of-the-art (Hochanadel, 1990). The economic and recovery benefits of starting polymer floods earlier in life has been clearly demonstrated; however, the typical Class 4 reservoir cannot benefit from starting polymer injection early because most Class 4 reservoirs are already in the tertiary stage.

\subsubsection{Propagation and Retention}

Although some polymer retention is beneficial, excess polymer retention or degradation reduces polymer concentration and mobility control and ultimately results in reduced oil recovery. Polymer degradation by bacteria or oxygen can be controlled by biocide treatment and system design. Polymer retention includes both adsorption and mechanical entrapment effects. Hydrolyzed polyacrylamides are known to adsorb more than biopolymers. Gao (1987) stated that inaccessible pore volume must be considered when evaluating polymer retention. Screening tests for polymer retention are recommended. The API standard (1990) recommends performing dynamic corefloods in native reservoir cores at reservoir conditions. Huh et al. (1990) found the amount of entrapment to be a function of polymer flux (i.e., retention is maximized at high concentrations and rates). Gao (1992) found that laminations in the reservoir and their angles affect polymer retention and recommended determining lamination angle as part of the polymer screening process.

\subsubsection{Mechanical Degradation}

Polymers exhibit varying susceptibility to mechanical degradation. Biopolymers are less susceptible to mechanical degradation than hydrolyzed polyacrylamides. With hydrolyzed polyacrylamides, susceptibility to mechanical degradation increases as the molecular weight and, accordingly, viscosity increases. Equipment design and preshearing are conventional approaches to reducing mechanical degradation effects. 
Gao (1991a, 1991b) approached the shear degradation issue with crosslinked, low-molecularweight polyacrylamides. Because of the characteristics of crosslinked polymers, low-crosslinkingdensity gelled polymers under high shear conditions, like those near a wellbore, should exhibit improved injectivity. Since they reheal at low shear conditions, like those away from the wellbore, these gelled polymer systems should be less sensitive to shear degradation. Gao's laboratory work (Gao, 1991a, 1991b) verified improved injectivity and rehealing under low shear conditions.

Taber and Seright (1992) described advantages of horizontal wells in polymer floods. For a given injection pressure, fluid velocity at the sandface is lower than with vertical wells, decreasing the potential for shear degradation. Higher injection rates, which could be achieved with horizontal injection wells, would also decrease polymer residence time, thereby reducing the long-term stability requirements for the polymer.

\subsubsection{Injectivity}

Injectivity and mechanical degradation issues are often interrelated, as is evident in Gao's work with crosslinked low-molecular-weight polyacrylamides. Field projects often experience reduced injectivity that can delay oil recovery and/or lead to injection overpressuring and formation parting. Polymer plugging can result from polymer solution properties, reservoir properties, or surface mixing and wellbore problems. Fletcher et al.'s work (1992) indicated that fractures, whether natural or hydraulically created, greatly influence polymer injectivity. In unfractured wells, their work indicated that injectivity reductions result from face plugging and are a function of cumulative polymer flux. In fractured wells, Fletcher et al. found that filtered polyacrylamide and unfiltered Xanthan could be injected without significant injectivity loss or fracture growth.

Treiber and Yang (1986) investigated polymer plugging in corefloods and found plugging to be a function of four factors: (1) cumulative polymer volume per cross sectional area, (2) core permeability, (3) hydrodynamic size of the polymer, and (4) core mineralogy, particularly clays. Their work indicated that core composition and polymer-rock interactions significantly influence polymer plugging. Treating the wellbore with organic cations prior to polymer injection reduced subsequent polymer plugging.

\subsubsection{Current Research Activity}

\subsubsection{DOE Supporting Research}

At the University of Southern Mississippi (McCormick and Hester, 1994), research is focusing on water-soluble copolymers for mobility and conformance control applications. Copolymer synthesis represents a major part of the effort. Research activity at NIPER (NIPER/BDM, 1994) is continuing to focus on developing polymer systems for harsher environments and on polymer retention. Stability of a low-anionic polyacrylamide polymer reported to be stable in higher salinity environments is being evaluated. Lamination angle effects on polymer retention in cores at residual oil saturation are being further explored. Some effort is also directed toward modeling using the UTCHEM simulator.

\subsubsection{DOE Cost-Shared Field Demonstration Program}

DOE has initiated cost-shared field demonstration projects with operators in Class 1 fluvialdominated deltaic and Class 2 shallow-shelf carbonate reservoirs. Proposals in Class 3 slope-basin and basin clastic reservoirs are currently being evaluated. The University of Kansas' Class 1 project (section 4.2.5.2) incorporates polymers along with gel polymers and reservoir management. No Class 2 projects specifically note polymer flood applications. One of the Class 3 proposals notes that polymers may be one of the technologies employed (OGJ, 1994). 


\subsubsection{Research Needs}

In a 1991 study, NIPER and K\&A (1991) listed four near-term research needs for polymer flooding: (1) improved injection protocols, (2) improved polymers with better injectivity, higher salinity and temperature limits, and better propagation, (3) better knowledge of factors affecting injectivity and propagation, and (4) environmentally acceptable biocides. Technology thrusts addressing these needs have previously been described. For Class 4 reservoirs, research associated with improved injection protocols, polymer propagation, and polymer injectivity have the highest priority. Additional effort is needed to improve the TORIS polymer predictive model so that more reliable estimates of potential oil recovery from polymer floods can be made.

\subsection{Microbial Processes}

Microbial enhanced oil recovery (MEOR) technologies have evolved significantly in recent years. MEOR technologies recover oil through several different mechanisms including surfactant generation, wettability alterations, gaseous byproducts, and plugging. MEOR processes can be used for wellbore stimulation or cleanup, permeability modification, microbially enhanced waterflooding, polymer flooding, and coning mitigation. While high recovery efficiencies like those achievable with miscible processes $\left(\mathrm{CO}_{2}\right.$ or surfactant) may not be experienced, MEOR technologies, like conformance control technologies, can be economical at moderate oil prices.

Topics covered in this section include the relationship of MEOR to the Class 4 oil resource, recent technology thrusts, constraints, screening criteria and procedures, Class 4 field activity, current research activity, and research needs.

\subsubsection{Relationship to the Class 4 Oil Resource}

The TORIS analysis of future recovery potential does not estimate future recovery potential from MEOR processes. However, salinity, permeability, and temperature screening indicates that many Class 4 reservoirs listed in the TORIS database would be amenable to MEOR processes. Stepp and Bryant (1994) determined that about one-third of the reservoirs in DOE's Energy Reservoir Data Base having more than 20 million barrels original oil-in-place passed the following screening criteria: injected and connate water salinities less than $100,000 \mathrm{ppm}$, permeability greater than $75 \mathrm{mD}$, and depth less than 8,000 feet corresponding to a temperature less than $170^{\circ} \mathrm{F}$. Percentages of reservoirs amenable to MEOR technologies for key Class 4 states of Texas, Oklahoma, California, and Wyoming are 29,17, 59, and 42 percent, respectively. Although these percentages are not restricted to Class 4 reservoirs, the percentages do provide an indicator of possible Class 4 potential by region.

Field applications of MEOR processes in Class 4 reservoirs have not been specifically noted in technical literature.

\subsubsection{Screening Criteria and Procedures}

Bryant $(1990,1991)$ published both screening criteria and screening procedures for MEOR processes. MEOR applications must first pass screening criteria (Table 4.8), then the process must be tailored to the application. As in application of most IOR processes, defining the reservoir and well characteristics is essential. Having defined the reservoir and well characteristics, the type of microorganisms must be matched to the problem, and the laboratory screening procedures (Table 4.9) performed. In many aspects, MEOR technologies are similar to gel polymer technologies in that tailoring to individual applications is required. 


\begin{tabular}{|c|c|}
\hline 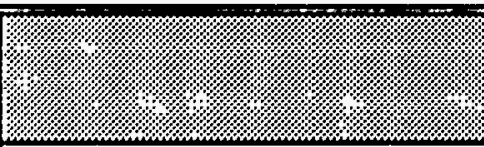 & 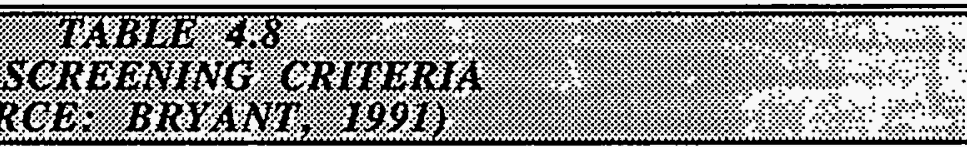 \\
\hline Parameter & Recommended Range \\
\hline Salinity & $<15 \%$ sodium chloride; total TDS may be higher \\
\hline Temperature/depth & $<170^{\circ} \mathrm{F} ;<8,000 \mathrm{ft}$ \\
\hline Trace minerals & $<10-15$ ppm of arsenic, mercury, nickel, selenium \\
\hline Reservoir rock permeability & $>50$ millidarcies, unless highly fractured \\
\hline Indigenous microorganisms & $\begin{array}{l}\text { Compatible with injected microorganisms in selected } \\
\text { MEOR process }\end{array}$ \\
\hline Crude oil type & $\begin{array}{l}>15^{\circ} \text { API; not enough information available yet for } \\
\text { heavier crude oils }\end{array}$ \\
\hline Residual oil saturation & $>25 \%$; may be some exceptions \\
\hline Well spacing & $\begin{array}{l}<40 \text { acres; a response can generally be seen sooner on } \\
\text { closer well spacing }\end{array}$ \\
\hline
\end{tabular}

\begin{tabular}{|l|l|}
\hline \multicolumn{1}{|c|}{ Parameter } & \multicolumn{1}{c|}{ Screening Procedure } \\
\hline Microorganism used & $\begin{array}{l}\text { Determine potential mechanisms for increasing oil } \\
\text { production. }\end{array}$ \\
\hline Salinity & $\begin{array}{l}\text { Use compatibility testing to assay for microbial growth } \\
\text { and metabolism. }\end{array}$ \\
\hline Temperature/depth & $\begin{array}{l}\text { Use compatibility testing to assay for microbial growth } \\
\text { and metabolism under reservoir conditions. }\end{array}$ \\
\hline Trace minerals & Use compatibility testing to determine. \\
\hline Reservoir rock permeability & $\begin{array}{l}\text { If multiwell process, conduct a single-well injectivity test } \\
\text { and coreflooding studies. }\end{array}$ \\
\hline Indigenous microorganisms & $\begin{array}{l}\text { Use compatibility testing to assay for microbial growth } \\
\text { and metabolism under reservoir conditions. }\end{array}$ \\
\hline
\end{tabular}

\subsubsection{Constraints}

MEOR applications are constrained by the lack of widespread industry experience and confidence in their success in proper applications. Prior DOE-sponsored projects have demonstrated that MEOR technology has potential, but predictability of MEOR technology has not been demonstrated and documented (Bryant, 1993). Additionally, successful applications in projects with higher target oil saturations need to be demonstrated. 


\subsubsection{Recent Technology Thrusts}

Potential applications of MEOR technologies have widened significantly as a result of focused research and technology transfer efforts, much of which has been performed by NIPER. NIPER's efforts have focused in the areas of database development, culture banking, mechanistic understanding, modeling and simulation development, microbially enhanced waterflooding, and plugging or permeability modification technologies (Bryant, 1993).

NIPER developed an MEOR Field Project Data Base documenting reservoir characteristics where MEOR technologies have been applied (Bryant, 1991). Trends evident from the project data were used to develop and revise published MEOR screening criteria. As of late 1993, the database contained data on 69 different field projects with additional entries planned in the near future (Bryant, 1993). In a somewhat correlative effort, NIPER has also developed a culture bank of microorganisms capable of improving oil mobilization under a wide variety of conditions.

Laboratory development work, as reported by Bryant (1993), has demonstrated that: (1) microbial compatibility tests between injected and indigenous mechanisms are essential, (2) microbial cells are important to oil mobilization and recovery, (3) combinations of Bacillus and Clostridium species perform more effectively than either species alone, (4) reservoir wettability can be altered by microbial action, and (5) low concentrations of certain additives improve microbial performance. MEOR process research has focused on microbial well stimulations, microbially enhanced waterflooding, microbial permeability modification, and microbial wellbore cleanup technologies.

In conjunction with laboratory development work, NIPER has developed a microbial simulation model (Chang et al., 1991). The model incorporates microbial growth and decay, microbial deposition, chemotaxis, diffusion, convective dispersion, tumbling, and nutrient consumption effects (Bryant, 1993). Laboratory results are being considered in the simulator development effort. At present, the model does not incorporate or predict enhanced oil recovery effects which reduce residual oil saturation.

NIPER has conducted field demonstrations of microbially enhanced waterflooding in the Delaware-Childers and Chelsea-Alluwe (non-Class 4 reservoirs) fields in northeast Oklahoma. The initial 20-acre MEOR pilot in the Mink Unit, Delaware-Childers field led to a larger 380-acre, fieldscale pilot in the nearby Phoenix lease in the Chelsea-Alluwe field. Production rate increases for the Mink Unit and Phoenix projects were 13\% and 19.6\%, respectively (Bryant et al., 1994). Nutrient costs, the primary cost in an MEOR process, for the Mink Unit and Phoenix projects were $\$ 3.24$ and $\$ 2.33$ per incremental barrel of oil, respectively. Significantly, no operating problems were encountered before or during either project.

Bryant (1994) discusses potential microbial applications for North Sea production. North Sea challenges include: (1) necessity of operating from platforms with limited storage capacity, (2) the wide spacing of wells, (3) highly faulted reservoirs, (4) higher than typical temperatures, (5) in some cases, high clay content, and (6) brines with fairly high salinity and hardness. Potential conformance control applications were noted. Bryant's article succinctly summarizes the multiple facets of microbial EOR.

\subsubsection{Current Research Activity}

\subsubsection{DOE Supporting Research}

In the recent past, two national laboratories have participated in MEOR research. At Idaho National Engineering Laboratory, research was directed towards developing MEOR systems applicable to reservoirs containing medium to heavy oils and towards evaluating wettability effects on oil recovery (McCoy, 1994). Several Class 4 reservoirs listed in the TORIS database contain medium-gravity crudes to which this research would be applicable. At Brookhaven National Laboratory, research was directed towards MEOR applications in higher temperature and pressure 
applications (Premuzic and Lin, 1994). Biochemical interactions with Alabama Smackover crudes were being evaluated.

At NIPER, research is focusing on performing (1) microbial single-well stimulation field tests, (2) further developing coreflooding experimental procedures, (3) determining microbial retention and adsorption effects in porous media, and (4) incorporating laboratory and field data into the MEOR process simulation package (NIPER/BDM, 1994).

\subsubsection{DOE Cost-Shared Field Demonstration Program}

DOE has initiated cost-shared field demonstration projects with operators in Class 1 fluvialdominated deltaic and Class 2 shallow-shelf carbonate reservoirs. Proposals in Class 3 slope-basin and basin clastic reservoirs are currently being evaluated. One Class 1 project incorporates MEOR technology. Hughes Eastern proposes to stimulate indigenous microorganisms in the Carter sandstone, North Blowhorn field, Alabama using inorganic (fertilizer) nutrients. Intent is to preferentially plug the more porous zones of previously waterswept areas. No Class 2 projects incorporate MEOR technologies. In the Class 3 proposals, a consortium proposes combining horizontal well and MEOR technologies (OGJ, 1994).

\subsubsection{Research Needs}

According to Bryant (1993), MEOR technology research needs exist in the following areas:

(1) Improving the predictability of MEOR technology. Improved predictability will occur as laboratory and field data are integrated, and appropriate modeling and simulation work are performed.

(2) Obtaining microbially enhanced field data in reservoirs with higher remaining oil saturations; i.e., don't just test MEOR processes in reservoirs that are in the advanced secondary stage. .

(3) Developing more cost-effective nutrients.

(4) Selecting or adapting microorganisms for harsher temperature and salinity environments.

Additional field demonstrations and improved predictability are the research needs that will most affect Class 4 reservoirs.

\subsection{Alkaline And Alkaline-Surfactant-Polymer (ASP) Processes}

Alkaline projects using strong alkalis have limited potential considering the alkaline consumption and operations problems experienced in historical projects (Dauben, 1991). Weak alkalis reduce these problems, but by themselves do not generate high enough $\mathrm{pH}$ values to lower interfacial tension (IFT) and mobilize oil. While conventional surfactant floods generate low IFT and mobilize significant oil, costs are too high with concentrations typically used. However, weak alkalis and low concentrations of surfactant can exhibit synergistic effects which lower IFT and mobilize oil at costs low enough to be feasible at moderate oil prices (French et al., 1988). The process employing weak alkalis, a low concentration of surfactant, and polymer for mobility control is known as the ASP process. Current trends are to use the alkali in combination with surfactants and polymers (Lorenz, 1988; Krumrine and Falcone, 1987).

Topics covered in this section include the relationship of alkaline and ASP processes to the Class 4 oil resource, screening criteria, constraints, recent technology thrusts, and current research directions. Research needs for the ASP process complete this section. 


\subsubsection{Relationship to the Class 4 Resource}

The TORIS analysis of future recovery potential (see Chapter 2) indicates no potential from the alkaline process in the implemented technology case. As technology moves from the implemented to the advanced level, potential from the alkaline process increases, especially at the intermediate $\$ 20 /$ barrel oil price. At that price using advanced technology (which does not consider advances from the ASP process), alkaline recovery potential represents about $10 \%$ of the total recovery potential. At higher oil prices, the percentage contribution from alkaline processes decreases as other, more efficient recovery processes become economic. Considering the cost and performance advantages of the ASP process, future recovery potential in Class 4 reservoirs from alkaline processes is probably underestimated.

Alkaline-polymer projects in Class 4 reservoirs have been limited to two Mitchell Energy projects in the Alba field, Subsclarksville reservoir in the Cretaceous, Salt-Related Play of East Texas. Higher acid contents in the $15^{\circ}$ to $16^{\circ}$ API gravity crude favored the alkaline-polymer process. Reported production volumes from these two projects, which were started in 1972 and 1980, were 209 barrels of oil per day (Moritis, 1992).

Although a field project has not been started, crude oil from the Class 4 Government Wells reservoir in the N. Government Wells field in the Jackson Strandplain/Barrier Island Play exhibits favorable alkaline reactivity. NIPER has developed a surfactant-enhanced alkaline polymer (or ASP) formulation for this crude oil (Gall, 1993; Llave et al., 1991). Acid number of the $20^{\circ}$ API oil is $0.7 \mathrm{mg} \mathrm{KOH} / \mathrm{g}$ of oil (Llave et al., 1991), a relatively low acid number for a reactive crude.

\subsubsection{Screening Criteria}

The screening criteria used by the NPC (1984) for the implemented and advanced technology levels are summarized in Table 4.10. Since the advantages of the ASP process had not yet been defined, the NPC screening criteria primarily apply to conventional alkaline flooding.

Screening criteria for the ASP (or surfactant-enhanced alkaline) process were developed by NIPER (Table 4.11; Lorenz and Peru, 1989; Gall, 1993). French and Burchfield (1990) provide a detailed discussion of these screening criteria. Note that the screening criteria specify parameters not typically available without laboratory evaluation. To be a candidate for surfactant-enhanced alkaline flooding, a reservoir should: (1) contain little or no gypsum, (2) exhibit a divalent ion exchange capacity less than 5 milliequivalents per kilogram, and (3) have an in situ pH greater than 6.5. Although crude oils having high acid numbers are desirable, high-acid-number crude oils are not essential for the process (Lorenz, 1988).

\begin{tabular}{|c|c|c|}
\hline 19: & 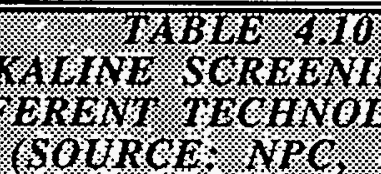 & \\
\hline Parameter & $\begin{array}{l}\text { Implemented } \\
\text { Technology }\end{array}$ & $\begin{array}{c}\text { Advanced } \\
\text { Technology }\end{array}$ \\
\hline Reservoir Temperature, ${ }^{\circ} \mathrm{F}$ & $<200$ & $<200$ \\
\hline Brine Salinity, ppm & $<100,000$ & $<200,000$ \\
\hline Permeability, mD & $>20$ & $>10$ \\
\hline Oil Gravity, ${ }^{\circ} \mathrm{API}$ & $<30$ & $<30$ \\
\hline Oil Viscosity, cP & $<90$ & $<100$ \\
\hline Rock Type & Sandstone & Sandstone \\
\hline
\end{tabular}




\begin{tabular}{|c|c|}
\hline 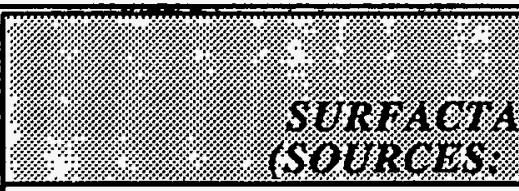 & 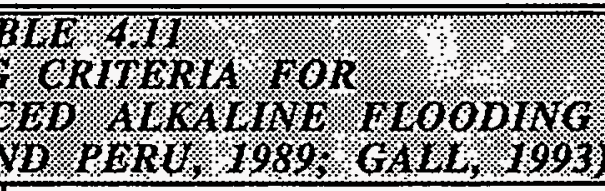 \\
\hline Parameter & Criteria \\
\hline Oil Viscosity, $\mathrm{cP}$ & $<100$ \\
\hline Permeability, mD & $>10$ \\
\hline Brine Salinity, ppm & $<200,000$ \\
\hline Temperature, ${ }^{\circ} \mathrm{F}$ & $\begin{array}{l}<200 \\
(\approx 9,000 \mathrm{ft} \text { depth })\end{array}$ \\
\hline Acid Number, mg KOH/g oil & $>0.3$ desirable (not essential) \\
\hline Clay Content & moderate, dependent upon type \\
\hline Gypsum & $\begin{array}{l}<0.1 \% \\
(<10,000 \mathrm{ppm} \text { sulfate })\end{array}$ \\
\hline $\begin{array}{l}\text { Divalent ion } \\
\text { exchange capacity, } \\
\text { meq/Kg }\end{array}$ & $\begin{array}{l}<5 \\
(<1 \% \text { montmorillonite or } \\
<.005 \text { equivalent fraction } \\
\text { divalent ions in brine })\end{array}$ \\
\hline $\mathrm{pH}$ & $\begin{array}{l}>6.5 \\
\left(<.01 \text { mole fraction } \mathrm{CO}_{2} \text { in gas }\right)\end{array}$ \\
\hline
\end{tabular}

Gall (1993) summarized the laboratory procedures required to evaluate ASP process potential for a given reservoir:

(1) determine the reservoir mineral, brine, and oil properties and compare with screening criteria to determine feasibility,

(2) determine whether the oil is interfacially reactive with alkalis and alkali and surfactant mixtures. Interfacial tension experiments are typically performed. A crude oil rating system developed by Smith (1993) for estimating alkaline reactivity without specific IFT testing is one alternative for rapid screening of candidate crude oils.

(3) quantify the extent of alkali-mineral reactions,

(4) quantify the extent of surfactant losses, and

(5) measure mobilized oil in coreflooding experiments.

Once the above laboratory data are available, a reservoir-specific economic evaluation must be performed.

\subsubsection{Constraints}

Dauben (1991) analyzed field projects to determine constraints to field applications of the alkaline process. Strong alkali floods are constrained by excessive consumption and operational problems. These constraints fostered research with weak alkalis and the ASP processes. Although incremental recovery using the ASP process was excellent in the White Castle and West Kiehl field projects, the ASP process has not yet been widely applied. Although research and limited field 
projects indicate significant potential for this process, field applications of the ASP process are still constrained by the lack of well-documented field data. To some extent, the ASP process may be constrained by association with the many failures experienced with past alkaline floods using strong alkalis.

\subsubsection{Recent Technology Thrusts}

Recent research and technology thrusts have focused on the ASP process, because it avoids the alkaline consumption and operations problems of the strong alkali process, reaps benefits from synergism between the alkaline and surfactant agents, and is potentially applicable to light as well as heavy oils. The research and development effort is directed toward defining the parameters controlling effectiveness of the process and demonstrating the technology in field applications.

Recent technology thrusts have focused on (1) interfacial tension (IFT) lowering, (2) injection strategy, (3) polymer and alkaline-surfactant interactions, and (4) field tests. The following section discusses these areas including successful field tests in a Wyoming Minnelusa (non-Class 4) reservoir and an onshore Louisiana project (non-Class 4 reservoir).

\subsubsection{Interfacial Tension (IFT) Lowering}

Historically, alkaline projects have been considered only in reservoirs where crude oils exhibit high acid numbers, with higher acid numbers generally being associated with lower gravity crudes (Lorenz and Peru, 1989). Laboratory results (French et al., 1990; French and Burchfield, 1990) indicate that, with certain crudes, significant IFT lowering can occur in low-acid-number crude oils using the ASP system. However, each oil behaves differently, so synergism and IFT lowering must be determined at reservoir conditions for each oil (French et al., 1990). With acidic crudes, ASP systems typically cause a rapid lowering of IFT from alkali reactions with the crude while sustained low IFT results from the synthetic surfactant (French et al., 1988). With non-acidic crudes, IFT lowering results from synergism and may occur rapidly or slowly depending upon the crude oil (French et al., 1990).

\subsubsection{Injection Strategy}

ASP process effectiveness varies with the injection strategy used. French and Josephson (1991) compared oil recovery in Berea sandstone cores using different injection strategies using crude oil from the Hepler field (Kansas). Their work confirmed the benefit of alkaline preflushes for controlling surfactant consumption and adsorption. Although highest recovery was observed when an alkaline surfactant slug was followed by polymer, recovery with a single slug (after the preflush) containing alkali-surfactant-polymer was nearly as high, and oil recovery occurred more quickly. This strategy was recommended for the Hepler field project (section 4.5.5.1).

\subsubsection{Polymer and Alkaline-Surfactant Interactions}

Research has confirmed that polymer-surfactant interactions affect the properties of a developed ASP system. Corefloods associated with the Hepler field project (section 4.5.5.1) exhibited polymer-surfactant interactions (French and Josephson, 1991). French and Josephson (1993) established that polymer-surfactant interaction was affected by $\mathrm{pH}$, ionic strength, crude oil composition, and the properties of the polymers and surfactants. Interactions included phase separation, precipitation, and viscosity loss. Adverse effects on polymer rheology were lessened when oil was present and $\mathrm{pH}$ values were higher. Pitts (1994a) found that when surfactant concentrations were higher, IFT increases with polymer addition were lessened. Research regarding polymer interactions is intertwined with injection strategy research. 


\subsubsection{Field Tests of the ASP Process}

\section{West Kiehl Field, Wyoming}

The West Kiehl Field in Wyoming produces from a Minnelusa reservoir. Production from the solution-gas drive reservoir decreased rapidly after discovery in 1985 . Ultimate primary recovery efficiency was estimated at $11 \%$ of the OOIP (Clark et al., 1988). Reservoir permeability is 350 $\mathrm{mD}$. The operator evaluated waterflooding, polymer flooding, alkaline-polymer waterflooding, and alkaline-surfactant-polymer (ASP) flooding. Based on analyses that indicated the ASP process would ultimately recover $56 \%$ of the OOIP versus $40 \%$ with the other processes, the operator implemented the ASP process in 1987, only two years after initial discovery (Clark et al., 1988).

The West Kiehl Unit injection strategy involved several steps: (1) initial water injection to establish base injectivity, (2) then sodium carbonate, (3) then sodium carbonate and surfactant, (4) then sodium carbonate, surfactant, and polymer. Once the desired chemical slug volume had been injected, a tapered polymer slug was injected. A 0.37 pore volume ASP solution was injected, followed by a tapered polymer slug beginning in 1991 (Meyers et al., 1992). Although injection pressures were allowed to exceed the formation parting pressure, no adverse effects on recovery have been noted. More than a tenfold increase in daily oil production was observed within months of starting injection. Through November 1991, the ASP project had produced about 100,000 barrels of incremental oil at a cost (incremental cost over waterflood) of $\$ 3.94$ per incremental barrel (Meyers et al., 1992). Estimated ultimate recovery efficiency is $60.6 \%$ of the OOIP, higher than originally estimated, which would reduce incremental costs to $\$ 2.13$ per incremental barrel.

DOE is funding a detailed evaluation of the project (Pitts, 1994b) (1) to further quantify incremental oil recovery, (2) to quantify the effects of chemical slug volume, and (3) to determine the economic ramifications of the ASP technology.

\section{White Castle Field, Louisiana}

Shell field tested cosurfactant-enhanced alkaline flooding in a steeply dipping sand in the White Castle field in onshore Louisiana. Although reservoir dip $\left(45^{\circ}\right)$ is much steeper than the 0 to $5^{\circ}$ range in the offshore Gulf of Mexico reservoirs that are Shell's ultimate target for the process, reservoir and fluid characteristics are similar and gravity effects can be accounted for during simulation (Falls et al., 1992). To define the affected pore volume and flow patterns and to separate formation brine from the alkaline slug, the reservoir was preflooded with $\mathrm{NaCl}$ brine to residual oil saturation (Falls et al., 1992). Sodium carbonate was used in the chemical slug after initial injection indicated significant injectivity reductions with a sodium silicate slug. Chemical slug volume was 0.27 pore volume, followed by a 1.85 pore volume $1 \% \mathrm{NaCl}$ chaser slug. Analysis indicated the process recovered $38 \%$ of the waterflood residual oil, and the chemical slug propagated through the reservoir with predictable losses (Falls et al., 1992).

Shell evaluated the effect of dip angle on oil recovery in sandpack floods and found oil recovery to be consistent with theory (Nelson, 1993). As a result of the White Castle test and laboratory investigations, Shell developed a "surfactant-induced drainage" process where surfactants are injected into watered-out producers near the top of steeply dipping reservoirs (Nelson, 1993). Mobilized oil is produced by gravity effects and polymer is not required.

\subsubsection{Current Research Activity}

\subsubsection{DOE Supporting Research}

Surtek is performing a detailed evaluation of the ASP process in the West Kiehl field, Minnelusa reservoir project in Wyoming. Results of this project (section 4.5.4.4) are quite favorable. Detailed evaluation of the West Kiehl ASP project will provide operators improved information to evaluate potential applicability of the ASP process to their reservoirs (Pitts, 1994b). 
DOE is funding mechanistic research on the ASP process. Surtek's research is directed towards defining interactions of an alkaline agent, a surfactant, and a polymer on a fluid-fluid and a fluid-rock basis. Initial work indicates that surfactant-alkali IFT reduction synergism is reduced by the presence of polymer (Pitts, 1994a). Surtek is also researching how to improve economics of the ASP process. At the Illinois Institute of Technology (IIT), research is focused on $\mathrm{pH}$ buffering with mixed alkali systems as a means of improving ASP costs and effectiveness (Wasan, 1994; Rudin and Wasan, 1993).

At NIPER, research is focusing on weak alkalis and the ASP process. Current research is (1) investigating polymer-surfactant interactions, (2) investigating the effect of wettability on oil recovery, and (3) comparing oil recovery with different ASP formulations in heterogeneous field cores (NIPER/BDM, 1994). The research is interconnected with evaluation of the ASP process in the Hepler field in Kansas (see next paragraph). Light-scattering is being evaluated as an experimental technique for evaluating polymer-surfactant interactions. Wettability effects are being evaluated in Berea sandstone cores using crude oil from the Hepler oil field. Preliminary coreflooding results with heterogeneous field core indicate that mobility control affects oil recovery more than size of the chemical slug (NIPER/BDM, 1994).

NIPER and Russell Petroleum evaluated a potential application of the ASP process in the fluvial-deltaic Tucker sand, a local equivalent of the Bartlesville sand, in the Hepler field in Kansas. Initial laboratory work developed an effective ASP formulation (French et al., 1990). Advanced analytical techniques like $X$-ray computer tomography, petrographic image analysis, and a minipermeameter indicated that compartmentalization and lamination extend to the microscale (French, 1994a). Field tracer tests were also performed. The high degree of heterogeneity found in field cores and less than anticipated oil recovery in corefloods led to a recommendation to not implement the ASP process in the Hepler field (French, 1994b). If the operator conducts a polymer flood and establishes that good field sweep efficiency could be obtained, the ASP process will be reconsidered at a later date. Since Class 4 reservoirs are not as heterogeneous as fluvial-deltaic reservoirs, ASP process demonstration in Class 4 reservoirs should be less influenced by reservoir heterogeneities.

\subsubsection{DOE Cost-Shared Field Demonstration Program}

DOE has initiated cost-shared field demonstration projects with operators in Class 1 fluvialdominated deltaic and Class 2 shallow-shelf carbonate reservoirs. Proposals in Class 3 slope-basin and basin clastic reservoirs are currently being evaluated. No Class 1 or 2 projects specifically note alkaline or ASP processes. One Class 3 proposal in a California reservoir incorporates the ASP process along with other technologies (OGJ, 1994).

\subsubsection{Research Needs}

Research needs related to the alkaline and ASP processes are listed below:

(1) develop an improved understanding of injection strategy, specifically addressing the issue of polymer and alkali-surfactant interactions,

(2) develop a database of fluid and reservoir data required for screening reservoirs for the ASP process (mineral content, oil characteristics, brine characteristics, $\mathrm{CO}_{2}$ content, cation exchange capacity, etc.),

(3) conduct well-documented field tests of the ASP process in less heterogeneous reservoir classes (such as Class 4), and

(4) continue surfactant and mixed surfactant research striving to reduce costs of effective surfactant systems.

Of these, injection strategy and additional field tests are most important to the Class 4 oil resource. 


\subsection{Surfactant Process}

Being a miscible process, the surfactant process can recover significant oil. However, field results with surfactants have been unpredictable, costs are front-end loaded, and current chemical systems are uneconomic at moderate oil prices (Pope, 1993). Field projects have also exhibited high sensitivity to reservoir heterogeneities. As a result, industry perceptions are somewhat negative, and research in surfactant development has diminished. However, the process can be highly efficient and, if improvements are made, applicable to a large number of reservoirs, including those in Class 4.

Topics included in this section are the relationship of surfactant flooding to the Class 4 oil resource, screening criteria, constraints, recent technology thrusts, current research activity, and research needs.

\subsubsection{Relationship to the Class 4 Oil Resource}

The TORIS analysis of future recovery potential from Class 4 reservoirs (see chapter 2) confirms that recovery potential using surfactants is highly dependent on oil price and technology advancements. With implemented technology, measurable recovery potential, and then only $6 \%$ of the total potential, exists only with the higher $\$ 30$ per barrel oil price. With advanced technology, recovery potential using surfactants rises to $36 \%$ of the total potential at the higher $\$ 30$ per barrel oil price. At a $\$ 20$ per barrel oil price and advanced technology, recovery potential using surfactants is still $25 \%$ of the total potential. The Class 4 recovery potential associated with the surfactant process is significant, and technology development efforts will benefit from synergism between alkaline-surfactant-polymer (ASP) and surfactant research.

Although small surfactant projects have been performed in Class 4 plays in Texas's Jackson and Southern Oklahoma's Desmoinesian plays, the Rocky Mountain area has seen the largest (and most well-documented) surfactant projects, the Big Muddy and Bell Creek projects (NIPER/BDM, 1994a). At present, no surfactant projects are known to be active in Class 4 reservoirs.

\subsubsection{Screening Criteria}

The screening criteria used by the NPC (1984) for the implemented and advanced technology cases are summarized in Table 4.12.

In the advanced technology case, the process becomes applicable to either sandstone or carbonate reservoirs. Temperature, salinity, permeability, and viscosity limits are also extended. Although salinity-temperature levels in Class 4 reservoirs do not generally restrict surfactant applications, surfactant applications are constrained by process economics. Chemical and/or process changes that result in more cost-effective systems will expand surfactant recovery potential in the Class 4 oil resource.

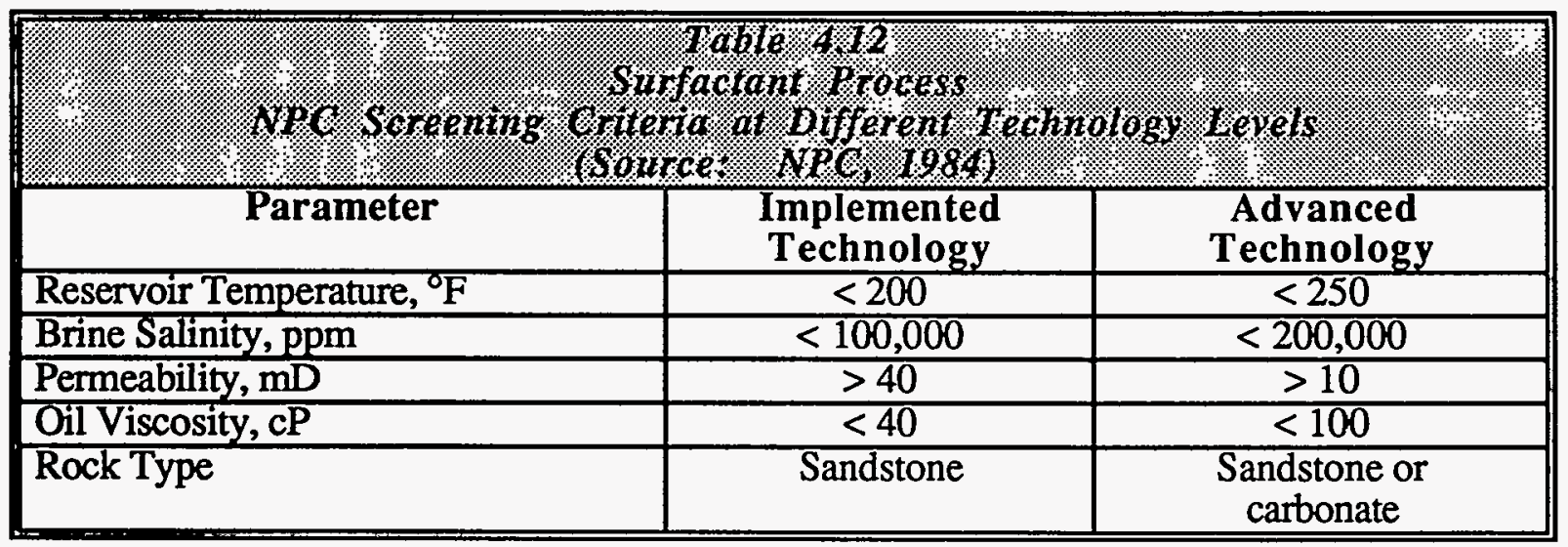




\subsubsection{Constraints}

Dauben (1991) analyzed field projects to determine constraints to field applications of the surfactant process. Surfactant floods were found to be constrained by excessive chemical loss, polymer limitations (section 4.3), process design and operations, and an inherent design weakness. The inherent design weakness refers to the need for two dissimilar fluid slugs to travel in sequence and remain intact as they travel through the reservoir.

Field experience indicates that (1) preflushes to protect surfactant slugs from excessive salinity and hardness have been ineffective and that (2) chemical systems must be effective in the presence of both injection brine and formation water (Kalpacki, et al., 1990). Since surfactants encounter a variety of salinity and hardness environments as they move through a reservoir, chemical systems that maintain their effectiveness in a wide range of environments are desirable. Although technology advances have been made in this area, more broadly applicable chemical systems are still needed. From a cost-effectiveness standpoint, these chemical systems should also incorporate industrial-grade rather than laboratory-grade surfactants.

\subsubsection{Recent Technology Thrusts}

Surfactant research has focused on developing improved chemical systems that are more salinity tolerant, effective in varying salinity conditions encountered in the reservoir, and that do not separate as the chemical slug moves through the reservoir. Recent technology thrusts discussed in this section include (1) more cost-effective mixed surfactant systems, (2) surfactants effective in higher temperature and salinity environments, (3) research tool development (chemical EOR database and laboratory screening procedures, and (4) more cost-effective surfactant flooding approaches.

\subsubsection{Mixed Surfactant Systems}

Mixed surfactant systems are mixtures of surfactants rather than surfactant-alcohol mixtures encountered in conventional surfactant systems. Mixed surfactant systems are (1) more costeffective than conventional systems, (2) adaptable to a broader range of reservoir conditions, (3) more tolerant of widely varying conditions in the reservoir, and (4) not as susceptible to chromatographic separation as the chemicals move through the reservoir (Llave et al., 1991). Synergistic effects in properly formulated mixtures of two to three surfactants yield solutions that exhibit properties better than any of the surfactants individually.

NIPER has been investigating how surfactant structure and combinations of surfactant affect the performance of mixed surfactant systems. Research and findings are summarized here:

(1) Llave et al. (1991) studied the effects of component substitution, salinity, ratio of components, total surfactant concentration, and surfactant type on the behavior of mixed surfactant systems. Results indicate:

a) The molecular weight and branching structure of the primary sulfonate-type surfactant affect phase behavior. For mixed systems, longer chain lengths favor good solubilization and low IFT values. The combined effect of chain length and branching in the primary surfactant can alter the system requirement for secondary salinity-tolerant surfactant.

b) Ethoxylated secondary surfactants affect salinity tolerance of the mixture with the effect varying with molecular weight and branching-structure of the ethoxylated surfactant. Shorter hydrocarbon chain lengths and branching in the secondary ethoxylated surfactants improve solubility and salinity tolerance. 
c) Ethoxylated sulfates improve salinity tolerance more than ethoxylated sulfonates when the primary surfactant is a sulfonate-type surfactant.

d) The proportion of primary and secondary (salinity-tolerant) surfactants affects the favorable salinity range of the mixed surfactant system.

e) The range of salinity tolerance is affected by the total surfactant concentration in the mixed system.

(2) Llave et al. (1993) investigated the performance of mixtures of a well-studied anionic primary surfactant with ethoxylated anionic/nonionic surfactants. Results indicate:

a) Ethoxylated surfactants can improve solution behavior of the overall system.

b) Ethoxylated nonionic surfactants yield higher salinities compared to ethoxylated anionic surfactants.

c) The proportion of surfactant component in solution is critical to balancing solubilization capacity and enhanced salinity tolerance.

This basic research regarding the effects of surfactant structure(s) on oil recovery, when interrelated with information contained in the chemical EOR database, provides the foundation for continuing development of more cost-effective surfactant systems.

\subsubsection{High-Temperature, High-Salinity Surfactants}

NIPER has investigated three potential surfactant systems for high-temperature and highsalinity environments: (1) ethoxylated sulfonates, (2) ethoxylated carboxylates, and (3) amine oxides (Gall, 1993). Amine oxide surfactants exhibit improved salinity tolerance and reduced alcohol requirements (Olsen, 1989). However, field applications are constrained by the large volumes of chemicals required. Carboxymethylated ethoxylated (CME) surfactants are adaptable for application in harsh environments (Olsen and Josephson, 1987; Strycker, 1989), but surfactant losses are too high. Sacrificial agents to reduce surfactant loss are not effective at optimum reservoir conditions (Gall, 1989). Work on ethoxylated sulfonate systems has largely been in conjunction with mixed surfactant systems.

\subsubsection{Chemical EOR Database and Expert System}

Considering the wide range of prior research and surfactant possibilities, a chemical EOR database has been developed to organize laboratory and field information (Llave, 1992). The database includes both a literature reference section and a surfactant information section crossreferencing and identifying data on specific surfactants and chemicals. Long-range, the database may evolve into some level of expert system to assist formulators in developing chemical systems for specific reservoirs.

\subsubsection{Laboratory Screening Procedures}

In developing surfactant systems, the performance of myriad combinations of surfactants must be evaluated. Conventional phase behavior measurements using salinity scans are time consuming. Llave and Olsen (1988) established that phase inversion temperature (PIT) could be used as a more rapid, preliminary screening measurement. Phase inversion temperature is that temperature at which a water-in-oil emulsion reverts to an oil-in-water emulsion or vice versa. NIPER developed semi-automated, computer-monitored equipment for measuring the phase inversion temperature. Results from PIT measurements are used to determine appropriate salinity ranges, then the timeconsuming salinity scans are performed in only those selected ranges.

$\mathrm{X}$-ray imaging methods and visualization have become integral to surfactant development studies. Imaging of fluid saturations during corefloods provides insight regarding the effectiveness of surfactant and polymer systems at mobilizing oil and regarding the effects of rock properties and reservoir heterogeneities on fluid movements (Gall, 1993). 


\subsubsection{Cost-Recovery Balance}

Kalpakci et al. (1990) describe a low-tension polymer flood approach for cost-effective chemical flooding. The process involves coinjection of polymer and low concentration surfactant followed by a polymer mobility control slug. Although recovery efficiency is not as great as conventional surfactant processes, recovery does increase, chemical costs are lower, and chemical costs are not all incurred on the front end. Although Nelson (1989) was critical of low concentration surfactant flooding, his discussion did not consider added polymer.

Low-tension polymer flooding sacrifices oil recovery in return for lower chemical cost. The premise highlights that chemical flooding must optimize economic recovery, not oil recovery. In simulation work for North Sea surfactant floods, Jacobsen and Hovland (1994) evaluated economy, defined as maximum discounted net cash, and found that optimum economy was achieved when typically less than $50 \%$ of the technical potential, or maximum incremental oil recovery, was recovered. This concept of optimum cash recovery rather than optimum oil recovery must be kept at the forefront as development work for improved surfactant systems continues.

\subsubsection{Current Research Activity}

\subsubsection{DOE Supporting Research}

At the University of Texas, research effort is focusing on improving the economics of the surfactant process through simulation studies of alternative design strategies (Pope and Sepehrnoori, 1994). The outlined research includes improvements in simulator capability, then optimization of the surfactant process using the simulator.

At Columbia University, research effort is focusing on the mechanisms underlying surfactant adsorption and precipitation on reservoir minerals (Somasundarin, 1994). The end objective is to better understand and control surfactant losses.

The Morgan State Fossil Energy Consortium is investigating alternative surfactants for light oil recovery at elevated temperatures and high brine concentrations (DOE, 1994). Phillips Petroleum is a private sector collaborator in this project.

At NIPER, research is continuing on mixed surfactant systems (NIPER/BDM, 1994b). Phase behavior evaluations are directed toward identifying optimal salinity conditions for different chemical systems. NIPER's Automated Phase Inversion Temperature (PIT) apparatus, salinity, and alkane scans are being used to determine the range of application conditions. Current work is investigating the effect of anionic-nonionic components of the mixture on optimal conditions. As optimal conditions are identified, oil recovery with different injection strategies is being evaluated in coreflooding experiments.

\subsubsection{DOE Cost-Shared Field Demonstration Program}

DOE has initiated cost-shared field demonstration projects with operators in Class 1 fluvialdominated deltaic and Class 2 shallow shelf carbonate reservoirs. Proposals in Class 3 slope-basin and basin clastic reservoirs are currently being evaluated. No Class 1 or Class 2 projects specifically incorporate surfactant flooding technology. None of the proposals received for Class 3 propose surfactant-flooding technology (OGJ, 1994). The low level of interest in field projects reflects adverse economics at present and with costs and oil prices perceived in the near future.

\subsubsection{Research Needs}

In 1993 DOE sponsored a chemical EOR workshop with one purpose being to assess chemical EOR research needs (NIPER/DOE, 1993). Identified research needs specific to surfactants include:

(1) additional evaluation of large slug, low concentration processes (like low-tension polymer floods) which aid economics by reducing front-end chemical costs, 
(2) further investigation of horizontal well applications to lower front-end cost loading or target reservoir sections having higher oil saturations (Taber, 1993),

(3) increased investigation of combination processes (like the ASP process, gel polymer and surfactants), preferably combinations which exhibit synergism, investigation of foam mobility control in addition to polymer mobility control,

(5) further development of PC-based chemical simulators, including horizontal well models, and

(6) investigation of chemical flooding applications in fractured reservoirs.

The continued research need for improved chemical systems underlies the above specific research items. To some extent, ongoing research is constrained by limited supplies of new chemical formulations as chemical manufacturers divert their efforts to other more profitable arenas. Chemical supply becomes even more critical for potential field applications.

\subsection{Steam Process}

Steam projects in Class 4 reservoirs have historically been focused in California, although projects have been conducted in Texas and Oklahoma. Existing steam projects are particularly influenced by economics and environmental regulations. Technology advances will play a role in improving economics and complying with environmental regulations. Outside California, new steam projects face typical technical constraints plus the lack of a thermal infrastructure.

Topics covered in this section include the relationship of the steam process to the Class 4 oil resource, screening criteria, constraints, recent technology thrusts, current research activity, and research needs.

\subsubsection{Relationship to the Class 4 Oil Resource}

The TORIS analysis of future recovery potential from Class 4 reservoirs (see Chapter 2) indicates that steam process potential could be realized primarily from expansions of ongoing steamfloods. With implemented technology levels, steam project expansion potential represents about $15 \%$ of the total potential in the $\$ 20$ and $\$ 30$ per barrel oil price cases. With advanced technology, new steam applications begin to make a contribution at the higher $\$ 30$ per barrel oil price, approaching $5 \%$ of the total potential.

Improved oil production from California's Class 4 steam projects is about 22,000 barrels of oil per day (Moritis, 1992) with major projects in the Vedder/Pyramid Hills and San Ardo/King City Plays. In the San Ardo field, both Mobil and Texaco operate major projects in the Aurignac and Lombardi reservoirs (NIPER/BDM, 1994). In the Vedder/Pyramid Hills Play, Shell's Mount Poso steamflood is the primary thermal project. In Texas, steam operations have been conducted in the Cretaceous, Salt-Related and Jackson Barrier/Strandplain Plays. In southem Oklahoma, a Mobiloperated steam project is active in a 4th Deese sand in the Southern Oklahoma Desmoinesian Play. Steam projects have not been noted in Class 4 reservoirs in the Rocky Mountain states.

\subsubsection{Screening Criteria}

The screening criteria used by the NPC (1984) for the implemented and advanced technology cases are summarized in Table 4.13. 


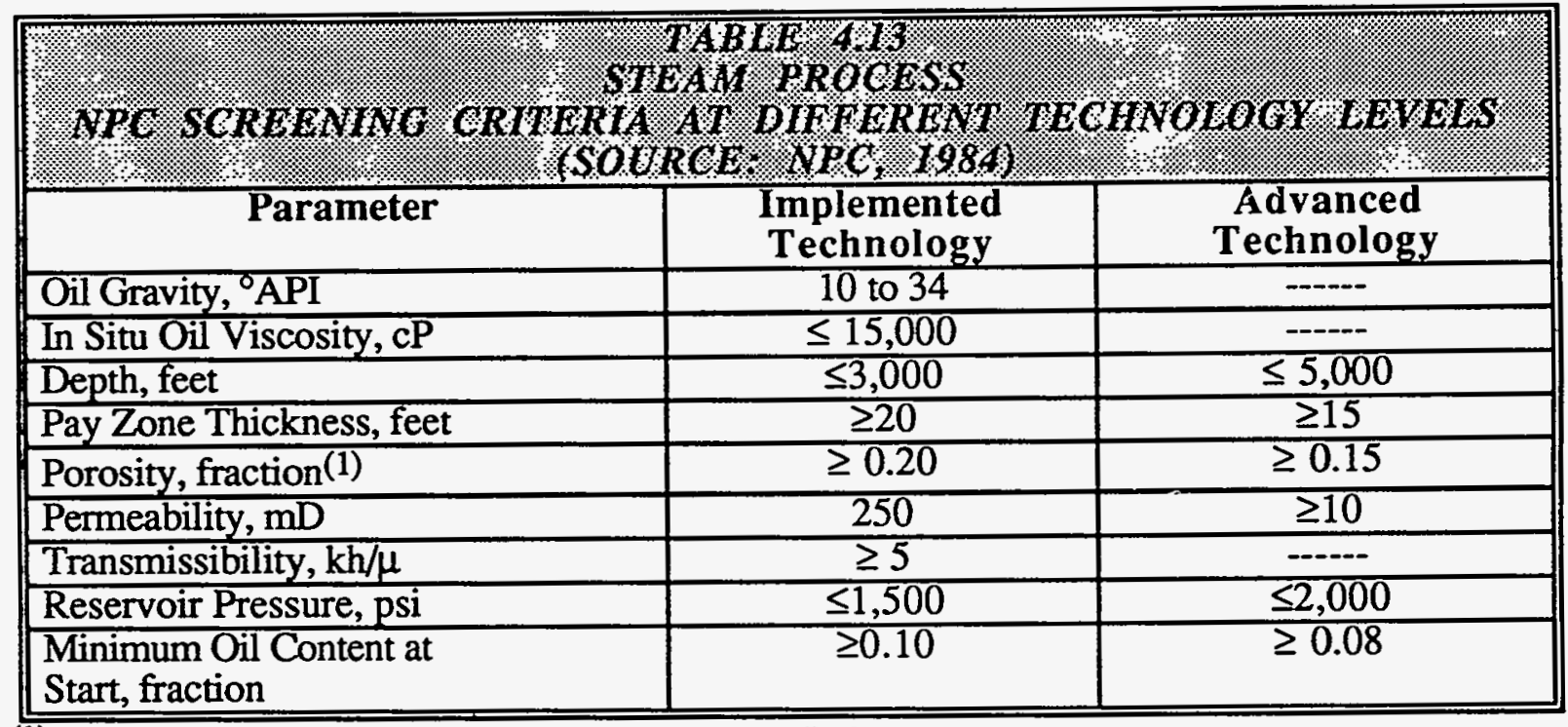

(1) Ignored if minimum oil content criterion satisfied.

The depth and net pay thickness criteria recognize heat loss effects. As technology improves from the implemented to the advanced technology level, the depth criterion increases from 3,000 to 5,000 feet while minimum net pay thickness decreases from 20 to 15 feet. The minimum permeability criterion also decreases significantly, from $250 \mathrm{mD}$ down to $\geq 10 \mathrm{mD}$. For Class 4 reservoirs, the depth and net pay criteria represent the primary criteria. In California, where Class 4 steam production is focused, depths and net pays in existing projects fall within the implemented technology criteria.

\subsubsection{Constraints}

Dauben (1991) analyzed steamdrive field projects to determine constraints to field applications considering steam cycling operations on individual wells as part of the steamdrive process. Steam operations were found to be constrained by gravity override, reservoir heterogeneity, downhole completions, and steam generation costs. Gravity segregation represents the primary performance constraint while environmental regulations greatly influence steam generating costs. Steam's high mobility accentuates reservoir heterogeneity's effect. Downhole completion constraints recognize that prudent design and operations practices are not always followed.

Sarathi (1993) outlined technical difficulties (i.e., constraints) for steam injection processes. These difficulties include: (1) reservoir definition, (2) poor conformance and capture efficiency, (3) low injection/production ratio, (4) excessive heat losses or poor net energy ratio, (5) sand control, (6) wellbore damage, (7) emulsion production, and (8) boiler feedwater and low-grade fuel options: Sarathi (1993) specifically noted steam quality measurement and high temperature instruments and materials as operations constraints.

Air quality regulations constrain both existing and new steam operations, particularly in California where the bulk of steam operations are currently located. Outside California, steam operations are constrained by the lack of thermal infrastructure (vendors, equipment, experience, etc.).

\subsubsection{Recent Technology Thrusts}

Although steamflood technology has made significant advances during the past three decades, the technology is far from mature and ample room exists to improve the process and the ultimate recovery in both ongoing and future projects. During the early 1980 s, although the need for 
efficiency was recognized, very little attention was paid to improving the operation since oil prices were high. The focus of research during the early 1980s was to extend the application of steam to different reservoir settings and explore the use of chemical additives to improve the sweep efficiency. During this time period, research was also directed towards combining other EOR processes, such as gas or caustic flood processes, with steam to enhance recovery. The oil price collapse of the mid-1980s forced the steamflood operators to move away from research directed at improving the process to research that contributed to lowering the recovery cost. The current trends are to develop technology and practices that improve the efficiency of field operation.

During the past ten years, noticeable advances in steamflood practices have been made that enable operators to manage the injected heat more efficiently and improve profitability. Topics covered in this section include advances in steam distribution practices, subsurface equipment and methods, process improvements directed towards enhancing steamflood recovery, advances in reservoir management practices, and simulation.

\subsubsection{Advances in Steam Distribution Practices}

In a steamflood, the wet (two-phase) steam leaving the steam generator is injected into the reservoir through a network of pipelines called the steam distribution system. Up until the late 1970 s, it was commonly assumed that the two phase steam would divide evenly at various branching points (such as the tees and wyes) in the network and arrive at the wellhead with approximately the same quality as the generator output, or proportionately less after adjustment for heat losses in the lines. Research by Chevron, however, showed that widely different steam qualities can arrive at the wellheads (Hong, 1978). As a result of further research into the problems of phase splitting, the use of tees in the dead-end configuration was adopted by the industry to achieve uniform steam quality distribution (Sarathi and Olsen, 1992). However, recent wellhead flow rate and quality measurements indicate that uneven quality splits commonly occur whenever the ratio of split volumes at dead-end tees deviates considerably from 1:1 (Peake, 1992; Jones and Williams, 1991). The range of steamflow conditions that produce acceptable quality splits has been determined (Chien and Schrodt, 1992). Insertion of nozzles directly down stream of impacting tees or use of large diameter tees in the network can increase the range of flow conditions for which acceptable quality split occurs (Hong and Griston, 1994).

\subsubsection{Steam Flow and Steam Quality Measurement and Control}

Proper evaluation and management of a steamflood require an accurate determination of energy entering the formation. The enthalpy or total heat entering the formation is strongly dependent upon the steam quality and rate of steam injection. Currently, orifice plates are used to measure the rate, and fixed or variable chokes operating at critical flow conditions are used to control the well injection rate (Redus et al., 1988 ; Griston, 1989; Chien and Schrodt, 1992). Recent advances in this area have been limited to improving the accuracy of correlations used for converting orifice or choke readings into rates (Surbey et al., 1988; Chien et al., 1992; Chien, 1993).

Steam quality, which enters into the calculation of steam generator efficiency and wellhead injection rate using devices such as the critical choke, is even more difficult to measure. Sarathi and Olsen discussed in detail the various oilfield steam quality measurement practices and their limitations (Sarathi and Olsen, 1992). Recent advances in surface online steam quality measurement techniques include the neutron densitometer technique (Wan, 1990) and development of improved correlations to estimate steam quality from orifice plate data (Chien and Schrodt, 1992; Blacker and Bellaci, 1994). A satisfactory technique does not yet exist to measure downhole steam quality.

\subsubsection{Subsurface Equipment and Methods}

Since the mid-1980s, major emphases have been placed on measuring downhole parameters and altering operations on the basis of specific in situ data. This led to the improvement or 
development of new subsurface equipment and methods in the past decade to inject steam simultaneously into multiple zones and exercise control over steam injection profiles.

Parallel tubing methods developed in the mid-1980s (Hong, 1987; Anderson and Hutchinson, 1983) to inject steam simultaneously into two or more independent sands using a common wellbore are now extensively being used in the U.S. and overseas steamflood operations.

Some control of where the steam enters the reservoir can be accomplished using limited entry perforation schemes. The scheme, patented in the mid-1980s (Hong et al., 1987), is used to inject constant quality steam between two or more targeted intervals through limited entry outlets. Downhole critical velocity chokes (Webb, 1988) are employed to achieve the limited entry outlets. A theoretical framework for limited entry perforation has been developed (Chiou and Owens, 1992).

\subsubsection{Injection Profiling}

Measurement of steam injection profiles is important so that adjustments may be made to assure that steam is contacting the oil-bearing formation. Since the mid-1980s, industry has expended considerable effort to increase the reliability of profile survey data. Radioactive tracer measurement of steam injection profiles using gamma ray logging tools is one such innovation (Nguyen and Stevens, 1988); however, data interpretation is difficult due to lack of knowledge of the flow stream lines in the injection wells. Current efforts are directed at improving data analysis methods so that injection profiles may be determined more reliably (Griston, 1990).

\subsubsection{Process Improvements}

During the past decade, considerable efforts have been expended to improve recovery, reduce gravity override, and manage the injected heat more efficiently. These practices have improved steamflood economics, as discussed below.

\section{Infill Drilling}

This is a relatively new practice in steamflood projects. Infill drilling is directed at improving steamflood recovery in projects that utilize a five-spot configuration, such as the Kern River Field, California. The infill drilling involves converting the normal 2.5 -acre five-spot patterns to inverted nine-spot patterns by drilling infill producers at the midpoints of pattern boundaries. The object of infill drilling is to recover the oil that would otherwise be bypassed by the injected steam. Texaco was the first operator to practice infill drilling in a steamflood (Restine et al., 1987). Although infill drilling accelerated production and recovered oil from the so called blind spots (pockets of bypassed oil), some steam injection practitioners think it does not increase the ultimate recovery. Decisions to drill infill wells have historically been based on accelerated economics, not on incremental recovery (Blevins, 1990).

\section{Slimhole Wells}

Like infill drilling, this is a new practice in steamflood projects and was designed to reduce drilling and completion costs. A slimhole is different from a conventional well, in that no downhole equipment such as packers and tubing is used, lowering drilling and completion costs. Slimholes allow the dedication of injectors to individual sandbodies to improve sweep efficiency and production. The low cost of slimhole drilling allowed Chevron to drill 38 slimhole producers and ten observation wells, for about the same investment required to drill seven conventional dual string wells (Dennis et al., 1994). This project, implemented in a Midway-Sunset California property, increased the daily oil production from 1,800 barrels to 2, 600 barrels (Dennis et al., 1994). 


\section{Horizontal Wells}

The use of horizontal wells in a steamflood to recover oil from blind spots is an emerging technology (Spiers and Warren, 1994; Jespersen and Fontaine, 1993; Buller, 1992; Carpenter and Dazet, 1992; Dickinson et al., 1992; Sahuquet et al., 1990; Huang and Hight, 1989; Dietrich, 1987). By placing horizontal producers at or near the bottom of a steamflood interval along the pattern boundary, oil in the steam gravity override zone which is bypassed by steam can be captured. UNOCAL has used a horizontal injector to efficiently heat a previously bypassed portion of the reservoir and successfully recovered incremental oil (Buller, 1992). Shell's horizontal well steamflood experience in California indicates that horizontal thermal wells are prolific oil producers. Production rates from horizontal wells average 2.6 to 6 times those of vertical wells (Carpenter and Dazet, 1992). Use of horizontal wells in steamflood operations improved the sweep efficiency, oil-steam ratio, and project profitability (Spiers and Warren, 1994).

\section{Mobility Control Techniques}

Mobility control techniques are processes that attempt to improve the displacement efficiency and vertical sweep efficiency of the steamdrive. These techniques include waterflood after steamflood (Hong, 1987; Ault et al., 1985), steam-foam (Patzek and Koinis, 1990; Mohammadi et al., 1989), and water-alternating-steam processes (Hong and Stevens, 1992; Bautista and Friedmann, 1994). Chevron and Texaco implemented the waterflooding after steamflood process in California in the early $1980 \mathrm{~s}$, but discontinued the practice due to adverse production problems and questionable benefits (Sarathi, 1991). Although the steam-foam process for sweep efficiency improvement proved to be effective in field applications, the process has not generated much enthusiasm among operators due to questionable economics with oil prices less than $\$ 20 / \mathrm{bbl}$ (Sarathi and Olsen, 1993). The water-alternating-steam process (WASP) is akin to the wateralternating-gas injection process, a proven mobility control technique in the gas injection process. One major benefit of WASP is the reduction or elimination of steam breakthrough (Blevins, 1990). Chevron has implemented this mobility control technique at the West Coalinga and Cymric Fields, California, and claims to have succeeded in eliminating steam breakthrough problems and in improving sweep and recovery efficiency (Hong and Stevens, 1992; Bautista and Friedmann, 1994). In addition, cost-effective high temperature polymer gels have been developed and successfully applied in California steamflood projects to mitigate steam channeling and premature steam breakthrough (Hunter et al., 1992; Littlefield et al., 1992).

\subsubsection{Reservoir Management}

Since the price collapse of the mid-1980s, increased emphasis has been placed by steamflood operators on improving steamflood reservoir management practices. Industry now recognizes that improvements in steamflood reservoir management are the only way to increase performance and keep production costs down (Schmidt, 1990). Blevins (1990) defines steamflood reservoir management as those practices which include reservoir monitoring, heat management, water management, and conducting the operation in compliance with applicable environmental regulations.

Reservoir monitoring includes surveys conducted during the course of a steamflood project to gather information necessary for developing and updating the reservoir description. These surveys are conducted in injection, production, and observation wells. Recent advances in steamflood monitoring techniques include the use of cased-hole pulsed neutron capture logs to quantitatively predict the in situ steam distribution and steam breakthrough time (Guo et al., 1993; Guo, 1991; Masse et al., 1991), pressure survey in observation wells, cross-hole seismic profiles (Paulson et al., 1992) and use of surface deformation measurement tools to map areal migration of steam (Bruno and Bilak, 1994). Since typical steamflood fuel costs over the life of a project are on the order of five to ten times the initial investment, effective heat management practices are being 
emphasized by operators (Ziegler et al., 1993). Recent advances in monitoring tools and interpretation techniques have greatly enhanced an operator's ability to implement sound, economical heat management practices.

\subsubsection{Simulation and Performance Prediction}

Advances in computer hardware and numerical solution techniques in the past 15 years have made it possible to develop complex thermal simulators and conduct fieldwide simulations (Hong et al., 1992; Blunschi, 1987). Advances in thermal simulation techniques have contributed to the development of advanced steamflood implementation techniques and operational practices (Kumar, 1990; Hong, 1988; Hong, 1991; Chu, 1993a; Chu, 1993b; Hong, 1993). Newer and more reliable steamflood performance prediction models are being developed using historical production data (Torabzadeh et al., 1990; Harrigal and Wilcox, 1992).

\subsubsection{Current Research Activity}

The technical challenges facing steamflood operators in this low oil price environment are related to finding the most cost-effective ways of applying known technologies to maximize production and minimize operating costs. The current industry research effort is focused on developing better heat management and reservoir description techniques to reduce operational cost and improve the bottom line profit. Some of these issues were discussed in the previous section.

\subsubsection{DOE Supporting Research}

At NIPER, research is focused on improving the understanding of light and heavy oil production using steam and on using this understanding to accelerate the development and expansion of the domestic resource base. Towards this end, NIPER is establishing a hightemperature, high-pressure steamflood laboratory that will allow steamflood experiments to be conducted at field conditions. Initial research will focus on developing steamflood operational parameters to recover high pour point crude oil from sucrosic dolomite reservoirs.

NIPER is working with the Naval Petroleum Reserve No. 3 (NPR-3) to develop ways to improve recovery efficiency and economics of the NPR-3 light oil steamflood project. Simulation studies are also being conducted at NIPER to assess steamflood potential of Gulf Coast heavy oil reservoirs (Sarkar and Sarathi, 1993a, 1993b).

DOE is funding steamflood mechanistic research at Stanford University and the University of Southern California (USC). Stanford is working on several areas: (1) studies directed towards understanding the effects of steamflood conditions on flow properties, such as the relative permeability and steam flow behavior in fractured reservoirs, (2) improvement of well testing methodologies for steamflood injection and production wells, and (3) development of improved steamflood performance prediction models. Research at USC is directed towards understanding rock-fluid interaction mechanisms in steamflood reservoirs and the influence of micro- and macroscale heterogeneities on steamflood performance. In addition, DOE is sponsoring a project at Lawrence Livermore National Laboratory (LLNL) to apply borehole electromagnetic methods to monitor in situ changes in electrical conductivity during steamflood. The goal of this project is to develop practical tools to locate the steamfront and tools for mapping oilfield structure.

\subsubsection{DOE Cost-Shared Field Demonstration Program}

DOE has awarded contracts for cost-shared field demonstration projects in Class 1 fluvialdominated deltaic and Class 2 shallow-shelf carbonate reservoirs. Steam processes were not involved in any of the projects which were awarded.

In Class 3 slope-basin and basin clastic reservoirs, which includes a portion of California's thermal operations, DOE received 31 cost-shared field demonstration proposals with about onethird of the proposals involving steam operations in California (OGJ, 1994). Diverse technologies 
covering a range of reservoir, process, operations, and economic issues were incorporated in the various proposals. DOE anticipates making awards in September 1994.

\subsubsection{Research Needs}

Many technological advances are needed in the future to extend the application of steamflood technology to difficult reservoir settings and to improve the process efficiency. Additional understanding of basic reservoir properties and geology, refinement of data gathering instruments, improved heat management practices, improved mobility control techniques, and performance prediction techniques must be developed if the large amount of additional domestic resources are to be recovered economically. Selected research needs include:

(1) improvements in steam quality measurement and control,

(2) improved methods for splitting steam uniformly at pipe branches,

(3) improved steam injection profiling and control methods,

(4) development of better techniques for heat management and steam generation,

(5) improved subsurface equipment and completion techniques,

(6) improvement in horizontal well completion and sand control techniques for the hightemperature environment,

(7) development of cost-effective methods to deplete bypassed zones, and

(8) development of thermal techniques to recover heavy oil from environmentally sensitive areas.

\subsection{In Situ Combustion Process}

The in situ combustion process is applicable to and has potential in selected Class 4 reservoirs, as evidenced by the number of early projects tried in Class 4 reservoirs (NIPER/BDM, 1994), but operators must overcome negative perceptions from past project failures before the process will be widely applied. This section covers the relationship of the in situ combustion process to the Class 4 oil resource, screening criteria, constraints, recent technology thrusts, current research activity, and research needs.

\subsubsection{Relationship to the Class 4 Oil Resource}

The TORIS analysis of future recovery potential from Class 4 reservoirs (see chapter 2) indicates minimal potential from the in situ combustion process at implemented technology levels representing only 28 million barrels (of 1,839 million barrels) of oil at the $\$ 30$ per barrel oil price. With the advanced technology level, in situ combustion potential increases to 350 million barrels at the higher $\$ 30$ per barrel oil price representing $8 \%$ of the total recovery potential.

The in situ combustion process does not measurably impact overall Class 4 IOR production. Forest Hill Company currently operates an oxygen-enriched project in the Harris sand of the Forest Hill field in the Texas Cretaceous, Salt-Related Play. Bleakley (1987) reported project goals of 1,750 barrels of oil per day from this 125 -well project.

In situ combustion has been tested in several projects over a wide geographical area in the past (NIPER/BDM, 1994). In Texas, in situ combustion has been tested in the Jackson Barrier/Strandplain Play, in the Carrizo sand in the Slocum field in the Texas Cretaceous, SaltRelated Play and in the Woodbine "C" reservoir, Trix-Liz field in the Woodbine Fault Line Play. In Oklahoma, Mobil conducted a pilot in the 4th Deese sand in the Cox Penn Unit in the Southern Oklahoma Desmoinesian Play. In California, Mobil conducted a successful 30-well project in the Aurignac reservoir of the San Ardo field. In the Rocky Mountain region, Tenneco conducted an unsuccessful in situ combustion pilot in the South Hospah field. 


\subsubsection{Screening Criteria}

The screening criteria used by the NPC (1984) for the implemented and advanced technology cases are summarized in Table 4.14.

With implemented technology, in situ combustion can be applied in reservoirs up to 11,500 feet depth versus 3,000 feet for steam. Although viscosity limits are more restrictive, 5,000 cP versus $15,000 \mathrm{cP}$ for steam, the permeability limit falls to $35 \mathrm{mD}$ from $250 \mathrm{mD}$ for steam. With implemented technology, reservoir pressure is limited to 2,000 psi. The most significant changes with the advanced technology case are the reservoir pressure criterion increasing from 2,000 to 4,000 psi and the minimum net pay criterion decreasing from 20 to 10 feet.' Many Class 4 reservoirs fall within the screening criteria for the in situ combustion process.

\subsubsection{Constraints}

Dauben (1991) analyzed in situ combustion field projects to determine constraints to field applications. In situ combustion projects were found to be constrained by (1) poor sweep efficiency with the large volumes of noncombustible gases (assuming air injection) flowing through the reservoir, (2) erosion/corrosion in equipment, and (3) oil treating. Many problems experienced in early in situ combustion projects were related to inadequate reservoir characterization.

Improvements in technology and operating practices addressing these constraints have been made, but there is a shortage of current, well-documented field tests demonstrating the success of these improvements and the current economic potential of the process. New project starts are being constrained by operator perceptions from past projects, lack of demonstrated success with new technologies, and a shortage of current industry personnel with direct in situ combustion experience.

Technology thrusts discussed in this section include: (1) use of ISC process in carbonate reservoirs, (2) the double displacement process, (3) the horizontal well ISC process, (4) the pressure up-blowdown process, (5) the combustion override split-production horizontal well process, (6) the use of foam, and (7) hydrogen peroxide injection as an alternative to air or oxygen injection.

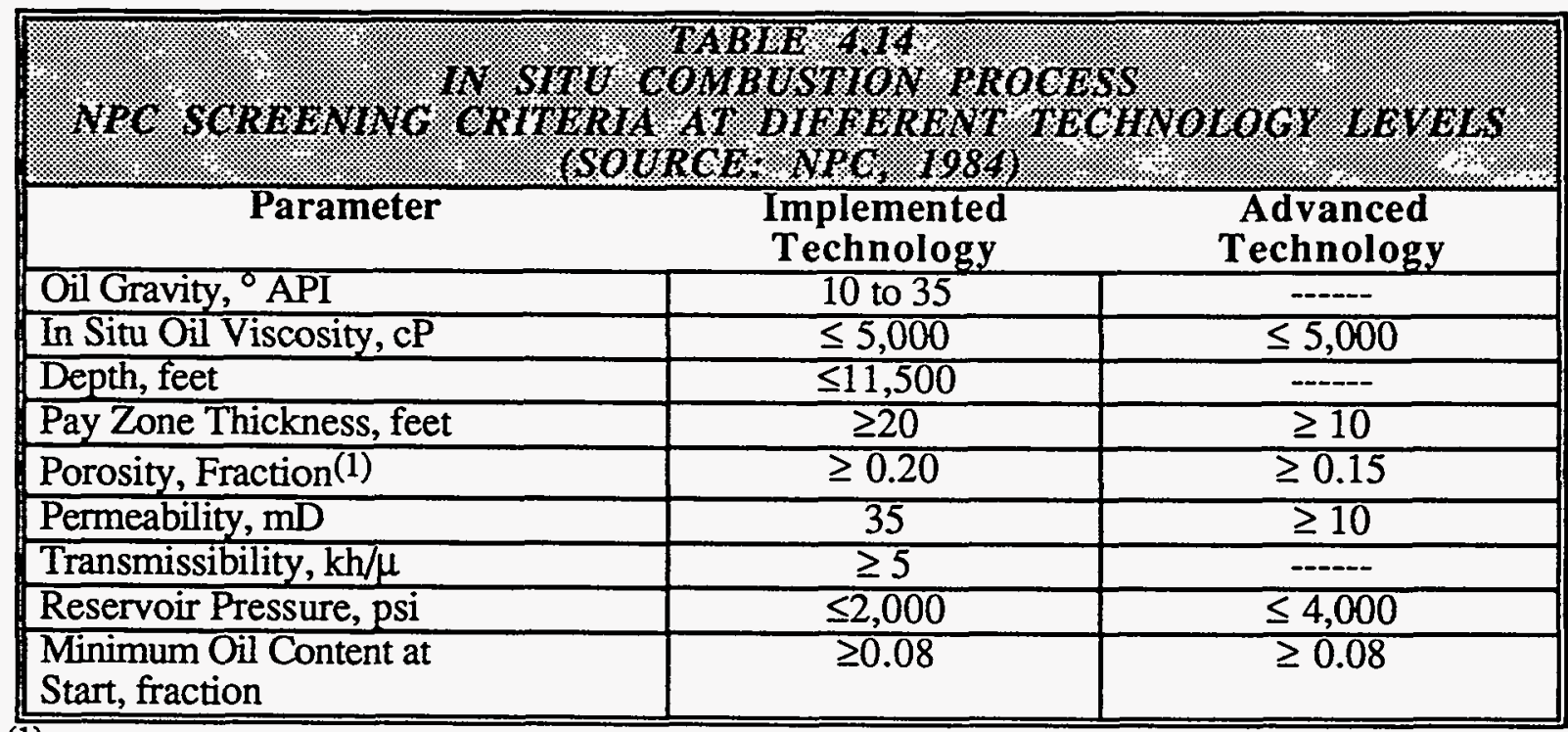

(1) Ignored if minimum oil content criterion satisfied. 


\subsubsection{Recent Technology Thrusts}

Despite the poor track record of in situ combustion (ISC) in the field and its reputation as the problem-prone EOR technology, industry interest in the process remains high due to the success of several field projects (notably in Canada) in very diversified reservoirs. Even in the U.S., interest in the process has been revived because of Koch's success in implementing this technology in deep carbonate reservoirs. Notable advances have been made during the past 15 years in the application of ISC to many reservoir settings. The main thrust in the U.S. has been to use the ISC technique as a means to repressurize and recover oil from deep, light-oil reservoirs. These and other advances are discussed below.

\subsubsection{Use of ISC in Carbonate Reservoirs}

Until 1984, ISC was considered applicable only to sandstone reservoirs because of their more favorable reservoir parameters. In 1985, Koch challenged this notion for the first time and implemented in situ combustion projects in the deep, thin, low-permeability carbonate reservoirs of the Williston Basin in North and South Dakota. Because of the uniqueness and proprietary nature of the projects, project details were not made public until 1994 ( Kumar et al., 1994; Miller, 1994). Koch's projects involve injection of air into deep carbonate reservoirs to pressurize and ignite the formation and displace the oil. The noteworthy aspect of these projects is that they violated many of the published screening criteria and yet proved to be commercially successful. The reservoir properties for these projects are compared to published screening guides in Table 4.15. The combined daily oil production from Koch's ISC projects in early 1994 was 4,900 barrels, which essentially doubled the reported 1992 U.S. daily oil production of 5,200 barrels from eight active ISC projects (Moritis, 1992).

\begin{tabular}{|c|c|c|c|c|c|c|}
\hline 1. & \multicolumn{5}{|c|}{ 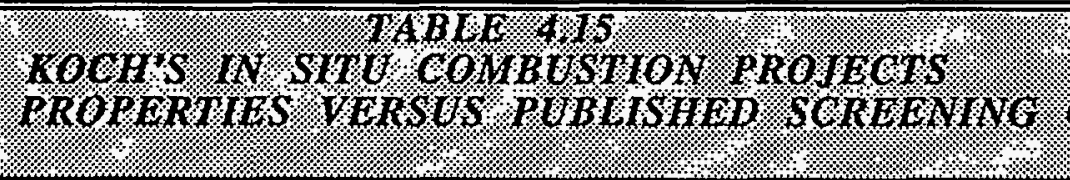 } & 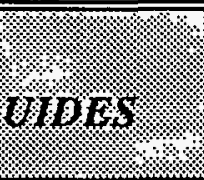 \\
\hline Properties & $\begin{array}{c}\text { Iyoho } \\
(1978)\end{array}$ & $\underset{(1982)}{\text { Chu }}$ & $\begin{array}{c}\text { NPC (1984) } \\
\text { Advanced } \\
\text { Technology }\end{array}$ & $\begin{array}{l}\text { MPHU* } \\
\text { (Miller, } \\
\text { 1994) }\end{array}$ & $\begin{array}{c}\text { Buffalo } \\
\text { (Miller, } \\
\text { 1994) }\end{array}$ & $\begin{array}{l}\text { Capa } \\
\text { Madison } \\
\text { Miller, } \\
\text { 1994) }\end{array}$ \\
\hline Oil Gravity, ${ }^{\circ} \mathrm{API}$ & $10-40$ & $<40$ & - & 39 & 31 & 43 \\
\hline $\begin{array}{l}\text { In Situ Oil } \\
\text { Viscosity, cP }\end{array}$ & $\leq 1,000$ & $=$ & $\leq 5,000$ & 0.48 & 2.1 & 0.28 \\
\hline Depth, ft & $=$ & $<12,000$ & - & 9,500 & 8,450 & 8,400 \\
\hline $\begin{array}{l}\text { Payzone Thickness, } \\
\mathrm{ft}\end{array}$ & $5-50$ & - & $\geq 10$ & 18 & 10 & 20 \\
\hline Porosity $\%(\approx)$ & $>20$ & $>16$ & $>15$ & 17 & 20 & 10 \\
\hline Permeability, mD & $>300$ & $>100$ & $\geq 10$ & 5 & 10 & 1 \\
\hline Oil Saturation, $S_{0}$ & $>50$ & $>35$ & $>53$ & 57 & 55 & 58 \\
\hline $\begin{array}{l}\text { Reservoir Pressure, } \\
\text { psi }\end{array}$ & $<4,000$ & - & $\leq 4,000$ & 4,500 & 4,200 & 4,200 \\
\hline$\approx S_{0}$ & $>0.077$ & $>0.1$ & $>0.08$ & 0.1 & 0.11 & 0.06 \\
\hline
\end{tabular}

*Medicine Pole Hill Unit 


\subsubsection{Double Displacement Process}

In 1994, Amoco Production Company, in partnership with DOE, initiated a unique in situ combustion project to recover oil from a deep, watered-out light oil reservoir in the West Hackberry Field in Cameron Parish, Louisiana. The goal of this Amoco/DOE Class 1 mid-term program is to utilize ISC to create a gas cap to push the encroached water column downward towards the original-water-oil contact and allow oil to drain by gravity (Fassihi et al., 1993). The process of displacing a water-invaded oil column by an expanding gas cap is called the double displacement process (Carlson, 1988).

\subsubsection{Horizontal Well ISC Process}

The use of horizontal wells as producers in ISC projects is becoming increasingly popular with Canadian operators due to increased production performance and substantial reduction in operating problems, such as sand production and low gas-oil ratios (Morgan, 1993; Ames et al., 1994). The reduced operating problems were attributed to the extremely low drawdown during oil flow towards the producers. Canadian experience indicates that, in bottom-water-drive reservoirs, recovery by ISC can be enhanced by placing horizontal wells between the overlying combustion gas cap and the underlying aquifer (Ames et al., 1994). In the U.S., horizontal wells were used in a Southeast Kansas in situ combustion project, but the results were disappointing (Satchwell et al., 1994). The horizontal well ISC process may find application in some bottom-water-drive Class 4 reservoirs, such as the Slocum field in Texas.

\subsubsection{Pressure Up-Blowdown Combustion Process}

This is a relatively new variation of the conventional combustion process (patented by BP Resources, Canada) to minimize channeling and improve recovery in highly viscous crude oil reservoirs (Hallam and Donnelly, 1988; McGee et al., 1988). The process, developed as a followup to cyclic steam stimulation, is designed to exploit a highly viscous crude oil reservoir with high mobility contrast. In this process, as the initial step, a heat link is established between the injector and producer by injecting steam into the reservoir. The reservoir is then alternatively pressurized and depressurized to advance the combustion front and produce the mobilized oil. The process, field tested in Canada in the mid-1980s, proved to be very effective in recovering immobile oil and may find application in some California Class 4 reservoirs, such as the Paris Valley and Lynch Canyon fields (NIPER/BDM, 1994). The earlier DOE cost-shared in situ combustion projects in these fields (Shipley et al., 1980; Stair, 1980) failed because of poor oil mobility.

Another variation of this process, which is currently being field tested in Canada, is the "pressure cycling in situ combustion process" (Marjerrison and Fassihi, 1994). This process is a cyclic in situ combustion process that involves periods of high-rate air injection followed by zero injection.

\subsubsection{The Combustion Override Split-Production Horizontal Well (COSH) Process}

This process is a new approach to combustion processes (patented by Alberta Oil Sands Technology and Research Authority (AOSTRA), Alberta, Canada) that combines the high recovery potential of a gravity drainage mechanism with the energy efficiency of the combustion process to improve oil recovery while minimizing the negative aspects of the combustion process (Kisman and Lau, 1994). The process is essentially a gravity drainage process and, as such, its applicability is limited to thick, dipping reservoirs with good vertical permeability, such as the Potter sand of Midway-Sunset Field, California. The process, while not yet field tested, may find application in Class 4 reservoirs such as the Sho-Vel-Tum Field of southern Oklahoma. 


\subsubsection{Use of Foam in ISC Process}

The use of foam to improve sweep efficiency is a relatively new concept in ISC projects. The concept, field tested in Russia, appeared to be a technical success and holds promise for reducing gas channels and improving production (Abasov and Kismetov, 1991; Mamedov and Bocserman, 1992). In the reported projects, $24,000 \mathrm{bbl}$ of foam-forming surfactant solution (2\% active), stabilized with $0.1 \%$ high temperature polymer solution, was injected into three combustion wells over a five-month period. Injection of the foaming solution resulted in 55,000 barrels of incremental oil.

\subsubsection{Hydrogen Peroxide In Situ Combustion Project}

Recently, a U.S. patent was issued for the use of hydrogen peroxide instead of air as the fluid to initiate and sustain combustion (Bayless and Williams, 1989). Laboratory combustion tube runs indicate that the process can recover substantial amounts of oil, while overcoming the drawbacks of conventional steam or ISC thermal processes (Moss and Moss, 1994).

\subsubsection{Current Research Activity}

Amoco is the only U.S. operator currently conducting in situ combustion-related research in the U.S. In 1990, Amoco formed an industry consortium to evaluate the air injection, in situ combustion process in deep, high-pressure, light-oil reservoirs. DOE, through BDM-Oklahoma, is participating in the Amoco in situ combustion research consortium to encourage further advancement of ISC technology. The aim of this research is to experimentally identify and quantify effects of pressure on the process, and the effects of the combustion products on crude oil recovery.

\subsubsection{DOE Supporting Research}

DOE is funding in situ combustion kinetic research at Stanford University. The aim of this research is to evaluate the effects of different reservoir parameters on the in situ combustion process. The project is primarily investigating the effects of various heavy metals found in the rock and crude on process behavior.

At NIPER, the thermal research group is currently compiling an in situ combustion handbook aimed at helping independent operators. The purpose of this compendium project is to document the valuable experience of past in situ combustion experts and encourage operators to consider implementing field projects.

\subsubsection{DOE Cost-Shared Field Demonstration Program}

DOE has awarded a contract to Amoco for a cost-shared field demonstration project in a Class 1 fluvial-dominated deltaic reservoir that utilizes combustion technology to mobilize and recover light oil from a deep, watered-out reservoir. The project is to be implemented in the West Hackberry Field located in Cameron Parish, Louisiana, near Lake Charles (Fassihi and Gillham, 1993).

Although DOE has not yet announced awardees for Class 3 slope-basin and basin clastic reservoirs cost-shared field demonstration projects, none of the proposals incorporate in situ combustion technology (OGJ, 1994). 


\subsubsection{Research Needs}

In situ combustion has many attractive features and, from the energy utilization point of view, is the most efficient of all thermal methods. The process is equally applicable to thin and thick reservoirs as well as to deep formations containing very light oil. In situ combustion is the only EOR process proved to be effective for recovering oil from reservoirs underlain by water (Horne et al., 1982). The performance of in situ combustion, however, is reservoir-specific, and the operating conditions must be tailored to the reservoir under consideration (Moore et al., 1988).

While considerable progress has been made in understanding the kinetics of in situ combustion and the mechanisms that lead to combustion failure, further research is needed to understand the interrelationship between the kinetics of thermal cracking and low temperature oxidation reactions. According to Farouq Ali (1994), a concerted research effort is needed in the following areas:

(1) definition of the effects that reservoir heterogeneities (geology, mineralogy, rock parameters) have on air and fluid flow in the reservoir and their effect on process performance, and

(2) development of reliable numerical simulators that take into consideration both reaction kinetics and complex geological features of the reservoir.

It is well known that in situ combustion projects are plagued with operational problems, and technological advances are needed to overcome these problems. Miller (1994) lists the following as the primary in situ combustion operation problems:

(1) explosion hazards,

(2) injection well failures,

(3) inadequate compression volume,

(4) poor sweep efficiency with high volume inert gas production,

(5) corrosion in high GOR wells,

(6) flue gas disposition with hydrogen sulfide content, and

(7) poor compressor design leading to low efficiency and frequent failure.

While progress has been made in recent years to mitigate some of those problems, the solutions are far from satisfactory.

\subsection{Carbon Dioxide $\left(\mathrm{CO}_{2}\right)$ Processes}

Carbon dioxide recovery processes, primarily miscible flooding, contribute a significant portion of the enhanced oil recovery production in the United States. Most miscible flooding projects are located in geographic areas having access to a $\mathrm{CO}_{2}$ pipeline infrastructure. For Class 4 reservoirs, the northern Rocky Mountain region is the only area having potential access to an existing $\mathrm{CO}_{2}$ pipeline structure. Other Class 4 areas will incur higher $\mathrm{CO}_{2}$ costs because of their lack of access to the supply infrastructure. Although recovery efficiencies with cyclic $\mathrm{CO}_{2}$ stimulation treatments may be lower than with miscible floods, cyclic treatments can be economic under certain reservoir and economic conditions. The TORIS estimates of recovery potential from $\mathrm{CO}_{2}$ do not include any potential contribution from immiscible or cyclic $\mathrm{CO}_{2}$ stimulation treatments.

Topics included in this section are the relationship of $\mathrm{CO}_{2}$ processes to the Class 4 oil resource, screening criteria, constraints, recent technology thrusts, current research activity, and research needs. 


\subsubsection{Relationship to the Class 4 Oil Resource}

The TORIS analysis of future recovery potential from Class 4 reservoirs (chapter 2) indicates that $\mathrm{CO}_{2}$ miscible flooding offers moderate potential for the Class 4 oil resource at the higher $\$ 20$ and $\$ 30$ per barrel oil prices. Recovery potential with implemented technology at $\$ 20$ and $\$ 30$ per barrel oil prices is 101,000 and 170,000 barrels, respectively, representing 7 and $9 \%$ of the total potential, respectively. With advanced technology, potential recovery volumes decrease about 30,000 barrels, but the percentage contributions drop to 2 to $3 \%$ of the total potential as other more efficient processes come into play. TORIS estimates do not include potential recovery from cyclic stimulation (huff ' $n$ ' puff) or immiscible $\mathrm{CO}_{2}$ floods.

$\mathrm{CO}_{2}$ processes have not measurably affected Class 4 production. Texaco conducted three small miscible projects in the Frio Play (Magnet Withers, Withers North, and Pickett Ridge fields) in Texas in the early to mid-1980s (Pautz et al., 1992; NIPER/BDM, 1994a). Although the projects were considered technically successful and economically promising (Pautz et al., 1992), the projects were not continued. Suspected reasons for the projects not being continued were lack of an available $\mathrm{CO}_{2}$ source combined with declining oil prices. Small pilot projects have also been conducted in Texas' Cretaceous, Salt-Related Play (Pittsburg field) and Oklahoma's Southern Oklahoma Desmoinesian Play (Sho-Vel-Tum field) (Pautz et al., 1992). Most interest, and some activity, in cyclic $\mathrm{CO}_{2}$ stimulation treatments has been in the northern Rocky Mountain region (NIPER/BDM, 1994a).

\subsubsection{Screening Criteria}

Since the NPC (1984) screening criteria only address $\mathrm{CO}_{2}$ miscible flooding, only two criteria are specified: (1) reservoir pressure should be sufficient to reach miscibility, and (2) crude gravity $\geq 25^{\circ}$ API. Screening criteria remain the same at the advanced technology level, but the advanced technology case allows higher recovery through using larger $\mathrm{CO}_{2}$ slugs and mobility control agents (chapter 2). The pressure criterion effectively limits miscible operations to reservoirs more than 2,000 feet deep (Taber and Martin, 1983). Klins' (1984) screening criteria recognized API gravity, pressure, depth, and temperature limits, but also added a viscosity criterion of $12 \mathrm{cP}$ or less.

Like other IOR processes, $\mathrm{CO}_{2}$ miscible screening criteria identify reservoirs where the process won't work, but additional screening concepts must be used to determine candidate reservoirs. Flanders et al. (1993) used economic screening concepts to evaluate the economic viability of $\mathrm{CO}_{2}$ floods in small- to medium-size fields. Sensitivities to $\mathrm{CO}_{2}$ cost, tax incentives, depth, pore volume, operating costs, and start-up costs were evaluated. Economic viability was found to be very field-specific, with a primary variable being start-up costs. Start-up costs include things like tubular condition, wellbore integrity, completion type, conversion of wells to $\mathrm{CO}_{2}$ injection, workovers in producers and injection wells, facility modifications, $\mathrm{CO}_{2}$ compression recycling plant, corrosion prevention measures, etc. Start-up costs and operating costs are depth dependent. The single biggest factor affecting economic viability is the $\mathrm{CO}_{2}$ supply and delivery infrastructure (NIPER and K\&A, 1991).

Rivas et al. (1992) performed a parametric study using a numerical simulator to determine optimum reservoir candidates among reservoirs passing the basic screening criteria. Reservoir parameters examined included temperature, pressure, porosity, permeability, dip, API gravity, oil saturation, net oil sand thickness, minimum miscibility pressure, saturation pressure, remaining oil-in-place, and reservoir depth. Parameters that influenced $\mathrm{CO}_{2}$ flood performance the most were API gravity, oil saturation, and reservoir pressure. Optimum conditions for these parameters were $36^{\circ}$ API, $60 \%$ oil saturation, and pressure at the time of injection of about $200 \mathrm{psi}$ over minimum miscibility pressure. 
The NPC screening criteria do not address cyclic $\mathrm{CO}_{2}$ stimulation well selection criteria. Thomas and Monger-McClure (1991) evaluated performance trends for light-oil cyclic $\mathrm{CO}_{2}$ stimulation treatments and suggested the following well selection guidelines:

(1) Desirable reservoir characteristics include shallower reservoirs, operating below the minimum miscibility pressure, a thick pay interval, a mobile-water or free-gas saturation, and an adequate drive mechanism.

(2) Treatments are well suited to high water-cut wells since high oil saturations are not required.

(3) Wells should exhibit mechanical integrity.

(4) Baseline production data should be available.

In evaluating experience with cyclic $\mathrm{CO}_{2}$ treatments in Wyoming, Carlisle (1992) confirmed the importance of mechanical integrity and added two additional caveats:

(1) Wells with thief zones or extensive fractures are not good treatment candidates.

(2) Wells with good initial (not current) oil production rates are preferred.

In their cyclic $\mathrm{CO}_{2}$ stimulation program in southwest Wyoming, Amoco (Passmore, 1991) found containment (i.e., no thief zones or extensive fracturing) was critical to success. In one reservoir, their well selection criteria considered prior waterflood response rather than Carlisle's primary production.

\subsubsection{Constraints}

Dauben (1991) analyzed field projects to determine constraints to field applications of the $\mathrm{CO}_{2}$ processes. He listed four constraints: (1) reservoir heterogeneity, (2) mobility control, (3) injectivity, and (4) operations. Of these constraints, mobility control is the primary constraint. Reservoir heterogeneity constraints can be addressed through reservoir characterization. Injectivity constraints can be addressed through project design. Although costs are higher than with waterflooding, operations-related constraints can be addressed through equipment selection and operating practices. Mobility control affects flooding operations, whether miscible or immiscible. With cyclic $\mathrm{CO}_{2}$ stimulation operations, containment problems replace mobility control as a primary constraint.

For any $\mathrm{CO}_{2}$ project, $\mathrm{CO}_{2}$ supply and cost constrain field applications. Natural $\mathrm{CO}_{2}$ sources with the corresponding supply infrastructure are shown in Figure 4.4. Except for a portion of the Class 4 resource in the northern Rocky Mountains, other Class 4 locations must depend on high purity manmade sources such as fertilizer plants, flue gas absorption and cleanup, or commercial $\mathrm{CO}_{2}$ (truck) delivery. In most cases, commercial $\mathrm{CO}_{2}$ (truck) sales represents the only viable source, especially for cyclic $\mathrm{CO}_{2}$ treatments. In 1992, the cost differential between pipeline and truck costs in the northern Rocky Mountain area was more than threefold (Branting and Whitman, 1992). This cost differential effectively prohibits large-scale flooding and discourages less efficient cyclic treatments. However, Amoco considered cyclic $\mathrm{CO}_{2}$ treatments using trucked $\mathrm{CO}_{2}$ in the Salt Creek field sufficiently encouraging to plan additional treatments (Passmore, 1991). 


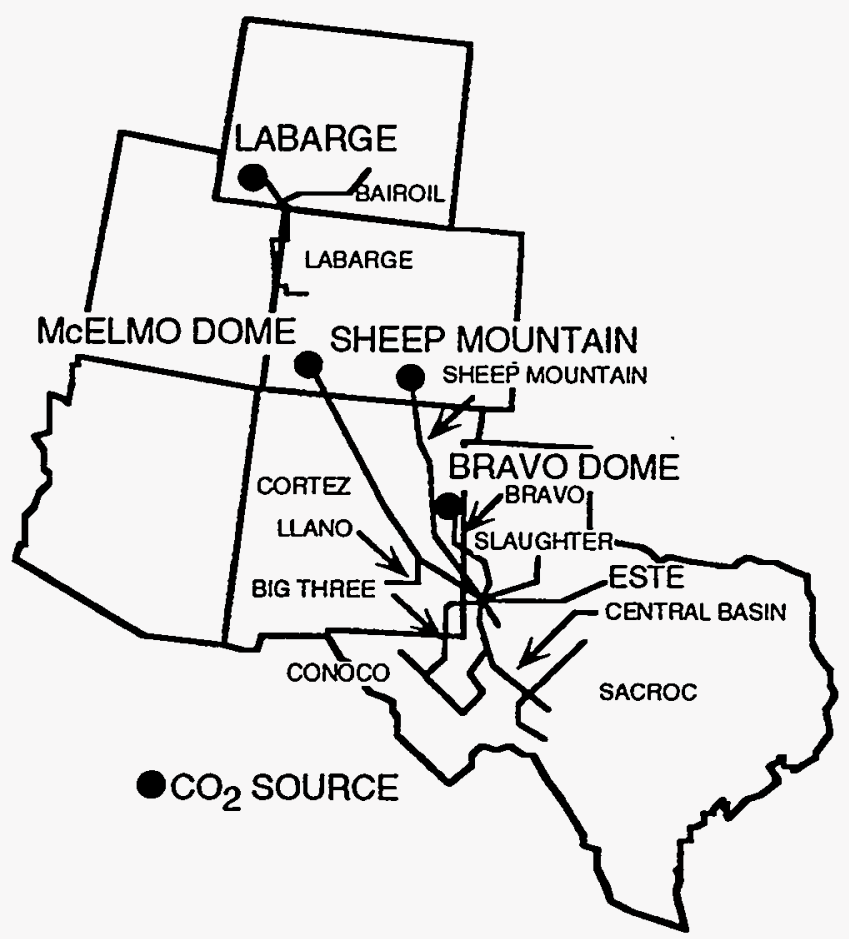

\section{Figure 4.4 Major $\mathrm{CO}_{2}$ Pipelines Servicing the Permian Basin} and the Rocky Mountain States (Source: DOE, 1993)

\subsubsection{Recent Technology Thrusts}

Mobility control and predictability are two areas of technology activity in $\mathrm{CO}_{2}$ flooding. For selected medium- to low-gravity crudes in the Class 4 resource, immiscible $\mathrm{CO}_{2}$ flooding may be an option. Since a large portion of the Class 4 oil resource is distant from existing $\mathrm{CO}_{2}$ infrastructure, cyclic $\mathrm{CO}_{2}$ treatments have potential application. This section reviews technology thrusts in mobility control, predictability, immiscible $\mathrm{CO}_{2}$ flooding, and cyclic $\mathrm{CO}_{2}$ stimulation treatments.

\subsubsection{Mobility Control}

Methods which are being investigated for mobility control in $\mathrm{CO}_{2}$ floods include foams, polymer gels, gas viscosifiers, and, most recently, precipitation methods. Both foams and gel polymers, which have been applied in field tests, are receiving the most industry attention.

\section{Foams}

Foam positively affects gas mobility by replacing the gas relative permeability and viscosity with a lower relative permeability and higher gas-foam viscosity. Both effective gas permeability and apparent viscosity of the foam depend on foam quality and texture. Foam apparent viscosity or rheology depends on both foam quality and foam texture. Experimental results show that foam apparent viscosity (1) increases sharply as foam quality, the ratio of gas volume to total foam volume, becomes greater than $90 \%$ and (2) depends on shear rate with shear thinning, shear thickening, and no rate effects all having been observed (Chung, 1993; Yang and Reed, 1989).

Foam effectiveness depends on foam generation, foam transport, and foam stability. The major controlling factors in foam generation are gas flow rate, liquid volume fraction, and surfactant concentration (Chung, 1993). Oil saturation, pore structure, system pressure, and surfactant type also affect foam generation (Friedmann and Jensen, 1986). Surfactant losses through adsorption and precipitation influence foam generation and foam transport. Oil is known to adversely affect foam stability. 
Three choices exist for foam emplacement in a $\mathrm{CO}_{2}$ flood (Jonas et al., 1990): (1) $\mathrm{CO}_{2}$ displacing a single slug of surfactant, (2) alternate injection of surfactant in brine and $\mathrm{CO}_{2}$ (SAG), and (3) simultaneous injection of $\mathrm{CO}_{2}$ and surfactant. From a reservoir standpoint, rapid alternate injection approximates simultaneous injection. Operations considerations exert a large influence on simultaneous injection versus SAG injection, and, with SAG injection, the length of the cycles.

In field projects, potential foam benefits include: (1) improved $\mathrm{CO}_{2}$ utilization, (2) reduced gas production and associated recycling costs, and (3) increased oil production (Hoefner et al., 1994). Increased oil production can result from operating at higher bottomhole pressures with foam, acceleration, improved sweep efficiency, and, if operations are gas-facility constrained, by less shut-in production.

Foam behavior in porous media is a complex phenomenon with much remaining to be learned. Field applications add even more complexity for understanding and applying foams. Field test approaches range from one-well tests (Chevron's Rangely Weber Sand Unit, Colorado (Jonas et al., 1990)) to extensive research-oriented tests (Phillips' DOE test in New Mexico's East Vacuum Grayburg San Andres Unit (Stevens and Martin, 1994)) to commercialization programs like that conducted by Mobil (Hoefner et al., 1994).

Mobil's commercialization program had a specific objective of defining economic potential of foam treatments in a variety of reservoir conditions. Four field tests were conducted in two different reservoirs. Mobil focused on "learning by doing" in the field (Hoefner et al., 1994), recognizing that research and laboratory work can only go so far, especially considering the complexities of the foam process. Although Mobil did not report specific economic performance, additional field tests are planned.

\section{Polymer Gels}

The $\mathrm{CO}_{2}$ flood environment places special requirements on gel polymer treatments. Gels for $\mathrm{CO}_{2}$ floods must form and then be stable in the low $\mathrm{pH}$, carbonated brine environment. Gels created via the conventional chromium redox process are known to be unstable in such an environment. As with gel polymers for other applications (section 4.2), well selection and treatment guidelines heavily influence treatment success rates. Two field projects illustrate gel polymer applications in $\mathrm{CO}_{2}$ floods.

In their Lick Creek Meakin Sand Unit immiscible $\mathrm{CO}_{2}$ project in Arkansas, Phillips Petroleum Company tested foam, aluminum citrate gels, chromium redox gels, and Halliburton's K-Trol ${ }^{\mathrm{TM}}$ VC process, in that order (Moffitt and Zornes, 1992). The Halliburton K-Trol ${ }^{T M}$ VC process involves the injection of a low viscosity acrylamide monomer which undergoes in situ polymerization and simultaneous crosslinking with an organic crosslinking agent. The created gels are strong, rigid, and stable in a low $\mathrm{pH}$ environment. In this project, the foam and aluminum citrate gels did not have sufficient strength for the high permeability channels. Four chromium redox and $10 \mathrm{~K}-\mathrm{Trol}^{\mathrm{TM}}$ treatments were performed. Although more costly, the K-Trol ${ }^{\mathrm{TM}}$ treatments exhibited more positive production response in offset producers. $\mathrm{K}$-Trol ${ }^{\mathrm{TM}}$ treating costs were $\$ 3.73$ per incremental barrel of oil.

Amoco used acrylamide-polymer/chromium (III) carboxylate gels in their Wertz $\mathrm{CO}_{2}$ flood in southwest Wyoming (Borling, 1994). $\mathrm{CO}_{2}$ flooding was started in the fractured Tensleep reservoir in 1986. Major $\mathrm{CO}_{2}$ breakthrough occurred and conformance problems were evident, as well as significant declines in production. Foam treatments using surfactant were attempted first, but only short-term conformance control resulted, particularly when natural fractures were present. Amoco conducted gel polymer treatments in ten injection wells. Criteria, in order of priority, for selecting candidate wells were: 


$$
\begin{aligned}
& \text { (1) pattern reserves, } \\
& \text { (2) historic fluid injection conformance, } \\
& \text { (3) offset production well performance, } \\
& \text { (4) injection fluid cycle time, and }
\end{aligned}
$$

Posttreatment analysis indicated pattern lives were extended by nearly two years with incremental reserves per pattern ranging from 35,000 to 140,000 barrels. Individual treatment payout times ranged from 1.1 to 3.7 months.

\section{Gas Viscosifiers}

Several approaches have been explored for increasing viscosity of the $\mathrm{CO}_{2}$ gas, thereby improving mobility control:

(1) viscosifying the carbon-dioxide-rich phase by adding polymers as direct thickeners (Dandge and Heller, 1987),

(2) in situ polymerization of soluble monomers in supercritical carbon dioxide (Terry et al., 1987), and

(3) viscosifying the carbon-dioxide-rich phase by adding entrainers (Llave et al., 1990).

Dandge and Heller (1987) at New Mexico's Petroleum Recovery Research Center (PRRC) found that the $\mathrm{CO}_{2}$ solubility of presently available polymers was limited. PRRC's work with synthesized ionomers was discouraging and research was discontinued (Chung, 1993). Bae and Irani (1990) at Chevron found that commercially available polysiloxanes are effective viscosifying agents for $\mathrm{CO}_{2}$ when used in combination with cosolvents. The viscosity of $\mathrm{CO}_{2}$ was increased by two orders of magnitude. Terry et al. (1987) found that, while monomers could be polymerized in situ, no increases in apparent viscosity were observed.

NIPER (Llave et al., 1990; Strycker and Llave, 1991; Raible, 1992) has investigated entrainers (or cosolvents) for $\mathrm{CO}_{2}$ mobility control. Cosolvents can increase the viscosity and density of the $\mathrm{CO}_{2}$ gas and enhance the extraction of oil compounds into the $\mathrm{CO}_{2}$ rich phase. Raible (1992) found that:

(1) If reservoir conditions are sufficient to achieve miscibility, reservoirs are not candidates for entrainers, since the gas phase at miscible conditions will already be saturated with crude oil.

(2) Only a limited number of cosolvents are potential additives. Cosolvents must be miscible with the gas phase at reservoir conditions, must have limited solubility in the oil phase, and must exhibit limited brine solubility.

(3) Higher molecular weight cosolvents such as isooctane are not as effective as lower molecular weight cosolvents such as propane. Although oil recovery in corefloods using propane as a cosolvent was higher, only small increases in gas viscosity were noted.

Although potential may exist with the different gas viscosifying methods, industry interest and activity appears focused in the foam and gel polymer areas.

\section{Precipitation Methods}

Alcohol-induced salt precipitation is one profile modification method that is being studied (Zhu and Tiab, 1992; Zhu and Raible, 1994; Chung, 1993). This method is based on a salt precipitation process resulting from the injection of concentrated brine and alcohol slugs. Mixing of the alcohol 
and concentrated brine cause a reduction in salt solubility and precipitation of solid salt. Since brine and alcohol have a higher relative permeability in watered-out zones, this method selectively plugs the more permeable flow paths. Claimed advantages include: (1) less crossflow effect with lower viscosity fluids, (2) miscibility with connate waters, (3) relative independence from adsorption, temperature, and fluid $\mathrm{pH}$ effects, and (4) precipitated salts are relatively stable in high salinity, low pH environments of $\mathrm{CO}_{2}$ floods (Zhu and Raible, 1994; Chung, 1993).

Laboratory results (Zhu and Raible, 1994) indicate: (1) higher salt concentrations form larger salt crystals which grow with time, (2) ethanol is more effective than methanol, (3) cores with permeabilities modified by salt precipitation are resistant to salt dissolution by subsequent waterfloods with low-salinity brines, and (4) salt precipitation increased oil recovery in $\mathrm{CO}_{2}$ corefloods.

\subsubsection{Predictability Issues}

Chung (1993) identified four problems associated with predicting performance of gas displacement operations. These problems are:

(1) inadequate representation of fluid phase behavior,

(2) incomplete mixing of injection gas and reservoir oil,

(3) reservoir heterogeneities, particularly those related to permeability; i.e., permeability distribution, fracture configuration, location of faults, and

(4) simulation and modeling techniques.

Current NIPER work regarding performance prediction improvements is summarized in Section 4.9.5.1 under DOE Supporting Research.

\subsubsection{Immiscible $\mathrm{CO}_{2}$ Displacement}

Immiscible $\mathrm{CO}_{2}$ flooding is an alternate IOR method for heavy oil recovery, particularly for reservoirs deeper than 4,000 feet or less than 20 feet thick. Recovery mechanisms include oil viscosity reduction, oil swelling, solution gas drive, and hydrocarbon extraction. NIPER (Chung, 1993; Chung and Burchfield, 1987) has been actively involved in developing physical property measurements of $\mathrm{CO}_{2}$-heavy oil mixtures, coreflooding tests, and mobility control improvements. NIPER-developed $\mathrm{CO}_{2}$-heavy oil correlations are now used as references for heavy oil properties (Chung, 1993). Coreflooding tests indicate that recovery with immiscible, high pressure $\mathrm{CO}_{2}$ flooding can be as high as observed with miscible flooding. Mobility control methods which have been examined include the surfactant-enhanced WAG process and the entrainer (cosolvent) process.

\subsubsection{Cyclic $\mathrm{CO}_{2}$ Treatments (Huff ' $n$ ' Puff)}

Efficiency of cyclic $\mathrm{CO}_{2}$ treatments has been evaluated in several field tests in both heavy and light oils. Observations from several field test programs are summarized here. These field tests illustrate that, while simulation may help design treatments for a given application, field treatment data best determine the optimum economic design for a given reservoir and field. Under the right circumstances, cyclic $\mathrm{CO}_{2}$ treatments have been proven to be economical, although recovery is admittedly lower than with flooding processes.

\section{Big Sinking Field, Kentucky}

IFP (Miller et al., 1994) documented the results of a field-scale cyclic $\mathrm{CO}_{2}$ program in the Big Sinking field in Kentucky. Reservoir depth is $1,300 \mathrm{feet}$, pressure is $150 \mathrm{psi}$, and oil gravity is $36^{\circ}$ API. From 1985-1994, 390 treatments were performed in 240 wells. Treating procedures are as follows: $\mathrm{CO}_{2}$ is trucked in and injected down the annulus, the well is shut-in for about 10 days 
then placed back on pump. Treatment sizes ranged from 20 to 120 tons per well. Observed $\mathrm{CO}_{2}$ efficiencies were in the 0.87 to $1.41 \mathrm{MCF} / \mathrm{bbl}$ range. From an economic standpoint, the smaller 20-ton treatments yielded the highest $\mathrm{CO}_{2}$ efficiency.

\section{Wyoming Experience (Wyoming Carbonics, Inc.)}

Wyoming Carbonics performed 29 cyclic $\mathrm{CO}_{2}$ treatments during 1990-1991 (Carlisle, 1992). Well selection and treatment guidelines were developed from the experience gained with these treatments. Wells with thief zones or extensive fractures do not make good candidates for treatment. Good initial production potential is more important than current production rate. Other guidelines for equipment, operating practices, and $\mathrm{CO}_{2}$ soak time as a function of reservoir pressure were developed. For low-pressure $(<400 \mathrm{psi})$ reservoirs, shut-in times of only 5 to 8 days are recommended. For moderate-pressure ( 400 to 1,000 psi) reservoirs, shut-in times from 10 to 14 days are recommended. For high-energy (1,000 to 2,400 psi) reservoirs, shut-in times from 15 to 30 days are recommended.

\section{Wyoming Experience (Amoco)}

During 1990, Amoco conducted 13 cyclic $\mathrm{CO}_{2}$ treatments in Wyoming in five different oil fields (Passmore, 1991). Design criteria included creating a 50\% $\mathrm{CO}_{2}$ saturation 150 feet from the wellbore. $\mathrm{CO}_{2}$ was injected over a 1- to 2-week period, followed by a soak period averaging 35 days. In the Lost Soldier and Wertz fields, where treatments were conducted at pressures above the minimum miscibility pressure, four of seven treatments were considered economically successful. In the Salt Creek field, treatments were conducted at pressures below minimum miscibility pressure. In Salt Creek, two of three treatments exhibited poor containment. Among other things, Amoco concluded: (1) containment was critical, (2) injecting $\mathrm{CO}_{2}$ down the tubing-casing annulus was preferable, and (3) treatments needed to be optimized to smaller volumes and shorter soak times (Passmore, 1991).

\section{Texas Gulf Coast (Texaco)}

Haskin and Alston (1989) outlined overall results from 28 well treatments in Texas Gulf Coast Miocene reservoirs. Gravities ranged from $23^{\circ}$ to $30^{\circ}$ API and viscosities ranged from 2 to $33 \mathrm{cP}$. Texaco concluded: (1) viscosity reduction and oil swelling were the primary recovery mechanisms, (2) soak times of 2 to 3 weeks were better than either shorter or longer times, and (3) oil-cut response from the initial treatment can guide selection of wells for multiple cycles of $\mathrm{CO}_{2}$ treatments.

\subsubsection{Current Research Activity}

\subsubsection{DOE Supporting Research}

The Petroleum Recovery Research Center in New Mexico is conducting a joint industry, university, and government project evaluating the use of foam for mobility control and fluid diversion in a $\mathrm{CO}_{2}$ flood. The field site is in the East Vacuum Grayburg San Andres Unit in southeast New Mexico. Favorable production response was obtained from the initial foam test (Martin et al., 1994). Additional foam tests are being conducted, and alternative foam generation schemes are being investigated.

At Stanford, research is exploring viscous and gravity effects in 2-D and 3-D flow experiments (Orr, 1994). By quantifying the relationships between process mechanisms, displacement processes which take advantage of crossflow in heterogeneous media can be designed. At Morgantown, research is focusing on (1) scaling thermodynamics, (2) models of fluid flow and miscible fingering that conform to current scaling theory, and (3) experiments and modeling for the development of surfactant-based mobility control on the basis of either leave-behind lamellae or fluid dispersions (Smith, 1994). At the University of California-Berkeley, research is focused on 
understanding the mechanisms of mobility control with foam (DOE, 1994). Current effort is directed toward modeling foam displacement and toward developing surfactant screening procedures.

At NIPER, research is continuing on improving gas flood performance prediction ability and on mobility control methods (NIPER/BDM, 1994b). Performance prediction research is focusing on interfacial tension behavior of oil-water phases with $\mathrm{CO}_{2}$ dissolution and on developing a more accurate compositional prediction method for $\mathrm{CO}_{2}$-water-hydrocarbon systems. Alternatives to the Peng-Robinson Equation of State are being evaluated. Mobility control research is evaluating selective placement of polymer gels and the precipitation of salts and chemicals. Napthalene precipitation as a profile modification technique is currently being evaluated. Polynuclear aromatic compounds such as napthalene are highly soluble in a ketone solvent, but precipitate when mixed with water. The theory behind this method is that injection of an aromatic solution into a water zone or channel would cause precipitation of the napthalene, thus blocking the water zone. Cosolvent and $\mathrm{NaCl}$ effects on precipitation and phase behavior are being determined in phase behavior studies.

\subsubsection{DOE Cost-Shared Field Demonstration Program}

DOE has initiated cost-shared field demonstration projects with operators in Class 1 fluvialdominated deltaic and Class 2 shallow-shelf carbonate reservoirs. Proposals in Class 3 slope-basin and basin clastic reservoirs are currently being evaluated.

Two Class 1 projects incorporate $\mathrm{CO}_{2}$ process technology. American Oil Recovery is comparing waterflood, $\mathrm{CO}_{2}$ WAG injection, and cyclic $\mathrm{CO}_{2}$ injection in the Cypress Sandstone in the Mattoon field in Illinois. The $\mathrm{CO}_{2}$ WAG process will be conducted under immiscible conditions since slim-tube miscibility data indicate that miscibility pressure exceeds the formation parting pressure (Baroni, 1994). Texaco is evaluating $\mathrm{CO}_{2}$ miscible displacement in a watered-out reservoir in Port Neches field in the inland waters of southeast Texas. This project also incorporates a horizontal $\mathrm{CO}_{2}$ injection well located along the original oil-water contact. Reservoir pressure will be raised above the minimum miscibility pressure by injecting salt water.

Four of 11 Class 2 projects incorporate some aspect of $\mathrm{CO}_{2}$ technology. Texaco is evaluating the $\mathrm{CO}_{2}$ huff ' $n$ ' puff process in the Central Vacuum Unit in southeast New Mexico. The Utah Geological Survey plans to evaluate secondary/tertiary potential in five fields in the Paradox basin of Utah, then conduct a small $\mathrm{CO}_{2}$ flood in one of the fields. Oxy USA is combining several technologies (cross wellbore tomography, 3-D seismic, horizontal flood fronts created by hydraulic fracturing, cyclic $\mathrm{CO}_{2}$ stimulation treatments) in Texas San Andres reservoirs. Phillips is combining horizontal injection wells with $\mathrm{CO}_{2}$ flooding in a Texas San Andres reservoir.

Two of the Class 3 proposals incorporate $\mathrm{CO}_{2}$ technology (OGJ, 1994). Chevron proposes immiscible $\mathrm{CO}_{2}$ flooding in the Miocene Antelope/Monterey shale in Buena Vista, California. Parker and Parsley proposes a $\mathrm{CO}_{2}$ pilot in the fractured Spraberry reservoir in West Texas. These proposals may not be those selected for awards by DOE.

Industry interest in $\mathrm{CO}_{2}$ processes is reflected by the number of cost-shared field demonstration projects (and proposals) incorporating the technology, often in combination with other improved oil recovery technologies.

\subsubsection{Research Needs}

In a 1993 analysis, Chung (1993) summarized the state of the art and listed research needs. These research needs are primarily related to mobility control or improved understanding of phase behavior and the displacement process. Combination applications with horizontal well technologies also represent a research need. Specific mobility control needs are for improved channel-block methods, improved understanding of foams, and other novel permeability modification methods. 
Mobility control and combination horizontal well applications represent the greatest research needs. For Class 4 reservoirs which are, by and large, located distant from the $\mathrm{CO}_{2}$ supply infrastructure, cyclic $\mathrm{CO}_{2}$ stimulations have potential. Well selection and application guidelines need additional development.

\subsection{Numerical Simulation And Modeling}

Computer reservoir simulation techniques have advanced significantly over the years. State-ofthe-art desktop simulators are now available to perform both history matching and predictive numerical modeling of virtually every improved oil recovery process. Computer reservoir modeling has evolved due to the efforts of both the federal government and the petroleum industry. Although many of the commercially available reservoir simulators are state-of-the-art PC-based models, most are very expensive to purchase and require experienced staff to perform simulation studies.

The main objective of this chapter is to summarize the various features of the publicly available simulators which have been developed by DOE. Such publicly available simulators can be used by independent operators and others as reservoir management tools to define reservoir constraints on production and to design processes for improved oil recovery (IOR). The advantages of using publicly available simulators are numerous. First, the expense incurred in purchasing them is insignificant when compared to similar commercially available simulators. Second, most publicly available simulators are relatively user-friendly and require low-cost hardware for operation.

From a reservoir management point of view, reservoir simulators are critical for the proper selection and design of improved oil recovery processes for field application. Reservoir simulators are valuable tools for determining the sensitive parameters that affect particular IOR processes and for determining the most efficient design for project implementation or modification. Simulators can be used to optimize overall recovery process design, assess the risk in applying the process, and quantify the economic viability of recovery processes. Commercial reservoir simulators are ayailable from many vendors and consulting firms, and many major oil companies have developed sophisticated in-house simulators to fit specific simulation needs. Detailed reservoir simulation studies are probably more critical and beneficial to independent operators who are faced with limited budgets and technical expertise. Hence, publicly available simulators become a very important tool for selecting and designing the appropriate IOR process. Therefore, continued development and improvement of these publicly available simulators becomes a significant research need for the industry.

\subsubsection{Public Domain Reservoir Simulators}

DOE has funded the development of numerous publicly available numerical reservoir simulators in the last decade, including a black oil simulator (BOAST), a pseudo-miscible simulator (MASTER), and various modified versions of these two basic simulators. The purpose of this section is to describe the applications, features, and computer requirements of the reservoir simulators which have been developed by DOE, as summarized in Table 4.16. These simulators have a wide range of applicability, including simulating primary recovery, secondary recovery, and improved oil recovery processes.

The widely used BOAST and the less utilized MASTER simulators were initially developed to run on main frame computer systems and were written in FORTRAN. With the expanded use of personal computers (PCs), the BOAST model, and subsequently the MASTER model, were modified and compiled to run in a PC environment. Initially, the movement to the PC environment resulted in the loss of some of the computational capabilities. For example, the capability and power of the $\mathrm{PC}$ hardware determined the maximum possible number of grid blocks, the maximum number of iterations, and the maximum number of time steps, which limited the accuracy of the simulations. Today, with the advancement in computer hardware capabilities, the PC-based 


\begin{tabular}{|c|c|c|c|}
\hline \multicolumn{4}{|l|}{ (3., } \\
\hline Name of Simulator & Applications & Features & $\begin{array}{l}\text { Computer } \\
\text { Requirements }\end{array}$ \\
\hline BOAST II & $\begin{array}{l}\text { Primary depletion } \\
\text { Secondary recovery } \\
\text { Waterflooding } \\
\text { Pressure maintenance by } \\
\text { water or gas injection }\end{array}$ & $\begin{array}{l}\text { Restart option } \\
\text { Multiple PVT regions } \\
\text { Multiple rock regions } \\
\text { Different aquifer models }\end{array}$ & $\begin{array}{l}80386 \text { and up } \\
4 \text { megabyte memory }\end{array}$ \\
\hline BOAST 3-PC & $\begin{array}{l}\text { Primary depletion } \\
\text { Secondary recovery } \\
\text { Waterflooding } \\
\text { Pressure maintenance by } \\
\text { water or gas injection } \\
\text { Steeply dipping reservoirs }\end{array}$ & $\begin{array}{l}\text { Multiple PVT regions } \\
\text { Multiple rock regions } \\
\text { Different aquifer models } \\
\text { Post-processor for 2-D } \\
\text { visualization } \\
\text { 3-D, 3-phase simulator }\end{array}$ & $\begin{array}{l}80386 \text { and up } \\
4 \text { megabyte memory } \\
\text { Math coprocessor }\end{array}$ \\
\hline BOAST-VHS & $\begin{array}{l}\text { Primary depletion } \\
\text { Secondary recovery } \\
\text { Waterflooding }\end{array}$ & $\begin{array}{l}\text { 3-D, 3-phase simulator } \\
\text { Horizontal, slanted, and } \\
\text { vertical wells } \\
\text { Dynamic redimensioning }\end{array}$ & $\begin{array}{l}640 \mathrm{~KB} \text { RAM minimum } \\
\text { Math coprocessor } \\
386 \text { or } 486 \text { processor } \\
\text { preferred } \\
\text { EGA or VGA support }\end{array}$ \\
\hline $\begin{array}{l}\text { MASTER } \\
\text { "MISC4" a newly } \\
\text { developed PC-version }\end{array}$ & $\begin{array}{l}\text { Miscible or immiscible } \\
\text { gas flooding }\end{array}$ & $\begin{array}{l}\text { 3-D, 3-phase simulator } \\
\text { Multicomponent, pseudo } \\
\text { miscible } \\
\text { Tracks oil, gas, water, up } \\
\text { to } 4 \text { solvent species, and a } \\
\text { surfactant. } \\
\text { Multiple PVT regions (10) }\end{array}$ & $\begin{array}{l}\text { Mainframe computer, or } \\
80386 \text { and up } \\
4 \text { megabyte memory }\end{array}$ \\
\hline MTS & $\begin{array}{l}\text { Microbial and nutrient } \\
\text { transport } \\
\text { Permeability reduction } \\
\text { caused by cell clogging }\end{array}$ & $\begin{array}{l}\text { 3-D, 3-phase simulator } \\
\text { Multicomponent } \\
\text { Porosity change and perm } \\
\text { reduction } \\
\text { No microbial oil recovery } \\
\text { mechanisms }\end{array}$ & Mainframe computer \\
\hline $\begin{array}{l}\text { PC-GEL } \\
\text { or } \\
\text { "BEST GEL"-mainframe }\end{array}$ & $\begin{array}{l}\text { Polymer flooding } \\
\text { Polymer gel treatment } \\
\text { Tracer test simulation } \\
\text { Primary depletion } \\
\text { Waterflooding } \\
\text { Secondary recovery }\end{array}$ & $\begin{array}{l}\text { 3-D, 3-phase simulator } \\
\text { Multicomponent } \\
\text { Transport of up to } 5 \\
\text { chemical species } \\
\text { Gelation kinetics } \\
\text { Polymer and gel rheology } \\
\text { Adsorption of each } \\
\text { chemical species }\end{array}$ & $\begin{array}{l}\text { PC-version, } 640 \mathrm{~KB} \mathrm{RAM} \\
\text { minimum } \\
\text { Math coprocessor } \\
386 \text { or } 486 \text { processor } \\
\text { EGA or VGA support }\end{array}$ \\
\hline
\end{tabular}


simulators are capable of performing a wide range of large-scale history matching and performance-prediction simulations. On the other hand, some of the more recent advances in reservoir simulation techniques, such as finite element methods and fractal modeling, which require high speed and large storage computing capabilities, are currently available only with commercial main-frame-based reservoir simulators.

\subsubsection{Black Oil Applied Simulation Tool (BOAST, BOAST II)}

The Black Oil Applied Simulation Tool or BOAST simulator was developed by DOE and was originally released to the public in 1982 (Fanchi et al., 1982). BOAST was developed as a simplified reservoir model for simulating primary depletion, pressure maintenance by water or gas injection, and secondary recovery operations. BOAST is a three-dimensional, three-phase black oil reservoir simulator that models the multiphase flow of oil, water, and gas in porous media. BOAST utilizes the implicit pressure/explicit saturation (IMPES) formulation for solving finitedifference equations and incorporates line-successive, overrelaxation (LSOR) or direct elimination solution options for solving the pressure equations. This model has been widely utilized by the industry, academia, and research institutions, and was found to provide reasonably accurate predictions of reservoir performance under most circumstances.

Defined operational limitations of BOAST, however, resulted in the release of a modified version of the model, called BOAST II, in 1987 and the subsequent release of a PC version of the model in 1989. The modifications included in the BOAST II model included the addition of numerous features to improve the versatility of the model for use in full field simulations (Fanchi et al., 1987). The improvements to BOAST that were included in BOAST II were primarily the addition of the following: numerous user-friendly enhancements, such as data input and output improvements, restart capabilities, and initialization data checks; reservoir engineering features, such as an optional three phase relative permeability algorithm, multiple rock and PVT regions, and additional aquifer models; well model features, such as individual well GOR and WOR constraints, minimum oil/water production constraints, and multiple wells per grid block; and numerical features, such as iterative matrix solution methods, inactive grid block capability, and options for reducing numerical dispersion. These improvements greatly improved the accuracy of the model predictions and improved the program run time. The improved BOAST II model was released by DOE in 1989 in a PC version which was found to compare reasonably well with commercial reservoir simulators (Stapp and Allison, 1989).

Further improvements were made to the PC version of BOAST II by BDM Federal as part of a study conducted by Louisiana State University to "Assist in the Recovery of Bypassed Oil in the Gulf of Mexico" (DOE Contract DE-AC22-92BC14831). The resulting BOAST 3-PC model includes numerous enhancements that have increased the applicability and efficiency of the BOAST II model. One of the main features added was a gravity drainage or dipping reservoir option to allow the simulator to accurately model recovery in steeply dipping reservoirs, such as those flanking Gulf of Mexico salt domes. The code was also modified to improve the subroutines for handling three phase relative permeability and to improve the overall simulator execution speed. The streamlining of the code and recompilation using a 32-bit processor has resulted in a 386/486 PC-based model which runs approximately 3.7 times faster than the original PC version of BOAST. In addition, two post processors were added to BOAST 3-PC to generate plots of oil, water, and gas production rates, GOR, cumulative production, and other output parameters versus time, and to generate color areal or cross-sectional displays of model output parameters (saturation, pressure, rates, GOR, etc.) at various time steps (Young, et al., 1993; Mathematical \& Computer Services, Inc., 1993b). 


\subsubsection{Miscible Applied Simulation Techniques for Energy Recovery (MASTER)}

The Miscible Applied Simulation Techniques for Energy Recovery reservoir simulator, MASTER, was developed by DOE as a simplified model for simulating miscible and immiscible gas flooding projects (Ammer and Brummert, 1991). MASTER is a four component (oil, water, gas, and solvent), three-dimensional, three-phase flow model based on the original BOAST simulator code. The model allows simulation of the injection of up to four solvent slugs or species and a surfactant. The solvent phase can be defined as any of the typical injected gases, carbon dioxide, nitrogen, hydrocarbon gas, or flue gas. The miscibility of the solvent phase with the hydrocarbon gas, oil, and water phases is accounted for in the simulator. Miscibility is simulated utilizing the mixing parameter approach to calculate effective fluid densities and viscosities (Todd and Longstaff, 1972; Watkins, 1982). Mobility control can be simulated in MASTER as a function of local surfactant concentration to reduce the mobility of the solvent phase. The model also accounts for the precipitation of asphaltenes and the associated permeability reduction. The miscible features in MASTER can be easily bypassed in the model to simulate immiscible injection processes, although projections are known to be less accurate in the immiscible mode due to problems with the bubble point pressure tracking scheme when solvent injection occurs below the minimum miscibility pressure. The model can also be operated as a standard black oil simulator to simulate primary and secondary recovery processes.

Under the Louisiana State University project (Assist in the Recovery of Bypassed Oil in the Gulf of Mexico; DOE Contract DE-AC22-92BC14831), the MASTER code was modified to allow the simulator to be run efficiently in the 386/486 PC environment (Mathematical \& Computer Services, Inc., 1993a). The code modifications incorporated into this model, called MISC4, include the removal of the option to allow injection of up to four different solvent slugs, instead allowing the injection of only one solvent. This greatly reduced the memory requirements for the simulator, allowing it to run more efficiently on a PC. The two post processors which were added to BOAST 3-PC were also added to MISC4 to facilitate the display of output data.

\subsubsection{Black Oil Applied Simulation Tool for Vertical/Horizontal/Slant Wells (BOAST-VHS)}

A PC-based simulator was developed in 1992 by NIPER for simulating the performance of horizontal and slanted wells in oil reservoirs. The Black Oil Applied Simulation Tool for Vertical/Horizontal/Slant Wells, BOAST-VHS, is a three-dimensional, three-phase, finite difference black-oil simulator which is based on the original BOAST code. Many of the features that were included in the revision of BOAST to BOAST II were not included in this model due to operating system memory constraints. The model can be used to accurately simulate primary depletion, pressure maintenance, and basic secondary recovery operations using any combination of vertical, horizontal, and slanted wells. The various features and the operating aspects of BOAST-VHS are described in detail in the model user's guide, which is available from DOE (Chang et al., 1992).

\subsubsection{Polymer Applications Simulator (PC-GEL)}

In 1990, NIPER developed a PC-based simulator for predicting the performance of gel polymer applications in oil reservoirs (Gao and Chang, 1990). PC-GEL is a three-dimensional, three-phase permeability modification simulator developed by incorporating an in situ gelation model into the BOAST black oil simulator. The features included in the simulator are: 1) transport of up to five chemical species, 2) gelation reaction kinetics of the polymer with crosslinking agents, 3) rheology of the polymer and gel, 4) inaccessible pore volume to macromolecules, 5) adsorption of chemical species on rock surfaces, and 6) permeability reduction caused by adsorption of polymer and gel. The PC-GEL simulator is useful for simulating and optimizing any 
combination of primary production, waterflooding, polymer flooding, and permeability modification treatments. A detailed description of the model features and operations is contained in the PC-GEL user's guide and documentation manual, which are available from DOE (Chang and Gao, 1993).

\subsubsection{Microbial Transport Simulator (MTS)}

The Department of Energy and NIPER are currently developing a public domain reservoir simulator for simulating and modeling microbial and nutrient transport in porous media (Chang et al., 1991). The Microbial Transport Simulator, MTS, is a three-dimensional, three-phase, multicomponent simulator that was developed by incorporating microbial growth and transport algorithms into the BOAST black oil simulator. Specific algorithms which have been integrated into the simulator account for microbial growth and transport, nutrient transport and consumption, and porosity and permeability changes resulting from clogging of pores due to microbial growth and transport. This simulator can accurately predict the propagation of microbes and nutrients in porous media for the design of laboratory coreflood experiments and for predicting improved oil recovery from injection profile modification using microbial processes. Additional research is being conducted at NIPER to examine improved oil recovery mechanisms resulting from microbial injection processes, including the impacts that microbial processes have on the relative permeability relationships and hydrocarbon saturation in oil reservoirs. This research is focusing on defining the combined oil recovery effects of microbial transport systems, including impacts of the byproducts of microbial growth (surfactants, acids, alcohols, and various gases). With the incorporation of the these oil recovery aspects into MTS, this simulator will be a valuable tool for use in predicting the performance of microbially enhanced oil recovery (MEOR) processes and perhaps for modeling bioremediation processes for underground contamination involving hydrocarbon products or other inorganic and organic compounds.

\subsubsection{Commercial Reservoir Simulators}

Although this chapter mainly focuses on reservoir simulators developed under DOE contracts, it is important to mention that advanced simulators are commercially available with state-of-the-art capabilities, such as user-friendly input data systems, geologic data mapping packages, postprocessor 3-D visualization packages. These integrated systems offer researchers and operators state-of-the-art technologies which can enhance their capabilities in terms of reservoir management, reservoir development, and process prediction studies. It is well beyond the scope of this report to discuss the specific capabilities of the multitude of simulators which are commercially available to oil and gas operators. This section focuses on some of the advanced computational techniques which are being developed to more accurately and cost effectively simulate petroleum reservoirs.

Recent advancements in numerical simulation capabilities are primarily being achieved by the exploitation of the rapidly expanding computational and memory capabilities of computer software and hardware systems. Some recent advancements in petroleum industry numerical simulators include: (1) improvements in recovery process simulation capabilities, (2) development of advanced computational algorithms, (3) the use of artificial intelligence, (4) the use of geostatistical methods and automatic gridding capabilities to define geologically complex reservoirs, and (5) the incorporation of advanced image processing techniques in post-processors.

\subsubsection{Recovery Process Simulation Capabilities}

The evolution of oil and gas recovery methods has directly resulted in improvements in the ability to numerically simulate these processes, especially through the exploitation of the expanded memory and computational capabilities of computer systems. Vast improvements have been made in the last decade in the three-dimensional simulation of two-phase (oil-water, gas-water) and three-phase flow in porous media. Advanced simulators are being developed to simulate virtually all recovery processes, including: thermal processes (steam flooding and in situ combustion), 
chemical processes (surfactant, polymer, alkaline, and alkaline-surfactant-polymer), gel polymer applications, miscible and immiscible gas injection processes $\left(\mathrm{CO}_{2}\right.$, nitrogen, flue gas, and hydrocarbon gas), and microbial processes. For accurately simulating compositional change through various phases, compositional simulators and algorithms are being developed for gas (e.g., $\mathrm{CO}_{2}$ ) and thermal injection processes using an equation-of-state approach. Simulators are also being developed to model complex recovery problems such as production from tight gas sands, production of coal bed methane, recovery of oil and gas from naturally fractured reservoirs (dual porosity/permeability simulators), and to study formation damage mechanisms. Advanced models are being developed to simulate the propagation of induced fractures in oil and gas reservoirs including the development of capabilities to predict fracture orientation. Advanced numerical well models are also being integrated into numerical reservoir simulators to account for wellbore hydraulics in complex situations, such as horizontal wells. Optimization software is being developed and incorporated into numerical simulators to optimize recovery processes, wellbore hydraulics, and even production or injection facilities.

\subsubsection{Computational Algorithms}

The increased calculation speed and memory capabilities of computer systems have facilitated the incorporation of advanced computational algorithms into reservoir simulators. The accuracy of reservoir simulation is being improved dramatically through the utilization of finite element formulations and fully implicit solution formulations. New numerical solvers are also being developed, including iterative and parallel solvers and preconditioners for iterative numerical schemes. Parallel calculation algorithms are being developed to exploit parallel and massively parallel computing capabilities. Local and adaptive grid refinement capabilities are being developed to more accurately simulate complex fluid-flow problems, such as coning, frontal advance, and near wellbore phenomena.

\subsubsection{Artificial Intelligence}

Artificial intelligence methods are being successfully developed for use in numerical reservoir simulation. Expert systems are being considered to provide solutions to complex problems, such as: the prediction of input variables where data are missing or questionable, the selection of optimum recovery processes based on reservoir parameters and performance, the identification of sensitive variables which impact specific recovery process efficiency, the selection of optimum injectant composition (e.g., gel polymer formulations) based on reservoir parameters, and selection of the optimum simulator for use in history matching and predicting reservoir performance. An index is developed inside the simulator to determine local areal needs for grid refinement and implicit formulation. Artificial intelligence is also being considered to automatically perform complex, time intensive operations, such as reservoir performance history matching or the construction of input datasets.

\subsubsection{Modeling Geologically Complex Reservoirs}

Advanced computational capabilities can successfully be applied to the modeling of geologically complex reservoirs. Geostatistical methodologies are being incorporated into numerical simulators to predict values for reservoir parameters, such as porosity and permeability between known data points in heterogeneous reservoirs. These reservoir complexities are being estimated using sophisticated numerical techniques, such as kriging, conditional simulation, simulated annealing, and fractal simulation. Also, complex numerical methods are being devised to automatically generate the optimum three-dimensional grid scheme for use in simulating process performance in geologically complex reservoirs.

\subsubsection{Image Processing}

Another area which is benefiting significantly from advanced computational capabilities is the interpretation of simulator output data. Image processing techniques are being developed and 
utilized for the rapid visualization of simulator output data, which greatly reduces the time required to interpret simulator results by virtually eliminating the need to review reams of hardcopy output data matrices at numerous time steps. The use of three-dimensional visualization software, graphical displays, animation, and even virtual reality can make a once cumbersome task enjoyable for simulation experts and nonexperts alike.

\subsubsection{Reservoir Simulation Research Needs}

Research needs for the improvement of reservoir simulation capabilities primarily relate to improving the cost effectiveness and availability of reservoir simulators for predicting the performance of improved recovery processes. The industry as a whole has continued to exploit the advancing computational capabilities of desktop and mainframe computer systems to develop simulators that are more user-friendly, more accurately predict recovery process performance, and more effectively display simulator output. However, these simulators are not available to many operators due to the cost of purchasing the simulators, the cost of contracting simulation services, or the lack of technical expertise.

The continued development of more accurate, cost-effective, and user-friendly publicly available simulators is probably the most significant research need for the industry. The IMPES method used by current publicly available simulators has limitations modeling certain reservoir conditions (i.e., coning, near bubble-point conditions, steep concentration gradients). Accuracy of publicly available simulators would benefit from development of fully implit models. If accurate, cost-effective, and user-friendly simulators can be made readily available to the industry, many operators would utilize these tools to design or evaluate improved recovery processes. A system should be developed to allow less sophisticated operators access to technical experts who can provide guidance for the development of input datasets, the operation of the simulators, and the interpretation of results. These objectives could be met through DOE funding support to the Petroleum Technology Transfer Council, NIPER, universities, and other research institutions.

\subsection{Wellbore And Facilities}

The demonstration of improved technologies for reducing the costs of drilling, completing, recompleting, and stimulating wells and operating production and injection facilities is a significant research need for extending the economic life of producing fields and improving the recovery of oil. The industry as a whole has always focused on developing ways to reduce development and operating costs and to improve production, but often the transfer of these technologies does not effectively occur, so that many operators are unaware of the benefits of implementing these technologies. This is especially the case with the smaller operators and independent operators who tend to lack the technical expertise to define and implement newer methods. The purpose of this section is to describe some of the areas where the demonstration of improved technologies would benefit the operators of Class 4 reservoirs and the industry as a whole. This chapter does not assume to define the state-of-the-art in all areas related to drilling and production operations; rather, this section presents some of the more obvious technologies which operators could focus on to improve recovery operations.

\subsubsection{Drilling Technology}

Drilling techniques have improved significantly since the days of cable tool rigs, with significant improvements in drilling systems and procedures, particularly the advent and improvement of directional and horizontal drilling methods and the development of innovative drilling measurement systems The demonstration and transfer of these technologies could benefit the industry through reduction in the costs of drilling, completing, and operating. 


\subsubsection{Improved Drilling Systems}

The industry has developed many innovative systems for reducing the cost of drilling wells and improving the integrity of wells before and after completion. Improved drill bits have been developed by the industry to increase penetration rates through various formations and to facilitate the transport and removal of drill cuttings. For example, the development of the polycrystalline diamond (PDC) bits has greatly improved drilling efficiency in certain formations and could, through further development, improve penetration rates and drilling efficiency by as much as four times in certain vertical well applications (Joshi, 1991). The development of improved tubular goods for drilling and completion in harsh environments could also reduce drilling costs through reduction of failures and long-term well costs through reduction in corrosion problems. The continued development of slimhole drilling methods can also reduce drilling costs through the use of smaller hole size. The development of effective coiled tubing drilling systems will allow dramatic reductions in drilling costs through the reduction of rig time for vertical, deviated, and horizontal wells (Schuh and Joshi, 1991). Advanced mud systems continue to be developed to improve drilling hydraulics and cuttings transport and to reduce formation damage in sensitive formations. More importantly, in these times of increasingly stringent regulatory requirements, the development of environmentally safe drilling systems is paramount, especially for use in environmentally sensitive areas such as wetlands and offshore.

\subsubsection{Directional Drilling Methods}

Improvements in directional drilling methods provide the benefits of increased accuracy in the placement of deviated wellbores and the capability to drill extensions or laterals from existing wellbores to improve recovery. Advancements in steering tools, downhole assemblies, and drilling methodologies have improved directional drilling capabilities to the point where resolution is well within 20 feet of the target (Joshi, 1991). Drilling costs are reduced as accuracy and equipment are improved since fewer steering runs are required for course correction and since longevity of the downhole assemblies and steering tools is extended. The further development of capabilities to cost effectively drill ultrashort to long radius extensions from existing wells could provide cost reduction for placing new, clean wellbores in desired locations instead of drilling new wells. Ultrashort radius extensions (up to 200 feet), short radius extensions (100 to 450 feet), medium radius extensions (500 to 3000 feet), and long radius extensions from existing wellbores have applications in primary, secondary, and enhanced oil recovery projects for the improvement of ultimate recovery.

\subsubsection{Horizontal Drilling Methods}

Horizontal drilling and completion technologies have advanced rapidly in the last decade, which has resulted in the expanded application of horizontal wells, improvements in well productivity, and the reduction of costs associated with drilling and completing horizontal wells. The demonstration of improved methods for designing, drilling, evaluating, and completing horizontal wells will help to further reduce costs and expand applicability of horizontal wells. Horizontal wells have been successfully applied in the following applications: (1) naturally fractured reservoirs to intersect fracture systems, (2) thin or low permeability reservoirs to increase area to flow, (3) gas storage reservoirs to meet peak deliverability demands, (4) more permeable reservoirs to solve gas or water coning problems, and (5) as injection or production wells in waterfloods and EOR projects to increase injection rates or to improve sweep efficiency (Mutalik and Joshi, 1993; Coffin, 1993; and Taber and Seright, 1992). Although horizontal wells are more expensive than vertical wells, the productivity increases and recovery improvements typically more than justify the increased expenditures (JPT, 7/93). Horizontal drilling costs have fallen as innovative methodologies have been developed and applied, and as operators gain experience in drilling in particular fields. 
The constraints that affect the successful application of horizontal wells relate primarily to reservoir characterization, completion technologies, and cost implications. Understanding the factors which impact horizontal well productivity and the proper characterization of target reservoirs has a significant impact on the success of horizontal wells. Significant factors which impact horizontal well productivity include reservoir thickness, reservoir heterogeneities, and permeability anisotropies, all of which impact the length and location of the lateral section of horizontal wells (Crouse, 1992). Improvements in the understanding of these factors and methods of characterizing target formations could increase the applicability and productivity of horizontal wells. Productivity could also be improved through the development of improved methods for completing, stimulating, and working over horizontal wells, and the development of a better understanding of the formation damage mechanisms in horizontal wells. The reduction of horizontal drilling and completion costs could also increase the applicability of horizontal wells. The effective transfer of improved horizontal well technologies as the industry moves up the learning curve is a significant factor in continued cost reductions.

\subsubsection{Drilling Measurement Systems}

The capability to obtain real time data as wells are drilled has advanced significantly in the last decade. Improvements in the reliability and accuracy of measurement while drilling (MWD) systems has significantly reduced drilling costs by reducing the number of trips that must be made to remove the drillstring and obtain data. Further advancements in pulsed mud, acoustic, and "look ahead" systems could further improve drilling efficiency and supply more reliable formation data. Significant drilling cost savings can also be realized through improvements in the capability to more accurately steer the drillstring during directional drilling, reducing the number of check shot runs and directional correction maneuvers required for a well. The capability to accurately analyze formation fluids and test formation flow rates and pressures with drillstem tests more costeffectively and reliably could also improve drilling costs. Likewise, the reliability and accuracy of coring and open-hole logging techniques coupled with drill systems could improve overall drilling costs, since logging equipment failures continue to be a significant source of lost rig time. Many drilling measurement system advancements are being made by the oil companies and service sector alike, but the demonstration of some of the more innovative cost-saving methodologies and equipment could help to expand the applicability and utilization of these technologies. Benefits to the industry at large include drilling cost savings, prevention of formation damage or loss in well productivity or injectivity, and improvements in formation data accuracy.

\subsubsection{Well Completion and Recompletion Technology}

The industry can benefit from the development and demonstration of improved, cost-effective methods for completion, recompletion, workover, and stimulation of wells. Often the expense of such operations prevents operators from implementing projects that could significantly improve recovery and extend field life. Many operators have developed improved methods for the completion, recompletion, workover, and stimulation of wells, but the transfer of these methods to other operators is often not achieved.

\subsubsection{Completion Methods}

The development and demonstration of innovative completion methods continues to be an area where advancements in design and procedures can yield cost savings, improvements in well productivity and longevity, and improved recovery of oil. Specific areas where improvements can be of the most benefit are tubular and cementing systems, perforation systems, sand control, and corrosion control. The advent of slimhole drilling systems allows cost reduction through the use of smaller tubing strings, while improved tubulars can increase the longevity of wells in harsh environments. The advancement of casing and liner cementing systems can improve cement bond to prevent the behind-pipe migration of produced or injected fluids and eliminate the need for block squeezing. The optimization of perforation systems can improve completion efficiency by reducing 
formation damage and increasing injectivity or productivity. The industry has continued to improve perforation gun design and efficiency to insure that optimum perforations are placed in desired locations in wellbores. The development of underbalanced completion methods helps to prevent formation damage and improve perforation clean-up. Improved completion fluids can also reduce the likelihood of formation damage. Finally, design and optimization of corrosion control and chemical programs can insure quality completions for the life of projects.

\subsubsection{Recompletion and Workover Methods}

The development of improved or innovative recompletion and workover techniques can improve project economics and optimize recovery. Recompletion programs are often required for injectors and producers to enhance the performance of improved recovery processes. Project performance can be enhanced from both the recovery and economic standpoints through the development and demonstration of improved methods for the isolation of thief zones, the plugging of high water production zones, and to increase injection into unswept zones. (Specific research needs for conformance control technologies are outlined in section 4.2). Workover programs are often required in older fields to repair mechanical problems in wells. Cost-effective, low-risk workover methods for repairing casing and tubing leaks or to correct communication problems could provide benefits to many operators. Also important is the development of improved sand control methods.

\subsubsection{Well Stimulation Methods}

The development and demonstration of improved well stimulation methods to enhance well productivity can significantly benefit operators, especially with respect to marginal production operations. The industry continues to develop innovative methods for hydraulic fracturing, matrix stimulation, and wellbore clean-up. The development of improved fracturing systems and methodologies, computer programs for design optimization, and quality control instrumentation and procedures can reduce hydraulic fracturing costs and help to optimize fracture placement to improve well injectivity or productivity. Matrix stimulation techniques, such as acidizing and acid fracturing, continue to be employed by the industry to improve well productivity and injectivity. Innovative, reservoir-specific acidizing methodologies could reduce the cost and frequency of acid jobs and improve poststimulation performance. The industry could also benefit from the demonstration of reduced-cost wellbore clean-up methods for removing scale, alphaltenes, paraffin build-up, or for correcting other near-wellbore problems that limit productivity or injectivity. Well testing techniques and pressure transient analysis software are important tools for diagnosing problem wells and optimizing treatments.

\subsubsection{Production and Injection Facilities}

Surface facility limitations and problems often result in lost production, reduced well productivity, and environmental problems. Many facility problems result from the use of outdated or nonfunctional equipment, improper facility design, and poor operator practices. The implementation of improved methods of operation and the modification of surface facilities can often result in immediate cost savings and extend the life of fields. For instance, simple operational modifications can often result in significant power savings, which is typically a dominant component of operating costs (Pellegrino and Scott, 1989). The demonstration of improved systems and operating procedures for fluid separation and treatment, distribution and gathering, and artificial lift could encourage many operators to implement cost-saving practices.

\subsubsection{Separation and Treatment Facilities}

The proper design and operation of surface separation and treatment facilities is becoming increasingly important to operators as production from many fields approaches the economic limit and, more importantly, as more stringent regulatory restrictions are implemented. Separation equipment optimization efforts to improve the separation of produced oil, water, and gas can often 
result in cost savings (e.g., water treatment) and can even result in well productivity increases through optimization of system pressures. Gas recovery systems can be improved to reduce emissions and to increase gas supply for on-site use. One of the most significant operating costs in many fields is for water treatment and disposal, so improved systems for cleaning up produced water and innovative disposal methodologies have wide applicability. Also, demonstration of systems to improve injection water quality could help to increase waterflood recovery in many fields. Since water treatment and injection costs account for a significant portion of typical operating costs, it is important to demonstrate methods for attaining an economic balance between the increased recovery resulting from improved water quality and the costs required to achieve the desired level of water quality.

\subsubsection{Distribution and Gathering Systems}

The improvement or modification of production gathering systems and injection distribution systems can also afford operators significant cost savings and improve recovery. The gathering systems in many fields were designed for full field operations, and as economic limits are approached, the systems are often inefficient. Many gathering systems are beyond design life and are poorly maintained, so operators are at risk from an environmental standpoint. Unfortunately, most operators cannot afford to replace gathering systems, so development of innovative ways to modify these systems could be of benefit. Cost reductions on the production and gathering side can also be achieved through the use of automatic well test systems and well pump-off controllers. Improvements in injection distribution systems can also improve operating costs and recovery. Many water injection systems are simply turned around gathering systems, which often leads to the injection of the debris which has accumulated on the inside of the old flow lines or bacterial growth in the injection water. These can result in excessive pumping costs and in the plugging of injection wells, which necessitates remedial action. The development of cost-effective injection systems and system treatment methods can significantly reduce operating costs. Injection system optimization in enhanced recovery projects is also important for extending the productive life of fields.

\subsubsection{Artificial Lift Methods}

Optimization of artificial lift methods is also an important aspect for reducing operating costs and extending field life. Improved methods for analyzing and optimizing beam pumping unit performance can result in immediate and significant cost reductions. Many fields utilize more expensive hydraulic pumping systems which can also be optimized through innovative methods to improve recovery and reduce costs. An example is the use of jet pumps to lift higher volumes of fluids in waterflood operations. High volume lift equipment (i.e., electric submersible pumps) can also be utilized in waterflood or improved recovery projects to improve recovery and lifting costs.

\subsubsection{Field Operations and Reservoir Management}

The critical components of proper reservoir management include: (1) the thorough analysis of field drilling, completion, recompletion, workover, and facilities operations, (2) the identification of problem areas and the subsequent selection of appropriate improved technologies and practices, and (3) the implementation of these technologies and practices in the field. The development and implementation of reservoir management strategies can result in significant reductions in operating costs and increases in production and reserves. The optimization of field operations requires the integration of knowledge of the reservoir, geological, and production characteristics of the field, the history and status of wellbores, and the condition and operation of injection and production facilities. An interdisciplinary approach to field optimization is required, an approach which utilizes the expertise of drillers, reservoir engineers, geologists, production engineers, and field personnel to develop strategies for reducing costs, increasing production, and improving recovery. Field optimization should be a continuous process during the life of any field, but often operators 
do not have the knowledge, manpower, or financial resources required to undertake such efforts. The demonstration of the development and implementation of innovative field optimization strategies and the subsequent transfer of results to operators could have a significant and positive impact on the domestic oil industry.

\subsection{Environmental Issues}

Operators face a plethora of environmental regulations. Public perceptions of the oil industry are bolstered by major events such as the Valdez oil spill. Although perceptions may be inaccurate, operators face increased scrutiny from both regulators and the public. Rather than discussing specific environmental regulations, this section discusses environmental issues at the conceptual level. Readers are referred to the Class 4 technical report (NIPER/BDM, 1994) or original legislation for information regarding specific regulations. Where possible, discussion is further focused to the Class 4 resource.

A prior NIPER study (Crocker et al., 1991) focused on specific environmental RD\&D needs associated with oil and gas production. The majority of identified needs were associated with drilling and injection operations. The following analysis discusses these and other issues associated with future IOR operations within the context of four subject groupings: (1) project and well development issues, (2) project operational issues, (3) IOR process-specific issues, and (4) general industry environmental trends.

\subsubsection{Project and Well Development Issues}

Much of the Class 4 resource is in mature fields. In implementing an IOR project in mature fields, an operator must be cognizant of the environmental aspects of past activities on the lease and of the effects of previously abandoned and shut-in wells on future IOR operations. Since most IOR projects will involve drilling new or replacement wells, drilling environmental concerns must also be considered.

\subsubsection{Environmental Risk Assessment}

The Comprehensive Environmental Response Compensation and Liability Act of 1980 (CERCLA) assigns responsibility for clean-up of hazardous substances to owners and operators of a facility or property. Both current and past owners can be liable, regardless of whether the party was directly involved in the polluting activity. Environmental risk assessments establish baseline data for a given lease. This baseline data is important for measuring the environmental impacts of IOR operations and for "due diligence" liability protection (McNeill et al., 1993). In contemplating a future IOR project, an operator must assess environmental risk exposure and the potential effects of that risk exposure on the overall company (Wright, 1994). Demonstration of actions that limit environmental risk exposure, thus increasing IOR project potential, continue to be a research need.

\subsubsection{Previously Abandoned Wells}

Previously abandoned wells present potential communication problems. Because of these communication problems, the potential exists for contaminating surface or freshwater zones. Besides being an environmental liability, communication problems can impair sweep efficiency and result in loss of costly injection fluids. In mature fields like many of the Class 4 reservoirs, abandoned wells may require rework. Cost-effective procedures for identifying, testing, and reworking previously abandoned wells need further demonstration.

\subsubsection{Shut-In Wells}

The TORIS abandonment analysis (chapter 2) indicates that about two-thirds of the Class 4 improved recovery process potential is at risk of being abandoned by 2000 . Considering present economic conditions and project development time frames, IOR projects will not have been started 
in a large portion of the Class 4 resource by 2000 . Thus, many existing wells will be shut-in or temporarily abandoned. Industry studies indicate that, if these wells are permanently abandoned, the economics of reentry or redrilling may preclude future IOR projects. Although regulatory agencies have made efforts to spell out temporary abandonment terms, conditions, and procedures (Smith et al., 1993), the industry trend is still towards shortening the time period between well shut-in and permanent plug and abandonment.

Casing salvage practices associated with conventional plugging practices usually preclude future reentry. Haynes (1994) outlines how revised procedures leaving the casing in the hole could still satisfy environmental concerns while preserving the option of well reentry. Development of low-cost, environmentally acceptable abandonment procedures which preserve future access is a critical research need. Gaining regulatory agency acceptance is a crucial aspect of research in this area.

\subsubsection{Drilling}

According to the TORIS estimate, infill drilling, alone or in combination with polymer or profile modification techniques, has the most future potential for Class 4 reservoirs (chapter 2). New projects in the primarily mature Class 4 reservoirs may also involve significant redrilling. Drilling-related wastes represent about $2 \%$ of the U.S. exploration and production waste (Thurber, 1992). Drilling wastes represent a small percentage of total wastes because produced water is considered part of the waste stream. Although a small percentage, drilling waste is quite visible and can contain multiple hazardous materials. Drilling practices exert a major influence on both the hazard and volume of drilling waste. Considering the importance of drilling to future Class 4 potential, drilling practices will heavily influence development costs and potential environmental liabilities of future IOR projects.

Thurber (1992) subdivided drilling waste management practices into four areas: (1) selecting lower-toxicity drilling additives, (2) using high-performance, drilled-solids-removal equipment, (3) proper arrangement of equipment, and (4) proper wellsite water management (Thurber, 1992). Multiple managed reserve pit systems process waste as it is generated and isolate wastes of differing degrees of contamination (Ballantine, 1993). Annular reinjection methods can be utilized to dispose of solid wastes as a slurry in appropriate subsurface formations (Andersen and Witt, 1993). Dry drilling locations can be achieved by integrating mud engineering, solids control, and dewatering technologies to minimize volume and reduce whole mud cost (Wojtanowicz, 1993a). Considering waste disposal costs, reduced-waste drilling practices may be less costly as well as more environmentally acceptable. According to Thurber (1992), closed-loop mud systems are justified when drilling fluid, drilling fluid dilution, and fluid-disposal costs exceed about $\$ 6$ to $\$ 10$ per barrel.

Well design and drilling equipment also affect waste minimization. The type of drilling fluid can affect solids volumes (Bieler et al., 1993). In general, the more quickly a well is drilled, the less the environmental impact. Well designs which downsize wellbore sections decrease waste volumes. Slimhole drilling technologies can reduce drilling time and drilling fluid and solids volumes. Slimhole wells, however, may not meet Class II injection well requirements (section 4.12.2.3). Future conversion to injection should be considered in drilling any new well in a new IOR project.

By using a systems approach, industry has improved drillsite management practices. Yet, optimized drillsite management practices are not routinely applied. Technology transfer through demonstration of optimum practices tailored to given geographic regions and reservoirs is needed to realize the Class 4 drilling-related potential. 


\subsubsection{Remedial Workovers and Stimulation Treatments}

IOR projects often require remedial workovers in existing wells. Stimulation treatments are required in new wells, and many existing wells are restimulated. The chemicals and materials used in workovers and stimulation treatments require safe handling procedures prior to and during treatments. Excess or spent treating fluids may require special disposal. In disposal, care must be taken to prevent contaminating a larger volume of fluids.

\subsubsection{Project Operational Issues}

Changes inherent to IOR projects cause certain operational activities to increase, and increased activity creates some environmental issues. Areas where environmental concerns may arise include: (1) production chemical usage, (2) radioactive tracers, (3) Class II injection wells, (4) leak and spill prevention, and (5) naturally occurring radioactive material (NORM) contamination.

\subsubsection{Production Chemical Usage}

Increased fluid volumes associated with IOR injection projects generally cause increased usage of production chemicals. Production chemicals include corrosion inhibitors, scale inhibitors and scale removal chemicals, biocides, demulsifiers, defoamers, etc. Issues to be addressed include chemical handling procedures, disposal of excess chemical when treating chemicals are changed, drum or container disposal, and toxicity of the oil, water, and solids where portions of the chemicals end up. Just like with drilling, Caudle and Bansal (1993) recommend a systems approach where design either reduces, optimizes, or eliminates chemical usage. Demonstration of the interaction between system design and chemical usage and of cost-effective, comprehensive compliance programs represents a research need.

\subsubsection{Radioactive Tracers}

Radioactive tracers in inter-well tracer studies, injection profile surveys, and completion (both fluid- and solid-tagging) fluids are important tools for reservoir management. As regulatory requirements have increased, radioactive tracer services have become a contract service offered by wireline companies or specialized vendors. Of the different applications, the common injection profile survey using 131 iodine represents one of the more hazardous applications (Abernathy et al., 1994). Safe operations require a joint effort between the tracer service contractor, the pumping service operator, the wireline contractor, and the well operator. Postjob monitoring and procedures are an important aspect of radioactive tracer applications (Abernathy et al., 1994).

Although injection profile surveys using radioactive tracers are widely accepted by industry, environmental concerns with attendant costs are renewing interest in alternative injection profile methods, such as the differential temperature survey. Development and demonstration of nonradioactive injection profile techniques represent a research need for IOR processes.

Although interwell radioactive tracers, when properly applied, are not as hazardous as radioactive injection profile surveys (Abernathy et al., 1994), environmental concerns are still directing applications towards nonradioactive tracers. Brookhaven National Laboratory is researching perfluorocarbon tracer technologies for IOR applications (ACTI, 1994). Vapor phase tracers have been developed, and research is continuing on aqueous phase tracers. Other inorganic chemicals like nitrate are also commonly used for interwell tracer studies.

\subsubsection{Class II Injection Wells}

Injection wells in waterflooding and IOR operations are classified as Class II injection wells, and, as such, are subject to mechanical integrity tests (MITs). Mechanical integrity means both the absence of leaks in the tubing (internal mechanical integrity) and the absence of flow from the injection zone through channels in the cement (external mechanical integrity). External mechanical integrity is normally demonstrated initially through cementing records (Browning and Smith, 
1993). Wireline logging techniques are available for evaluating channeling or fluid flow beyond casing (Crocker et al., 1991). Internal mechanical integrity testing can be performed by a variety of methods. Required frequency of mechanical integrity testing depends on the layers of protection provided by well design and whether the injection well is a new or existing well. EPA has proposed more stringent standards for newly drilled or converted Class II injection wells which could affect development and operating costs (Worrell, 1994; Smith and Browning, 1993).

Recent studies indicate the magnitude of the MIT problem. Browning and Smith (1993) report failure rates of $3 \%$ to $12 \%$ with actual rates known to be higher due to operator pretesting to ensure wells pass the MIT test. Browning and Smith concluded that nearly two-thirds of MIT failures are due to casing failures, with one-fifth of those casing failures allowing injection fluids outside the casing. A 1986 study by the Oklahoma Corporation Commission provided similar statistics (OCC, 1986). In Browning and Smith's study, about one-fourth of those wells with casing failures were plugged within 60 days from the MIT test. Development and demonstration of cost-effective workover procedures for reestablishing mechanical integrity in injection wells represents a research need for IOR injection operations.

\subsubsection{Leak and Spill Prevention}

Increased fluid production and injection volumes, installation of injection systems, expansion of lease facilities, and overall increased lease activity provide increased opportunities for leaks and spills. Design, maintenance, and operations practices all influence the probability of leaks and spills occurring. Knowing that leaks and spills can occur, contingency plans must be in place, both for regulatory purposes and for safety and environmental considerations.

\subsubsection{NORM Contamination}

IOR projects frequently involve significant reworking of the production facilities. Tubular goods, flowlines, separators, and tanks are often upgraded or resized. Naturally occurring radioactive material (NORM), when present, often concentrates in scale or sludge in the equipment. The presence of NORM contamination is considered a nonlinear event; that is, absence now does not mean NORM contamination will never be present (MacDowell and Gray, 1993). Since scaling can increase with injection projects, the potential for NORM contamination increases in injection projects. NORM-contaminated materials require special handling procedures to reduce exposure. Decontamination may be required before equipment disposal. Decontamination processes, which can be either mechanical or chemical (Diyashev et al., 1994), are costly and present hazards themselves. Operators have a fiduciary and legal responsibility to establish an effective NORM management program (MacDowell and Gray, 1993). Experience indicates that NORM can be managed (Smith, 1987), but demonstration of cost-effective NORM monitoring and management programs represents a research need.

\subsubsection{IOR Process-Specific Issues}

Environmental issues vary depending on the nature of the IOR process. More important issues for the IOR processes discussed in previous sections of chapter 4 are included for conformance control systems, chemical floods, $\mathrm{CO}_{2}$ processes, and thermal operations.

\subsubsection{Conformance Control}

Past and current conformance control applications rely heavily on gel polymer applications using the hazardous chromium redox system. Safety issues provide a strong driving force for developing alternative, less hazardous chemical systems. Continued research for alternative systems is critical to realizing the profile modification/infill drilling potential estimated by TORIS. 


\subsubsection{Chemical Flooding}

Storage and handling concerns must be addressed in any chemical flooding operation. Waste management practices (section 4.12.4.1) heavily influence the degree to which storage and handling become an environmental concern. Polymers for mobility control are a common element in chemical floods. Acrylamide polymers in particular are subject to bacterial degradation and usually require increased system treatment with biocides. Biocides by nature are hazardous chemicals. Continuing research for effective, but less hazardous, biocides is important. Significant advances could reduce the environmental costs associated with processes using polymers.

Polymers, surfactants, and alkaline agents may require special handling and storage requirements. From a human exposure standpoint, polymer and surfactant requirements are similar to those required for production chemicals. Alkaline agents used in the alkaline or alkalinesurfactant-polymer processes require additional handling precautions.

\subsubsection{3 $\mathrm{CO}_{2}$ Processes}

The $\mathrm{CO}_{2}$ processes pose a variety of environmental and safety hazards. $\mathrm{CO}_{2}$ is a heavier-thanair gas which, if released to the environment in large quantities, can settle in low places endangering health. $\mathrm{CO}_{2}$ is also a "greenhouse" gas which may, according to some opinions, contribute to global warming. Recycle operations involving gas compression and other processing equipment present air quality concerns. Produced gas from cyclic $\mathrm{CO}_{2}$ stimulation treatments may become contaminated with $\mathrm{CO}_{2}$ requiring separation and processing equipment or making flaring difficult. Corrosion problems associated with $\mathrm{CO}_{2}$ operations may increase equipment failures causing increased spill and leak frequency. Demonstration of improved procedures for $\mathrm{CO}_{2}$ operations are an important research need relevant to environmental issues.

\subsubsection{Thermal Processes}

Thermal IOR operations present both air and water quality concerns. Air-pollutant sources include steam generators, compressor exhaust gases with in situ combustion projects, and wellhead emissions. Site-preparation activities themselves can generate significant quantities of air pollutants (Sarathi, 1991). Wellhead emissions associated in the past with steam operations can be controlled by casing-vapor-recovery systems (Peavy and Braun, 1991). Air quality concerns represent the main environmental concern associated with thermal operations. In certain areas, fresh water supply represents a constraint, as does produced water disposal. Completion technologies must consider the thermal stresses encountered in steam and in situ combustion projects. Well failures can endanger fresh water zones.

\subsubsection{General Industry Environmental Trends}

In the environmental arena, general industry effort is focused in waste management practices and integrated engineering design. Waste management practices influence both the hazard and volume of wastes. Integrated engineering design affects the hazard, quantity, and disposal costs of wastes. Taken together, waste management and integrated engineering design influence cost. Field demonstration of environmentally responsible practices increases technology transfer and is valuable for image management.

\subsubsection{Waste Management (Minimization) Practices}

Waste management involves waste reduction, reuse (reclaim and reuse materials in their original form), recycling, treatment, and responsible disposal (Owens, 1994). Waste minimization, both in quantity and hazard, are primary objectives. Although drillsite waste-reduction practices may be most visible, significant opportunities for waste minimization exist in routine operations. Source reduction is the optimum choice but reuse and recycling play a role. In recycling, care should be taken to determine if recycling is actually disposal which may be creating environmental 
problems (i.e., burning for energy recovery). A waste management program requires management commitment in terms of dollars and staff time. Implementation costs include equipment, development of operating procedures, and staff training.

Source reduction techniques, the most important component of waste management, may involve: (1) product substitution, (2) inventory control, (3) reduced water use, (4) housekeeping and routine inspection, (5) equipment maintenance and repair, (6) in-process recycling, (7) preplanning, (8) segregation of wastes, (9) contractor selection, and (10) other innovations (Savage, 1993). In addition to environmental benefits, the revised operating practices may improve efficiency and equipment life.

All operators practice waste management. However, demonstration of the economic benefits (and reduced liabilities) from comprehensive waste management programs represents a research need for mature operations like most of those in Class 4 reservoirs.

\subsubsection{Integrated Engineering Design}

Wojtanowicz (1993b) coined the term environmental control technology to refer to a preventive, design function in environmental management. The premise behind the approach is that when petroleum engineers and other industry professionals examine the environmental aspects of the processes, they can find ways to change the processes (including reservoir fluid production and injection) to minimize interactions between the oilfield and its environment. Although waste management is a part of environmental control technology, many other, more comprehensive concepts are included. The key strategy is to minimize the problem through engineering and design rather than dealing with the problem's aftermath.

\subsubsection{Field Demonstration}

Armstrong (1994) indicates that "sustainable development" is the environmental vision for the next century. Sustainable development means "development that meets the needs of the present without compromising the ability of future generations to meet their own needs." To change perceptions that the oil industry is not compatible with sustainable development, companies have to demonstrate responsibility within their company, be more active in a public relations and educational role, and reduce their own energy use and consumption (Armstrong, 1994).

Industry practices and public perceptions of the oil industry change only through education and visible action. Field demonstrations incorporating sound environmental practices transfer technology to others in industry. Increased knowledge leads to usage, which results in improved industry credibility. What better place to demonstrate sound practices than in the generally mature reservoirs in Class 4 ?

\subsection{References}

\subsubsection{Infill Drilling}

Barbe, A. and D.J. Schnoebelen, 1986, Quantitative analysis of infill performance-Robertson Clearfork Unit: SPE 15568 61st Annual Technical Conference, New Orleans, Louisiana, October.

Barber, A.H., C.J. George, L.H. Stiles, and B.B. Thompson, 1983, Infill drilling to increase reserves - actual experience in nine fields in Texas, Oklahoma, and Illinois: Journal of Petroleum Technology, vol. 35, No. 9, August, p. 1530-38.

Biglarbigi, K., G.W. Paul, and K.M. Ray, 1994, A methodology for prediction of oil recovery by infill drilling: SPE/DOE 27761 Ninth Symposium on Improved Oil Recovery, Tulsa, Oklahoma, April. 
Delaney, R.P. and P.B. Tsang, 1982, Computer reservoir continuity study at Judy Creek: Journal of Canadian Petroleum Technology, vol. 21, No. 1, February, p. 38-44.

Driscoll, V.J., 1974, Recovery optimization through infill drilling-concepts, analysis, and field results: SPE 4977 43rd Annual Technical Conference, Houston, Texas, October.

DOE Report, 1994, Supporting technology for advanced oil recovery, Infill Drilling Predictive Model (IDPM): Department of Energy Report, DOE/BC-94/4/SP, July.

George, C.J. and L.H. Stiles, 1978, Improved techniques for evaluating carbonate waterfloods in West Texas: Journal of Petroleum Technology, vol. 30, No. 11, November, p. 1547-54.

Ghauri, W.K., 1980, Production technology experience in a large carbonate waterflood, Denver Unit, Wasson San Andres Field: Journal of Petroleum Technology, vol. 32, No. 9, September, p. 1493-1502.

Ghauri, W.K., A.F. Osborne, and W.L. Magnuson, 1974, Changing concepts in carbonate waterflooding - West Texas Denver Unit Project - an illustrative example: Journal of Petroleum Technology, vol. 26, No. 6, June, p. 595-606.

Gould, T.L. and M.A. Munoz, 1982, An analysis of infill drilling: SPE 11021 51st Annual Technical Conference, New Orleans, Louisiana, September.

Gould, T.L. and A.M.S. Sarem, 1989, Infill drilling for incremental recovery: Journal of Petroleum Technology, vol. 41, No. 3, March, p. 229-237.

Holm, L.W., 1980, Infill drilling vs. tertiary oil recovery vs. more imports: Journal of Petroleum Technology, vol. 32, No. 7, July, p. 1169-1174.

Hunter, C.D., 1988, The development of a marginal Clearfork waterflood prospect: SPE 20128 Permian Basin Oil and Gas Recovery Symposium, Midland, Texas, March.

ICF and BEG (Texas Bureau of Economic Geology), 1990a, Production potential of unrecovered mobile oil through infield development: integrated geologic and engineering studies-overview: Department of Energy Report, DOE/BC/14000-3, August.

ICF and BEG (Texas Bureau of Economic Geology), 1990b, An assessment of the reserve growth potential of the San Andres/Grayburg Carbonate (South Central Basin Platform) Play in Texas: Department of Energy Report DOE/BC/14000-4, August.

ICF and BEG (Texas Bureau of Economic Geology), 1990c, An assessment of the reserve growth potential of the Clearfork Platform Carbonate Play in Texas: Department of Energy Report $\mathrm{DOE} / \mathrm{BC} / 14000-5$, August.

ICF and BEG (Texas Bureau of Economic Geology), 1990d, An assessment of the reserve growth potential of the Frio Barrier-Strandplain Play in Texas: Department of Energy Report DOE/BC/14000-6, August.

ICF Resources Incorporated, 1991, Infill drilling model development project- summary reports: Department of Energy Report DOE/BPO, DE-AC-22-91BC14839, December.

Interstate Oil and Gas Compact Commission, 1993, An evaluation of known remaining oil resources in the United States: vol. 9, November.

Kendall, J.J., G.C. Killberg, L.G. Zambrano, and J.E. Valusek, 1992, New technologies aid multidisciplinary success in 80-year-old field: Petroleum Engineer International, vol. 64, No. 12, December, p. 14-18.

Lucia, F.J. and G.E. Fogg, 1989, Geologic/stochastic mapping of heterogeneity in a carbonate reservoir-Dune (Grayburg) Field, Crane County, West Texas: SPE 19597 64th Annual Technical Conference, San Antonio, Texas, October. 
Malik, Z.A., B.A. Silva, R.M. Brimhall, and C.H. Wu, 1993, An integrated approach to characterize low-permeability reservoir connectivity for optimal waterflood infill drilling: SPE 25853 Rocky Mountain Regional/Low Permeability Reservoirs Symposium, Denver, Colorado, April.

National Petroleum Council, 1984, Enhanced Oil Recovery; Washington, D.C.

Stiles, L.H., 1976, Optimizing waterflood recovery in a mature waterflood, The Fullerton Clearfork Unit: SPE 6198 45th Annual Technical Conference, New Orleans, Louisiana, October.

van Everdingen, A.F. and H.S. Kriss, 1980, A proposal to improve recovery efficiency: Journal of Petroleum Technology, vol. 32, No. 7, July, p. 1164-1168.

Zambrano, L.G, G.C. Killberg, and J.J., Kendall, 1992, An integrated approach to evaluate the upside potential of a mature field, Countyline Unit, Sho-Vel-Tum Field, Oklahoma: SPE 24871 67th Annual Technical Conference, Washington, D.C., October.

\subsubsection{Conformance Control Technologies}

Acock, A.M. and J.C. Reis, 1994, Oil recovery improvement through profile modification by thermal precipitation: SPE/DOE 27831 Ninth Symposium on Improved Oil Recovery, Tulsa, Oklahoma.

Avery, M.R. and J.A. Sutphen, 1989, Field evaluation of production well treatments in Kansas using a crosslinked, cationic polymer gel: in Proceedings of the Eighth Tertiary Oil Recovery Conference, Wichita, Kansas, March.

Borling, D.C., 1994, Injection conformance control case histories using gels at the Wertz field $\mathrm{CO}_{2}$ tertiary flood in Wyoming: SPE/DOE 27825 Ninth Symposium on Improved Oil Recovery, Tulsa, Oklahoma, April.

Dauben, D.L., 1991, Part II, EOR field case histories: in Research Needs to Maximize the Economic Producibility of the Domestic Oil Resource, Department of Energy Report NIPER527, October, p. 232-521.

Deterding, J.M., F.D. Sutterfield, and T.E. Burchfield, 1993, Final Report, National Institute for Petroleum and Energy Research (NIPER): Department of Energy Report NIPER-685, December, $603 \mathrm{p}$.

Doe, P.H., A. Moradi-Araghi, J.E. Shaw, and G.A. Stahl, 1987, Development and evaluation of EOR polymers suitable for hostile environments-part 1: copolymers of vinylpyrrolidone and acrylamide: SPE Reservoir Engineering, vol. 2, No. 4, November, p. 461-467.

Dovan, H.T. and R.D. Hutchins, 1987, Development of a new aluminum-polymer gel system for permeability adjustment: SPE Reservoir Engineering, vol. 39, No. 5, May, p. 177-183.

Fielding, R.C., Jr., D.H. Gibbons, and F.P. Legrand, 1994, In-depth drive fluid diversion using an evolution of colloidal dispersion and new bulk gels-an operational case history of North Rainbow Ranch Unit: SPE/DOE 27773 Ninth Symposium on Improved Oil Recovery, Tulsa, Oklahoma, April.

Fogler, H.S., 1994, Characterization and modification of fluid conductivity in heterogeneous reservoirs to improve sweep efficiency: in Enhanced Oil Recovery, Progress Review No. 76, Quarter Ending September 30, 1993, Department of Energy report DOE/BC-93/4, August, p. 51-53.

French, T.R., H.W. Gao, and K.M. Bertus, 1988, Crosslinking dry xanthan gum for profile modification in oil reservoirs: Department of Energy Report NIPER-339, May, 30 p. 
Gao, H.W., 1987, Mobility control in oil recovery by chemical flooding, state-of-the-art review: Department of Energy Report NIPER-146, January, 95 p.

Gao, H.W., 1991a, Effects of degree of hydrolysis and shear on gelation reaction kinetics and gel strength: Department of Energy Report NIPER-488, February, 17 p.

Gao, H.W., 1991b, A study of the flow behavior of flexible polymer gels as potential mobility control agents in porous media: Department of Energy Report NIPER-553, September, 11 p.

Gao, H.W. and T.E. Burchfield, 1993, The effects of layer permeability contrast and crossflow on the effectiveness of polymer gel treatments in polymer floods and waterfloods: SPE 25453 Production Operations Symposium, Oklahoma City, Oklahoma, March.

Gao, H.W. and M.M. Chang, 1990, A three-dimensional, three-phase simulator for permeability modification treatments using gelled polymers: Department of Energy Report NIPER-388, March, $70 \mathrm{p}$.

Gao, H.W., M.M. Chang, T.E. Burchfield, and M.K. Tham, 1990, Studies of the effects of crossflow and initiation time of a polymer gel treatment on oil recovery in a waterflood using a permeability modification simulator: SPE/DOE 20216 Seventh Symposium on Enhanced Oil Recovery, Tulsa, Oklahoma, April.

Gao, H.W., M.M. Chang, T.E. Burchfield, and M.K. Tham, 1993, Permeability modification simulator studies of polymer-gel-treatment initiation time and crossflow effects on waterflood oil recovery: SPE Reservoir Engineering, vol. 8, No. 3, August, p. 221-227.

Green, D.W. and G.P. Willhite, 1994, Improving reservoir conformance using gelled polymer systems: in Enhanced Oil Recovery, Progress Review No. 76, Quarter Ending September 30, 1993, Department of Energy Report DOE/BC-93/4, August.

Jack, L.M., L.G. Schoeling, and D.W. Green, 1991, Overview of gelled polymer projects conducted in central Kansas: in Proceedings of the Ninth Tertiary Oil Recovery Conference, Wichita, Kansas, March.

Kalpakci, B., Y.T. Jeans, N.F. Magri, and J.P. Padolewski, 1990, Thermal stability of scleroglucan at realistic reservoir conditions: SPE/DOE 20237 Seventh Symposium on Enhanced Oil Recovery, Tulsa, Oklahoma, April.

Llave, F.M. and R.E. Dobson, Sr., 1994, Field application of surfactant-alcohol blends for conformance control: SPE 28618, pending publication.

Llave, F.M., T.E. Burchfield, and R.E. Dobson, Jr., 1990, A novel method of developing indepth permeability modification using surfactant-alcohol blends: SPE 20484 65th Annual Technical Conference, New Orleans, Louisiana, September.

Lockhart, T.P. and P. Albonico, 1992, A new gelation technology for in-depth placement of $\mathrm{Cr}^{+3}$ /polymer gels in high-temperature reservoirs: SPE/DOE 24194 Eighth Symposium on Enhanced Oil Recovery, Tulsa, Oklahoma, April.

Mack, J.C. and J.E. Smith, 1994, In-depth colloidal dispersion gels improve oil recovery efficiency: SPE/DOE 27780 Ninth Symposium on Improved Oil Recovery, Tulsa, Oklahoma, April.

Mody, B.G., 1992, Polymer treatments of wells have economic benefits: The American Oil and Gas Reporter, vol. 35, No. 9, September, p. 55-62.

Mody, B.G., R.S. McKitrick, and D. Shahsavari, 1988, Proper application of crosslinked polymer decreases operating costs: SPE 17288 Permian Basin Oil and Gas Recovery Conference, Midland, Texas, March. 
Moradi-Araghi, A., 1994, Application of low-toxicity crosslinking systems in production of thermally stable gels: SPE/DOE 27826 Ninth Symposium on Improved Oil Recovery, Tulsa, Oklahoma, April.

Mumallah, N.A., 1988, Chromium (III) propionate: a crosslinking agent for water-soluble polymers in hard oilfield brines: SPE Reservoir Engineering, vol. 3, No. 1, February, p. 243250.

Needham, R.B. and P.H. Doe, 1987, Polymer flooding review: Journal of Petroleum Technology, vol. 39, No. 12, December, p. 1503-1507.

NIPER/BDM, 1994a, Geological and production characteristics of strandplain/barrier island reservoirs in the United States: Department of Energy Report NIPER/BDM-0027, July.

NIPER/BDM, 1994b, Quarterly technical progress report, January 1-March 31, 1994 for management and operating contract for the Department of Energy's National Oil and Related Programs: Department of Energy Report NIPER/BDM-0022, April, 143 p.

OGJ, 1994, DOE tallies Class III oil recovery field projects: Oil and Gas Journal, vol. 92, No. 30 , July 25, p. 108-111.

PEI, 1992, Operators seek economical production fluid performance: Petroleum Engineer International, vol. 64, No. 10, October, p. 32-33.

Raible, C. and T. Zhu, 1992, Application of polymer gels for profile modification and sweep improvement of gas flooding: Department of Energy Report NIPER-632, December, 31 p.

Ryles, R.G., 1988, Chemical stability limits of water-soluble polymers used in oil recovery processes: SPE Reservoir Engineering, vol. 3, No. 1, February, p. 23-34.

Schoeling, L.G., E.L. Cole, T.L. Phares, and W.J. Weatherbie, 1993, Permeability modification demonstration project: University of Kansas, Energy Research Center, Technology Transfer Series 93-7, September, 79 p.

Seright, R.S., 1993, Improved techniques for fluid diversion in oil recovery, first annual report: Department of Energy Report DOE/BC/14880-5, December, 263 p.

Seright, R.S. and J. Liang, 1994, A survey of field applications of gel treatments for water shutoff: SPE 26991 III-Latin American/Caribbean Petroleum Engineering Conference, Buenos Aires, Argentina, April.

Southwell, G.P. and S.M. Posey, 1994, Applications and results of acrylamidepolymer/chromium(III) carboxylate gels: SPE/DOE 27779 Ninth Symposium on Improved Oil Recovery, Tulsa, Oklahoma, April.

Sydansk, R.D., 1988, A new conformance-improvement-treatment chromium(III) gel technology: SPE/DOE 17329 Enhanced Oil Recovery Symposium, Tulsa, Oklahoma, April.

Sydansk, R.D. and P.E. Moore, 1992, Gel conformance treatments increase oil production in Wyoming: Oil and Gas Journal, vol. 90, No. 3, January 20, p. 40-45.

Vossoughi, S. and C.S. Buller, 1989, Permeability modification by in-situ gelation using a newly discovered bio-polymer: SPE 19631 64th Annual Technical Conference, San Antonio, Texas, October.

Vossoughi, S. and A. Putz, 1991, Reversible in-situ gelation by the change of $\mathrm{pH}$ within the rock: SPE 20997 International Symposium on Oilfield Chemistry, Anaheim, California, February.

Whittington, L.E., D.G. Naae, and R.W. Braun, 1994, Brine-initiated gels-a new water shut-off agent: SPE/DOE 27830 Ninth Symposium on Improved Oil Recovery, Tulsa, Oklahoma, April.

Zhu, T. and C. Raible, 1994, Improved sweep efficiency by alcohol-induced salt precipitation: SPE/DOE 27777 Ninth Symposium on Improved Oil Recovery, Tulsa, Oklahoma, April. 


\subsubsection{Polymers for Mobility Control}

American Petroleum Institute, 1990, Recommended practices for evaluation of polymers used in enhanced oil recovery operations: first edition, API PR63, June.

Cole, E.L., 1988, An evaluation of the Big Muddy field low-tension flood demonstration project: Department of Energy Report DOE/BC/10830-0, December, 151 p.

Cole, E.L. and D.L. Dauben, 1987, An evaluation of the Robinson M-1 commercial scale demonstration of enhanced oil recovery by micellar-polymer flood: Department of Energy Contract AC19-85BC10830, October.

Dauben, D.L., 1991, part II, EOR field case histories: in Research Needs to Maximize the Economic Producibility of the Domestic Oil Resource, Department of Energy Report NIPER527, October, p. 232-521.

Doe, P.H., A. Moradi-Araghi, J.E. Shaw, and G.A. Stahl, 1987, Development and evaluation of EOR polymers suitable for hostile environments-part 1-copolymers of vinylpyrrolidone and acrylamide: SPE Reservoir Engineering, vol. 2, No. 4, November, p. 461-467.

Fletcher, A.J.P., S.P. Lamb, and P.J. Clifford, 1992, Formation damage from polymer solutionsfactors governing injectivity: SPE Reservoir Engineering, vol. 7, No. 2, May, p. 237-246.

Gall, B., 1993, Chemical flooding technology: in Final Report, National Institute for Petroleum and Energy Research (NIPER), Department of Energy Report NIPER-685, December, p. 151235.

Gao, H.W., 1987, Mobility control in oil recovery by chemical flooding, state-of-the-art review: Department of Energy Report NIPER-146, January, 95 p.

Gao, H.W., 1991a, Effects of degree of hydrolysis and shear on gelation reaction kinetics and gel strength: Department of Energy Report NIPER-488, February, $17 \mathrm{p}$.

Gao, H.W., 1991b, A study of the flow behavior of flexible polymer gels as potential mobility control agents in porous media: Department of Energy Report NIPER-553, September, 11 p.

Gao, H.W., 1992, The effect of lamination angle on polymer retention: Department of Energy Report NIPER-630, September, $14 \mathrm{p}$.

Hamaker, D.E. and G.D. Frazier, 1982, Manvel enhanced oil recovery pilot-design and implementation: SPE/DOE 7088 Fifth Symposium on Improved Methods for Oil Recovery, Tulsa, Oklahoma, April..

Hochanadel, S.M., M.L. Lunceford, and C.W. Farmer, 1990, A comparison of 31 Minnelusa polymer floods with 24 Minnelusa waterfloods: SPE/DOE 20234 Seventh Symposium on Enhanced Oil Recovery, Tulsa, Oklahoma, April.

Huh, C., E.A. Lange, and W.J. Cannella, 1990, Polymer retention in porous media: SPE/DOE 20235 Seventh Symposium on Enhanced Oil Recovery, Tulsa, Oklahoma, April.

Kalpakci, B., Y.T. Jeans, N.F. Magri, and J.P. Padolewski, 1990, Thermal stability of scleroglucan at realistic reservoir conditions: SPE/DOE 20237 Seventh Symposium on Enhanced Oil Recovery, Tulsa, Oklahoma, April.

Lorenz, P.B., 1991, Polymer flooding-state of the art review: in Research Needs to Maximize Economic Producibility of the Domestic Oil Resource, Department of Energy Report NIPER527, October, p. 81-88.

McCormick, C. and R. Hester, 1994, Responsive copolymers for enhanced petroleum recovery: in Enhanced Oil Recovery, Progress Review No. 76, Quarter Ending September 30, 1993, Department of Energy Report DOE/BC-93/4, August, p. 5-9.

National Petroleum Council, 1984, Enhanced Oil Recovery; Washington, D.C. 
Needham, R.B. and P.H. Doe, 1987, Polymer flooding review: Journal of Petroleum Technology, vol. 39, No. 12, December, p. 1503-1507.

NIPER/BDM, 1994, Quarterly technical progress report, January 1-March 31, 1994 for management and operating contract for the Department of Energy's National Oil and Related Programs: Department of Energy Report NIPER/BDM-0022, April, 143 p.

NIPER and K\&A, 1991, Research needs to maximize economic producibility of the domestic oil resource: Department of Energy Report NIPER-527, July 29, 521 p.

OGJ, 1994, DOE tallies Class III oil recovery field projects: Oil and Gas Journal, vol. 92, No. 30 , July 25, p. 108-111.

Pautz, J.F., C.A. Sellers, C. Nautiyal, and E. Allison, 1992, Enhanced oil recovery projects data base: Department of Energy Report NIPER-583, February, 344 p.

Pautz, J.F., R.A. Welch, and C.M. Nautiyal, 1994, Comparison of actual results of EOR field projects to calculated results of EOR predictive models: SPE/DOE 27763 Ninth Symposium on Improved Oil Recovery, Tulsa, Oklahoma, April.

Rivenq, R.C., A. Donche, and C. Noik, 1989, Improved scleroglucan for polymer flooding under harsh reservoir conditions: SPE 19635 64th Annual Technical Conference, San Antonio, Texas, October.

Ryles, R.G., 1988, Chemical stability limits of water-soluble polymers used in oil recovery processes: SPE Reservoir Engineering, vol. 3, No. 1, February, p. 23-34.

Sohn, W.O., B.K. Maitin, and H. Volz, 1990, Preconditioning concepts in polymer flooding in high salinity reservoirs-laboratory investigations and case histories: SPE Reservoir Engineering, vol. 5, No. 4, November, p. 503-507.

Taber, J.J. and R.S. Seright, 1992, Horizontal injection and production wells for EOR or waterflooding: SPE 23952 Permian Basin Oil and Gas Recovery Conference, Midland, Texas, March.

Talash, A.W. and L.W. Strange, 1981, Summary of performance and evaluation in the West Burkburnett chemical waterflood project: SPE 10162 56th Annual Technical Conference, San Antonio, Texas, October.

Tracy, G.W. and D.L. Dauben, 1981, An evaluation of the North Burbank Unit tertiary recovery test: Department of Energy Report DOE/BC/10033-2, August, 29 p.

Treiber, L.E. and S.H. Yang, 1986, The nature of polymer plugging and a wellbore treatment to minimize it: SPE/DOE 14948 Fifth Symposium on Enhanced Oil Recovery, Tulsa, Oklahoma, April.

Vossoughi, S. and A. Putz, 1991, Reversible in-situ gelation by the change of $\mathrm{pH}$ within the rock: SPE 20997 International Symposium on Oilfield Chemistry, Anaheim, California, February.

Widmeyer, R.H. and R.G. Pindell, 1981, Manvel enhanced recovery pilot-performance evaluation: SPE/DOE 9793 Second Joint Symposium on Enhanced Oil Recovery, Tulsa, Oklahoma, April.

\subsubsection{Microbial Processes}

Bryant, R.S., 1990, Screening criteria for microbial EOR processes: Department of Energy Report NIPER-478, September, 17 p.

Bryant, R.S., 1991, Microbial enhanced oil recovery-state of the art review: in Research Needs to Maximize Economic Producibility of the Domestic Oil Resource, Department of Energy Report NIPER-527, October, p. 63-80. 
Bryant, R.S., 1993, Microbial EOR processes: in Final Report, National Institute for Petroleum and Energy Research (NIPER), Department of Energy Report NIPER-685, December, p. 325351.

Bryant, R.S., 1994, Microbial enhanced hydrocarbon recovery and its potential for application to North Sea reservoirs: Trans. IChemE, vol. 72, Part A, March, p. 144-151.

Bryant, R.S., A.K. Stepp, K.M. Bertus, and T.E. Burchfield, 1994, Microbial enhanced waterflooding field tests: SPE/DOE 27751 Ninth Symposium on Improved Oil Recovery, Tulsa, Oklahoma, April.

Chang, M.M., F.T.H. Chung, R.S. Bryant, H.W. Gao, and T.E. Burchfield, 1991, Modeling and laboratory investigation of microbial transport phenomena in porous media: SPE 22845 66th Annual Technical Conference, Dallas, Texas, October.

McCoy, L., 1994, Microbial enhanced oil recovery and wettability research program: in Enhanced Oil Recovery, Progress Review No. 74, Quarter Ending March 31, 1993, Department of Energy Report DOE/BC-93/2, March, p. 128-132.

NIPER/BDM, 1994, Quarterly technical progress report, January 1-March 31, 1994 for management and operating contract for the Department of Energy's National Oil and Related Program: Department of Energy Report NIPER/BDM-0022, April, 143 p.

OGJ, 1994, DOE tallies Class III oil recovery field projects: Oil and Gas Journal, vol. 92, No. 30, July 25, p. 108-111.

Premuzic, E.T. and M.S. Lin, 1994, Effects of selected thermophilic microorganisms on crude oils at elevated temperatures and pressures: in Enhanced Oil Recovery, Progress Review No. 74, Quarter Ending March 31, 1993, Department of Energy Report DOE/BC-93/2, March, p. 132-134.

Stepp, A. and R.S. Bryant, 1994, Microbial EOR an affordable solution: The American Oil and Gas Reporter, vol. 37, No. 3, March, p. 75-78.

\subsubsection{Alkaline and Alkaline-Surfactant-Polymer (ASP) Processes}

Clark, S.R., M.J. Pitts, and S.M. Smith, 1988, Design and application of an alkaline-surfactantpolymer recovery system to the West Kiehl Field: SPE 17538 Rocky Mountain Regional Meeting, Casper, Wyoming, May.

Dauben, D.L., 1991, part II, EOR field case histories: in Research Needs to Maximize the Economic Producibility of the Domestic Oil Resource, Department of Energy Report NIPER527, October, p. 232-521.

Falls, A.H., D.R. Thigpen, R.C. Nelson, J.W. Ciaston, J.B. Lawson, P.A. Good, R.C. Veber and G.T. Shahin, 1992, A field test of cosurfactant-enhanced alkaline flooding: SPE/DOE 24117 Eighth Symposium on Enhanced Oil Recovery, Tulsa, Oklahoma, April.

French, T.R., 1994a, Surfactant-enhanced alkaline flooding field project: in Enhanced Oil Recovery, Progress Review No. 74, Quarter Ending March 31, 1993, Department of Energy Report DOE/BC-93/2, March, p. 23.

French, T.R., 1994b, Evaluation of a site in Hepler (KS) oil field for a surfactant-enhanced alkaline chemical flooding project: Department of Energy Report, Pending/Draft in Review, July.

French, T.R. and T.E. Burchfield, 1990, Design and optimization of alkaline flooding formulations: SPE/DOE 20238 Seventh Symposium on Enhanced Oil Recovery, Tulsa, Oklahoma, April. 
French, T.R. and C.B. Josephson, 1991, Alkaline flooding injection strategy: Department of Energy Report NIPER-563, September, 27 p.

French, T.R., D.A. Peru, and S.D. Thornton, 1988, Low pH alkaline chemical formulations: Department of Energy Report NIPER-375, October, 55 p.

French, T.R. and C.B. Josephson, 1993, The effect of polymer-surfactant interaction on the rheological properties of surfactant enhanced alkaline flooding formulations: Department of Energy Report, NIPER-635, February, 24 p.

French, T.R., C.B. Josephson, and D.B. Evans, 1990, The effect of alkaline additives on the performance of surfactant systems designed to recover light crude oils: Department of Energy Report NIPER-506, October, 47 p.

Gall, B., 1993, Chemical flooding technology: in Final Report, National Institute for Petroleum and Energy Research (NIPER), Department of Energy Report NIPER-685, December, p. 151235.

Krumrine, P.H. and J.S. Falcone, Jr., 1987, Beyond alkaline flooding-design of complete chemical systems: SPE 16280 International Symposium on Oilfield Chemistry, San Antonio, Texas, February.

Llave, F.M., B.L. Gall, T.R. French, L.A. Noll, and S.A. Munden, 1991, Phase behavior and oil recovery investigations using mixed and alkaline-enhanced surfactant systems: Department of Energy Report NIPER-567, December, 93 p.

Lorenz, P.B., 1988, Combination alkaline-surfactant flooding, a state-of-the-art review: Department of Energy Report NIPER-349, October, 29 p.

Lorenz, P.B. and Peru, D.A., 1989, Guidelines help select reservoirs for $\mathrm{NaHCO}_{3}$ EOR: Oil and Gas Journal, vol. 87, No. 37, September 11, p. 53-57.

Meyers, J.J., M.J. Pitts, and K. Wyatt, 1992, Alkaline-surfactant-polymer flood of the West Kiehl, Minnelusa Unit: SPE/DOE 24144 Eighth Symposium on Enhanced Oil Recovery, Tulsa, Oklahoma, April.

Moritis, G., 1992, EOR increases $24 \%$ worldwide; claims $10 \%$ of U.S. production: Oil and Gas Journal Survey, vol. 90, No. 16, April 20, p. 51-79.

National Petroleum Council, 1984, Enhanced Oil Recovery; Washington, D.C.

Nelson, R.C., 1993, Laboratory and field performance of a surfactant/alkali flood: in NIPER-DOE Chemical EOR Workshop, Department of Energy Report NIPER-698, August, p. 28-29.

NIPER/BDM, 1994, Quarterly technical progress report, January 1-March 31, 1994 for management and operating contract for the Department of Energy's National Oil and Related Programs: Department of Energy Report NIPER/BDM-0022, April, 143 p.

OGJ, 1994, DOE tallies Class III oil recovery field projects: Oil and Gas Journal, vol. 92, No. 30, July 25 , p. $108-111$.

Pitts, M.J., 1994a, Investigation of oil recovery improvement by coupling an interfacial tension agent and a mobility control agent in light oil reservoirs: in Enhanced Oil Recovery, Progress Review No. 76, Quarter Ending September 30, 1993, Department of Energy Report DOE/BC93/4, August, p. 1-5.

Pitts, M.J., 1994b, Detailed evaluation of the West Kiehl alkaline-surfactant-polymer field project and its application to mature Minnelusa waterfloods: in Enhanced Oil Recovery, Progress Review No. 76, Quarter Ending September 30, 1993, Department of Energy Report DOE/BC93/4, August, p. 42-48.

Rudin, J. and D.T. Wasan, 1993, Surfactant-enhanced alkaline flooding, buffering at intermediate alkaline pH: SPE Reservoir Engineering, vol. 8, No. 4, November, p. 275-280. 
Smith, J.E., 1993, How to rate crude oils for alkaline flooding potential-a study based on 239 crude oils: SPE 25171 International Symposium on Oilfield Chemistry, New Orleans, Louisiana, March.

Wasan, D.T., 1994, Surfactant-enhanced alkaline flooding for light oil recovery-in Enhanced Oil Recovery, Progress Review No. 76, Quarter Ending September 30, 1993, Department of Energy Report DOE/BC-93/4, August, p. 12-14.

\subsubsection{Surfactant Process}

Dauben, D.L., 1991, part II, EOR field case histories: in Research Needs to Maximize the Economic Producibility of the Domestic Oil Resource, Department of Energy Report NIPER527, October, p. 232-521.

DOE, 1994, Surfactant development for enhanced oil recovery: in Project Facts Sheet, Oil Technology Program, Department of Energy, August, p. A-219.

Gall, B.L., 1989, The use of sacrificial agents to reduce carboxymethylated ethoxylated surfactant loss during chemical flooding: Department of Energy Report NIPER-447, September, 27 p.

Gall, B., 1993, Chemical flooding technology: in Final Report, National Institute for Petroleum and Energy Research (NIPER), Department of Energy Report NIPER-685, December, p. 151235.

Jakobsen, S.R. and F. Hovland, 1994, Surfactant flooding: technical and economic conditions to succeed: SPE/DOE 27824 Ninth Symposium on Improved Oil Recovery, Tulsa, Oklahoma, April.

Kalpakci. B., T.G. Arf, J.W. Barker, A.S. Krupa, J.C. Morgan, and R.D. Neira, 1990, The low-tension polymer flood approach to cost-effective chemical EOR: SPE/DOE 20220 Seventh Symposium on Enhanced Oil Recovery, Tulsa, Oklahoma, April.

Llave, F.M., 1992, Development of a chemical flooding EOR literature database system: Department of Energy Report NIPER-609, August, 14 p.

Llave, F.M. and D.K. Olsen, 1988, Development of an automated system for phase inversion temperature measurements: Department of Energy Report NIPER-318, June, 28 p.

Llave, F.M., B.L. Gall, T.R. French, L.A. Noll, and S.A. Munden, 1991, Phase behavior and oil recovery investigations using mixed and alkaline-enhanced surfactant systems: Department of Energy Report NIPER-567, December, 93 p.

Llave, F.M., T.R. French, and P.B. Lorenz, 1993, Evaluation of mixed surfactants for improved chemical flooding: Department of Energy Report NIPER-631, February, 100 p.

National Petroleum Council, 1984, Enhanced Oil Recovery; Washington, D.C.

Nelson, R.C., 1989, Chemically enhanced oil recovery-the state of the art: Chemical Engineering Progress, vol. 85, No. 3, March, p. 50-57.

NIPER/BDM, 1994a, Geological and production characteristics of strandplain/barrier island reservoirs in the United States: Department of Energy Report NIPER/BDM-0027, July.

NIPER/BDM, 1994b, Quarterly technical progress report, January 1-March 31, 1994 for management and operating contract for the Department of Energy's National Oil and Related Programs: Department of Energy Report NIPER/BDM-0022, April, 143 p.

NIPER/DOE, 1993, NIPER-DOE Chemical EOR Workshop: Department of Energy Report NIPER-698, August, 92 p.

OGJ, 1994, DOE tallies Class III oil recovery field projects: Oil and Gas Journal, vol. 92, No. 30 , July 25 , p. 108-111. 
Olsen, D.K., 1989, Use of amine oxide surfactants for chemical flooding EOR: Department of Energy Report NIPER-417, August, 37 p.

Olsen, D.K. and C.B. Josephson, 1987, Carboxymethylated ethoxylated surfactants: Department of Energy Report NIPER-228, July, 54 p.

Pope, G.A., 1993, Observations about surfactant flooding and future implications: in NIPERDOE Chemical EOR Workshop, Department of Energy Report NIPER-698, August, p. 24-29.

Pope, G.A. and K. Sepehrnoori, 1994, Development of cost-effective surfactant flooding technology: in Enhanced Oil Recovery, Progress Review No. 76, Quarter Ending September 30, 1993, Department of Energy Report DOE/BC-93/4, August, p. 14-16.

Taber, J.J., 1993, Can horizontal injection (and production) wells save chemical flooding: in NIPER-DOE Chemical EOR Workshop, Department of Energy Report NIPER-698, August, p. 21-24.

Somasundaran, P., 1994, Surfactant loss control in chemical flooding-spectroscopic and calorimetric study of absorption and precipitation on reservoir minerals: in Enhanced Oil Recovery, Progress Review No. 76, Quarter Ending September 30, 1993, Department of Energy Report DOE/BC-93/4, August, p. 19-22.

Strycker, A., 1989, Selection and design of ethoxylated carboxylates for chemical flooding: Department of Energy Report NIPER-449, September, 61 p.

\subsubsection{Steam Process}

Anderson, G.W. and S.O. Hutchinson, 1983, Concentric steaming string downhole apparatus: U.S. Patent No. 4,399,865, August 23.

Ault, J.W., W.M. Johnson, and G.N. Kamilos, 1985, Conversion of steamfloods to low quality steam and/or hot water injection projects: SPE 13604 California Regional Meeting, Bakersfield, California, March.

Bautista, L.S. and F. Friedmann, 1994, Water-Alternating Steam Process (WASP) alleviated downdip steam migration in Cymric field: SPE/DOE 27794 Ninth Symposium on Improved Oil Recovery, Tulsa, Oklahoma, April.

Blacker, H.F. and I.J. Bellaci, 1994, Determination of injector steam quality and flow rate from orifice data and wellhead pressure: SPE 27868 Western Regional Meeting, Long Beach, California, March.

Blevins, T.R., 1990, Steamflooding in the U.S.-a status report: Journal of Petroleum Technology, vol. 42 , No. 5, May, p. 545-554.

Blunschi, J.H., 1987, Simulation of a 12-pattern field trial of light-oil steamflooding: SPE 16735 62nd Annual Technical Conference, Dallas, Texas, October.

Bruno, M.S. and R. Bilak, 1994, Cost-effective monitoring of injected steam migration using surface deformation analysis: SPE 27888 Western Regional Meeting, Long Beach, California, March.

Buller, S.M., 1992, Evaluation of horizontal, radial, and vertical injection wells in a pilot steamflood: SPE 24630 67th Annual Technical Conference, Washington, D.C., October.

Carpenter, D.E. and S.G. Dazet, 1992, Horizontal wells in a steamdrive in the Midway Sunset field: SPE 24127 Eighth Symposium on Enhanced Oil Recovery, Tulsa, Oklahoma, April.

Chien, S.F., 1993, Critical flow properties of wet steam: SPE 25804 International Thermal Operations Symposium, Bakersfield, California, February. 
Chien, S.F. and J.L.G. Schrodt, 1992, Determination of steam quality and flow rate using pressure data from an orifice meter and a critical flow meter: SPE 24832 67th Annual Technical Conference, Washington, D.C., October.

Chien, S.F., J. Anderson, C.L. Redus, J.W. Scott and P.L. Sigwardt, 1992, Method and apparatus for controlling the mass rate of steam in steam distribution system: U.S. Patent No. $5,141,055$, August 25.

Chiou, C.S. and J.D. Owens, 1992, Field performance of steam injection profile control using limited entry perforation: SPE 24081 Western Regional Meeting, Bakersfield, California, March.

Chu, C., 1993a, Optimal choice of completion intervals for injectors and producers in steamfloods: SPE 25787 International Thermal Operations Symposium, Bakersfield, California, February.

Chu, C., 1993b, A new method of steamflooding oil reservoirs using staggered scheduling of injection/production: SPE 25879 International Thermal Operations Symposium, Bakersfield, California, February.

Dauben, D.L., 1991, Part II, EOR field case histories: in Research Needs to Maximize the Economic Producibility of the Domestic Oil Resource, Department of Energy Report NIPER527, October, pp. 232-521.

Dennis, E.L., K.R. Johnson, and R.H. Kirby, 1994, Case study of a vertical expansion using slimhole steam injectors: SPE 27795 Ninth Symposium on Improved Oil Recovery, Tulsa, Oklahoma, April.

Dickinson, W., E. Dickinson, H. Dykstra, and J.M. Nees, 1992, Horizontal radials enhance oil production from a thermal project: Oil and Gas Journal, vol. 90, No. 18, May 4, p. $116-124$.

Dietrich, J.K., 1987, The Kern River horizontal well steam pilot: SPE 16346 California Regional Meeting, Ventura, California, April.

Griston, S., 1989, Evaluation of two phase steam flow through an orifice: SPE 19700 Annual Technical Conference, San Antonio, Texas, October.

Griston, S., 1990, Evaluation of radioactive tracer surveys for steam injection wells: SPE 20031 California Regional Meeting, Ventura, California, April.

Guo, D.S., 1991, Pulsed neutron capture logging in steamfloods-a hostile environment: Paper 8A 11, Institute of Electrical and Electronic Engineer Nuclear Science Symposium, vol. 2, p. 1125-1129.

Guo, D.S., M.E. Smith, and K.E. Tucker, 1993, The use of pulsed neutron capture logging for reservoir management in the Midway-Sunset field: SPE 25807 International Thermal Operations Symposium, Bakersfield, California, February.

Harrigal, R.L. and G.G. Wilcox, 1992, An improved steamflood analytical modeling toolupdating old methodologies with new approaches to increase engineering productivity: SPE 24434 Seventh SPE Petroleum Computer Conference, Houston, Texas, July.

Hong, K.C., 1978, Two phase flow splitting at a pipe tee: Journal of Petroleum Technology, vol. 30, No. 2, February, pp. 290-296.

Hong, K.C., 1987, Guidelines for converting steamflood to waterflood: SPE Reservoir Engineering, vol. 2, No. 1, February, p. 67-76.

Hong, K.C., 1988, Steamflood strategies for a steeply dipping reservoir: SPE Reservoir Engineering, vol. 3, No. 2, May, p. 431-439.

Hong, K.C., 1991, Optimum well location for steamflooding steeply dipping reservoirs: SPE 21771 California Regional Meeting, Long Beach, California, March. 
Hong, K.C., 1993, Effects of steam quality and injection rate on steamflood performance: SPE 25788 International Thermal Operations Symposium, Bakersfield, California, February.

Hong, K.C. and C.E. Stevens, 1992, Water-alternating-steam process improves project economics at West Coalinga field: SPE Reservoir Engineering, vol. 7, No. 4, November, p. 407-413.

Hong, K.C. and S. Griston, 1994, Two phase flow splitting at an impacting tee: SPE 27866 Western Regional Meeting, Long Beach, California, March.

Hong, K.C., S. Griston, and S.D. Cook, 1987, More effective means for controlled injection of steam into multiple sands: 16th Annual Convention of the Indonesian Petroleum Association, Jakarta, Indonesia, October, p. 227-245.

Hong, K.C., J.H. Blunschi, C.C. Cease, and D.L. Madison, 1992, Reservoir management of a light oil steamflood pilot in the SOZ fault block, Elk Hills field: SPE 24037 Western Regional Meeting, Bakersfield, California, March-April.

Huang, W.S. and M.A. Hight, 1989, Evaluation of steamflood processes with horizontal wells: SPE Reservoir Engineering, vol. 4, No. 1, February, p. 69-76.

Hunter, B.L., R.S. Buell, and T.A. Abate, 1992, Application of a polymer gel system to control steam breakthrough and channeling: SPE 24031 Western Regional Meeting, Bakersfield, California, March-April.

Jespersen, P.J. and T.J.C. Fontaine, 1993, The Tangleflags North pilot-A horizontal well steamflood: The Journal of Canadian Petroleum Technology, vol. 32, No. 5, May, p. 52-57.

Jones, J. and R.L. Williams, 1991, A two phase flow splitting device that works: SPE 21532 International Thermal Operations Symposium, Bakersfield, California, February.

Kumar, M., 1990, Injection schedule and production strategies for optimizing steamflood performance: SPE 20763 65th Annual Technical Conference, New Orleans, Louisiana, September.

Littlefield, B.A., P.D. Fader, and B.W. Surles, 1992, Case histories of new low-cost fluid isolation technology: SPE 24802 67th Annual Technical Conference, Washington, D.C., October.

Masse, P.J., T.C. Gosney , and D.L. Long, 1991, Use of pulsed neutron capture logs to identify steam breakthrough: SPE Formation Evaluation, vol. 6 , No. 3, September, p. 319-326.

Mohammadi, S.S., D.C. Van Slyke, and B. Ganong, 1989, Steam foam pilot project in DomeTumbador, Midway-Sunset field: SPE Reservoir Engineering, vol. 4, No. 1, February, p. 716.

Moritis, G., 1992, EOR increases 24\% worldwide; claims 10\% of U.S. production: Oil and Gas Journal, vol. 90, No. 16, April 20, p. 51-79.

Nguyen, T.V. and C.E. Stevens, 1988, The use of inert gas radioactive tracers for steam injection profiling: SPE 17419 California Regional Meeting, Long Beach, California, March.

NIPER/BDM, 1994, Geological and production characteristics of strandplain/barrier island reservoirs in the United States: Department of Energy Report NIPER/BDM-0027, July.

National Petroleum Council, 1984, Enhanced Oil Recovery; Washington, D.C.

OGJ, 1994, DOE tallies Class III oil recovery field projects: Oil and Gas Journal, vol. 92, No. 30, July 25, p. 108-111.

Patzek, T.W. and M.T. Koinis, 1990, Kern River steam foam pilot: SPE 18786 California Regional Meeting, Bakersfield, California, April. 
Paulson, B.N.P., M.E. Smith, K.E. Tucker, and J.W. Fairborn, 1992, Characterization of a steamed oil reservoir using cross-well seismology: The Leading Edge, vol. 11, No. 7, July, p. 24-32.

Peake, W.T., 1992, Steam distribution surveillance and analysis: SPE 24079 Western Regional Meeting, Bakersfield, California, March-April.

Redus, C.L., D.M. Schoen, S.F. Chien, and D. Hall, 1988, Kern River field test of a steam quality measurement technique: SPE 17445 California Regional Meeting, Long Beach, California, March.

Restine, J.L., W.G. Graves, and R. Elias, 1987, Infill drilling in a steamflood operation-Kern River field: SPE Reservoir Engineering, vol. 2, No. 2, May, p. 243-248.

Sahuquet, B.C., A.M. Spreux, B. Corre, and M.P. Guiltard, 1990, Steam injection in a low permeability reservoir through a horizontal well in Lacq Superieur field: SPE 20526 65th Annual Technical Conference, New Orleans, Louisiana, September.

Sarkar, A.K. and P.S. Sarathi, 1993a, Feasibility of steam injection process in a thin, lowpermeability heavy oil reservoir of Arkansas: Department of Energy Report NIPER-661, January.

Sarkar, A.K. and P.S. Sarathi, 1993b, Evaluation of steamflood potential of Texas Gulf Coast reservoirs-A simulation approach: Department of Energy Report NIPER-722, September.

Sarathi, P.S., 1991, Thermal EOR technology, state-of-the-art review: in Research Needs to Maximize Economic Producibility of the Domestic Oil Resource, Department of Energy Report NIPER-527, October, p. $106-128$.

Sarathi, P.S., 1993, Thermal EOR methods: in Final Report, National Institute for Petroleum and Energy Research (NIPER), Department of Energy Report NIPER-685, December, p. 271-323.

Sarathi, P.S. and D.K. Olsen, 1992, Practical aspects of steam injection processes-A handbook for independent operators: Department of Energy Report NIPER-580, October, p. 238-255.

Sarathi, P.S. and D.K. Olsen, 1993, Analysis of field application of foams for oil production symposium: Department of Energy Report NIPER-681, May, p. 3.

Schmidt, R.L., 1990, Thermal enhanced oil recovery-current status and future needs: Chemical Engineering Progress, vol. 86, No. 1, January, p. 47 -59.

Spiers, A.B. and P.B. Warren, 1994, Horizontal well experience in California thermal reservoirs: Paper No. HWC 94-56, Canadian SPE/CIM/CANMET International Conference on Recent Advances in Horizontal Well Applications, Calgary, Alberta, Canada, March.

Surbey, D.W., B.G. Kelkar, and J.P. Brill, 1988, Study of subcritical flow through multiple orifice valves: SPE Production Engineering, vol. 3, No. 1, February, p. 103-108.

Torabzadeh, S.J., M. Kumar, and V.T. Hoang, 1990, Performance correlations for steamflood field projects: SPE 20036 California Regional Meeting, Ventura, California, April.

Wan, P.T., 1990, Measurement of steam quality using a neutron densitometer: Paper CIM/SPE 90-88, CIM and SPE Joint International Technical Meeting, Calgary, Alberta, Canada, June.

Webb, C.H., 1988, Downhole fixed choke for steam injection: U.S. Patent No. 4,700,244, September 13.

Ziegler, V.M., R.B. Crookston, S.J. Sanford, and J.M. Merrell, 1993, Recommended practices for heat management of steamflood projects: SPE 25808 International Thermal Operations Symposium, Bakersfield, California, February. 


\subsubsection{In Situ Combustion Process}

Abasov, M.T. and T.V. Kismetov, 1991, Oil field development using in situ combustion with foam systems and alkaline solutions: Sixth European IOR Symposium, Stavanger, Norway, May.

Ames, B.G., R.E. Grams, and F.N. Pebdani, 1994, Improved sweep efficiency through the application of horizontal well technology in a mature combustion EOR project-Battrum Field, Saskatchewan, Canada: Paper ISC 11, DOE/NIPER Symposium on In Situ Combustion, Tulsa, Oklahoma, April.

Bayless, J.H. and R.E. Williams, 1989, Recovery of viscous oil from geological reservoirs using hydrogen peroxide: U.S. Patent No. 4,867,238, September 19.

Bleakley, W.B., 1987, Making new production technology work for you: Petroleum Engineer International, vol. 59, No. 1, January, p. 20-22.

Carlson, L.O., 1988, Performance of Hawkins Field Unit under gas drive pressure maintenanceoperations and development of an enhanced oil recovery project: SPE/DOE 17324 6th Improved Oil Recovery Symposium, Tulsa, Oklahoma, April.

Chu, C., 1982, State-of-the-art review of fireflood field projects: Journal of Petroleum Technology, vol. 34, No. 1, January, p. 19-36.

Dauben, D.L., 1991, Part II, EOR field case histories: in Research Needs to Maximize the Economic Producibility of the Domestic Oil Resource, Department of Energy Report NIPER527, October, p. 232-521.

Farouq-Ali, S.M., 1994, Redeeming features of in situ combustion: Paper ISC 1, DOE/NIPER Symposium on In Situ Combustion, Tulsa, Oklahoma, April.

Fassihi, M.R. and T.H. Gillham, 1993, The use of air injection to improve the double displacement process: SPE 26374 68th Annual Technical Conference, Houston, Texas, October.

Hallam, R.J. and J.K. Donnelly, 1988, Pressure-up blow-down combustion-a channeled reservoir recovery process: SPE 18071 63rd Annual Technical Conference, Houston, Texas, October.

Horne, J.S., I.S. Bousaid, T.L. Dore, and L.B. Smith, 1982, Initiation of an in situ combustion project in a thin oil column underlain by water: Journal of Petroleum Technology, vol. 21, No. 10, October, p. 2233-2243.

Iyoho, A.W., 1978, Selecting enhanced oil recovery processes: World Oil, vol. 186, No. 11, November, p. 61-64.

Kisman, K.E. and E.C. Lau, 1994, A new combustion process utilizing horizontal wells and gravity drainage: The Journal of Canadian Petroleum Technology, vol. 33, No. 3, March, p. $39-45$.

Kumar, V.K., M.R. Fassihi, and D.V. Yannimaras, 1994, Case history and appraisal of the Medicine Pole Hills Unit air injection project: SPE/DOE 27792 Ninth Improved Oil Recovery Symposium, Tulsa, Oklahoma, April.

Mamedov, Y.G. and A.A. Bocserman, 1992, Application of improved oil recovery in U.S.S.R.: SPE/DOE 24162 Eighth Improved Oil Recovery Symposium, Tulsa, Oklahoma, April.

Marjerrison, D.M. and M.R. Fassihi, 1994, Performance of Morgan pressure cycling in situ combustion project: SPE/DOE 27793 Ninth Improved Oil Recovery Symposium, Tulsa, Oklahoma, April. 
McGee, B.C.W., R.J. Hallam, B.I. Nzekwu, and C.M.F. Galas, 1988, A pressure observation well for monitoring and optimizing the pressure-up blow-down combustion process: Paper No. 234 Fourth UNITAR Conference on Heavy Crude and Tar Sands, Edmonton, Alberta, Canada, August.

Miller, R.J., 1994, Koch's experience with deep in situ combustion-keynote address: DOE/NIPER Symposium on In Situ Combustion, Tulsa, Oklahoma, April.

Moore, R.G., D.W. Bennion, and M.G. Ursenbach, 1988, A review of in situ combustion mechanisms: Paper No. 50 Fourth UNITAR Conference on Heavy Crude and Tar Sands, Edmonton, Alberta, Canada, August.

Morgan, R.J., 1993, Can horizontal wells inject life into an old combustion project?: Presented at the Fifth Petroleum Conference of the South Saskatchewan Section, Regina, Saskatchewan, Canada, October.

Moritis, G., 1992, EOR increases $24 \%$ worldwide, claims $10 \%$ of U.S. production: Oil and Gas Journal, vol. 90, No. 16, April 20, p. 51- 79.

Moss, J.T. Jr. and J.T. Moss, Sr., 1994, Enhanced oil recovery using hydrogen peroxide injection: Paper ISC 14 DOE/NIPER Symposium on In Situ Combustion, Tulsa, Oklahoma, April.

NIPER/BDM, 1994, Geological and production characteristics of strandplain/barrier island reservoirs in the United States: Department of Energy Report NIPER/BDM-0027, July.

National Petroleum Council, 1984, Enhanced Oil Recovery; Washington, D.C.

OGJ, 1994, DOE tallies Class III oil recovery field projects: Oil and Gas Journal, vol. 92, No. 30, July 25, p. 108-111.

Satchwell, R.M., L.A. Johnson, Jr., and R. Trent, 1994, Shallow oil production using horizontal wells with enhanced oil recovery techniques: Paper ISC 12 DOE/NIPER Symposium on In Situ Combustion, Tulsa, Oklahoma, April.

Shipley, R.G., Jr., R.F. Meldau, P.D. White, and J.W. Patek, 1980, Paris Valley combination thermal drive pilot demonstration test: Final Report, Department of Energy Report DOE/SAN/1000-3, September.

Stair, J.R., 1980, Lynch Canyon combination thermal drive project: Final Report, Department of Energy Report DOE/ET/12086-1, November.

\subsubsection{Carbon Dioxide $\left(\mathrm{CO}_{2}\right)$ Processes}

Bae, J.H. and C.A. Irani, 1990, A laboratory investigation of thickened CO 2 process: SPE 20467 65th Annual Technical Conference, New Orleans, Louisiana, September.

Baroni, M.R., 1994, Applications of advanced petroleum production technology and wateralternating-gas injection for enhanced oil recovery-Mattoon Oil Field, Illinois: in Enhanced Oil Recovery, Progress Review No. 76, Quarter Ending September 30, 1993, Department of Energy Report DOE/BC-93/4, August, p. 86-91.

Borling, D.C., 1994, Injection conformance control case histories using gels at the Wertz field $\mathrm{CO}_{2}$ tertiary flood in Wyoming: SPE/DOE 27825 Ninth Symposium on Improved Oil Recovery, Tulsa, Oklahoma, April.

Branting, J.K.M. and D.L. Whitman, 1992, The feasibility of using $\mathrm{CO}_{2}$ EOR techniques in the Powder River Basin of Wyoming: SPE 24337 Rocky Mountain Regional, Casper, Wyoming, May. 
Carlisle, C., 1992, Our first nine months' experience with $\mathrm{CO}_{2}$ cyclic stimulation in Wyoming oil fields (August 1990-April 1991): Proceedings of the Seventh Wyoming Enhanced Oil Recovery Symposium, Laramie, Wyoming, May.

Chung, T.H., 1993, Gas Flooding Technology: in Final Report, National Institute for Petroleum and Energy Research (NIPER), Department of Energy Report NIPER-685, December, p. 237270.

Chung, F.T.H. and T.E. Burchfield, 1987, Research aimed at immiscible $\mathrm{CO}_{2}$ flooding: Oil and Gas Journal, vol. 85, No. 17, April 27, p. 76-82.

Dandge, D.K. and J.P. Heller, 1987, Polymers for mobility control in $\mathrm{CO}_{2}$ floods: SPE 16271 International Symposium on Oilfield Chemistry, San Antonio, Texas, February.

Dauben, D.L., 1991, part II, EOR field case histories: in Research Needs to Maximize the Economic Producibility of the Domestic Oil Resource, Department of Energy Report NIPER527, October, p. 232-521.

DOE, 1993, A review of slope-basin and basin clastic reservoirs in the United States: Class III Technical Report, Department of Energy, December.

DOE, 1994, Mechanisms of mobility control with foam: in Project Facts Sheet, Oil Technology Program, Department of Energy, August, p. A-229.

Flanders, W.A., R.A. McGinnis, and A.G. Shatto, 1993, $\mathrm{CO}_{2}$ EOR economics for small-tomedium-size fields: SPE 26391 68th Annual Technical Conference, Houston, Texas, October.

Friedman, F. and J.A. Jensen, 1986, Some parameters influencing the formation and propagation of foams in porous media: SPE 15087 California Regional Meeting, Oakland, California, April.

Haskin, H.K. and R.B. Alston, 1989, An evaluation of $\mathrm{CO}_{2}$ huff ' $n$ ' puff tests in Texas: Journal of Petroleum Technology, vol. 41, No. 2, February, p. 177-184.

Hoefner, M.L., E.M. Evans, J.J. Buckles, and T.A. Jones, 1994, $\mathrm{CO}_{2}$ foam- results from four development field trials: SPE/DOE 27787 Ninth Symposium on Improved Oil Recovery, Tulsa, Oklahoma, April.

Jonas, T.M., S.I. Chou, and S.L. Vasicek, 1990, Evaluation of a $\mathrm{CO}_{2}$ foam field trial- Rangely Weber Sand Unit: SPE 20468 65th Annual Technical Conference, New Orleans, Louisiana, September.

Klins, M.A., 1984, Carbon dioxide flooding, basic mechanisms and project design: International Human Resources Development Corporation, Boston, Massachusetts, 267 p.

Llave, F.M., F.T.H. Chung, and T.E. Burchfield, 1990, Use of entrainers in improving mobility control of supercritical $\mathrm{CO}_{2}$ : SPE Reservoir Engineering, vol. 5, No. 1, February, p. 47-51.

Martin, F.D., J.P. Heller, and W.W. Weiss, 1994, Field verification of $\mathrm{CO}_{2}$ foam: in Enhanced Oil Recovery, Progress Review No. 76, Quarter Ending September 30, 1993, Department of Energy Report DOE/BC-93/4, August, p. 23-24.

Miller, B.J., C.P. Bardon, and P. Corlay, 1994, $\mathrm{CO}_{2}$ huff ' $n$ ' puff field case- five-year program update: SPE 27677 Permian Basin Oil and Gas Recovery Conference, Midland, Texas, March.

Moffit, P.D. and D.R. Zornes, 1992, Postmortem analysis: Lick Creek Meakin Sand Unit immiscible $\mathrm{CO}_{2}$ waterflood project: SPE 24933 67th Annual Technical Conference, Washington, D.C., October.

National Petroleum Council, 1984, Enhanced Oil Recovery; Washington, D.C.

NIPER/BDM, 1994a, Geological and production characteristics of strandplain/barrier island reservoirs in the United States: Department of Energy Report NIPER/BDM-0027, July. 
NIPER/BDM, 1994b, Quarterly technical progress report, January 1-March 31, 1994 for management and operating contract for the Department of Energy's National Oil and Related Programs: Department of Energy Report NIPER/BDM-0022, April, 143 p.

NIPER and K\&A, 1991, Research needs to maximize economic producibility of the domestic oil resource: Department of Energy Report NIPER-527, July 29, 521 p.

OGJ, 1994, DOE tallies Class III oil recovery field projects: Oil and Gas Journal, vol. 92, No. 30, July 25 , p. 108-111.

Orr, F.M., Jr., 1994, Scaleup of miscible flood processes: in Enhanced Oil Recovery, Progress Review No. 74, Quarter Ending March 31, 1993, Department of Energy report DOE/BC-93/2, March, p. 34-39.

Passmore, R., 1991, Amoco's experience with $\mathrm{CO}_{2}$ cyclic stimulation in Wyoming, 1990-91: Proceedings of the Seventh Wyoming Enhanced Oil Recovery Symposium, Laramie, Wyoming, May.

Pautz, J.F. C.A. Sellers, C. Nautiyal, and E. Allison, 1992, Enhanced oil recovery projects data base: Department of Energy Report NIPER-583, February, 344 p.

Raible, C., 1992, Improvement in oil recovery using cosolvents with $\mathrm{CO}_{2}$ gas floods: Department of Energy Report NIPER-559, January, 24 p.

Rivas, O., S. Embid, and F. Bolivar, 1992, Ranking reservoirs for carbon dioxide flooding processes: SPE 23641 Second Latin American Petroleum Engineering Conference, Caracas, Venezuela, March.

Smith, D.H., 1994, Quantification of mobility control in enhanced oil recovery of light oil by carbon dioxide: in Enhanced Oil Recovery, Progress Review No. 74, Quarter Ending March 31, 1993, Department of Energy report DOE/BC-93/2, March, p. 32-34.

Stevens, J.E. and F.D. Martin, 1994, $\mathrm{CO}_{2}$ foam field verification pilot test at EVGSAU-Phase IIIB-project operations and performance review: SPE/DOE 27786 Ninth Symposium on Improved Oil Recovery, Tulsa, Oklahoma, April.

Strycker, A. and F.M. Llave, 1991, Improvement of sweep efficiency and mobility control in gas flooding: Department of Energy Report NIPER-502, April, 28 p.

Taber, J.J. and F.D. Martin, 1983, Technical screening criteria for the enhanced recovery of oil: SPE 12069 58th Annual Technical Conference, San Francisco, California, October.

Terry, R.E., A. Zaid, C. Angelos, and D.L. Whitman, 1987, Polymerization in supercritical $\mathrm{CO}_{2}$ to improve $\mathrm{CO}_{2}$ /oil mobility ratios: SPE 16270 International Symposium on Oilfield Chemistry, San Antonio, Texas, February.

Thomas, G.A. and T.G. Monger-McClure, 1991, Feasibility of cyclic $\mathrm{CO}_{2}$ injection for light-oil recovery: SPE Reservoir Engineering, vol. 6, No. 2, May, p. 179-184.

Yang, S.H. and R.L. Reed, 1989, Mobility control using $\mathrm{CO}_{2}$ foams: SPE 19689 Annual Technical Conference, San Antonio, Texas, October.

Zhu, T. and C. Raible, 1994, Improved sweep efficiency by alcohol-induced salt precipitation: SPE/DOE 27777 Ninth Symposium on Improved Oil Recovery, Tulsa, Oklahoma, April.

Zhu, T. and D. Tiab, 1992, Improved sweep efficiency by selective plugging of highly watered out zones by alcohol induced precipitation: CIM 92-74 presented at 1992 CIM Annual Technical Meeting, Calgary, Alberta, Canada, June. 


\subsubsection{Numerical Simulation}

Ammer, J.R. and A.C. Brummert, 1991, Miscible applied simulation techniques for energy recovery-version 2.0: Morgantown Energy Technology Center, Morgantown, West Virginia, February, (DOE/BC--91/2/SP), p. 1-110.

Chang, M.M. and H.W. Gao, 1993, User's guide and documentation manual for PC-GEL simulator: IIT Research Institute, NIPER-705, DE94000104, October, p. 1-53.

Chang; M.M., F.T-H. Chung, R.S. Bryant, H.W. Gao, and T.E. Burchfield, 1991, Modeling and laboratory investigation of microbial transport phenomena in porous media: SPE 22845 66th Annual Technical Conference, Dallas, Texas, October.

Chang, M.M., P. Sarathi, R.J. Heemstra, A.M. Cheng, and J.F. Pautz, 1992, User's guide and documentation manual for BOAST-VHS for the PC: IIT Research Institute, NIPER-542, DE92001021, January, p.1-83.

Fanchi, J.R., K.J. Harpole, and S.W. Bujnowski, 1982, BOAST: A three-dimensional, threephase black oil applied simulation tool: Department of Energy Report DOE/BC/1033-3, vol. 1 and 2, DE83000529, September.

Fanchi, J.R., J.E. Kennedy, and D.L. Dauben, 1987, BOAST II: A three-dimensional, threephase black oil applied simulation tool: Department of Energy Report DOE/BC-88/2/SP, DE88001205, December, p.1-161.

Gao, H.W. and M.M. Chang, 1990, A three-dimensional, three phase simulator for permeability modification treatments using gelled polymers: Department of Energy Report NIPER-388, DE90000227, March.

Mathematical \& Computer Services, Inc., 1993a, User's guide and documentation manual for MISC4, report submitted to Louisiana State University under Department of Energy Contract DE-AC22-92BC14831, February.

Mathematical \& Computer Services, Inc., 1993b, User's guide and documentation manual for BOAST 3, report submitted to Louisiana State University under Department of Energy Contract DE-AC22-92BC14831, July.

Stapp, L.G. and E.C. Allison, 1989, Handbook for personal computer version of BOAST II- a three-dimensional, three-phase black oil applied simulation tool: Department of Energy Report DOE/BC-89/3/SP, December.

Todd, M.R. and W.J. Longstaff, 1972, The development, testing, and application of a numerical simulator for predicting miscible flood performance: Journal of Petroleum Technology, vol. 24, July, p. 874-882.

Watkins, R.W., 1982, The development and testing of a sequential semi-implicit four component reservoir simulator: SPE 10513 6th Symposium on Reservoir Simulation, New Orleans, Louisiana, February, p. 347-368.

Young, M.A., S.P. Salamy, T.K. Reeves, W.K. Sawyer, 1993, South Marsh Island Block 73 field reservoir simulation study B-35 Sand, Reservoir K: BDM International Company, Morgantown, West Virginia, Department of Energy Contract DE-AC22-92BC14831, October, p. 1-37.

\subsubsection{Wellbore and Facilities}

Crouse, P., 1992, Screening and economic criteria for horizontal well technology: SPE 23617 Second Latin American Petroleum Engineering Conference, Caracas, Venezuela, May.

Coffin, P., 1993, Horizontal well evaluation after 12 years: SPE 26618 68th Annual Technical Conference, Houston, Texas, October. 
JPT, 1993, Horizontal technology-moving the driller closer to the driver's seat-Journal of Petroleum Technology, vol. 45, No. 7, July, p. 608.

Joshi, S.D., 1991, Horizontal well technology: Pennwell Publishing Co., Tulsa, Oklahoma.

Mutalik, P.N. and S.D. Joshi, 1993, Correct application spells horizontal success: The American Oil and Gas Reporter, vol. 36, No. 7, July, p. 69-77.

Pellegrino, V.L. and G.T. Scott, 1989, Oilfield power-technology and cost control: Journal of Petroleum Technology, vol. 41, No. 4, April, p. 389-393.

Schuh, F. and S.D. Joshi, 1991, Horizontal well technology practices: SPE Short Course Notes, Houston, Texas, April 1-5.

Taber, J.J. and R.S. Seright, 1992, Horizontal injection and production wells for EOR or waterflooding: SPE 23952 Permian Basin Oil and Gas Recovery Conference, Midland, Texas, March.

\subsubsection{Environmental Issues}

Abernathy, S.E., S.E. Woods, and J.L. Taylor, III, 1994, Radioactive tracers in oil and gas production: practical considerations in the 1990's: SPE 27326 Second International Conference on Health, Safety, and Environment, Jakarta, Indonesia, January.

ACTI, 1994, Appendix A-national laboratory capabilities, Brookhaven National Laboratory, Advanced Computational Technology Initiative: Department of Energy Draft Report DOE/FE0308P, May, p. 44-46.

Andersen, E.E. and D.E. Witt, 1993, Guidelines for designing safe, environmentally acceptable downhole injection operations: SPE 25964 SPE/EPA Exploration and Production Environmental Conference, San Antonio, Texas, March.

Armstrong, K., 1994, Promoting sustainable development-strategies for the exploration and production industry: SPE 27113 Second International Conference on Health, Safety, and Environment, Jakarta, Indonesia, January.

Ballantine, W.T., 1993, Drillsite cost savings through waste management: SPE 26387 68th Annual Technical Conference, Houston, Texas, October.

Bieler, R., A.J.J. Leuterman, and C. Stark, 1993, Drilling fluids: making peace with the environment: Journal of Petroleum Technology, vol. 45, No. 1, January, p. 6-10.

Browning, L.A. and J.D. Smith, 1993, Analysis of the rate of and reasons for injection well mechanical integrity test failure: SPE 25967 SPE/EPA Exploration and Production Environmental Conference, San Antonio, Texas, March.

Caudle, D.D. and K.M. Bansal, 1993, Environmental considerations in production chemical usage: SPE 26010 SPE/EPA Exploration and Production Environmental Conference, San Antonio, Texas, March.

Crocker, M.E., M.P. Madden, and R. Porter, 1991, Identification of environmental RD\&D needs: Department of Energy Report NIPER-430, September, 93 p.

Diyashev, R.N., S.F. Takhautdinov, G.P. Antonov, I.R. Diyashev, V.I. Zaitsev, and F.M. Sattarova, 1994, Disposal of naturally occurring radioactive materials in oil production: SPE 27216 Second International Conference on Health, Safety, and Environment, Jakarta, Indonesia, January.

Haynes, C.D., 1994, In conflict: marginal reserves vs. regulator-enforced abandonment: SPE 27709 Permian Basin Oil and Gas Recovery Conference, Midland, Texas, March. 
MacDowell, P. and P.R. Gray, 1993, NORM: projected financial and fiduciary impacts on exploration and production operations: SPE 26386 68th Annual Technical Conference, Houston, Texas, October.

McNeill, R.O., T.M. Reed, and J.C. Hunnicutt, 1993, The importance of environmental site assessments of oil and gas properties prior to property purchase or sale-examples of environmental hazards: SPE 25954 SPE/EPA Exploration and Production Environmental Conference, San Antonio, Texas, March.

NIPER/BDM, 1994, Geological and production characteristics of strandplain/barrier island reservoirs in the United States: Department of Energy Report NIPER/BDM-0027, July.

OCC, 1986, Oklahoma saltwater enhanced recovery well annulus monitoring and pressure test survey: Oklahoma Corporation Commission, Oklahoma City, Oklahoma, July.

Owens, C.K., 1994, Exploration and production waste management guidelines from the E\&P forum: SPE 27153 Second International Conference on Health, Safety, and Environment, Jakarta, Indonesia, January.

Peavy, M.A. and J.E. Braun, 1991, Control of waste gas from a thermal EOR operation: Journal of Petroleum Technology, vol. 43, No. 6, June, p. 656-661.

Sarathi, P., 1991, Environmental aspects of heavy-oil recovery by thermal EOR processes: Journal of Petroleum Technology, vol. 43, No. 6, June, p. 662-721.

Savage, L.L., 1993, Even if you're on the right track, you'll get run over if you just sit theresource reduction and recycling in the oil field: SPE 26009 SPE/EPA Exploration and Production Environmental Conference, San Antonio, Texas, March.

Smith, A.L., 1987, Radioactive-scale formation: Journal of Petroleum Technology, vol. 39, No. 6, June, p. 697-706.

Smith, J.B. and L.A.Browning, 1993, Proposed changes to EPA class II well construction standards and area of review procedures: SPE 25961 SPE/EPA Exploration and Production Environmental Conference, San Antonio, Texas, March.

Smith, G.E., W.R. Smith, D.J. Littleton, and J. Simmons, 1993, Recent improvements in state regulatory programs and compliance practices: SPE 25932 SPE/EPA Exploration and Production Environmental Conference, San Antonio, Texas, March.

Thurber, N.E., 1992, Waste minimization for land-based drilling operations: Journal of Petroleum Technology, vol. 44, No. 5, May, p. 542-547.

Wojtanowicz, A.K., 1993a, Dry drilling location-an ultimate source reduction challenge-theory, design, and economics: SPE 26013 SPE/EPA Exploration and Production Environmental Conference, San Antonio, Texas, March.

Wojtanowicz, A.K., 1993b, Oilfield environmental control technology-a synopsis: Journal of Petroleum Technology, vol. 45, No. 2, February, p. 166-173.

Worrell, D.G., 1994, Exploration and production wastes and class II injection wells-current regulatory developments: SPE 27706 Permian Basin Oil and Gas Recovery Conference, Midland, Texas, March.

Wright, N.H., 1994, Environmental risk in the exploration and production business: SPE 27106 Second International Conference on Health, Safety, and Environment, Jakarta, Indonesia, January. 


\section{CHAPTER 5 \\ CONSOLIDATED CLASS 4 RESEARCH NEEDS}

The purpose of Chapter 5 is to summarize the Class 4 technological and methodological research needs in the areas of reservoir description and reservoir management, as discussed in Chapter 3, and in the IOR process and related areas, as discussed in Chapter 4. The research needs presented in this report primarily define areas where the development and demonstration of improved technologies, processes, methodologies, strategies, or operational practices, coupled with focused technology transfer activities, could help to increase the recovery of oil from Class 4 reservoirs.

Section 5.1 summarizes the significant characteristics of Class 4 reservoirs and their operators, who will have a direct impact on the utilization of improved methodologies and technologies. Section 5.2 summarizes the research needs related to reservoir description and reservoir management, including the general methodological research needs, the reservoir characterization research needs specific to Class 4 reservoirs, and general reservoir characterization research needs. The technological and methodological research needs for the IOR process and related areas are summarized in Sections 5.3 through 5.14. The advanced secondary recovery (ASR) process research needs in the areas of infill drilling, conformance control technologies, and polymers for mobility control, are summarized in Sections 5.3 through 5.5, respectively. The enhanced oil recovery (EOR) process research needs are discussed in Sections 5.6 through 5.11 for the following processes: (1) microbial, (2) alkaline and alkaline-surfactant-polymer, (3) micellarpolymer or surfactant, (4) steam injection, (5) in situ combustion, and (6) carbon dioxide injection. The IOR process-related research needs pertaining to numerical simulation and modeling, wellbore and facilities, and environmental issues are summarized in Sections 5.12 through 5.14.

\subsection{Characteristics of Class 4 Reservoirs and Operators}

Class 4 reservoirs are characteristically in the mature stage of their productive life (Figure 2.3). Under implemented technology, approximately two-thirds of the potentially recoverable oil in Class 4 reservoirs is at risk of abandonment by the year 2000. The majority of Class 4 reservoirs were discovered and developed several decades ago in the pre-modern era, when reservoir descriptive techniques and tools were primitive and the need for reservoir description was not widely recognized. Old E-logs run under largely unknown conditions with, by today's standards, poorly designed and calibrated tools and erratically kept records on production and injection volumes and reservoir operations constitute the major sources of currently available information for many Class 4 reservoirs.

A significant $40.5 \%$ of Class 4 reservoirs are currently operated by small independents (Figure 2.4). This percentage is considerably higher in the Texas and Oklahoma regions (49\% and $45 \%$, respectively-NIPER/BDM, 1994), which together contain nearly 12 billion barrels, over $62 \%$ of the Class 4 remaining oil-in-place (Figure 2.5). These figures for Class 4 are in general agreement with the figure for all domestic reservoirs, $43 \%$ of which were operated by independent producers in 1990 (IPAA, 1992).

Small independent operators have several unique characteristics that play an important role in their reservoir management strategies. Independents operate the vast majority of stripper wells (wells producing less than $10 \mathrm{BOPD}$ ); more than $60 \%$ of the wells operated by independents in Texas fall into this category (Milling et al., 1992; Dowd, 1990). Independent operators, especially smaller independents, have characteristically lower operating overhead and can profitably purchase and operate mature production that has reached its economic limit under large companies with higher overhead (Schoeling et al., 1994). However, capital and financial resources of small independents are limited; high-risk projects, projects that require large front-end investment, or 
projects that do not provide relatively quick payouts are not acceptable (Milling et al., 1992; Dowd, 1990). Most small independents have a small staff and some background in geology and/or engineering, but few have staff expertise in sophisticated technologies (Milling et al., 1992). Technology must generally be applied through consultants. Because many independent operators are unaware of how advanced technologies work, they and their financial backers are often reluctant to apply them (Dowd, 1990).

Some information needs of independent producers are summarized by Milling et al. (1992) and Dowd (1990). Most fall into the categories of (1) need for access to technological advances, (2) need for demonstrations of existing and emerging technologies, and (3) need for methodologies in new and existing technology application, reservoir description, and reservoir management.

\subsection{Research Needs in Reservoir Description and Reservoir Management}

Reservoir description in itself is very broad in scope, involving a diversity of tools and a broad spectrum of activities to predict or anticipate the effects of reservoir heterogeneity. Reservoir management is a still broader consideration, involving the carefully planned and calculated use of reservoir description in conjunction with reservoir monitoring and economic and environmental awareness to optimize removal of hydrocarbons. Both reservoir description and reservoir management use sophisticated technologies for information gathering and complex methodologies for collection, analysis, and synthesis of that information for reservoir decision making.

\subsubsection{RD\&D Needs-Reservoir Characterization and Reservoir Management Methodologies}

Methodologies that need to be developed and demonstrated in the reservoir characterization and reservoir management areas are related to database development, data integration, and development of application plans and strategies. Potential contributions include the following:

- A significant general reservoir characterization need is in development and demonstration of methodologies for design and construction of databases for reservoir characterization. Databases for information management are critical for reservoir management also, and methodologies for their design and development need to be demonstrated. Databases must have the flexibility to incorporate and identify information of different origins, scales, and quality.

- A second reservoir characterization methodology needed is that for integration by comparison, combination, correlation and/or other means of various geoscience and engineering data types. A closely related methodology need is for procedures for accurate scale adjustment for various information types to assure their proper representation at simulator grid-block scale for accurate prediction of reservoir performance.

- Additional methodologies are needed to address development of reservoir characterization strategies over a range of reservoir life stages ranging from youthful reservoirs undergoing initial development to mature reservoirs nearing abandonment.

- Methodology for design, implementation, and revision of reservoir management plans is a critical research need.

All of the above can be considered short-term needs which would be of benefit to Class 4 reservoirs, but development and refinement of such methodologies should carry into the mid-term and beyond. Demonstrations need to be analyzed and integrated with explicitly developed methodologies. Efficient transfer of the technology represented by these complex methodologies is very important. Computer-based systems have potential merit in capture and transfer of such information. 


\subsubsection{Class 4-Specific Research Needs in Reservoir Characterization}

Class 4 reservoirs will share in benefits from reservoir characterization and reservoir management methodologies developed and demonstrated as suggested in Section 5.2.2. They will benefit also from research results in the general reservoir characterization area as discussed in Section 5.2.4. However, Class 4 reservoirs also have very specific research needs. Conceptual, stochastic, and deterministic considerations will be important.

\section{Conceptual}

Conceptual models for application to Class 4 reservoirs are a definite research need. Models covering any or all of the depositional, diagenetic, tectonic or structural, and fluid content aspects of reservoir heterogeneity description can be addressed at basin, play, or reservoir scales. The appropriate scale varies among Class 4 regions as a function of transferability (see section 3.2). Specific development and demonstration needs from conceptual or analog sources include the following:

- Specifically, conceptual depositional models are needed to elucidate and make predictable: (1) overall deposit architecture; (2) external facies geometries, including presence or absence of "key" facies (e.g., eolian, tidal inlet, valley fill); (3) formation of strandplain versus barrier island deposits; and (4) internal fluid flow heterogeneities of depositional origin, such as crosscutting tidal inlets, interdune swale deposits within eolian facies, and others. The above features should be related to their primary controlling factors, such as tectonics, sediment supply, etc.

- Conceptual-level diagenetic studies are needed to further determine at what scale (basin, play, or reservoir) diagenetic analog information is transferable in the various Class 4 regions. Appropriate diagenetic models then need to be built to provide analog information on diagenesis for all Class 4 reservoirs. Relating early diagenetic features to depositional conditions, tectonics, etc., may reveal some predictable similarities in diagenetic features between reservoirs in basins with different development histories.

- Tectonic or structural models are important because they are related to prediction of depositional and diagenetic features, but also because they may predict important internal fluid-flow heterogeneities, such as faults and fractures.

- Study of hydrocarbon and nonhydrocarbon fluid composition variation, both within reservoirs and among reservoirs in the same and different plays and basins, may lead to predictive analog models for detection of reservoir compartmentalization.

Conceptual models in the areas discussed previously will also form the basis of stochastic models for application in Class 4 reservoirs. Demonstration of the methodologies for development of the various Class 4 conceptual models will be important byproducts benefiting Class 4 as well as other reservoir geologic classes. Conceptual-level models will have good applicability in Class 4 reservoirs, in which deterministic data are sparse and economics can not generally justify large or sophisticated data collection projects. Conceptual model needs should be addressed in the shortterm with continuation of efforts into the mid-term and beyond.

\section{Stochastic}

When transferable analog or conceptual sources of information appropriate for a Class 4 basin, play, or reservoir have been established, stochastic models of depositional, diagenetic, tectonic, etc., heterogeneities for application in Class 4 reservoirs can be constructed.

- Stochastic models for representation of Class 4 interwell-scale heterogeneities are a definite RD\&D need. Analog sources may include subsurface deposits, outcrops, or deposits in modern environments where information on the variability of the desired features or properties is available at the scale needed for modeling. 
- As in the case of conceptual models, demonstration of the methodologies for construction of stochastic models is a significant byproduct.

Stochastic model development is another short-term need with opportunity for continued development in the mid-term.

\section{Deterministic}

Class 4 specific needs in the deterministic or data acquisition and analysis area of reservoir characterization are mostly short-term and methodological in nature.

- In general terms, routine and innovative application of current and emerging technologies and demonstration of the appropriate associated methodologies for collection, analysis, and interpretation of data are the primary Class 4 research needs.

Additional needs, specific to particular sources of information, are discussed here.

- In the reservoir sampling area, methodologies for rock and fluid sampling guided by Class 4 depositional, diagenetic, etc., conceptual models need to be formulated and demonstrated. Methodologies are needed for linking difficult and expensive-to-measure reservoir properties, such as relative permeability, to more readily predictable features, such as components of a Class 4 conceptual model like depositional or diagenetic facies.

- Production and injection data collection protocols, databases, and data analysis systems for Class 4 reservoirs need to be developed. Methodologies for development of these products for various Class 4 regions, basins, plays, etc., are an important byproduct of these efforts. Identification and collection from Class 4 reservoirs of new production or injectionrelated data types and development of new techniques for extracting information on reservoir heterogeneities from existing Class 4 data are other pursuits that may prove beneficial.

- Guided by appropriate Class 4 conceptual models, optimum open and cased-hole wireline logging suites for various Class 4 reservoirs, plays, etc., can be established. Appropriate quality control protocols for data collection can be established in a similar manner. Methods for optimizing derivation of information from existing Class 4 wireline log data need to be demonstrated. Many Class 4 reservoirs could benefit from application of such procedures to old E-logs.

- Class 4 reservoirs can benefit from demonstration of Class 4 customized methodologies for design, application, and interpretation of pressure transient and tracer tests. The specific integration of these tests with other available data types in characterizing typical Class 4 heterogeneities is an additional methodology requiring development and demonstration.

In the context of application to Class 4 reservoir characterization, seismic techniques, including (1) 3-D surface and high-resolution techniques, (2) techniques involving extraction of reservoir properties from seismic signals, and (3) downhole, reflection, and cross-well techniques have potential to make significant contributions to recovery of the Class 4 resource.

- Each of the techniques listed above will require Class 4 specific application methodology development. Each technique will require unique designs and approaches for data collection, processing, and interpretation. Those designs and approaches will be guided by knowledge of the reservoir obtained from other data and from Class 4 conceptual or analog models.

- Demonstration of the methodologies for developing these designs and approaches is a definite Class 4 need. 


\subsubsection{General Research Needs in Reservoir Characterization}

General, non-Class 4-specific reservoir characterization research needs that will benefit Class 4 and other reservoir types equally also can be discussed in terms of conceptual, stochastic, and deterministic models.

- Conceptual modeling will benefit most over the short-term and beyond by ample demonstration of the basic methodologies for construction of depositional, diagenetic, tectonic, and fluid content models.

- Stochastic models, which depend on accurate analogs for their transferability, will be benefited greatly by improved conceptual modeling methodologies. Further improvement in evaluation of stochastic realizations (i.e., development of less time-consuming and computationally expensive approaches than full-scale reservoir simulation) is another area in which research is needed.

Several possible advances in the deterministic or data acquisition and analysis area may give substantial benefits to Class 4 as well as other reservoir classes.

- In reservoir rock and fluid sampling, new technologies meeting the following criteria are needed to obtain samples: (1) more cheaply, (2) at any desired location in the 3-D volume of the reservoir, (3) at any time or stage in reservoir development, and (4) under nativestate conditions. Slimhole coring technologies are a step in this direction. Continued development of techniques to determine important reservoir properties from small samples is also needed.

- Low-cost and highly automated collection and recording equipment for production, injection, and other pertinent reservoir data are required.

- Development of new logging tools that directly measure critical properties not accurately obtainable by current tools, such as permeability, and further improvements of cased-hole tools to allow detailed reservoir characterization in mature reservoirs are also important.

- More efficient reacting and non-reacting tracers will be needed at low cost, so their use will become more widespread and their interpretation more straightforward.

- Seismic applications for 3-D, reservoir property extraction, and downhole techniques could all benefit from lower costs, higher resolution, and use of three-component recording and analysis.

Many of the needs discussed in this section are related to advances in technology or extensive applications development that may not be realized in the short-term. Therefore, these developments could not be counted on to substantially prevent abandonments of Class 4 resources in the shortterm.

\subsection{Infill Drilling Research Needs}

Significant potential exists for the recovery of additional oil from Class 4 reservoirs through the implementation of infill drilling projects. Infill drilling can be applied to improve recovery as a stand alone process or in conjunction with other improved oil recovery processes. The key to the success of infill drilling is identifying the reservoir heterogeneities and complexities which limit recovery potential at current well spacing and understanding the relationship of these complexities to recovery at reduced well spacing. The research needs specific to infill drilling include the following: 
- Development and demonstration of improved methods for assessing and predicting the recovery potential for infill drilling through definition of interwell continuity and sweep efficiency improvements which can be attained by infill drilling. The application of improved reservoir characterization methods for defining these improvements is a key research need which could impact the oil recovery potential for infill drilling.

- Development and demonstration of improved methods for predicting reservoir characteristics between existing wells using geostatistical methodologies. The prediction of porosity, permeability, and fluid saturations between known datapoints is a significant research need for defining reservoir continuity and sweep efficiency and for the determination of infill drilling potential.

\subsection{Conformance Control Technologies Research Needs}

Conformance control technologies combined with infill drilling and polymer are important to realizing the Class 4 IOR potential. Historically, conformance control technologies have relied upon mechanical control or gel polymers. The conventional chromium redox system represents the most widely used gel polymer system. However, this system presents significant environmental hazards. Alternative systems or approaches with fewer health hazards are being explored, but further development is needed. Well selection, treatment design, and treatment procedure heavily influence the success of gel polymer treatments. Improved treatment design and modeling capabilities are needed. Expert system concepts incorporating field results would also be helpful in treatment design. Important research needs within the conformance control technology area are:

- Development of cost-effective, environmentally acceptable technologies as alternatives to the conventional chromium redox gel polymer system.

- Development of simulation and modeling capabilities including expert system concepts based on field data to improve treatment design capabilities.

- Demonstration of improved conformance control methods and transfer of technologies.

\subsection{Polymer Research Needs}

Polymers for mobility control are inherent to the chemical flooding processes. Although polymers with higher salinity and temperature tolerances are an industry-wide research need, temperatures and salinities of most of the Class 4 oil resource lie within salinity and temperature tolerances of existing polymer systems. For Class 4 applications, the following application-based parameters are more important polymer research needs:

- Development of improved polymer injection strategies

- Development of improved polymer systems, especially these with improved injectivity and increased ability to propagate through the reservoir.

\subsection{Microbial Process Research Needs}

Microbial enhanced oil recovery (MEOR) technologies use a variety of mechanisms to enhance oil recovery. MEOR Applications include wellbore stimulation and cleanup, permeability modification, polymer flooding, coning mitigation, and microbially enhanced waterflooding. Field projects have confirmed that microbially enhanced waterflooding mobilizes oil, but projects have been conducted in leases already near secondary depletion. Process potential needs to be demonstrated in reservoirs having higher initial oil saturations. Like conformance control technologies, MEOR technologies can be effective at moderate oil prices. To foster more widespread field applications, critical research needs are: 
- Development of improved prediction and modeling capability incorporating both laboratory and field data into model development to better define the EOR aspects of the process.

- Demonstration of microbially enhanced waterflooding in reservoirs having higher remaining oil saturations.

- Development of more cost-effective nutrients.

- Development and demonstration of improved microbial systems for application in higher temperature and salinity environments.

\subsection{Alkaline and Alkaline-Surfactant-Polymer (ASP) Process Research Needs}

Laboratory and field experience indicates that the weak alkali process has performance advantages over the strong alkali process used in the past. Weak alkalis reduce the chemical consumption and operational problems experienced with strong alkali floods. The ASP process, which combines weak alkalis and low concentrations of surfactant, exhibits synergistic effects. Although interactions with specific crude oils must be tested, data indicate the process is not restricted to crude oils with high acid numbers (typically lower gravity crudes). Oil recovery is sufficiently high and chemical costs sufficiently low that the process is feasible at moderate oil price. Being a relatively new concept, the ASP process still has several important research needs:

- Development of improved injection strategies, specifically addressing the issue of polymer and alkali-surfactant interactions.

- Development of fluid and reservoir databases containing data required for screening reservoirs for the ASP process.

- Development of field guidelines through demonstration in well-documented field tests. Crude oil from one Class 4 reservoir has been tested and an effective chemical system developed.

- Continued surfactant and mixed surfactant research striving to reduce chemical costs even further.

\subsection{Surfactant Process Research Needs}

At higher oil prices (or significantly lower chemical costs), the surfactant process has significant potential for the Class 4 oil resource. Moderate oil prices, negative industry perceptions, and chemical costs restrict current applications. Laboratory data indicate that mixed surfactant systems have potential for lowering chemical costs. Although current economic conditions discourage surfactant applications, long-term potential exists, especially if more economical chemical systems are developed. Important research needs for the surfactant process are:

- Development of more cost-effective chemical systems. Mixed surfactant system research appears promising and also benefits research on the ASP process.

- Investigation and demonstration of horizontal well applications to lower front-end cost loading.

- Investigation of combination processes, preferably those exhibiting recovery synergism.

- Investigation of foam mobility control.

- Further development of PC-based simulation models.

- Investigation of chemical flooding in fractured reservoirs. 


\subsection{Steam Process Research Needs}

Expansion potential exists in current Class 4 IOR projects and in selected new projects. Steam projects are particularly influenced by economics and environmental regulations. Current economic conditions are directing efforts to technologies that improve process efficiency. Operations research is directed towards improving steam and heat management. Reservoir-related research is directed towards improving reservoir sweep. For Class 4 reservoirs, the primary research needs related to improving efficiency are:

- Development of improved steam measurement and distribution technologies.

- Development of improved injection profiling and control methods.

- Development of improved subsurface equipment and completion technologies.

- Development of horizontal well and sand control technologies for the high temperature environment.

- Demonstration of economic project development in smaller projects in areas distant from existing steam infrastructure and in environmentally sensitive areas.

- Development of cost-effective methods to deplete bypassed zones.

\subsection{In Situ Combustion Process Research Needs}

The in situ combustion process is applicable to and has potential in selected Class 4 reservoirs, as indicated by the number of early projects tried in Class 4 reservoirs. Despite a poor track record and negative industry perceptions, interest in the in situ combustion process remains high due to the success of several field projects in Canada and recent U.S. projects in deep carbonate reservoirs. In situ combustion research needs fall within three areas:

- Determination of the effects of reservoir heterogeneities on air and fluid flow and the resulting effect on process performance.

- Development of reservoir simulators that take into consideration both reaction kinetics and complex geological features.

- Development of improved equipment and operating practices addressing problems such as explosion hazards, injection well failures, compressor design and reliability, inadequate compression volume, corrosion in high GOR wells, flue gas disposition, and poor sweep efficiency.

\section{$5.11 \mathrm{CO}_{2}$ Process Research Needs}

The miscible, immiscible, and cyclic $\mathrm{CO}_{2}$ processes all have potential for application in Class 4 reservoirs. However, geographical location distant from the existing $\mathrm{CO}_{2}$ supply infrastructure (except for parts of Wyoming) may limit applications to cyclic $\mathrm{CO}_{2}$ stimulation treatments. Where supply permits flooding operations, increasing sweep efficiency through mobility control and horizontal well technologies will be important to process economics. Primary research needs for the $\mathrm{CO}_{2}$ process are:

- Demonstration of cost-effective cyclic $\mathrm{CO}_{2}$ stimulation treatments.

- Development of improved mobility control technologies.

- Demonstration of horizontal well technologies in $\mathrm{CO}_{2}$ flooding applications. 


\subsection{Numerical Simulation and Modeling Research Needs}

The petroleum industry has continued to exploit the advancing computational capabilities of desktop and mainframe computer systems to develop simulators that are more user-friendly, that more accurately predict recovery process performance, and more effectively display simulator output. However, these simulators are not necessarily available to, or utilized by, many operators due to the cost of purchasing the simulator, contracting simulation services, or the lack of required technical expertise. Specific research needs relative to numerical simulation include the following:

- Development of more accurate, cost effective, and user-friendly publicly available simulators is probably the most significant simulation research need for operators of Class 4 reservoirs. These types of simulators should be made more readily available. Many operators could utilize these tools to design and evaluate improved recovery processes.

- A system should be developed to allow less sophisticated operators access to technical experts who can provide guidance for the development of input datasets, the operation of simulators, and the interpretation of results. These objectives could be met through DOE funding support to the Petroleum Technology Transfer Council, NIPER, universities, and other research institutions.

\subsection{Wellbore and Facilities Research Needs}

The demonstration of improved technologies for reducing the costs of drilling, completing, recompleting, and stimulating wells, and operating production and injection facilities is a significant research need for extending the economic life of producing fields and improving the recovery of oil. Specific areas where the demonstration and transfer of improved methodologies and equipment could benefit operators include the following:

- Demonstration of improved drilling systems for reducing the cost of drilling wells and improving the integrity of wellbores after drilling, which could reduce long term operating costs. This includes the demonstration of environmentally safe drilling systems and improved drilling measurement systems.

- Demonstration of innovative directional and horizontal drilling techniques and the development and demonstration of methodologies for determining the applicability and potential for horizontal or deviated wells.

- Development and demonstration of improved, cost-effective methods for completion, recompletion, workover, and stimulation of wells and the transfer of these methods to other operators to reduce costs and increase the economic life of wells.

- Demonstration of improved systems and operating procedures for fluid separation and treatment, distribution and gathering, and artificial lift could encourage many operators to implement cost-saving practices. The demonstration of reservoir management methodologies, which includes the optimization of production and injection facilities, would benefit many smaller operators.

\subsection{Environmental Research Needs}

Environmental research needs impact all of the Class 4 resource. Increased scrutiny of operators by the public and regulators requires operators to demonstrate ever-increasing environmental responsibility. Of the multiple environmental concerns, the following research needs are most important for the Class 4 oil resource. 
- Demonstration of cost-effective waste management (minimization) practices, especially in drilling-related operations.

- Demonstration of integrated engineering design concepts in which petroleum engineering and environmental factors are considered in IOR project design.

\subsection{References}

Dowd, W.T., 1990, Technology transfer to U.S. oil producers-a policy tool to sustain or increase oil production: Department of Energy Report DOE/BC/14285-1, March, 77 p.

IPAA, 1992, Profile of independent producers: Independent Petroleum Association of America, Washington, D.C., 6 p.

Milling, M.E., B. Hardage, and A.L. Gilliland, 1992, Technology transfer needs and requirements for Texas independent oil and gas producers: Texas Independent Producers and Royalty Owners Association and The University of Texas at Austin, Bureau of Economic Geology, 33 p.

Schoeling, L.G., D.W. Green, G.P. Willhite, and W.L. Watney, 1994, Development of a model technology transfer program to assist independent operators: SPE/DOE 27783 Ninth Symposium on Improved Oil Recovery, Tulsa, Oklahoma, April. 